\title{
Health and Safety of
}

\section{Young Workers}

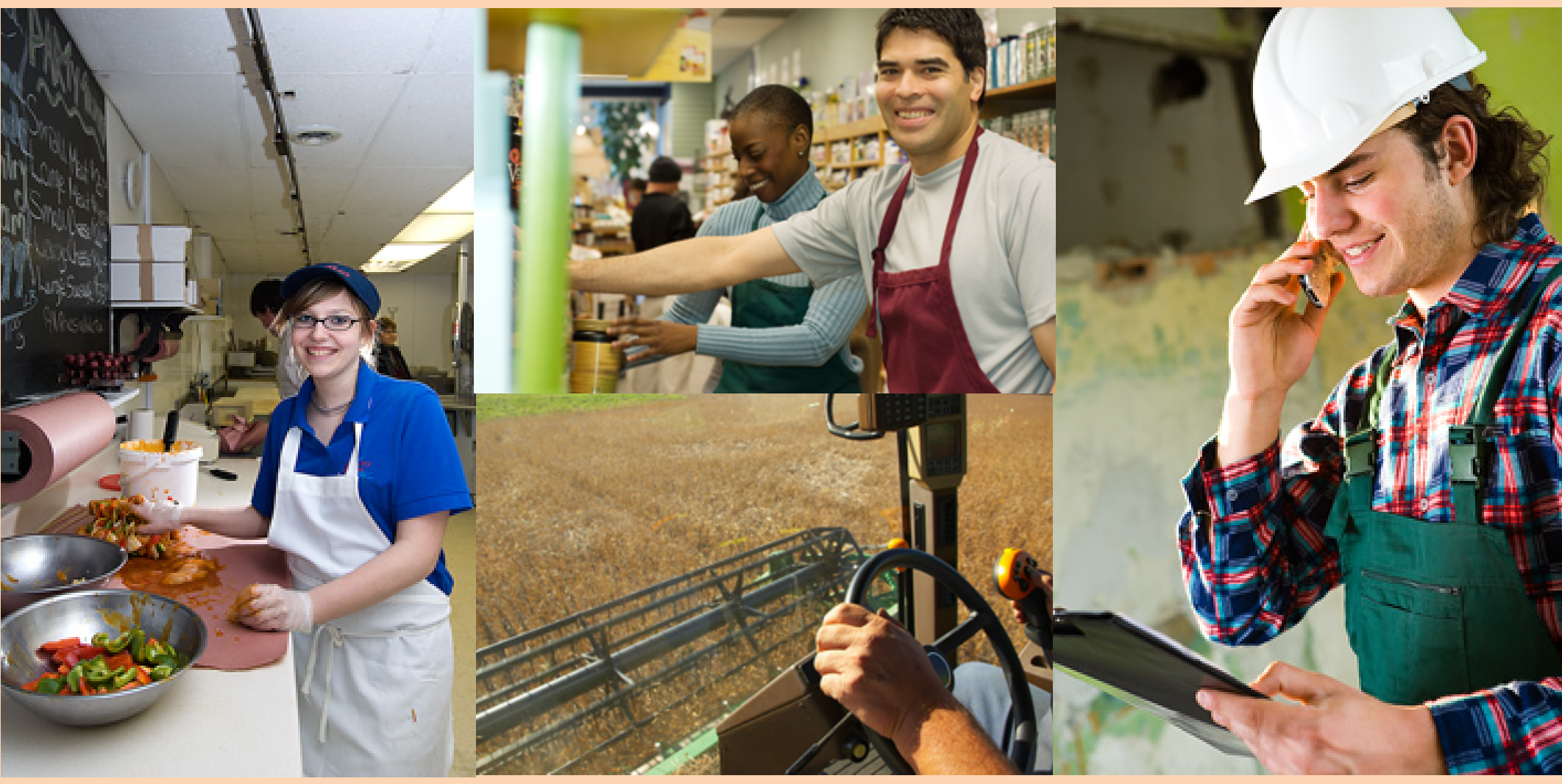

\section{Proceedings of a U.S. and Canadian}

\section{Series of Symposia}




\section{Disclaimer}

These Proceedings do not constitute endorsement of the views expressed or recommendations by the National Institute for Occupational Safety and Health (NIOSH). The opinions and conclusions expressed in the articles are those of each author and not necessarily those of NIOSH. All authors were provided the opportunity to review, update and correct statements attributed to them in these Proceedings. Recommendations are not final statements of NIOSH policy or of any agency or individual involved. They are intended to be used in advancing the knowledge needed for improving young worker safety and health. 


\title{
Health and Safety of Young Workers
}

\author{
Proceedings of a U.S. and \\ Canadian Series of Symposia
}

\section{Editors:}

Carol W. Runyan, MPH, PhD

Pediatric Injury Prevention, Education and Research (PIPER) program

Colorado School of Public Health, University of Colorado School of Medicine, and Children's Hospital Colorado

John Lewko, PhD

Center for Research in Human Development

Laurentian University

Kimberly Rauscher, MA, ScD

West Virginia University School of Public Health

Dawn Castillo, MPH

Division of Safety Research

National Institute for Occupational Safety and Health

Sara Brandspigel, MPH

Pediatric Injury Prevention, Education and Research (PIPER) program

Colorado School of Public Health, University of Colorado School of Medicine, and Children's Hospital Colorado 
This document is in the public domain and may be freely copied or reprinted.

\section{Disclaimer}

Mention of any company or product does not constitute endorsement by the National Institute for Occupational Safety and Health (NIOSH). In addition, citations to Web sites external to $\mathrm{NIOSH}$ do not constitute NIOSH endorsement of the sponsoring organizations or their programs or products. Furthermore, NIOSH is not responsible for the content of these Web sites. All Web addresses referenced in the document were accessible as of the publication date.

Ordering

To receive documents or other information about occupational safety and health topics, contact NIOSH at

Telephone: 1-800-CDC-INFO (1-800-232-4636)

TTY: 1-888-232-6348

E-mail: cdcinfo@cdc.gov

or visit the NIOSH Web site at www.cdc.gov/niosh

For a monthly update on news at NIOSH, subscribe to NIOSH ENews by visiting www.cdc.gov/niosh/eNews

DHHS (NIOSH) Publication No. 2013-144

May 2013 


\section{Acknowledgements}

The editors appreciate the assistance of the Joint Organizing Group throughout the project, the assistance of Ms. Katherine Collins in compiling the document, and senior staff at the National Institute for Occupational Safety and Health (NIOSH) for their review of an earlier draft. This project was supported by grants from NIOSH to the University of North Carolina Injury Prevention Research Center and from the Ontario Neurotrauma Foundation to the Laurentian University. 


\section{Foreword}

Young workers warrant special consideration to foster a safe and healthful entrée to the world of work. While there is consistent evidence that young workers are at increased risk for injury in the workplace, largely due to inexperience, the solutions and path forward are not straightforward. Efforts to facilitate opportunities for youth to gain meaningful job experiences that foster development of marketable job skills for their future need to be balanced with efforts to protect them from work-related injury and illness. Additionally, work is just one component of youths' lives and their transitions into adulthood. Family and social relationships and education are other important components of young workers' lives that have complex relationships with work that need to be considered.

Research on the impacts of youth work is conducted in multiple disciplines, with little interaction between them. These include the fields of business, law, psychology, public health, sociology, and youth development. NIOSH co-funded, with the Ontario Neurotrauma Foundation, a project that convened a unique series of symposia between 2007 and 2010 that brought together scholars from multiple disciplines, practitioners and business representatives from the U.S. and Canada to consider the implications of youth employment, and to make recommendations for moving forward, considering the complex relationships of work with other components of youth development. These Proceedings compile white papers (or subsequently published articles) that were developed to foster discussions at this series of symposia, along with an ambitious research and policy agenda that was spawned from these interdisciplinary discussions. White papers and articles were authored by business scholars, epidemiologists, health communicators, physicians, psychologists, and sociologists.

These Proceedings serve as a foundation for fostering interdisciplinary attention to the complex issues surrounding young worker safety and health, and serve to inform the many stakeholders who did not attend the invitational series of symposia. These Proceedings will be useful to scholars from multiple disciplines, practitioners (e.g. safety professionals, unions, business leaders and educators), and policy makers interested in expanding their knowledge about young worker safety and health.

$/ / \mathrm{s}$

John Howard, M.D.

Director

National Institute for Occupational Safety and Health

Centers for Disease Control and Prevention 
$($ vii $)$ 


\section{Table of Contents}

\begin{tabular}{l} 
Title \\
\hline Introduction \\
\hline Youth Employment and the Health and Safety Issues of Young \\
Workers in the U.S. and Canada: An Overview \\
\hline Identifying Good and Bad Jobs in Adolescence
\end{tabular}

Authors

Page

Carol W. Runyan, PhD, John 1

Lewko, PhD, Kimberly Rauscher, MA, ScD, Dawn Castillo, MPH

Dawn Castillo, MPH, John Lewko, 4 $\mathrm{PhD}$

Identifying Good and Bad Jobs in Adolescence

Jeremy Staff, PhD, John E. Schu- 26

lenberg, PhD, Jerald G. Bachman,

$\mathrm{PhD}$, Michael J. Parks, Matthew

VanEseltine, PhD

\begin{tabular}{ll}
\hline Assessing Adolescent Decision-Making Competence & Bat \\
\hline Work and its Positive and Negative Effects on Youth's Psycho- \\
social Development \\
\hline Risk Factors for Nonfatal Work Injury for Young Workers: A \\
Review of Two Relevant Literatures \\
\hline Tracking Work-Related Injuries among Young \\
Workers: An Overview of Surveillance in the \\
United States \\
- Appendix Davis-I
\end{tabular}

Baruch Fischhoff, PhD 46

Jeylan Mortimer, PhD 66

F. Curtis Breslin, PhD, Peter M. 80 Smith, PhD

Letitia Davis, ScD, EdM, Beatriz 105

Pazos Vautin, MPH

Prevalence of Working Conditions Associated with Adolescent Occupational Injury in the U.S.: A Review of Literature

A Review of the Research on How Work-Based

Kimberly J. Rauscher, MA, ScD,

126 Carol W. Runyan, MPH, PhD

Injury Risks are Distributed Across Youth's jobs in Canada

Peter M. Smith, PhD, F. Curtis

137

Breslin, PhD

The Unique Developmental Considerations of Youth-Related

Work Injuries

May Sudhinaraset and Robert W. 146

State of the Art in Young Worker Safety Interventions in the United States Blum, MD, PhD,

Susan Gallagher, MPH, Sara Rat- 147

- Appendix Gallagher-I

tigan, MS

- Appendix Gallagher-II

\begin{tabular}{lll}
\hline $\begin{array}{l}\text { A State of the Art Review of Knowledge Mobilization and Dis- } \\
\text { semination Practices Related to Occupational Safety \& Health }\end{array}$ & Peter Levesque, PhD & 167 \\
\hline Evaluating Interventions to Prevent Injuries to Young Workers & Harry Shannon, PhD & 176 \\
\hline $\begin{array}{l}\text { Setting an Agenda for Advancing Young Worker Safety in the } \\
\text { U.S. and Canada }\end{array}$ & $\begin{array}{l}\text { Carol Runyan, MPH, PhD, John } \\
\text { Lewko, PhD, Kimberly Rauscher, } \\
\text { MA, ScD }\end{array}$ & 190 \\
\hline Appendix I (List of Symposia Participants) & & 200 \\
\hline Appendix II (Symposia Agendas) & & 208
\end{tabular}




\section{Introduction}

Carol Runyan, MPH, PhD, Colorado School of Public Health

University of North Carolina Injury Prevention Research Center (at the time of this project)

John Lewko, PhD, Centre for Research in Human Development Laurentian University

Kimberly Rauscher, MA, ScD, West Virginia University School of Public Health

University of North Carolina Injury Prevention Research Center (during part of this project)

Dawn Castillo, MPH, National Institute for Occupational Safety and Health

\section{Background}

Working for pay, either after school or during the summer, is a usual part of teenage life throughout the US and Canada, with up to 80 percent of high school students working at least some time during the course of a year. Young workers (under age 25) are employed in multiple industries and engage in many types of tasks and, as a result, are exposed to a variety of workplace hazards, including operating dangerous tools, machinery, and vehicles and handling cash in settings prone to robbery. Training is sometimes minimal and adult supervision limited. Employers may not fully understand the laws or be motivated to comply with them or they may not recognize that these inexperienced workers need special attention. Those charged with enforcement may not have sufficient support to carry out their duties, in part because the public and policymakers are unaware of the importance of the issue. Despite these downsides, work can be an important component of adolescent development, helping teens and young adults develop valuable work skills, exercise autonomy, and achieve a greater degree of competence and financial independence.

Literature related to the health and safety of young workers appears in the domains of public health, youth development, social psychology, education, economics, labor law, and organizational psychology. However, there is very limited integration across these disciplines. Consequently, guidance for practice and policy can be fragmented at best. A report of the National Research Council (NRC), Institute of Medicine [1998] revealed a number of issues associated with young worker safety and youth development and made nearly 20 recommendations about surveillance, research and intervention efforts to improve safety for young workers, relying mostly on literature from public health and youth development. In the time since the NRC report was published, progress has been made in both research and programmatic efforts, but continued advancement of understanding and improvements in programs and policies are still important.

\section{The symposia series}

This series of symposia was designed with a goal of helping synthesize perspectives from a diverse group of participants so as to advance understanding of the benefits and risks of youth employment by bridging several disciplines and setting an agenda for future scientific and programmatic directions throughout the US and Canada. 
Representing the U.S.-Canadian partnership, the funded project team (Runyan, Lewko, Rauscher) developed the project with joint leadership from the University of North Carolina Injury Prevention Research Center (UNC IPRC) (Dr. Runyan) and Laurentian University in Ontario (Dr. Lewko). Dr. Rauscher joined the project at UNC IPRC and Ms. Castillo participated throughout the project as a representative of the National Institute for Occupational Safety and Health (NIOSH).

A Joint Organizing Group co-chaired by Drs. Runyan and Lewko provided guidance throughout the project. The organizing group included:

- Robert W. Blum, MD, PhD (William Gates, Sr. Chair in the Department of Population and Family Health Sciences, Johns Hopkins' Bloomberg School of Public Health);

- Letitia Davis, ScD, EdM, (Director, Occupational Health Surveillance Program, Massachusetts Department of Public Health);

- John Lewko, PhD ((Co-chair), Professor of Human Development, and Director, Centre for Research in Human Development, Laurentian University);

- Sandra Miller (Director of Innovation, Ontario Service Safety Alliance, Toronto, Ontario);

- Jeylan T. Mortimer, PhD (Professor of Sociology and Director of the Life Course Center, University of Minnesota);

- Kimberly Rauscher, ScD (Assistant Professor of Community Medicine, West Virginia University);

- Carol Runyan, MPH, PhD ((Co-Chair), Professor of Health Behavior and Health Education and Pediatrics at the University of North Carolina and Director of the Injury Prevention Research Center, University of North Carolina); and

- Richard Volpe, PhD (Professor of Human Development and Applied Psychology and Projects Director, Life Span Adaptation Projects, University of Toronto).

The role of the Joint Organizing Group was to provide a consistent source of input into all aspects of symposium development and knowledge. This included providing guidance on developing and carrying out a Delphi survey to define focus areas, and defining the structure and refining the content of the series; developing strategies to identify and recruit session participants so as to ensure diversity in content expertise, geographic, cultural, gender and ethnic representation, as well as achieving a mix of senior scholars, junior scholars and students; and identifying authors for white papers for each session.

The project team, with input from the Joint Organizing Group, designed the symposia series with the intent to provide a mechanism to identify issues of importance for improving the experience of young workers by examining literatures approaching youth labor from different perspectives. The goal was to formulate an interdisciplinary research agenda and consider strategies for appropriate policy and programmatic interventions to enhance the experience and reduce hazards and negative outcomes as well as the means by which knowledge transfer and dissemination can best occur among the research and public health practice and business communities concerned with young workers. The symposia series included two sessions in Canada and two in the United States, as follows:

- Symposium I: Youth Employment in Developmental Context, Toronto, Ontario, Canada, December 7 - 9, 2007;

- Symposium II: The Health Implications of Work among Youth, Chapel Hill, North Carolina, U.S., October 3-5, 2008; 
- Symposium III: Young Worker Health \& Safety Interventions and Knowledge Mobilization Strategies, Toronto, Ontario, Canada, June 20-22, 2009; and

- Symposium IV: Developing a Research and Policy Agenda to Improve Young Worker Health and Safety in the U.S. and Canada, Washington D.C., U.S., November 18-20, 2010.

For each of the first three symposia, the project team invited several authors to prepare white papers, setting the stage for integrative conversations. At each symposium, the participants generated ideas about additional needed research and areas in which knowledge was sufficient to drive action through policy and/or programs.

The first symposium focused on conceptual and theoretical grounding of youth development and work. Included in these Proceedings are a summary of an overview presentation by Dawn Castillo and John Lewko and three white papers from that symposium, authored by: Jeremy Staff, et al.; Baruch Fischhoff; and Jeylan Mortimer.

The second symposium focused on public health perspectives about young worker health and safety. Included in these Proceedings are five white papers authored by: F. Curtis Breslin and Peter M. Smith (two papers); Letitia Davis and Beatriz Pazos Vautin; Kimberly Rauscher and Carol W. Runyan; May Sudhinaraset and Robert W. Blum.

The third symposium focused on identifying evidence-based interventions to improve the experiences of young workers, discussing issues in evaluating interventions, and disseminating intervention practices more widely. Included in these proceedings are three white papers authored by: Susan Gallagher and Sara Rattigan; Peter Levesque; and Harry Shannon.

Most of the symposium white papers are included in this Proceedings document. Several authors declined the invitation to prepare their papers for this purpose. Authors also had the option of updating their papers and several chose to update and/or retitle their papers. All have received editing to standardize formatting and achieve clarity. One white paper (Sudhinaraset and Blum) is reprinted from a publication.

Following the first three symposia, a final symposium was held at which invited participants engaged in facilitated discussions directed at developing a research agenda pertinent to both the U.S. and Canada and outlining policy directions for the U.S. A paper from this final symposium appeared in Public Health Reports and is reprinted in these Proceedings.

A total of 64 individuals participated in the four symposia. To maintain both continuity and bring new ideas to the discussions, the project team also ensured that each meeting included individuals who had not previously participated as well as those who had participated before.

This Proceedings document contains a wealth of information derived from the symposia series and is being made available with the goal of enhancing the interdisciplinary knowledge base on young worker safety and health.

\section{References}

NRC (National Research Council) [1998]. Youth at work: Health, safety, and development of working children and adolescents in the United States. Washington, D.C.: National Academy Press.

Runyan CW, Lewko J, Rauscher K. (2012). Setting an agenda for advancing young worker safety in the U.S. and Canada. Public Health Reports. 127 (3): 246-52. 


\section{Youth Employment and the Health and Safety Issues of Young Workers in the U.S. and Canada: An Overview}

Dawn Castillo, MPH, National Institute for Occupational Safety and Health John Lewko, PhD, Centre for Research in Human Development Laurentian University

The following is a summary and update of overview presentations held at Symposium I: Youth Employment in Developmental Context. The purpose of these overview presentations was: a) to provide the context for youth employment in the U.S. and Canada; b) describe the extent and patterns of youth employment in each country; c) differentiate the policy environments affecting young workers in each country; and d) describe the hazards to which teens are exposed and the nature and magnitude of health outcomes associated with adolescent work injury in each country.

\section{United States}

\section{Definition and Distinguishing Characteristics for Young Workers}

There are a variety of definitions and age ranges for the term "young workers." For the purposes of the U.S. portion of this paper, young workers are defined as those less than 18 years of age. This definition reflects the ages at which most youth are engaged with the public educational system in the U.S. This definition also reflects the age at which U.S. child labor laws govern the types of permissible and prohibited employment for youth. With the exception of information on child labor laws, the information presented in this portion of the paper is broadly, but not exactly comparable, to the expanded age range up to 24 years of age (another common definition for young workers, including among many papers in this Proceedings.) For example, workers in their early 20s in the U.S. differ from adolescents in the amount of time they work and reasons for working, though the types of workplaces and jobs are similar, as are patterns of injury.

Similar to most adults, youth in the U.S. work to earn money. Both youth and their parents also recognize the positive role of work in building character, gaining job skills and as a step towards independence. While a primary motivator for work for youth and adults is money, how youth spend their money differs from adults, and is important for understanding the social context in which youth work in the U.S. Previous surveys of high school seniors, those students who are in their last year of public education in the U.S. and who are generally about 17 years of age, have demonstrated that working youth use their earnings primarily for personal items and car expenses (Table 1) [NCES 2012a]. For example, in 2001, 60\% of working high school seniors reported that they spent at least half of their earnings on personal items and $27 \%$ reported spending at least half of their earnings on car expenses (Table 1). Findings from this survey demonstrate that relatively small proportions of U.S. youth are contributing most of their earnings to family expenses, or towards saving for a college or trade education. There are differences by sociodemographic characteristics, however. For example, a higher proportion of 
black youth contributed at least half of their earnings to family expenses compared to all youth on average.

Table 1. Percent of U.S. Working High School Seniors Spending at Least Half of Their Earnings on Selected Categories, 2001

\begin{tabular}{|l|c|c|c|}
\hline & Total & White Non-Hispanic & Black Non-Hispanic \\
\hline Savings for education & $17 \%$ & $17 \%$ & $21 \%$ \\
\hline Car expenses & $27 \%$ & $29 \%$ & $25 \%$ \\
\hline Long range savings & $19 \%$ & $17 \%$ & $24 \%$ \\
\hline Personal items & $60 \%$ & $58 \%$ & $69 \%$ \\
\hline Family expenses & $13 \%$ & $8 \%$ & $29 \%$ \\
\hline
\end{tabular}

Source: University of Michigan, Institute for Social Research, Monitoring the Future, 2001.

Adapted from: National Center for Education Statistics. Youth Indicators, 2005: Trends in the Well-Being of American Youth, Indicator 38: Spending Patterns of High School Seniors. Responses are not mutually exclusive, thus totals do not sum to 100. [http://nces.ed.gov/programs/youthindicators/Indicators.asp?PubPageNumber=38\&ShowTablePage=TablesHTML/38.asp]. Date accessed: September 2012

There are a number of characteristics that differentiate young workers from their more mature counterparts in U.S. workplaces besides how earnings are spent. Youth are a unique segment of the workforce, with limited work experience, different patterns of employment from adults, and for the youngest workers less than 15 years of age, potentially unique risk factors for injury and illness associated with physical and psychosocial development. The need to balance demands of school and work also differentiates youth from older workers. And, in the U.S., there are regulations specific to young workers in addition to occupational safety and health regulations that apply to workers of all ages.

\section{Protection of Young Workers}

In the U.S., young workers are protected from work-related safety and health hazards by two sets of laws. Young workers are protected by occupational safety and health regulations which apply to youth as well as adult workers, and children and adolescents under 18 years of age are afforded additional protection through child labor laws. Whereas occupational safety and health regulations dictate conditions for safer work, such as what types of training and personal protective equipment are needed for specific types of work, child labor laws operate under the principle that some types of work are simply too dangerous for youth. Child labor laws identify the types of work that youth are allowed and not allowed to do.

Occupational safety and health regulations and child labor laws exist at both the federal and state levels in the U.S. The federal government provides oversight on occupational safety and health regulations and grants authority to some states to promulgate their own regulations that must be at least as protective as the federal regulations. Federal and state child labor laws have different jurisdictional coverage. For federal child labor laws to apply, there must be some type of commerce between states. When a youth's work is covered by both federal and state child labor laws, the stricter law applies. Many states require work permits or certificates that indicate approval of parents and/or schools for school-aged youth to work. 
U.S. federal child labor laws are bifurcated with different standards for children working in nonagricultural and agricultural occupations [WHD 2007, 2010]. The standards for nonagricultural occupations were primarily established in the late 1930s and 1940s, with few substantive revisions until recently [WHD 2012a]. The standards for agricultural occupations were promulgated in the early 1970s, without substantive revisions in the subsequent years. The differences between these two sets of standards include the minimum ages at which youth can work, and whether youth working for their parents are subject to the laws.

In nonagricultural occupations, youth 14- and 15-years of age are permitted to work in a limited set of jobs (for example most office jobs and many jobs in retail settings) with restrictions on the hours they may work, including restrictions against working during school hours and during late evening and early morning hours [WHD 2010]. The federal child labor laws do not regulate the hours that 16- and 17- year olds may work, though some state child labor laws do. At 16 years of age, youth are allowed to work in all nonagricultural occupations except 17 different types of work which have been declared by the U.S. Secretary of Labor to be especially hazardous. Examples of work that are prohibited for youth less than 18 years of age, termed Hazardous Orders in the U.S. federal child labor laws, include work in coal mining, logging and sawmilling, and work with power-driven woodworking machines.

In agricultural occupations, youth working for their parents are exempt from the federal child labor laws [WHD 2007]. Youth as young as 10 years of age are allowed to work in a limited set of jobs, with permission from their parents. An example of such permissible work is hand harvesting on small farms outside of school hours. At 14 years of age, youth are allowed to do work outside of school hours for all work except that which has been declared by the U.S. Secretary of Labor to be especially hazardous, termed Hazardous Orders. An example of work prohibited for youth less than 16 in agriculture is operating a tractor over 20 horsepower, though there is an exception which allows this work if the youth has taken a certified tractor operation class.

In 1998, a blue ribbon panel organized by the National Research Council (NRC) made a number of recommendations for improving young worker safety. One recommendation was for the Department of Labor to periodically review the adequacy of Hazardous Orders with input from the National Institute for Occupational Safety and Health (NIOSH), the U.S. federal agency responsible for research on worker safety and health [NRC 1998]. NIOSH provided the Department of Labor with a report in 2002 [NIOSH 2002]. NIOSH recommendations were based on analysis of numerous databases, and reviews of hundreds of scientific articles and publications. The recommendations included modifications to existing Hazardous Orders, as well as recommendations for an additional 17 Hazardous Orders. For each recommendation, NIOSH summarized relevant data and research.

There have been recent changes to child labor laws at the federal and state levels that are responsive to NIOSH recommendations or have been fostered by state level activities. In 2010, the Department of Labor enacted the most sweeping revisions to federal child labor laws in 30 years, including 25 changes for nonagricultural occupations recommended by NIOSH [WHD 2012a]. There have also been revisions to state child labor laws, including comprehensive changes in Massachusetts [Massachusetts Labor and Workforce Development 2013]. 


\section{Non-regulatory Efforts to Improve Young Worker Safety}

There are numerous efforts in the U.S. to improve young worker safety by non-regulatory means. These include efforts by public and private sectors.

At the federal level, the Department of Health and Human Services (DHHS) has set decennial goals to reduce the incidence of work-related injuries among adolescent workers. The current goal is to reduce work-related injuries among workers 15 to 19 years of age by $10 \%$ (from 2007 baseline levels) by 2020 [Healthy People 2020]. DHHS efforts to achieve these goals are centered within NIOSH (an agency within DHHS). NIOSH collects and supports data collection to monitor trends and emerging issues, funds research to understand contributing factors and to identify promising prevention strategies, and works with partners in the public and private sectors to encourage science-based prevention [NIOSH 2012a]. Notable NIOSH efforts include: supporting surveillance of young worker injuries to foster state-level prevention efforts [Commonwealth of Massachusetts 2012a, Davis and Vautin 2012, Oklahoma State Department of Health 2006, Oregon Department of Human Services 2008, OR-FACE 2009, Walters et al. 2010]; a comprehensive national initiative that has contributed to reductions in childhood agricultural injuries [CDC 2011, NIOSH 2012b]; and the development and promotion, with partners, of curricula that can be used to provide basic occupational safety and health information to teenagers [NIOSH 2012c]. The Department of Labor is also involved in non-regulatory efforts to improve young worker safety, has websites with numerous resources targeted to employers, parents, educators and youth [OSHA 2012, WHD 2012b], and supports a regional training center focused on young worker safety [CWYSH 2012]. And, numerous state entities are involved in promoting young worker safety, including agencies and groups in California [LOHP 2012], Massachusetts [Commonwealth of Massachusetts 2012b], Oregon [Oregon Health Authority 2012, OYWHSC 2012], and Washington [University of Washington 2012, WA DLI 2012].

Private sector groups are also involved in efforts to raise awareness of young worker safety issues. These include insurance companies [State Compensation Insurance Fund 2012, Texas Mutual Insurance Company 2012], professional associations such as the American Society for Safety Engineers [ASSE 2012], and non-profit groups such as the Child Labor Coalition [CLC 2012] and National Council for Occupational Safety and Health [NCOSH 2012]. Activities include periodic public service announcements, journal articles, safety pamphlets and fact sheets, poster contests, presentations, resources for employers, and training materials for young workers.

\section{Young Worker Employment}

In the U.S., formal employment of youth less than 18 years of age is common and increases with age throughout the teen years. Formal employment of teenagers begins as early as the $9^{\text {th }}$ grade, or about 14 years of age. For the period 1997 through 2003 , nearly $80 \%$ of students had worked by the time they finished their high school education as $12^{\text {th }}$ graders or seniors, about 17 years of age [BLS 2005]. Young worker participation in the work force has been relatively high in the United States compared to other developed countries [NRC 1998].

The U.S. economic downturn has impacted youth employment, with substantial decreases in the percentage of employed 16- and 17-year-old students in the past few years [NCES

2012b]. There are differences in student employment by race. In 2009, 20\% of white 16- and 
17-year-old students were employed compared to $9 \%$ of similarly aged black students, $9 \%$ of Hispanic students and $6 \%$ of Asian students.

In 2010, an estimated 1.4 million youth aged $16-17$ years were formally employed in the United States, with those working in nonagricultural industries working an average of 16.8 hours per week [BLS 2012a]. Young workers have different patterns of employment than older workers, including the types of industries where they work and their occupations. Young workers are most commonly employed in the services and trade sectors in the United States, with lesser but significant numbers employed in other industry sectors such as healthcare and social assistance, construction and agriculture (Figure 1). Most youth employed in services are employed in food services, and most employed in trade are in retail trade. Fifty-nine percent of all employed 16- and 17-year olds were employed in food services and retail trade in 2011 . The most common occupations of employed 16- and 17-year olds in 2011 were: food preparation and service (31\%) and sales (23\%) [NIOSH DSR 2012]. The workplaces and types of jobs held by youth influence the types of hazards they are exposed to, and the resultant injuries.

Figure 1. Employment of 16- and 17-year-olds by Industry Sector in the U.S., 2011

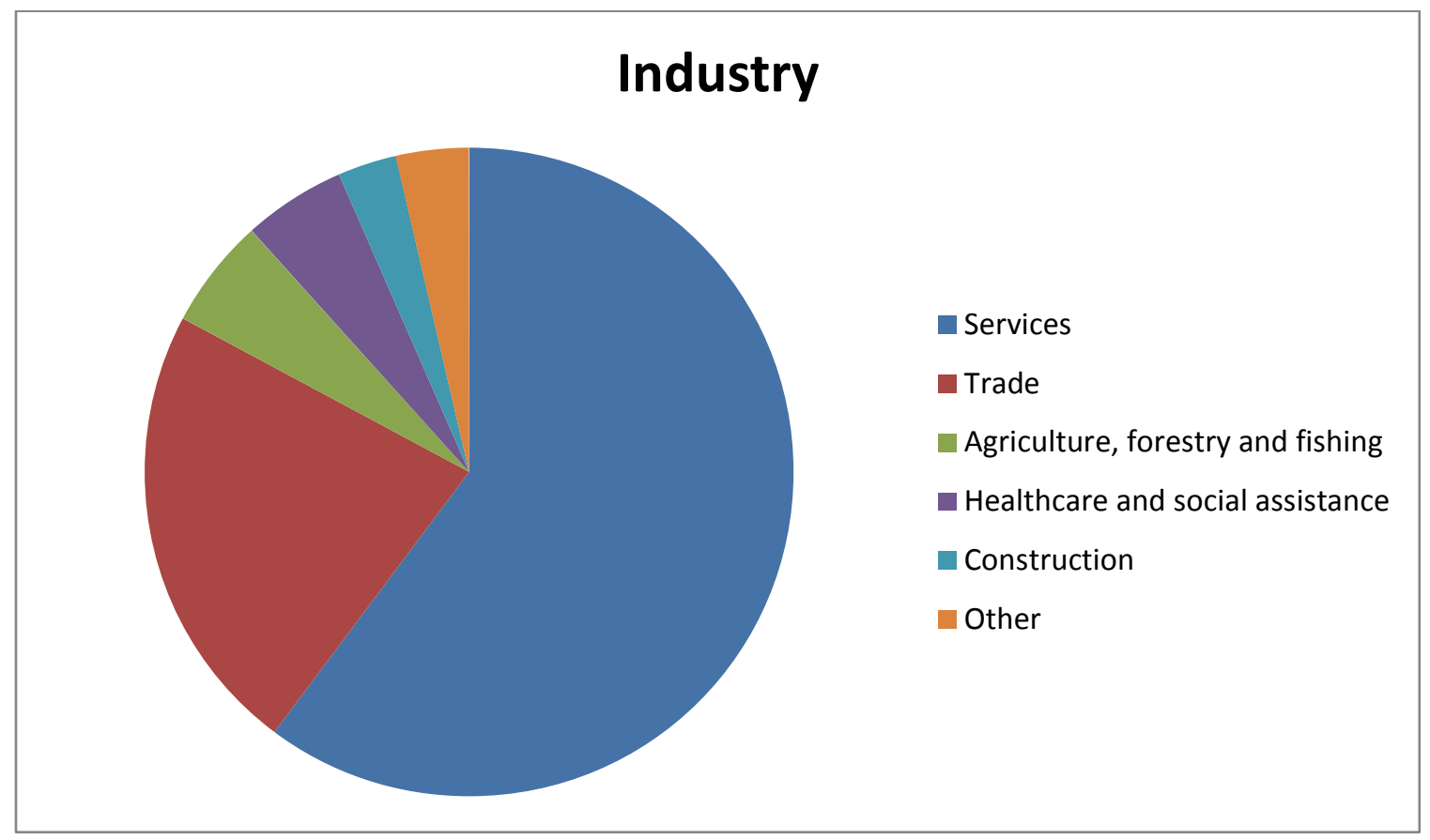

Source: Bureau of Labor Statistics, Current Population Survey. Unpublished analyses of 2011 Current Population Survey micro data by NIOSH Division of Safety Research, 2012. Note: Distribution is based on full-time equivalents (FTE; 1 FTE=2,000 hours worked per year in their primary job). 
Official U.S. employment statistics exclude youth less than 15 years of age who are known to work, especially in agriculture and informal employment. NIOSH has conducted periodic surveys of farm operators to estimate the numbers of youth who live and work on farms, and associated injuries. NIOSH estimates that more than 360000 youth less than 16 years of age worked on farms in 2009 , with only $10 \%$ of these youth reported as hired workers (versus working on their family's farm) [NIOSH 2012d]. In contrast, 43\% of the estimated 197000 16- and 17-year-olds who worked on farms were hired. Numbers of youth working on farms has decreased by about $1 / 3^{\text {rd }}$ between 2001 and 2009.

\section{Work-related Injuries}

The intent of this section of the paper is to provide an overview of the burden and patterns of injuries to workers less than 18 years of age in the U.S. The paper by Davis and Vautin [2012] in these Proceedings does an excellent job of describing available U.S. data on young worker injuries, presenting key statistics, and identifying the strengths and limitations of different data sources. Readers should refer to the Davis and Vautin paper for additional data on young worker injuries and a more comprehensive treatment of the methods, strengths and limitations of various data sources.

Work-related injuries are typically defined in the U.S. as injuries to workers sustained in the course of work. Injuries associated with commuting to and from work, and injuries to bystanders who are not working at the time of the injury, are excluded. For the most part, workrelated injury data are for formal work where there is an established employer-employee relationship. Data include injuries in family businesses, most commonly on family farms.

The U.S. has a comprehensive data system for work-related injury deaths, the Census of Fatal Occupational Injuries (CFOI), operated by the Bureau of Labor Statistics (BLS) within the Department of Labor. There are no minimum age requirements and the system includes deaths of the youngest workers (e.g. less than 16 years of age). In contrast, there is not a single definitive source of data on nonfatal work injuries. Rather, data are available from several agencies and data sources, each of which provides a limited view of the nonfatal work-related injury problem, with minimal attention to addressing injury severity and long-term outcomes. There are youth-specific concerns for some of the available data. Some data systems do not report data for youth less than 16 years of age. And, injuries associated with informal youth employment, such as lawn care, are not covered by systems based on employer reports and may not be captured in other systems such as emergency department-based systems. Piecing available data together provides insight into the size of the problem and patterns of work-related injuries, but must be recognized as incomplete with significant gaps [Davis and Vautin 2012].

In 2010, 34 youth less than 18 years of age died from injuries sustained at work in the U.S [Davis and Vautin 2012, BLS 2012b]. Nearly half (16) were younger than 16 years of age. Estimates of nonfatal work-related injuries among youth are available from a variety of sources. Variability in these estimates can largely be attributed to differences in the types of injury or workers included in each system. For example, in 2009, the BLS estimated 4350 injuries that resulted in at least one day from work among workers less than 18 years of age based on reports from private industry employers. That same year, an estimated 26600 youth less than 18 years of age were treated in emergency departments for work-related injuries [Davis and Vautin 2012]. There is overlap in types of injuries captured by each system (e.g. injuries report- 
ed by employers that resulted in at least one day away from work and also resulted in emergency department treatment), however, there are cases that would be in one system and not the other (e.g., cases reported to an employer that were not treated in an emergency department or treatment in an emergency department without any lost work days.) Additionally, there are work-related injuries that would not be captured in either system (e.g. injuries to youth that were treated in a medical clinic and did not result in any time away from work.) Thus, the number of work-related injuries to youth less than 18 years of age undoubtedly exceeded the estimated 26600 injuries treated in emergency departments in 2009, but it is unknown by how much.

Work-related injury deaths have a different epidemiology than nonfatal injuries. This is the case for young workers as well as older workers. With the exception of 15 year olds, workrelated fatality rates generally increase with age with the highest rates amongst the oldest workers (e.g. > 65 years of age) [Davis and Vautin 2012, Windau and Meyer 2005]. Rates for youth aged 16- and 17-years have been reported to be lower than those of young and middleaged workers (20 through 44 years of age) while rates for 15 year olds have been reported to be higher than young and middle-aged workers. The absence of employment data for youth younger than 15 precludes the ability to calculate a rate for the youngest workers. The relatively small difference in risk between adolescents and young and middle-aged adults, about $20 \%$ [Barkume 2000], is cause for concern. Adolescents under 18 years of age are prohibited by child labor laws from working in many of the most hazardous jobs. Though violations occur, and result in serious injury and death, employment data suggest that youth work to a lesser extent than adults in the most dangerous industries. If we look at the industry sectors with the highest fatality rates (mining, construction, transportation and agriculture) in 2004, the last year in the analysis which contrasted the rates of 15-year-olds with older workers [Davis and Vautin 2012; Windau and Meyer], only $8 \%$ of youth worked in these industries compared to $15 \%$ of adults, an approximate 2 -fold difference [NIOSH DSR 2007].

The types of events leading to young worker injury deaths are similar to those for adults with the three leading events for both youth and adults: events associated with transportation, such as operating motor vehicles and industrial vehicles, assaults, and contact with objects and equipment [BLS 2012b, CDC 2010, NIOSH 2003]. However, distribution of deaths by industry sector differs (Figure 2). Past research has shown that agriculture accounts for more young worker deaths than any other industry and a much higher proportion of young worker deaths compared to adult workers [NIOSH 2003]. The proportion of youth killed in retail was greater than for adults, whereas lower proportions of youth were killed in construction, services and manufacturing compared to adults. 
Figure 2. Industry Distribution of Work-related Injury Deaths for Youth (< 18 years of age) and All Workers, U.S., 1992-2000

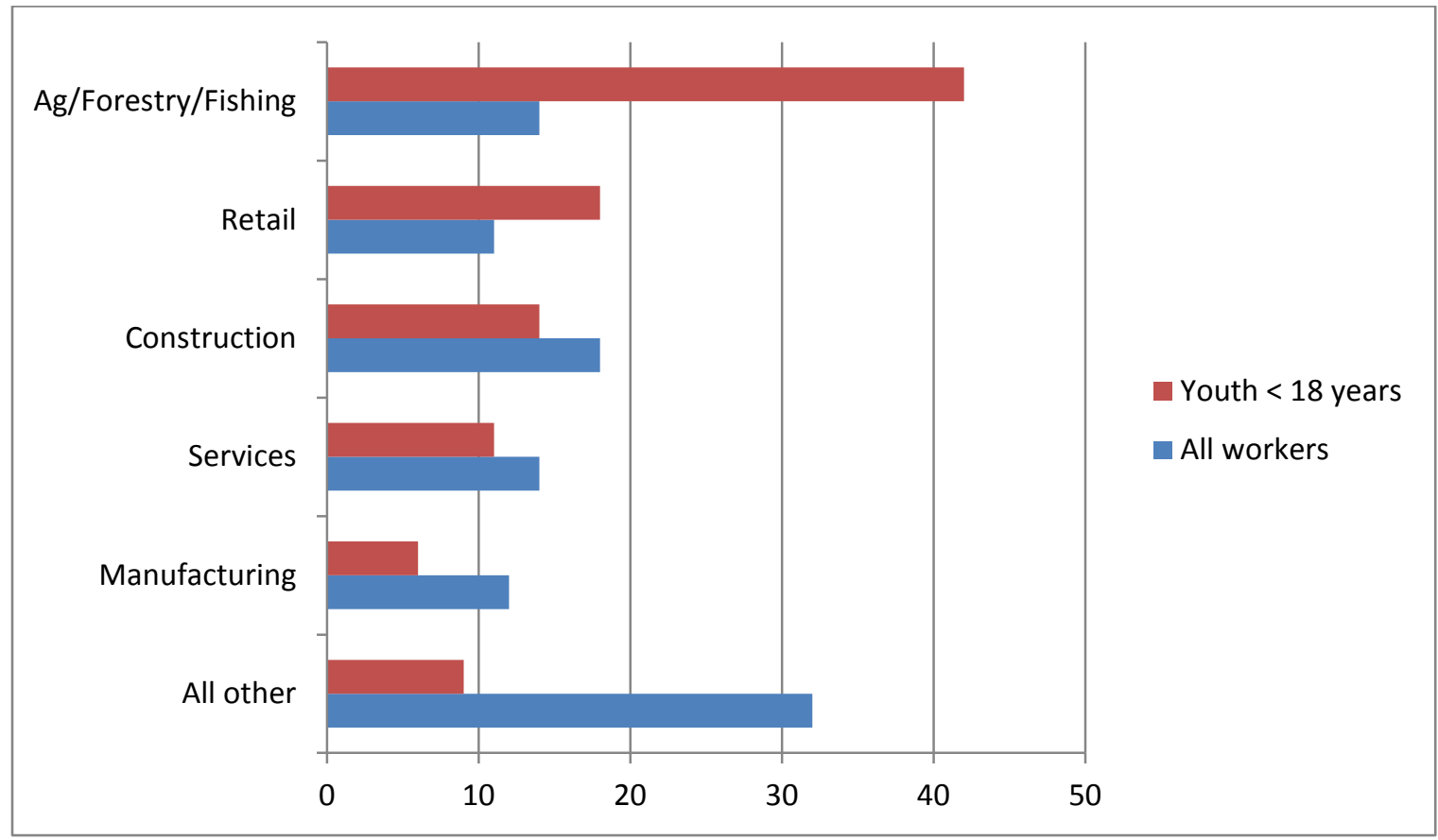

Source: Bureau of Labor Statistics, Census of Fatal Occupational Injuries Special Research Files, analysis by NIOSH. Note: Data exclude New York City deaths.

Adapted from: NIOSH [2003]. NIOSH Alert. Preventing deaths, injuries and illnesses of young workers. Cincinnati, OH: National Institute for Occupational Safety and Health, NIOSH Pub. No. 2003-128. [http://www.cdc.gov/niosh/docs/2003128/pdfs/2003128.pdf] Date accessed: October 2012.

Young worker deaths in agriculture are noteworthy. In addition to accounting for the largest number of deaths of any industry, previous research has suggested that the fatality rate is about four times greater than for youth working in other industries [Barkume et. al. 2000, Hard and Myers 2006] and comparable to the risk for young and middle-aged workers in agriculture. Nearly 2/3rds of the deaths in agriculture occurred among youth less than 16 years of age [Windau and Meyer 2005]. Nearly $60 \%$ of the deaths of youth in agriculture occurred on family farms. Farm family workers accounted for nearly $25 \%$ of all young worker deaths from 1998 to 2002.

Young worker fatality rates in the construction industry are also noteworthy. Youth working in construction were seven times more likely than their peers working in other industries to die on the job [Barkume 2000]. Additionally, data suggest that youth construction workers (ages 15 to 17 years) had twice the risk for dying as young and middle-aged construction workers (18 to 44 years of age).

Available data on nonfatal injuries suggest that youth generally have higher rates of nonfatal work-related injuries than older workers [Davis and Vautin 2012, NIOSH 2003], with workers 15- 17-years of age having approximately twice the rate of workers aged 25 years and older [CDC 2010]. While it is difficult to describe precisely the distribution of the types of injuries sustained by young workers given the different data sources, both emergency department data 
and data based on employer reports suggest that the leading types of young worker injuries are sprains/strains, lacerations, burns and abrasions [Barkume 2000, Commonwealth of Massachusetts 2012a, Windau and Meyer 2005]. Both emergency department data and data reported by employers identify the most common events leading to injury as contact with objects and equipment, falls, and bodily reaction/overexertion [CDC 2010, Windau and Meyer 2005]. Most nonfatal injuries among young workers occur in the accommodations/food services sector, followed by the retail trades [Commonwealth of Massachusetts 2012, Windau and Meyer 2005] (Figure 3).

Figure 3. Industry Distribution of Nonfatal Injuries with Days Away from Work Reported by Employers, U.S., 2003.

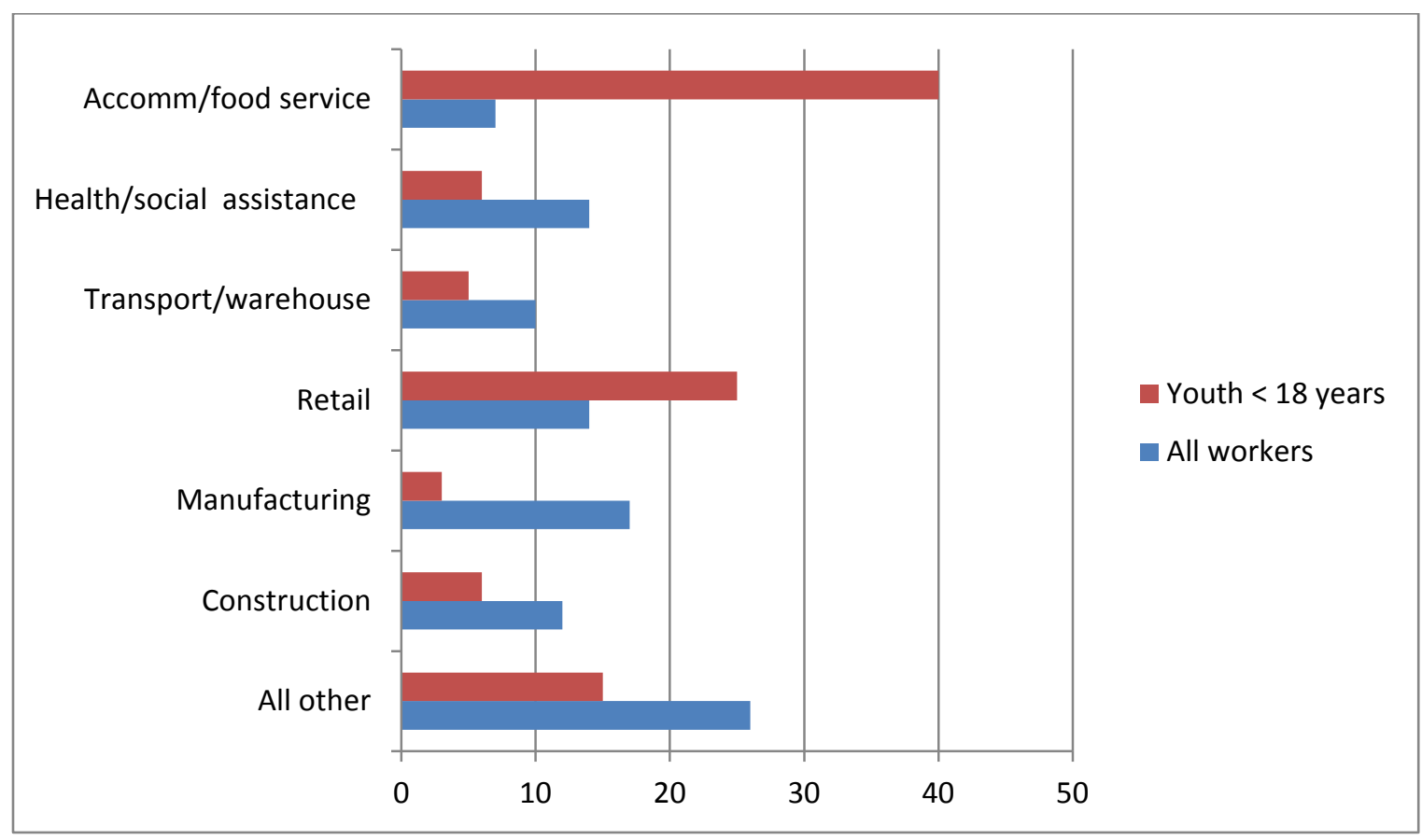

Source: Bureau of Labor Statistics, Survey of Occupational Injuries and Illnesses.

Adapted from: Windau and Meyer [2005]. Occupational injuries among young workers. Monthly Labor Review 128(10):11-23. [http://www.bls.gov/opub/m/r/2005/10/art2full.pdf] Date accessed: October 2012.

A national survey of youth working in retail and services conducted by Runyan and others [2007] provided information on the tasks that youth were performing in these jobs, as well as levels of training and supervision. This study demonstrated that youth performed a variety of tasks at work, and that there were differences by gender. For example, the study found that $84 \%$ of young female workers handled cash compared to only $43 \%$ of young males. In contrast, young males were more likely than females to lift heavy objects at work, and to work from heights. This study also found large proportions of youth doing work prohibited by federal child labor laws, and disappointing levels of safety training and supervision. Fifty-two percent of males and 43 percent of females reported doing tasks prohibited by federal child labor laws, such as using food slicers and operating box crushers. The study also found that young male 
workers were more likely to receive safety training than young females, but that young females received more supervision than males.

\section{Canada}

\section{Young Workers}

For decades, young people have represented a significant proportion of the Canadian workforce. Workplace experiences can begin as young as 12 years of age, and continue through most of one's life course. In Canada, at both the federal and provincial/territorial levels, young workers are defined as being between the ages of 15 and 24 [Lewko et. al. 2011]. Of the 18.7 million workers in the Canadian workforce in 2011, 2.8 million (16.6\%) of them were young workers, representing about two-thirds of Canadian youth [Statistics Canada, 2011a CANSIM table 282-0087].

There are currently no national large-scale surveys pertaining to youth workforce participation in Canada, nor is there a single source to which one can turn for a national picture of youth at work and their exposure to hazards. This reflects the fact that labor, and hence workplace issues are, for the most part, a provincial/territorial responsibility. The government of Canada establishes basic labor guidelines that pertain to youth under the age of 17, while the 10 individual provinces and 3 territories address specific youth workplace conditions and occupations. Statistics Canada, through its Canadian Labour Force Survey and Census, provide basic statistics and the Association of Workers' Compensation Boards of Canada (AWCBC) compile data from the 13 separate provincial/territorial workers' compensation boards on a range of factors that also include young workers. Two national surveys include a series of questions relating to youth employment (National Longitudinal Survey of Children and Youth - NLSCY; Canadian Community Health Survey - CCHS). However, neither of these surveys is specific to young workers, which complicates any effort to depict young workers at any level of detail. For farming, Canadian Agricultural Injury Reporting (CAIR) provides a national picture through its integrated surveillance project.

\section{Protection of Young Workers}

In Canada, the primary responsibility for occupational health and safety in workplaces rests with the 13 individual provincial and territorial governments. While the federal government provides a basic framework for protecting youth under the age of 17, each province/territory establishes a comprehensive set of regulations that govern workplace health and safety in general, and in some cases, young workers specifically. Only a small percentage of the legislation affecting young workers in Canada is administered at the federal level. The Canadian approach of provincial/territorial primacy in occupational health and safety differs from the U.S. approach that is more heavily guided by federal government legislation.

The focus of the Canadian federal legislation is on 1) promoting education and 2) protecting the health and safety of youth through controlling the type or quality of work that young people can undertake. The greatest percentage of legislation affecting young workers originates from the Canadian Labour Standards Code and its accompanying regulation. Simply stated, persons under the age of 17 can work, but only in occupations specified by regulation (any office or plant, in any transportation, communication, maintenance or repair service, or in any construc- 
tion work or other employment in a federal work, undertaking or business). In addition, they may be employed in such occupations only if they are not required by their provincial law to be in attendance at school, the work they are employed in is not contrary to prohibitions, the work is not in an underground mine, and it is not likely to be injurious to their health or endanger their safety [Canadian Labour Standards Regulation (s. 10 (1) (a-b))]4. According to the same legislation sources, persons under 17 years of age are restricted from working between 11:00 p.m. and 6:00 a.m. in any occupation. [Canadian Labour Standards Regulation (s. 10 (2))]4.

There are several age restrictions with respect to explosives at the federal level worth mentioning. Persons under 16 years of age are not to be employed or permitted to enter any dangerous building (except in the presence and direct supervision of an individual over the age of 21) [Explosives Regulation (s. 80)]5. Persons under 18 years of age cannot be in charge of or drive a vehicle transporting explosives or look after a vehicle transporting explosives overnight [Explosives Regulation (s. 63)]5. Persons under 21 years of age cannot be employed to drive a land vehicle transporting more than $2,000 \mathrm{~kg}$ of explosives [Explosives Regulation (s. 65)] 5.

Each province and territory builds on the basic framework of the federal government by establishing more detailed occupational health and safety regulations that specify the conditions of work, such as working at heights, and the rights and responsibilities of the worker, the employer, the Joint Health and Safety Committee, and in many cases, the supervisor. For example, Section 27 of the Ontario Occupational Health and Safety Act addresses the duties of supervisor, which applies to workers of all ages. In Section 27, specific mention is made of ensuring that a worker " $b$ ) uses or wears the equipment, protective devices or clothing that the worker's employer requires to be used or worn" as well as other duties such as advising in regard to potential or actual danger or providing written instructions [Ontario Ministry of Labour, 1990].

Promotion of education is advanced through compulsory school attendance and by restricting the amount of time that a young worker is permitted to spend on a job, given a particular age. Compulsory attendance (not working during the school day, unless the work is part of a learning experience) is set at 16 years of age for all jurisdictions other than Ontario and New Brunswick where the attendance requirement is under 18 years. Provinces and territories vary in the amount of time that a youth can work outside of the compulsory school hours, taking into account whether the work is being done on the same day as school, on a non-school day, over a number of school days, totalling of school and work time, total hours worked over 5 school days or over a week without 5 school days. Ontario and the Yukon Territory use only the federal time requirement that youth less than 17 years of age are not allowed to work between $11 \mathrm{pm}$ and $6 \mathrm{am}$. The provinces and territories vary with respect to time restrictions by age (1215 years in 2 provinces; <14 in 2 provinces; <16 years in 5 provinces; $15-18$ years in 1 province; $<18$ years in one province).

Protection of health and safety takes the form of legislation designed to control the quality of work that youth are allowed to perform. The various jurisdictions have used the Canada Labour Regulations which stipulate that "the work is not likely to injure health or endanger safety" in framing their own policies, that vary between jurisdictions. The recent review of legislation and policies [Lewko et al. 2011] reveal that, in addition to specifying the types of jobs that youth can enter, other conditions prevail at times, including consent for parent/guardian or a director in the jurisdiction, and supervision of training. There are 28 different occupations identified in the legislation across the Canadian jurisdictions. Entry to most jobs is controlled by a 
combination of age restriction and exception. For example, working in construction is totally prohibited in three provinces for youth under 16 years of age, and one province for youth under 18 years, while two provinces permit youth under 16 years and one province permits youth under 14 years to work in construction with parent/guardian consent.

The young worker policies that are similar across Canada are those that prohibit the employment of children and adolescents (1) bound by compulsory education, (2) in work that is dangerous to their health, safety, well-being or development, and (3) from handling or serving alcohol in licensed premises. All follow the federal legislation that persons bound by compulsory attendance are not to work during the time they are required to be at school. Alberta, British Columbia, Saskatchewan, Ontario and the Territories default to the federal policy with respect to the health and safety of young workers. However, half of Canada's jurisdictions have enacted additional policy to help protect young workers, which usually accompanies their respective Employment Standards or Labour Standards legislation. Policies on liquor and alcohol are determined at the provincial level and are somewhat consistent across the nation with minors prohibited from employment that handles or serves alcohol in licensed premises.

There are a number of additional factors across the country that are worth noting. Time restrictions imposed at the federal level state that no person under 17 years of age may work between 11:00 p.m. and 6:00 a.m. Every other jurisdiction except the Yukon Territory adds provisions of various types to protect young workers. The majority of the jurisdictions require written consent of a parent or guardian, and in some cases permission of the director, for a young worker to enter into a contract of employment. The majority of the time, written consent is required from the parent by the employer in order to permit a person who is younger than the prohibited employment age to work. Orientation and training are not consistent across the nation and supervision policies also vary by province. The most stringent of supervision policies comes from British Columbia where every general worker under the age of 18 must be supervised by an adult at least 19 years of age. British Columbia is unique in that employment legislation is in effect for both children employed generally and for children employed in the entertainment industry. Prince Edward Island is comparable in that it requires supervision of all work performed by workers less than 16 years of age. The rest of the supervision legislation across the country is limited in the sense that supervision is only required for certain work, ages, or time blocks.

Movement has been taking place in the legislation/policy areas that affect young workers. In British Columbia, the Occupational Health and Safety Regulation was amended in 2007, which expanded Part 3 to include "young" worker and the category of "new" worker [WorkSafeBC, 2012]. A new worker is anyone who is: new to the workplace, returning to a workplace at which hazards in that workplace have changed, affected by a change in the hazards of a workplace, or relocated to a new workplace (if hazards in that workplace are different from the hazards in the worker's previous workplace). In 2010, the Province of Ontario conducted a comprehensive review of Ontario's occupational health and safety system [Expert Advisory Panel on Occupational Health and Safety, 2010]. As a result, the category of "new" worker was incorporated with the policies pertaining to young workers.

Saskatchewan has new occupational health and safety legislation that requires young workers to obtain a certificate of employment before they can be employed in the province in most situations. All workers who are 14 years of age will have to provide their employer with a Youth 
Worker Readiness Certificate Course which includes (1) proof of age, (2) written consent from a parent or guardian and (3) a copy of their certificate. In addition the employer must keep the certificate in the employer record in case of future inspection.

Finally, the Youth Employment Act in the Province of Prince Edward Island is of particular interest because it is the only Act in Canada regarding occupational health and safety that focuses solely on youth. The occupational health and safety officer is capable of carrying out measures to ensure a youth's employment conditions meet the prescriptions of both the Youth Employment Act and the Occupational Health and Safety Act of the Province

\section{Non-regulatory Efforts to Improve Young Worker Safety}

In Canada, much of the non-regulatory efforts directed towards young workers come from the Worker's Compensation Boards of the individual provinces and territories. The Association of Workers Compensation Boards of Canada (AWCBC) recently completed a National Government/WCB Young Worker Health \& Safety Initiatives/Program Inventory that lists resources owned or managed by Canadian governments or Workers' Compensation Boards [AWCBC 2012a]. A large number of resources are organized around five themes: 1) programs or initiatives aimed at schools; 2) programs or initiatives aimed at employers and workers; 3 ) general project initiatives and programs that raise awareness on young worker health and safety issues and social marketing; 4) programs/resources aimed at parents of young workers; and 5) research. The AWCBC website [2012a] also identifies links to 22 other programs, such as Passport to Safety, or resources such as the Institute for Work and Health at the University of Toronto, that are relevant for young worker health and safety.

\section{Young Worker Employment}

For decades, young people between the ages of 15 and 24 have represented a significant proportion of the Canadian workforce. In 2011, there were approximately 1,240,000 males and 1,230,500 Canadian females ages $15-24$ years who had jobs [Statistics Canada, 2011a]. As Table 2 demonstrates, the employment rates for young Canadians have been relatively stable over the past several years. Approximately two-thirds of both females and males participate in the labor force, indicating that employment continues to be an important source of influence on youth development.

Table 2. Canadian Labour Force Participation (\%) by Sex and Age, from 2007 to 2011 (Young Workers, ages 15 - 24 years)

\begin{tabular}{|l|c|c|c|c|c|}
\cline { 2 - 6 } \multicolumn{1}{c|}{} & 2007 & 2008 & 2009 & 2010 & 2010 \\
\hline $\begin{array}{l}\text { Men } \\
15-24\end{array}$ & 67.4 & 68.0 & 65.7 & 64.4 & 64.7 \\
\hline $\begin{array}{l}\text { Women } \\
15-24\end{array}$ & 66.5 & 67.0 & 65.2 & 64.6 & 64.4 \\
\hline
\end{tabular}

Source: Statistics Canada 2011b, CANSIM, table 282-0002 
The National Longitudinal Study of Children and Youth is the only data set that provides limited workforce data for the widest range of Canadian young workers, from ages 12 to 21 years. Not surprisingly, participation increased with age, from $32.9 \%$ at 12 years to $94.4 \%$ at 21 years in 2005. As participation increases, so does the amount of time that Canadian youth spend at work. Virtually all of the working 12 year olds (92.9\%) spend very few hours (less than 10) at work.

Table 3. Full-time and Part-time Employment by Sex for 15-24 Year Olds, Canada, 2011

\begin{tabular}{|l|l|l|l|}
\hline \hline & Men & Women & Total \\
\hline $\begin{array}{l}\text { Full-time employ- } \\
\text { ment }\end{array}$ & 747300 & 551800 & 1419800 \\
\hline $\begin{array}{l}\text { Part-time em- } \\
\text { ployment }\end{array}$ & 492800 & 678700 & 1116000 \\
\hline \hline Total & 1276900 & 1258900 & 2535800 \\
\hline \hline
\end{tabular}

Source: Statistics Canada, 2011b CANSIM, table 282-0002.

As Table 3 shows, more males than females had full-time employment, while more females than males were employed part-time. Although the number of hours worked per week does not greatly differ between males and females for part-time work (less than 40 hours per week), males are more likely to work an excess of 40 hours per week than females (38\% and $21 \%$, respectively). This may reflect the gender differences in post-secondary school attendance, with more females than males attending, and completing, both secondary and post-secondary levels of education.

The large majority of youth enter the paid work force through the service sector, in such areas as accommodation and food services and the retail trades. The service sector is the largest employer of youth in Canada (54.5\%), with accommodation and food services being the most important employer within the service sector (21\%). Males and females are not equally represented within the various occupational sectors. More males tend to work in the physical labor-intensive jobs such as construction and mining (28\%, compared with $8 \%$ of females), whereas females tend to work in service sector settings more than males $(64 \%$ and $45 \%$, respectively). Although, in general, occupational sector does not differ according to age, physical labor-intensive jobs employ more young adult males than adolescent males $(59 \%$ and $49 \%$, respectively).

A more detailed picture that is specific to the service sector is presented in Table 4. The data are drawn from a survey of working youth in the Province of Ontario in 2008 [Lewko et al. 2010] and reflects the dominant role that the service sector, and in particular the restaurant and food service sector, plays in the early workplace learning experiences of youth. 
Table 4. Youth Employment in the Service Sector in Canada 2008.

\begin{tabular}{|c|c|}
\hline Type of business/service & Proportion of sample (\%) \\
\hline Restaurant and Foodservice & 52.70 \\
\hline Retail and Wholesale Distribution & 16.30 \\
\hline Tourism and Hospitality & 10.40 \\
\hline Offices and Related Services & 1.84 \\
\hline Vehicle Sales and Service & 1.18 \\
\hline Other & 16.60 \\
\hline
\end{tabular}

\section{School Attendance}

The CCHS national survey in 2005 reports that the majority (63\%) of working youth were attending school, most of whom worked part-time (70\%). Nearly a third (30\%) of youth who are in school also work full-time. In general, more females than males are in school. The proportions of males and females working part-time and full-time are fairly equal, whether they are attending school or not, with the exception of young adult females who are more likely to work full-time and attend school then males.

In 2008, a large majority of Ontario teens (91\%) reported working later than 7:00 PM on an evening before school and also reported working 2 or more nights during school. Most of these young workers were employed in the service sector, which exposed them to many types of hazards, some of which can lead to injury, or even death [Lewko et al. 2010; Statistics Canada, 2010c].

\section{Work-Related Injuries}

Canadian data on young worker injuries is diffuse and distributed across various sources. Injury statistics compiled at the federal level focus on federal jurisdiction industries, such as air transport, road transport, broadcasting, federal public service, and others, in which young workers would not be typically employed. Therefore, efforts to present a 'national' picture of youth workplace injuries relies on various sub-sets such as the Association of Workers' Compensation Boards of Canada, Statistics Canada, and the NLSCY and Canadian Community Health Survey.

Statistics on injuries and fatalities indicate that youth continue to work in various settings where they are exposed to hazardous conditions that can lead to injury or death. Across Canada in 2006 there were 15000 claim injuries (payment for loss of wages or permanent disability) from adolescents aged 15-19 (Table 5) and 35976 claims injuries from young adults aged 20-24 (Table 6). The increase is due to regulations on types of work allowed at older ages. Both tables provide an indication of the type of work environment from which the injuries were generated. For both age categories of Canadian young workers (15-19; 20-24 yrs), retail trade and manufacturing were common workplace sectors where injuries occurred. Data from the two national studies (NLSYC and CCHS) revealed that on-the-job injuries accounted for $8.6 \%$ of the reported youth injuries. An additional 3.1\% occurred while travelling to and from work. The data show that workplace injuries generally increase with age, with young adult workers being injured at a rate 1.5 times that of adolescent workers (3.9/100 workers vs. 2.6/100 workers). With respect to gender, for both adolescents and young adults, males are more likely to suffer a 
workplace injury than females, with young adults accounting for more injuries. Adolescent and young adult female injury rates do not differ.

Table 5. Accepted Claim Injuries for 15-19 Year Olds, Canada 2006

\begin{tabular}{|l|l|l|l|l|}
\hline \hline Industry & Males & Females & Unknown & Total \\
\hline Retail Trade & 2276 & 1354 & 18 & 3648 \\
\hline Manufacturing & 2507 & 373 & 9 & 2889 \\
\hline Accommodation, food and beverage services & 1417 & 1402 & 19 & 2838 \\
\hline Construction industries & 1415 & 58 & 12 & 1485 \\
\hline Wholesale retail & 765 & 128 & 5 & 898 \\
\hline Other & 2121 & 896 & 12 & 3029 \\
\hline \hline Total & $\mathbf{1 0 5 0 1}$ & $\mathbf{4 2 1 1}$ & $\mathbf{7 5}$ & $\mathbf{1 4 7 8 7}$ \\
\hline \hline
\end{tabular}

Source: AWCBC 2012b: National Work Injury Statistics Program

Table 6. Accepted Claim Injuries for 20-24 Year Olds, Canada 2006

\begin{tabular}{|l|l|l|l|l|}
\hline \hline Industry & Males & Females & Unknown & Total \\
\hline \hline Manufacturing & 7083 & 1138 & 17 & 8238 \\
\hline Retail Trade & 3915 & 2089 & 33 & 6037 \\
\hline Construction industries & 4974 & 219 & 27 & 5220 \\
\hline Accommodation, food and beverages services & 1563 & 1749 & 27 & 3339 \\
\hline Wholesale retail & 1955 & 272 & 13 & 2240 \\
\hline Other & 6578 & $\mathbf{4 2 8 0}$ & $\mathbf{4 4}$ & 10902 \\
\hline \hline Total & $\mathbf{2 6 0 6 8}$ & $\mathbf{9 7 4 7}$ & $\mathbf{1 6 1}$ & $\mathbf{3 5 9 7 6}$ \\
\hline \hline
\end{tabular}

Source: AWCBC 2012b: National Work Injury Statistics Program

Tables 7 and 8 identify the types of injuries that were the bases of accepted claims. Consistent with the large presence of young workers in the service sector, the major types of injuries were of the 'sprains and strains' type as well as 'cuts and bruises', with males out-pacing the females by over 2 to 1 . Of particular note is the exposure to more hazardous conditions that result in injuries that can impact future development and hence life chances. Both the adolescent (15-19) and young adult (20-24) workers sustained injuries of a traumatic nature. 
Table 7. Nature of Accepted Claim Injuries for 15-19 Year Olds, Canada 2006

\begin{tabular}{|l|l|l|l|l|}
\hline Nature of injury & Males & Females & Unknown & Total \\
\hline $\begin{array}{l}\text { Traumatic injuries to muscles, tendons, liga- } \\
\text { ments, joints, etc. }\end{array}$ & 3206 & 1525 & 24 & 4755 \\
\hline Open wounds & 2245 & 685 & 14 & 2955 \\
\hline Surface wounds and bruises & 1798 & 574 & 9 & 2381 \\
\hline Burns & 592 & 453 & 13 & 1058 \\
\hline $\begin{array}{l}\text { Traumatic injuries to bones, nerves, spinal } \\
\text { cord }\end{array}$ & 786 & 230 & 0 & 1016 \\
\hline Other & 1874 & $\mathbf{7 4 4}$ & 15 & $\mathbf{2 6 2 2}$ \\
\hline \hline Total & $\mathbf{1 0 5 0 1}$ & $\mathbf{4 2 1 1}$ & $\mathbf{7 5}$ & $\mathbf{1 4 7 8 7}$ \\
\hline
\end{tabular}

Source: AWCBC 2012b: National Work Injury Statistics Program

Table 8. Nature of Accepted Claim Injuries for 20-24 Year Olds, Canada 2006.

\begin{tabular}{|l|l|l|l|l|}
\hline Nature of injury & Males & Females & Unknown & Total \\
\hline $\begin{array}{l}\text { Traumatic injuries to muscles, tendons, liga- } \\
\text { ments, joints, etc. }\end{array}$ & 10189 & 4592 & 74 & 14855 \\
\hline Surface wounds and bruises & 3956 & 1291 & 15 & 5262 \\
\hline Open wounds & 4214 & 858 & 18 & 5090 \\
\hline $\begin{array}{l}\text { Traumatic injuries to bones, nerves, spinal } \\
\text { cord }\end{array}$ & 2015 & 375 & 8 & 2398 \\
\hline Other traumatic injuries and disorders & 1424 & 475 & 20 & 1919 \\
\hline Other & $\mathbf{4 2 7 0}$ & $\mathbf{2 1 5 6}$ & $\mathbf{2 6}$ & $\mathbf{6 4 5 2}$ \\
\hline \hline Total & $\mathbf{2 6 ~ 0 6 8}$ & $\mathbf{9 7 4 7}$ & $\mathbf{1 6 1}$ & $\mathbf{3 5 9 7 6}$ \\
\hline
\end{tabular}

Source: AWCBC 2012b: National Work Injury Statistics Program

While Tables 7 and 8 do not provide much insight into the nature of the trauma, the following two tables take us somewhat beyond the 'cause' category of the injury. Examination of Table 9 and Table 10 reveals that both age groups experienced traumatic force to the head and spine that could have had long-term negative implications for the young workers who were involved. 
Table 9. Part of Body Affected for Accepted Claim Injuries for 15-19 Year Olds, Canada 2006

\begin{tabular}{|l|l|l|l|l|}
\hline Part of Body & Males & Females & Unknown & Total \\
\hline \hline Head and neck & 1019 & 316 & 9 & 1344 \\
\hline Back/spine/spinal cord & 1811 & 790 & 14 & 2615 \\
\hline Upper extremities & 4286 & 1663 & 30 & 5979 \\
\hline Trunk & 776 & 267 & 6 & 1049 \\
\hline Lower extremities & 2125 & 810 & 14 & 2948 \\
\hline Multiple body parts & 358 & 250 & 1 & 609 \\
\hline Other & 126 & 115 & 1 & $\mathbf{2 4 3}$ \\
\hline \hline Total & $\mathbf{1 0 ~ 5 0 1}$ & $\mathbf{4 2 1 1}$ & $\mathbf{7 5}$ & $\mathbf{1 4 7 8 7}$ \\
\hline
\end{tabular}

Source: AWCBC 2012b: National Work Injury Statistics Program

Table 10. Part of Body Affected for Accepted Claim Injuries for 20-24 year olds, Canada 2006

\begin{tabular}{|l|l|l|l|l|}
\hline Part of Body & Males & Females & Unknown & Total \\
\hline \hline Head and neck & 2740 & 855 & 20 & 3615 \\
\hline Back/spine/spinal cord & 5689 & 2635 & 40 & 8364 \\
\hline Upper extremities & 8264 & 2575 & 38 & 10877 \\
\hline Trunk & 2454 & 980 & 22 & 3456 \\
\hline Lower extremities & 5458 & 1715 & 32 & 7205 \\
\hline Multiple body parts & 1160 & 712 & 9 & 1881 \\
\hline Other & $\mathbf{3 0 3}$ & $\mathbf{2 7 5}$ & 0 & 578 \\
\hline \hline Total & $\mathbf{2 6 0 6 8}$ & $\mathbf{9 7 4 7}$ & $\mathbf{1 6 1}$ & $\mathbf{3 5 9 7 6}$ \\
\hline
\end{tabular}

Source: AWCBC 2012b: National Work Injury Statistics Program

Traumatic injuries, such as those associated with the head and neck and back/spine/spinal cord, often result in complications that have long-term consequences and substantial costs. When both categories are combined, they account for $27 \%$ of the accepted injury claims from the $15-19$ year olds and 33\% of the claims from the injured $20-24$ year olds. This suggests that there may be a more serious undercurrent to the young worker injury dilemma than the 'sprains and strains' and 'cuts and bruises' mentioned previously. Underscoring this position is the recent research on occupational traumatic brain injury both in Canada [Colantonio et al. 2009] and the U.S. [Tiesman et al. 2011]. Each study represents the first in their respective countries and reinforces the importance of recognizing that traumatic injuries vary across levels of severity and hence differential long-term consequences and costs.

Similar to the earlier information on young workers in the U.S. each year, a number of Canadian young workers are fatally injured while working. However, unlike the fatality data available in the U. S., national data in Canada is more limited. The most accessible source of data on young worker fatalities comes from the Association of Workers' Compensation Boards of Canada (AWCBC), which collects information from all workers' compensation boards across the na- 
tion. The AWCBC reports that 109 young workers died during the 2008-2010 time frame. Thirty-one were youth ages 15-19 years, while the 20-24 year group accounted for 78 fatalities. No more detailed information is publically available regarding these fatalities. It can be assumed that a large number of these fatalities would have occurred in the Province of Ontario, where the Ministry of Labour reports 16 fatalities in the 15-24 year age group between 2008 and 2010.

Agricultural-related injuries led to 248 deaths in the 1-15 year age group across Canada between 1990-2008. A majority of the fatalities (81\%) were males and $44 \%$ of the fatalities were children under 5 years of age (5-9 yrs $-32 \%$; $10-14$ yrs $-24 \%)$. While most fatalities were related to work done by the child $(71 \%)$, in $79 \%$ of these situations, someone other than the child was doing the work that led to the fatality. [CAIR, 2011]

\section{Conclusion}

This overview of youth employment and health and safety issues of young workers in the U.S. and Canada demonstrates many similarities, and some differences. Despite the different definitions of young workers used in the U.S. and Canadian overviews, the predominance of young worker employment in services and retail trades is clear. Another similarity is engagement of both the public and private sectors indicating broad interest in improving the safety and well-being of young workers in both countries. Data limitations are another similarity. The absence of comprehensive injury data, and limited ability to identify the most severe and disabling injuries, hamstring the ability within both countries to use data to guide research and prevention. Though available data provide some insights into the burden and patterns of injury in each country, there are significant gaps that may be obscuring large numbers of injuries among some groups and may result in some compelling young worker injuries not being addressed.

There are substantive differences in the legal frameworks for protecting young workers in each country, with U.S. efforts largely centered in the federal government and Canadian efforts more centered in the provinces and territories. Despite the difference in legal frameworks and though the specifics vary, both countries include provisions to limit work interfering with the schooling of teenagers and to limit youth from working in especially dangerous work.

In conclusion, there are more similarities than differences in young worker experiences between the U.S. and Canada. This illustrates the potential for joint efforts in research and prevention and speaks to the value of this U.S. - Canadian series of symposia. There is undoubtedly much that we can learn from each other and opportunities to leverage our mutual interests.

Acknowledgement: Thanks to Audrey Reichard for analyzing U.S. Current Population Survey micro data.

Disclaimer: The findings and conclusions in this report are those of the authors and do not necessarily represent the views of the National Institute for Occupational Safety and Health or Laurentian University. 


\section{References}

ASSE (American Society of Safety Engineers) [2012]. ASSE target teen work safety tool kit. [http://www.asse.org//teensafety/index.php] Date accessed: October 2012.

AWCBC (Association of Workers' Compensation Boards of Canada) [2012a]. National Government/WCB Young Worker Health and Safety Initiatives/Program Inventory 2012/2013. http://www.awcbc.org/common/assets/english\%20pdf/2012-2013-national inventory.pdf. Date accessed: November 2012.

AWCBC (Association of Workers' Compensation Boards of Canada) [2012b]). National Work Injury Statistics - Fatalities, by Age and Jurisdiction 2008-2010.

Barkume A [2000]. Chapter 6. Occupational injuries, illnesses and fatalities. In, Report on the youth labor force. Washington, D.C.: Department of Labor. [http://www.bls.gov/opub/rylf/rylfhome.htm] Date accessed: October 2012.

BLS (Bureau of Labor Statistics) [2005]. Work activity of high school students: Data from the National Longitudinal Survey of Youth 1997. Washington, D.C.: U.S. Department of Labor, Bureau of Labor Statistics, USDL 05732. [ http://www.bls.gov/news.release/archives/nlsyth 04272005.pdf] Date accessed: October 2012.

BLS [2012a]. Employment and Earnings, January 2011. Household Data Annual Averages, Table 3. Employment status of the civilian noninstitutional population by age, sex and race; Table 22. Persons at work in nonagricultural industries by age, sex, race, Hispanic or Latino ethnicity, marital status, and usual full- or parttime status. [http://www.bls.gov/cps/cpsa2010.pdf] Date accessed: October 2012.

BLS [2012b]. Census of fatal occupational injuries - current and revised data: Table A-7. Fatal occupational injuries by worker characteristics and event or exposure, All United States, 2010. [http://www.bls.gov/iif/oshwc/cfoi/cftb0256.pdf] Data accessed: October 2012.

CAIR (Canadian Agricultural Injury Reporting) [2011]. Agricultural Fatalities and Hospitalizations in Ontario 19902008.

CAIR (Canadian Agricultural Injury Reporting) [2005]. Agricultural Fatalities in Canada 1990-2008.

CDC (Centers for Disease Control and Prevention) [2010]. Occupational injuries and deaths among younger workers --- United States, 1998-2007. By Estes CR, Jackson LL, Castillo DN. Morbidity and Mortality Weekly Report MMWR 59(15):449-455.

CDC [2011]. Ten great public health achievements --- United States, 2001-2010. Morbidity and Mortality Weekly Report MMWR 60 (19): 619-23.

[http://www.cdc.gov/mmwr/preview/mmwrhtml/mm6019a5.htm?s cid=mm6019a5 w] Date accessed: October 2012.

CYWSH (Center for Young Worker Safety and Health at Georgia Tech Research Institute) [2012]. Center for Young Worker Safety and Health at Georgia Tech Research Institute. [http://www.youngworker.gatech.edu/] Date accessed: October 2012.

CLC (The Child Labor Coalition) [2012]. Stop child labor: the Child Labor Coalition. [http://stopchildlabor.org/] Date accessed: October 2012.

Colantonio, A, McVittie, D, Lewko, J, Yin, J. [2009]. Traumatic brain injury in the construction industry. Brain Inj 2009; $23(11): 873-78$.

Commonwealth of Massachusetts [2012a]. Teens at work: Work-related injuries to teens in Massachusetts, 20052009. Boston, MA: Commonwealth of Massachusetts, Massachusetts Department of Public Health, Occupational Health Surveillance Program, Teens at Work: Injury Surveillance and Prevention Project, Spring 2012.

Commonwealth of Massachusetts [2012b]. Work-related injuries to workers under age 18. [http://www.mass.gov/eohhs/gov/departments/dph/programs/health-stats/ohsp/injuries-workersunder-18/] Date accessed: October 2012.

Davis L, Vautin BP [2013]. Tracking work-related injuries among young workers: An overview of surveillance in the United States. In, Health and safety of young workers: Proceedings of a U.S. - Canadian Series of Symposia. Cincinnati, $\mathrm{OH}$ : National Institute for Occupational Safety and Health.

Expert Advisory Panel on Occupational Health and Safety= [2010]. Report and Recommendations to the Minister of Labour. Toronto, Ontario. http://www.awcbc.org/common/assets/english\%20pdf/2012-2013national inventory.pdf. 
Hard DL, Myers JR [2006]. Fatal work-related injuries in the agriculture production sector among youth in the United States, 1992-2002. J Agromedicine 11(2): 57-65.

Healthy People 2020 [2012]. Occupational Safety and Health, Objective OSH-2.3, Reduce nonfatal work-related injuries, adolescent workers aged 15 to 19 years.

[http://www.healthypeople.gov/2020/topicsobjectives2020/objectiveslist.aspx?topicld=30]. Date accessed: October 2012.

Lewko, J., Hall, K., Egeh, G., Volpe, R., Fuhringer, C., \& Tremblay, C. L. [2011]. Current Health and Safety Policies Protecting Young Workers in Canada.

Lewko, J., Runyan, C., Tremblay, C., Staley, J., \& Volpe, R. (2010). Workplace Experiences of Young Workers in Ontario. Canadian Journal of Public Health: 101, 5; 380-384.

LOHP (Labor Occupational Health Program, UC Berkeley) [2012]. Youngworkers.org: California resource network for young workers' health and safety. [http://www.youngworkers.org/] Date accessed: October 2012.

Marshall, K. [2007]. The busy lives of teens. Perspectives on Labour and Income, 8(5), 5-11.

Massachusetts Labor and Workforce Development [2013]. Youth employment information. [http://www.mass.gov/lwd/labor-standards/dls/youth-employment/]. Date accessed: May 2013.

NCES (National Center for Education Statistics) [2012a]. Youth indicators 2005: Trends in the well-being of American youth: Indicator 38: Spending patterns of high school seniors. [http://nces.ed.gov/programs/youthindicators/Indicators.asp?PubPageNumber=38\&ShowTablePage=Tabl esHTML/38.asp]. Date accessed: September 2012.

NCES [2012b]. Youth indicators 2011: America's youth: Transitions to adulthood. Indicator 25: Employment of 16and 17-year old students. [http://nces.ed.gov/pubs2012/2012026/chapter3 25.asp] Date accessed: October 2012.

NCOSH (National Council for Occupational Safety and Health) [2012]. Young workers. [http://www.coshnetwork.org/node/18] Date accessed: October 2012.

NIOSH (National Institute for Occupational Safety and Health) [2002]. National Institute for Occupational Safety and Health (NIOSH) recommendations to the U.S. Department of Labor for changes to Hazardous Orders. Cincinnati, OH: National Institute for Occupational Safety and Health, May 3, 2002. [http://www.cdc.gov/niosh/docs/NIOSHRecsDOLHaz/pdfs/DOL-recomm.pdf]. Date accessed: October 2012.

NIOSH [2003]. NIOSH Alert: Preventing deaths, injuries and illnesses of young workers. By Mardis AL and Pratt SG. Cincinnati, OH: National Institute for Occupational Safety and Health, NIOSH Pub No. 2003-128. [http://www.cdc.gov/niosh/docs/2003-128/pdfs/2003128.pdf] Date accessed: October 2012.

NIOSH [2012a]. Young worker safety and health. [http://www.cdc.gov/niosh/topics/youth]. Date accessed: October 2012.

NIOSH [2012b]. Childhood agricultural injury prevention initiative. [http://www.cdc.gov/niosh/topics/childag/] Date accessed: October 2012.

NIOSH [2012c]. Talking safety: Teaching young workers about job safety and health. [http://www.cdc.gov/niosh/talkingsafety/] Date accessed: October 2012.

NIOSH [2012d]. Childhood agriculture injury prevention initiative: Childhood agriculture injury surveillance (CAIS) data: Farm youth demographic estimates: Table D-11. National estimates of working youth ( $<20$ years) on U.S. farms by type of farm and age group; Table D-15. National estimates of hired youth (<20 years) on U.S. farms by type of farm and age group. [http://www.cdc.gov/niosh/topics/childag/CAIS/default.html] Data accessed: October 2012.

NIOSH DSR (Division of Safety Research [2007]. Unpublished analyses of 2004 Current Population Survey micro data files. Morgantown, WV: National Institute for Occupational Safety and Health, Division of Safety Research.

NIOSH DSR [2012]. Unpublished analyses of 2011 Current Population Survey micro data files. Morgantown, WV: National Institute for Occupational Safety and Health, Division of Safety Research.

NRC (National Research Council) [1998]. Youth at work: Health, safety, and development of working children and adolescents in the United States. Washington, D.C.: National Academy Press.

Oklahoma State Department of Health [2006]. Injury updates: A report to Oklahoma injury surveillance participants: Work-related deaths among young workers under 25 years of age, Oklahoma, 1998-2004. Oklahoma City, OK: Oklahoma State Department of Health, Injury Prevention Service. 
Ontario Ministry of Labour. [1990]. Ontario Occupation Health and Safety Act.

Oregon Department of Human Services [2008]. Putting data to work: Oregon Worker Illness and Injury Prevention Program (OWIPP). Portland, OR: Oregon Department of Human Services, Public Health Division, Office of Environmental Public Health Toxicology, Assessment and Tracking Services (TATS).

[http://public.health.oregon.gov/HealthyEnvironments/WorkplaceHealth/Documents/Edition8Youngwor kers.pdf] Date accessed: October 2012.

OR-FACE (Oregon Fatality Assessment and Control Evaluation) [2009]. Young workers: Stay alive on the job! Portland, OR: Oregon Health \& Science University, Center for Research on Occupational and Environmental Toxicology, Oregon Fatality Assessment and Control Evaluation. HA-4-2 ${ }^{\text {nd }}$ edition. [http://www.ohsu.edu/xd/research/centers-institutes/croet/outreach/orface/publications/upload/YoungWorker2Ed.pdf] Date accessed: October 2012.

Oregon Health Authority [2012]. Young workers. [http://public.health.oregon.gov/HealthyEnvironments/WorkplaceHealth/Pages/youngworkers.aspx] Date accessed: October 2012.

OSHA (Occupational Safety and Health Administration) [2012]. Young workers you have rights! [http://www.osha.gov/youngworkers/] Date accessed: October 2012.

OYWHSC (Oregon Young Worker Health and Safety Coalition) [2012]. Oregon young employee safety - O [yes]. [http://www.oregonyoungworkers.org/home.html]. Date accessed: October 2012.

Runyan CW, Schulman M, Dal Santo J, Bowling JM, Agans R, Ta M [2007]. Work-related hazards and workplace safety of US adolescents employed in the retail and service sectors. Pediatrics 119(3): 526-534.

State Compensation Insurance Fund [2012]. Young worker safety. [https://www.statefundca.com] Date accessed: October 2012.

Statistics Canada. [2011a]. Table 282-0087: Labour Force Statistics by Sex and Age, CANSIM (database).

Statistics Canada. (2011b). Table 282-0002: Labour force characteristics by sex and age, CANSIM (database).

Texas Mutual Insurance Company [2012]. Workplace safety and the young worker. [http://www.texasmutual.com/employers/teenworkers.shtm] Date accessed: October 2012.

Tiesman, H. M., Konda, S., \& Bell, Lewko, J., [2011]. The epidemiology of fatal occupational traumatic brain injury in the U.S. American Journal of Preventive Medicine, 4(1), 61-67.

University of Washington. Health and safety awareness for working teens. [ http://www.uwworksafe.com/] Date accessed: October 2012.

Walters JK, Christensen KA, Green MK, Karam LE, Kincl LD [2010]. Occupational injuries to Oregon workers 24 years and younger: an analysis of workers' compensation claims, 2000-2007. American Journal of Industrial Medicine 53 (10): 984-94.

WHD (Wage and Hour Division) [2007]. Child labor requirements in agricultural occupations under the Fair Labor Standards Act (Child labor bulletin 102). Washington, D.C.: U.S. Department of Labor, Employment Standards Administration, Wage and Hour Division, WH-1295 (Revised June 2007).

WHD [2010]. Child labor provisions for nonagricultural occupations under the Fair Labor Standards Act. Washington, D.C.: U.S. Department of Labor, Wage and Hour Division, Child labor bulletin 101, WH-1330, Revised July 2010. [http://www.dol.gov/whd/regs/compliance/childlabor101 text.htm] Date accessed: October 2012.

WHD [2012a]. Updating Child Labor Regulations for the $21^{\text {st }}$ Century. [http://www.dol.gov/whd/cl/whdfsCLFR.htm]. Date accessed: September 2012.

WHD [2012b]. Youth rules! Preparing the $21^{\text {st }}$ century workforce. [http://youthrules.dol.gov/index.htm]. Date accessed: October 2012.

WA DLI (Washington State Department of Labor \& Industries). Teen workers. [http://www.Ini.wa.gov/WorkplaceRights/TeenWorkers/] Accessed: October 2012].

Windau J, Meyer S [2005]. Occupational injuries among young workers. Monthly Labor Review 128(10):11-23. [http://www.bls.gov/opub/mlr/2005/10/art2full.pdf] Date accessed: October 2012.

WorkSafeBC. [2012]. Occupational Health and Safety (OHS) Regulation. http://www2.worksafebc.com/publications/OHSRegulation/Home.asp. 


\title{
Identifying Good and Bad Jobs in Adolescence
}

\author{
Jeremy Staff, PhD, The Pennsylvania State University \\ John E. Schulenberg, PhD, The University of Michigan \\ Jerald G. Bachman, PhD, The University of Michigan \\ Michael J. Parks, The Pennsylvania State University \\ Matthew VanEseltine, PhD, Bowling Green State University
}

*Earlier versions of this manuscript were presented in Toronto, Ontario Canada as part of the Young Worker Symposium series (2007) and at the 2008 Annual Meeting of the American Sociological Association, Boston. This paper uses data from the Monitoring the Future study, which is supported by a grant from the National Institute on Drug Abuse (R01 DA01411). The first author gratefully acknowledges support from a Mentored Research Scientist Development Award in Population Research from the National Institute of Child Health and Human Development (K01 HD054467). The findings and conclusions in this report are those of the authors and do not necessarily represent the views of the sponsors. We thank Matthew Cox, Kathryn Johnson, and Donald Miller for constructive comments and other assistance. Correspondence can be sent to Jeremy Staff, Department of Sociology, The Pennsylvania State University, 211 Oswald Tower, University Park, PA 16802-6207 (E-mail: jus25@psu.edu).

Among adult workers, it is clear that characteristics of "bad" jobs include low pay and prestige, no healthcare benefits or pensions, inadequate social support, inflexible schedules, and nonstandard work arrangements [Kalleberg, Reskin, and Hudson 2000]. Among teenage workers, however, it is unclear whether all jobs are bad or whether certain jobs are better than others. Whereas some scholars have argued teenage work experiences are rarely beneficial [Steinberg and Cauffman 1995], recent research suggests otherwise, showing considerable variability in the quality-relevant job characteristics. For instance, Hirschman and Voloshin [2007] found that youth employed as lifeguards, athletic coaches, tutors, office clerks, or receptionists were in "good" jobs because they earned higher wages and worked fewer hours per week than youth who worked in retail, food service, or blue-collar jobs. Research by Mortimer and colleagues [Call and Mortimer 2001; Mortimer 2003; Mortimer, Harley, and Staff 2002; Mortimer and Staff 2004] shows that the employment conditions of teenagers vary across other important dimensions as well, such as amount of adult supervision and support; degree of extrinsic and intrinsic rewards; career potential; stressful features; and compatibility with school, family, and friends. These recent studies suggest that not all teenagers work in bad jobs, and that some types of jobs might be more beneficial than others.

In this study, we use nationally representative data from the ongoing Monitoring the Future study [Johnston, O'Malley, Bachman, and Schulenberg 2011a; 2011b] to show how twelfthgrade students' perceptions of work quality vary significantly by job type. In addition to work hours and hourly pay, we consider whether job type varies by three key dimensions of work quality: (1) age of coworkers and supervisors; (2) work conflict and stress; and (3) skill utilization and career potential. Furthermore, we control for other factors that may relate to job quality and type, such as academic orientation and school performance, educational expectations, work preferences, and sociodemographic characteristics. Finally, our use of large, nationally representative samples of students allows us to examine the potential moderating role of family socioeconomic origins on the relationship between job type and perceived job quality. 


\section{Characteristics of a Good Job in Adolescence}

There are at least three dimensions of paid work that we can use to distinguish good from bad jobs in adolescence. First, a good job can counter the common experience of agesegregation among youth. For many reasons, social scientists have long advocated that teenagers should work with adult coworkers and supervisors [see Staff, Messersmith, and Schulenberg 2009 for a review]. For instance, adult mentors can provide vocational guidance by teaching young workers valuable job-related skills, by facilitating connections to other adult supervisors and coworkers, or by providing references for future employment opportunities. Adult coworkers and supervisors may also provide educational guidance by showing young workers the educational requirements they will need for future professions, as well as helping them apply what they have learned in school at work. Adults in the workplace may also teach young workers valuable "softskills," such as how to be responsible, independent, and trustworthy; how to conduct oneself in an interview; and how to interact with customers and other coworkers. On the other hand, a characteristic of a bad job is an abundance of same-age coworkers. Adolescents who work primarily alongside teenage supervisors and coworkers will have fewer opportunities to learn vocational skills and positive work ethics from adult mentors. Furthermore, youth employed in agesegregated jobs may develop a tolerance for occupational deviance and display poor habits in the workplace [Wright and Cullen 2000].

Second, a good job allows youth to balance their multiple commitments to school, family, friends, and paid work [Mortimer 2003]. In particular, the compatibility of work with school has long been a salient issue for employed teenagers; scholars have especially worried that paid work may interfere with academic pursuits and thus compromise long-term socioeconomic attainment [Marsh and Kleitman 2005; Steinberg and Cauffman 1995]. Employment/school incompatibility in adolescence is also associated with heightened depressed mood and a reduced sense of well-being [Mortimer et al. 2002]. Furthermore, youth have higher rates of schoolrelated misconduct, alcohol use, and contact with the police when they believe that their jobs are interfering with their academic pursuits [Staff and Uggen 2003]. Excessive demands and stressors at work may further interfere with commitments to school, family, and friends, as well as push youth too quickly into more "adultlike" roles and leisure behaviors [Bachman and Schulenberg 1993]. Moreover, experiencing work stressors during adolescence is positively related to depressed mood, and negatively related to self-esteem and self-efficacy [Mortimer and Staff 2004; Finch, Shanahan, Mortimer, and Ryu 1991; Mortimer et al. 2002; Shanahan, Finch, Mortimer, and Ryu 1991]. Based upon this research, bad jobs involving high work demands, stressors and school incompatibility could have numerous undesirable effects on positive youth development.

Third, a good job provides skills and workplace knowledge as preparation for adult work, thus easing the transition to adulthood by allowing for stronger connections between adolescent and adult experiences. Skill utilization and learning opportunities on the job have also been shown to promote the development of both intrinsic and extrinsic occupational values in adolescence [Mortimer et al. 1996], and provide long-term vocational benefits in young adulthood [Mortimer 2003]. Skill utilization can improve relations with family and peers and diminish depressive affect among boys [Shanahan et al. 1991]. Research also shows that youth are less 
likely to use illicit drugs and alcohol when early work experiences are connected to future careers and provide young people with opportunities to learn new job skills [Staff and Uggen 2003].

High wages and limited hours of work per week may also signify a good job in adolescence [Hirschman and Voloshin 2007]. However, a long-standing critique of youth work is that most teenagers work for discretionary income (i.e., to buy clothes, music, and computer games or to spend on friends and social activities) rather than to help provide for the financial needs of the household or to save for future educational expenses, which may in turn engender a "premature affluence" in adolescence [Bachman 1983]. In addition, considerable research shows that students who work intensively during the school year (i.e., more than 20 hours per week during high school) have worse educational outcomes, and are more likely to engage in delinquency and substance use, than youth who work limited hours or not at all [Bachman and Schulenberg 1993; Bachman et al. 2011; Mortimer et al. 1996]. Some researchers, however, have challenged whether work hours indeed have a nonlinear effect on academic achievement and adjustment [Marsh and Kleitman 2005; Steinberg and Cauffman 1995], arguing that even moderate work hours may have adverse effects especially if other work conditions are poor.

In summary, although it is a debatable claim whether high pay and moderate work hours benefit working youth, most scholars agree that good jobs for teenagers involve adult coworkers and supervisors; compatibility with school, parents, and friends; and learning opportunities and career potential. Our purpose in this study is to examine the extent to which jobs vary in associations with these three types of work quality among national samples of high school seniors.

\section{Spurious Factors}

When assessing whether some types of adolescent jobs are better than others, it is important to control for other factors that may relate to job type and quality, such as academic orientation and performance, educational expectations, work preferences, and socioeconomic origins. For instance, students with little interest in school may find paid work more intrinsically and extrinsically rewarding than those youth who have greater commitment to and success in school [National Research Council 1998]. Youth with low academic engagement and educational aspirations may also be less likely to feel that their jobs are interfering with school, because their interest in education is already minimal. For these reasons, it is important to control for academic orientation, school performance, and educational expectations that may be spuriously related to perceptions of work quality and job type.

At the same time, students with a strong preference to work, and especially those youth who wish to spend long hours on the job, may rate jobs more favorably than youth who have little desire to work during adolescence, irrespective of the actual type of job they hold. Research shows that youth who are not employed perform worse in school and exhibit more delinquency and other problem behaviors when they desire to spend long hours on the job compared to when they desire moderate hours of work [Staff et al. 2010; Staff, Schulenberg, and Bachman 2010]. Therefore, when assessing whether some jobs are rated better than others, early work intensity preferences may constitute an important control for youth who are disengaged from school and perhaps striving for a more adultlike status. We therefore control for work intensity preferences. 
Finally, we control for gender, race/ethnicity, and family socioeconomic status (SES) because these factors influence whether teenagers work, how many hours they work, what types of jobs they hold, and the perceived quality of these early work experiences [U.S. Department of Labor 2000; Mortimer 2003]. For instance, though boys and girls are equally likely to be employed during the school year, boys average more hours of paid work than girls. In addition, boys report greater earnings and advancement opportunities but also greater demands and stressors, whereas girls report more learning opportunities than boys [Mortimer 2003]. Regarding race and ethnicity, white youth have higher rates of employment than African-American and Hispanic youth during the school year, but African-American and Hispanic teenagers average more hours of employment when they are employed. Socioeconomic background also influences early work experiences, as youth in lower income households are less likely to hold jobs but average longer hours of work than their high-SES counterparts [Entwisle, Alexander, and Olson 2000; Hirschman and Voloshin 2007; National Research Council 1998; Staff and Mortimer 2008]. Youth from disadvantaged family backgrounds are also more likely to work in dangerous jobs, and experience greater work demands and stressors than youth from more advantaged backgrounds [Mortimer 2003]. For these reasons, we control for gender, race/ethnicity, and family SES in the present study.

We also include these demographic factors in our analyses because they might condition the relationship between job type and perceptions of work quality. For instance, youth who reside in poor urban neighborhoods have fewer opportunities to find jobs than youth in higherSES neighborhoods [Newman 1999]. Thus, youth from economically disadvantaged backgrounds may rate jobs more favorably than other youth because disadvantaged youth find jobs harder to obtain. Moreover, longitudinal research on children in Baltimore shows that working teenagers who come from poor families often use part of their earnings for school supplies and to help financially support the household [Entwisle et al. 2000: p. 292]. Therefore, youth from lower SES backgrounds may be less likely to find that work is incompatible with school and family obligations than students from more advantaged families. For these reasons, it is important to assess whether the relationship between job type and quality is different for more and less advantaged youth.

\section{Data and Measures}

\section{The Monitoring the Future Study}

The data we analyze come from the Monitoring the Future (MTF) project, an ongoing cohort sequential and prospective study of middle and high school students [Johnston et al. 2011a; 2011b]. Each year, three-stage probability sampling procedures are used to select large, nationally representative samples of 12 th graders from both public and private high schools. Selfcompleted questionnaires using optical scanning and multiple forms were administered in school, usually in classroom settings. Approximately 90 percent of students respond to the baseline surveys, with nearly all nonresponse due to absenteeism. Our analysis sample is based upon a random one sixth of 12th graders from 1991 to 2006-those who completed the questionnaire form containing measures of the quality and type of work experiences during the 12th-grade school year. 
The present analyses are based on data from 12th-grade respondents with valid data on at least some of the outcome variables. Of the 36,590 students who provided information regarding their employment, approximately 30 percent of students were not currently employed. Of the remaining cases, 24,933 employed respondents in 2005 and 2006 were asked only two of the twelve questions used to construct our work quality measures. Thus, the number of cases for each outcome variable ranged from 20,765 to 24,229 . An additional 23 percent of respondents were missing information on at least one of our predictor variables (e.g., family background, race/ethnicity, school performance, and preference for work).

Though correlations between the job quality variables and an indicator of missing data were low, ranging from -.006 to .029 , we used multiple imputation to regain respondents who were missing information on at least one of the predictor variables in our study. To do this we used the proc MI and MIANALYZE commands available in SAS Version 9.1. We included all independent and dependent measures in the imputation procedure, but included only respondents with valid data on our outcome measures in these analyses. After imputation, the analysis sample ranged from 20,765 to 24,229 respondents.

\section{Outcome Variables}

Building upon the research discussed in the introduction -- especially that of Mortimer [2003] -- our measures of 12th-grade work quality include: (1) the age of coworkers and supervisors; (2) work stress and the compatibility of work with school, family, and friends; and (3) skill development and career potential. Descriptive statistics for all variables are shown in Table 1. 
Table 1. Descriptive Statistics

\begin{tabular}{|c|c|c|c|}
\hline & Mean or $\%$ & Std Dev & $\mathbf{N}$ \\
\hline \multicolumn{4}{|l|}{ Perceived Work Quality } \\
\hline Other workers within 2 or 3 yrs age & 2.912 & 1.477 & 24,221 \\
\hline Supervisor age 25 or younger & $14 \%$ & & 24,229 \\
\hline Job stress & 2.740 & 1.314 & 20,972 \\
\hline Role Conflict: Job interferes with family, school, and social life & 2.269 & 1.060 & 21,005 \\
\hline Skills utilization & 2.505 & 1.116 & 21,201 \\
\hline Happy for Life & 1.725 & 1.199 & 20,860 \\
\hline Stepping Stone & 1.958 & 1.313 & 20,811 \\
\hline Not Just for the Money & 2.795 & 1.456 & 20,765 \\
\hline \multicolumn{4}{|l|}{ Job Type } \\
\hline Newspaper route, yard work, or odd jobs & $5 \%$ & & 24,933 \\
\hline Fast food & $14 \%$ & & 24,933 \\
\hline Restaurant worker & $14 \%$ & & 24,933 \\
\hline Babysitting or childcare & $6 \%$ & & 24,933 \\
\hline Farm or agricultural work & $3 \%$ & & 24,933 \\
\hline Store clerk or salesperson & $26 \%$ & & 24,933 \\
\hline Office or clerical & $8 \%$ & & 24,933 \\
\hline Other job type & $24 \%$ & & 24,933 \\
\hline \multicolumn{4}{|l|}{ Work Intensity and Pay } \\
\hline High intensity work (>20 hours per week) & $38 \%$ & & 24,933 \\
\hline Average pay per hour (natural log) & .997 & .720 & 24,933 \\
\hline \multicolumn{4}{|l|}{ Background Characteristics } \\
\hline GPA (z-score) & .000 & 1.000 & 24,933 \\
\hline Expect college (z-score) & .000 & 1.000 & 24,933 \\
\hline Preference for work hours (z-score) & .000 & 1.000 & 24,933 \\
\hline Male & $46 \%$ & & 24,933 \\
\hline African American & $11 \%$ & & 24,933 \\
\hline Hispanic & $9 \%$ & & 24,933 \\
\hline Asian American & $3 \%$ & & 24,933 \\
\hline White & $76 \%$ & & 24,933 \\
\hline American Indian & $1 \%$ & & 24,933 \\
\hline Parent(s) highest education (z-score) & .000 & 1.000 & 24,933 \\
\hline
\end{tabular}

Age segregation. The MTF surveys included questions regarding the age of coworkers and supervisors in their senior-year jobs. Employed youth were asked, "How many of the other workers are within 2 or 3 years of your own age?" Respondents answered this question on a sixpoint scale ranging from 1 ("none") to 6 ("all"). On average, respondents reported "about half" of their coworkers were also teenagers. Employed youth were also asked, "How old is your supervisor?" (coded 1 = "25 years or younger"; 0 = "over 25"). As shown in Table 1, only 14 percent of youth in our sample worked with a supervisor under the age of 26.

Work conflict and stress. Respondents were asked the extent to which their paid job "interferes with education," "interferes with social life," and "interferes with family life." Respondents answered each of these items on a five-point scale ranging from 1 ("not at all") to 5 ("a great extent"). Our measure of role conflict is the average of these three items (Cronbach's alpha $=.82$ ). The measure of job stress was based on responses to the question, "To what extent 
does this job cause you stress and tension?" (coded on a five-point scale from 1, "not at all," to 5, "a great extent").

Skill development and career potential. A scale measuring skill development is formed from three items: "to what extent did this job use your skills and abilities-let you do the things you do best"; "teach you new skills that will be useful in your future work"; and "make good use of special skills you learned in technical, vocational, business, or professional studies." Responses to these items ranged from 1 ("not at all") to 5 ("a great extent"). These items were averaged (Cronbach's alpha $=.82$ ).

Finally, we used three separate outcome variables to indicate career potential in senior-year jobs. Respondents were asked to what extent is this: (1) "a job you could be happy doing for the rest of your life"; (2) "a good stepping-stone toward the kind of work you want in the long run"; (3) "the kind of work people do just for the money." Responses ranged on a five-point scale from 1 ("not at all") to 5 ("a great extent"). Responses for the question of "the kind of work people do just for money" were reverse coded so that high values imply that the job is not the type of job people do just for money. We did not combine the three items of career potential because the Cronbach's alpha was unacceptably low (Cronbach's alpha $=.61$ ), and preliminary analyses indicated that the three items related differently to predictors.

\section{Predictor Variables}

To assess whether some types of jobs are better than others, we included a detailed measure of job type. Based upon a listing of job categories, respondents were asked to report the job that "comes closest to the kind of work you have done for pay." Building upon research by Entwisle and colleagues [2000], we coded these jobs into eight categories. Unskilled jobs included: (1) fast-food work; (2) restaurant work or other food service positions; (3) farm and agriculture work; (4) store clerks and salespersons; and (5) other jobs. Semi-skilled jobs included (6) office or clerical positions. Finally, informal jobs included (7) babysitting or childcare; and (8) newspaper delivery, yard maintenance, and odd jobs. As shown in Table 1, 26 percent of employed 12th graders worked as store clerks or salespersons, and 28 percent worked in restaurants (14 percent in fast food and 14 percent in other restaurants). The large number of respondents (24 percent) who report working in other jobs suggests considerable diversity in jobholding among $12^{\text {th }}$ graders. Given that fast food jobs are relatively common, and also that such jobs are often implicated as low on work quality (as discussed earlier), we use fast food jobs as the comparison category.

Employed youth also reported the average number of hours they worked during the school year and their hourly wages. High-intensity work indicates whether the respondent averaged more than 20 hours per week in their job during the school year (coded $0=$ "1-20 hours"; $1=$ "21 or more hours per week"). Approximately 38 percent of youth worked intensively during the school year. Pay per hour indicates the respondent's hourly wage rate. We adjusted the hourly wage rate to the value of a dollar in 1991, and to minimize the potential effect of outliers in the data, hourly pay was transformed to the natural logarithm. Employed youth who reported zero wages were not included.

Measures of academic orientation and performance, work preferences, and sociodemographic background were included to control for other factors that may relate to perceived job quality and job type. Grade point average (GPA) was based on the respondent's self-reported 
GPA during the school year (coded on a nine-point scale ranging from $1=$ " $D$ " to $9=$ " $A$ "). Educational expectations indicated how likely respondents felt they will graduate from a four-year college (coded on a four-point scale from "definitely won't" to "definitely will"). We also measured respondents' preference for work based upon how many hours per week they wish they could work during the school year. The question asked respondents to "think about the kinds of paid jobs that people your age usually have. If you could work just the number of hours that you wanted, how many hours per week would you prefer to work?" Responses to this measure ranged on an eight-point scale from " 0 " to "31 or more" hours per week.

To ease interpretation, each of these measures was standardized by subtracting the mean from each variable and dividing by the standard deviation.

We included measures of gender (coded "male" = 1; "female" =0) and the highest educational degree of the mother or father. Highest educational degree of parent(s) is coded on a sixpoint scale from "grade school or less" to "graduate or professional school." If data were available for only one parent, that was used. If available for both parents, the higher educational level was used. The MTF data set also includes detailed measures of race/ethnicity. We created five dummy variables coded: (1) African American; (2) Hispanic (3) Asian American; (4) American Indian; and (5) White.

\section{Results}

\section{Are Some Jobs Better than Others?}

Age segregation. Tables $2 a$ and $2 b$ display the ordinary least squares (OLS) and logistic regression coefficients for each dimension of work quality (8 separate models). As shown in Model 1 , youth who work in fast-food jobs report younger coworkers compared to all other employed youth, even after controlling for GPA, college expectations, and work preferences, as well as individuals' SES, gender, and race/ethnicity. A simple comparison of the coefficients in Model 1 suggest that lawn, farm, clerical, babysitting, newspaper, and odd jobs provide the most exposure to older coworkers. Youth with high college aspirations and a strong desire for paid work report younger coworkers. High-SES youth had younger coworkers than low-SES youth. Asian-American youth report significantly older coworkers than white youth. 
Table 2a. Regression Estimates of Perceived Job Quality by Job Type

\begin{tabular}{|c|c|c|c|c|}
\hline Job Characteristics & $\begin{array}{l}\text { Model 1 } \\
\text { Young } \\
\text { Coworker }\end{array}$ & $\begin{array}{c}\text { Model 2 } \\
\text { Young } \\
\text { Supervisor }\end{array}$ & $\begin{array}{l}\text { Model 3 } \\
\text { Work } \\
\text { Conflict }\end{array}$ & $\begin{array}{c}\text { Model } 4 \\
\text { High Stress }\end{array}$ \\
\hline Restaurant worker (vs. fast food) & $\begin{array}{l}-.5011^{\star \star \star} \\
(.034)\end{array}$ & 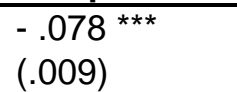 & $\begin{array}{l}-.1699^{\star \star \star} \\
(.027)\end{array}$ & 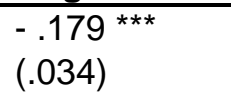 \\
\hline Store clerk or salesperson (vs. fast food) & $\begin{array}{l}-.607 \text { *** } \\
(.030)\end{array}$ & $\begin{array}{l}-.052 \text { *** } \\
(.008)\end{array}$ & $\begin{array}{l}-.192 \text { *** } \\
(.023)\end{array}$ & $\begin{array}{l}-.376 \text { *** } \\
(.029)\end{array}$ \\
\hline Office or clerical (vs. fast food) & $\begin{array}{l}-1.81 \text { *** } \\
(.040)\end{array}$ & $\begin{array}{l}-.141 \text { *** } \\
(.010)\end{array}$ & $\begin{array}{l}-.703 \text { *** } \\
(.031)\end{array}$ & $\begin{array}{l}-.645 \text { *** } \\
(.039)\end{array}$ \\
\hline Babysitting or childcare (vs. fast food) & $\begin{array}{l}-1.52 \text { *** } \\
(.046)\end{array}$ & $\begin{array}{l}-.073^{* * *} \\
(.011)\end{array}$ & $\begin{array}{l}-.685 \text { *** } \\
(.036)\end{array}$ & $\begin{array}{l}-.428 \text { *** } \\
(.045)\end{array}$ \\
\hline Farm or agricultural work (vs. fast food) & $\begin{array}{l}-1.32 * * * \\
(.056)\end{array}$ & $\begin{array}{l}-.141 \text { *** } \\
(.014)\end{array}$ & $\begin{array}{l}-.574 \text { *** } \\
(.043)\end{array}$ & $\begin{array}{l}-.634 \text { *** } \\
(.055)\end{array}$ \\
\hline Newspaper or yard work (vs. fast food) & $\begin{array}{l}-1.15^{\star \star \star} \\
(.047)\end{array}$ & $\begin{array}{l}-.061 \text { *** } \\
(.012)\end{array}$ & $\begin{array}{l}-.659 * * \star \\
(.037)\end{array}$ & $\begin{array}{l}-.733^{* * \star} \\
(.047)\end{array}$ \\
\hline Other job type (vs. fast food) & $\begin{array}{l}-.887 \text { *** } \\
(.031)\end{array}$ & $\begin{array}{l}-.067^{\text {*** }} \\
(.008)\end{array}$ & $\begin{array}{l}-.533 \text { *** } \\
(.024)\end{array}$ & $\begin{array}{l}-.525 \text { *** } \\
(.030)\end{array}$ \\
\hline High-intensity work (vs. low) & $\begin{array}{l}.009 \\
(.020)\end{array}$ & $\begin{array}{l}.015^{\star *} \\
(.005)\end{array}$ & $\begin{array}{l}.478^{\star \star \star} \\
(.016)\end{array}$ & $\begin{array}{l}.362^{\star \star \star *} \\
(.020)\end{array}$ \\
\hline Pay per hour (log) & $\begin{array}{l}-.016 \\
(.013)\end{array}$ & $\begin{array}{l}-.007 \text { * } \\
(.003)\end{array}$ & $\begin{array}{l}-.002 \\
(.010)\end{array}$ & $\begin{array}{r}.003 \\
(.012)\end{array}$ \\
\hline Background Factors & & & & \\
\hline GPA (z-score) & $\begin{array}{l}-.000 \\
(.010)\end{array}$ & $\begin{array}{l}-.012 \text { *** } \\
(.003)\end{array}$ & $\begin{array}{l}-.065 \text { *** } \\
(.008)\end{array}$ & $\begin{array}{l}-.044 \text { *** } \\
(.010)\end{array}$ \\
\hline Expect college (z-score) & $\begin{array}{l}.082^{\star \star \star} \\
(.010)\end{array}$ & $\begin{array}{l}-.001 \\
(.003)\end{array}$ & $\begin{array}{l}-.010 \\
(.008)\end{array}$ & $\begin{array}{l}-.041 \text { *** } \\
(.010)\end{array}$ \\
\hline Preference for work hours (z-score) & $\begin{array}{l}.032 \text { ** } \\
(.010)\end{array}$ & $\begin{array}{l}-.011 \text { *** } \\
(.003)\end{array}$ & $\begin{array}{l}-.132 \text { *** } \\
(.010)\end{array}$ & $\begin{array}{l}-.032 \text { ** } \\
(.010)\end{array}$ \\
\hline Male (vs. female) & $\begin{array}{l}-.025 \\
(.019)\end{array}$ & $\begin{array}{l}-.004 \\
(.005)\end{array}$ & $\begin{array}{l}.067^{\star \star \star *} \\
(.015)\end{array}$ & $\begin{array}{l}-.167 \text { *** } \\
(.019)\end{array}$ \\
\hline African American (vs. white) & $\begin{array}{r}.009 \\
(.032)\end{array}$ & $\begin{array}{l}.039 * * \star \\
(.008)\end{array}$ & $\begin{array}{l}-.118 \text { *** } \\
(.026)\end{array}$ & $\begin{array}{l}-.054 \\
(.032)\end{array}$ \\
\hline Hispanic (vs. white) & $\begin{array}{l}.061 \\
(.037)\end{array}$ & $\begin{array}{l}.046 \text { *** } \\
(.009)\end{array}$ & $\begin{array}{l}-.045 \\
(.027)\end{array}$ & $\begin{array}{l}-.072 \text { * } \\
(.033)\end{array}$ \\
\hline Asian American (vs. white) & $\begin{array}{l}-.107 \text { * } \\
(.054)\end{array}$ & $\begin{array}{l}.025 \\
(.014)\end{array}$ & $\begin{array}{l}.085 \text { * } \\
(.042)\end{array}$ & $\begin{array}{r}.068 \\
(.053)\end{array}$ \\
\hline American Indian (vs. white) & $\begin{array}{r}.056 \\
(.087)\end{array}$ & $\begin{array}{r}.022 \\
(.022)\end{array}$ & $\begin{array}{l}-.057 \\
(.065)\end{array}$ & $\begin{array}{r}.016 \\
(.083)\end{array}$ \\
\hline Parent(s) highest education (z-score) & $\begin{array}{l}.066 \text { *** } \\
(.010)\end{array}$ & $\begin{array}{l}.008 \text { ** } \\
(.002)\end{array}$ & $\begin{array}{r}.003 \\
(.007)\end{array}$ & $\begin{array}{r}.007 \\
(.010)\end{array}$ \\
\hline Intercept & $\begin{array}{l}3.707 \text { *** } \\
(.031)\end{array}$ & 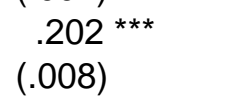 & $\begin{array}{l}2.422 \text { *** } \\
(.024)\end{array}$ & $\begin{array}{l}3.070 * \star \star \\
(.030)\end{array}$ \\
\hline Number of observations & 24,221 & 24,229 & 21,005 & 20,972 \\
\hline
\end{tabular}

Note. OLS regression estimates shown for young coworker, high stress, and job interference; Logistic regression estimates shown for young supervisor; Standard errors shown in parentheses; * $p<.05$, ** $p<.01,{ }^{\star \star \star} p<.001$ 
Table 2b. OLS Regression Estimates of Perceived Job Quality by Job Type

\begin{tabular}{|c|c|c|c|c|}
\hline Job Characteristics & $\begin{array}{c}\text { Model } 5 \\
\text { Use Skills }\end{array}$ & $\begin{array}{l}\text { Model } 6 \\
\text { Happy for } \\
\text { Life }\end{array}$ & $\begin{array}{l}\text { Model } 7 \\
\text { Stepping } \\
\text { Stone }\end{array}$ & $\begin{array}{c}\text { Model } 8 \\
\text { Not Just for } \\
\text { Money }\end{array}$ \\
\hline Restaurant worker (vs. fast food) & $\begin{array}{l}.212 * \star \star \\
(.028)\end{array}$ & $\begin{array}{l}.189 \text { *** } \\
(.030)\end{array}$ & 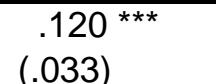 & $\begin{array}{l}.079 * \\
(.038)\end{array}$ \\
\hline Store clerk or salesperson (vs. fast food) & $\begin{array}{l}.324 \text { *** } \\
(.024)\end{array}$ & $\begin{array}{l}.219 \text { *** } \\
(.026)\end{array}$ & $\begin{array}{l}.264 \text { *** } \\
(.029)\end{array}$ & $\begin{array}{l}.300 * * * \\
(.033)\end{array}$ \\
\hline Office or clerical (vs. fast food) & $\begin{array}{l}1.025 \text { *** } \\
(.032)\end{array}$ & $\begin{array}{l}.776 \text { *** } \\
(.035)\end{array}$ & $\begin{array}{l}1.092 \text { *** } \\
(.038)\end{array}$ & $\begin{array}{l}.890 * \star * \\
(.043)\end{array}$ \\
\hline Babysitting or childcare (vs. fast food) & $\begin{array}{l}.770 \text { *** } \\
(.037)\end{array}$ & $\begin{array}{l}.900 * * * \\
(.041)\end{array}$ & $\begin{array}{l}.990 * * * \\
(.045)\end{array}$ & $\begin{array}{l}1.082 \text { *** } \\
(.050)\end{array}$ \\
\hline Farm or agricultural work (vs. fast food) & $\begin{array}{l}1.014 \text { *** } \\
(.046)\end{array}$ & $\begin{array}{l}1.228 \text { *** } \\
(.049)\end{array}$ & $\begin{array}{l}1.090 * * * \\
(.055)\end{array}$ & $\begin{array}{l}.953 * * * \\
(.061)\end{array}$ \\
\hline Newspaper or yard work (vs. fast food) & $\begin{array}{l}.468 \text { *** } \\
(.039)\end{array}$ & $\begin{array}{l}.582 \text { *** } \\
(.042)\end{array}$ & $\begin{array}{l}.480 \text { *** } \\
(.046)\end{array}$ & $\begin{array}{l}.248 \text { *** } \\
(.052)\end{array}$ \\
\hline Other job type (vs. fast food) & $\begin{array}{l}.737^{\star * *} \\
(.025)\end{array}$ & $\begin{array}{l}.725 \text { *** } \\
(.027)\end{array}$ & $\begin{array}{l}.724 \text { *** } \\
(.030)\end{array}$ & $\begin{array}{l}.652 \text { *** } \\
(.034)\end{array}$ \\
\hline High-intensity work (vs. low) & $\begin{array}{l}.173^{\star \star \star} \\
(.017)\end{array}$ & $\begin{array}{l}.121 \text { *** } \\
(.019)\end{array}$ & $\begin{array}{l}.130 \\
(.021)\end{array}$ & $\begin{array}{l}-.025 \\
(.023)\end{array}$ \\
\hline Pay per hour (log) & 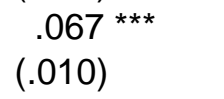 & $\begin{array}{r}.008 \\
(.011)\end{array}$ & $\begin{array}{l}.0611^{\star \star \star} \\
(.012)\end{array}$ & $\begin{array}{l}-.037^{* *} \\
(.014)\end{array}$ \\
\hline Background Factors & & & & \\
\hline GPA (z-score) & $\begin{array}{r}.006 \\
(.008)\end{array}$ & $\begin{array}{l}-.040 * * \star \\
(.009)\end{array}$ & $\begin{array}{l}-.017 \\
(.010)\end{array}$ & $\begin{array}{r}.007 \\
(.011)\end{array}$ \\
\hline Expect college (z-score) & $\begin{array}{l}-.010 \\
(.008)\end{array}$ & $\begin{array}{l}-.102 * \star \star \\
(.009)\end{array}$ & $\begin{array}{l}-.070 * \star \star \\
(.010)\end{array}$ & $\begin{array}{l}-.062 \text { *** } \\
(.011)\end{array}$ \\
\hline Preference for work hours (z-score) & $\begin{array}{l}.123^{* \star \star} \\
(.009)\end{array}$ & $\begin{array}{l}.061 \text { *** } \\
(.010)\end{array}$ & $\begin{array}{l}.085^{\star * \star} \\
(.013)\end{array}$ & $\begin{array}{l}-.010 \\
(.012)\end{array}$ \\
\hline Male (vs. female) & $\begin{array}{l}-.077^{\star * \star} \\
(.016)\end{array}$ & $\begin{array}{r}.015 \\
(.017)\end{array}$ & $\begin{array}{l}.078 \text { *** } \\
(.019)\end{array}$ & $\begin{array}{l}-.101 \text { *** } \\
(.021)\end{array}$ \\
\hline African American (vs. white) & $\begin{array}{l}.129 \text { *** } \\
(.025)\end{array}$ & $\begin{array}{l}.057 \text { * } \\
(.027)\end{array}$ & $\begin{array}{l}.053 \\
(.032)\end{array}$ & $\begin{array}{l}-.066 \\
(.035)\end{array}$ \\
\hline Hispanic (vs. white) & $\begin{array}{l}.107^{* \star \star} \\
(.027)\end{array}$ & $\begin{array}{r}.007 \\
(.030)\end{array}$ & $\begin{array}{l}-.056 \\
(.033)\end{array}$ & $\begin{array}{r}.050 \\
(.039)\end{array}$ \\
\hline Asian American (vs. white) & $\begin{array}{l}.075 \\
(.043)\end{array}$ & $\begin{array}{r}.038 \\
(.048)\end{array}$ & $\begin{array}{r}.043 \\
(.052)\end{array}$ & $\begin{array}{l}.169 \text { ** } \\
(.058)\end{array}$ \\
\hline American Indian (vs. white) & $\begin{array}{l}.216 \text { ** } \\
(.069)\end{array}$ & $\begin{array}{l}.143 \\
(.075)\end{array}$ & $\begin{array}{r}.125 \\
(.082)\end{array}$ & $\begin{array}{r}.106 \\
(.093)\end{array}$ \\
\hline Parent(s) highest education (z-score) & $\begin{array}{l}.014 \\
(.008)\end{array}$ & $\begin{array}{l}-.024 \text { ** } \\
(.009)\end{array}$ & $\begin{array}{l}-.010 \\
(.009)\end{array}$ & $\begin{array}{l}-.002 \\
(.011)\end{array}$ \\
\hline Intercept & $\begin{array}{l}1.903 \text { *** } \\
(.025)\end{array}$ & $\begin{array}{l}1.212 \text { *** } \\
(.027)\end{array}$ & $\begin{array}{l}1.342 \text { *** } \\
(.030)\end{array}$ & $\begin{array}{l}2.461 \text { *** } \\
(.033)\end{array}$ \\
\hline Number of observations & 21,201 & 20,860 & 20,811 & 20,765 \\
\hline
\end{tabular}

Note. Standard errors shown in parentheses; ${ }^{*} p<.05,{ }^{\star \star} p<.01,{ }^{\star \star \star} p<.001$ 
As shown in Model 2, youth employed in fast-food jobs are also more likely to work with supervisors 25 years or younger compared to those who work in other jobs. By contrast, youth employed in farm work and clerical positions are more likely to have older supervisors. In addition, low pay and high-intensity work also increase the odds of employment with a young supervisor, as does a low GPA. Again we found that high-SES youth had younger coworkers than low-SES youth. African-American and Hispanic youth were also more likely than white youth to have young supervisors.

Work conflict and stress. Youth employed in fast-food jobs are more likely to perceive that their jobs are interfering with school, friends, and family, in comparison to youth employed in other types of jobs (Model 3). Role conflict is greater among youth who are employed intensively versus moderately. GPA is also related to conflict levels; as GPA increases, levels of conflict decrease. Males report more job conflict than females, African-American youth report less conflict from their jobs than white youth, and Asian-American youth report significantly more role conflict from their jobs than white youth.

Youth in fast-food jobs report the highest job stress (Model 4). Intensive work (i.e., more than 20 hours per week) is associated with high levels of job stress. However, youth who prefer more work hours, irrespective of the actual hours they work, report lower levels of job stress compared to youth who prefer fewer hours. Adolescents with high educational expectations and GPAs report low levels of job stress. Males reported lower job stress compared to females, as do Hispanic youth compared to white youth.

Skill development and career potential. In Table $2 b$ we show the effects of job type on skill utilization and career potential. Again, youth in fast-food jobs report lower levels of skill utilization compared to youth in other jobs (Model 5). Skill utilization is higher among youth who work intensively and who earn higher hourly wages. Youth who prefer long hours of work report high levels of skill utilization. Compared to whites, African-American, Hispanic, and American Indian youth report more skill utilization. Males report less skill utilization compared to females.

Regarding career potential, adolescents who work in fast-food jobs are the least likely to report that they would be happy doing this job for the rest of their lives (Model 6). Highintensity workers report greater happiness in doing their job for the rest of their life compared to youth who moderate their work hours. Not surprisingly, as GPA and college expectations increase, youth's desire to maintain their current jobs for the rest of their life decreases, whereas work preferences are significantly and positively related to youth perceptions of their happiness in doing their job for the rest of their lives. SES was negatively related to happiness in doing their current job for the rest of their life.

Fast-food workers are also unlikely to feel that their job is a stepping stone to a future career (Model 7). A simple comparison of the coefficients shown in Table $2 \mathrm{~b}$ suggests that youth in office or clerical, farming, and babysitting jobs report the highest levels on the steppingstone outcome, compared to youth in fast-food jobs. Restaurant workers and store clerks also see their jobs as better stepping stones compared to fast-food employees, however this difference is not as large as the difference seen for farming, babysitting, and clerical jobs. In terms of job characteristics, youth who work intensively and earn higher wages report that their jobs are good stepping-stones, compared to youth in jobs that pay less and require less than 20 hours of 
work per week. Youth who prefer to work more report that their jobs are good stepping stones for a future career.

Finally, youth who work in fast-food jobs are the most likely of employed youth to be working only for the money (Model 8). Compared to adolescents in fast-food jobs, adolescents who work in clerical jobs, farming, and babysitting report they currently hold their jobs for reasons other than monetary gain. Interestingly, as pay per hour increases, youth are more likely to say that they are working just for the money. Youth with high college expectations also tend to hold their current jobs just for the money and are unlikely to consider their current jobs as good stepping-stones toward future careers (as shown in Model 7). In addition, males are more likely than females to work just to earn money, but males are also more likely than females to view their high school job as a stepping-stone to a future career (Model 7). Hispanic youth are also more likely to hold their jobs just for the money compared to white youth.

To help identify good and bad jobs, Figure 1 shows the expected values of work quality by job type based on the estimates shown in Tables $2 \mathrm{a}$ and $2 \mathrm{~b}$. Overall, it is clear that teenagers in fast food jobs describe them in more negative terms than do those in other jobs. For instance, youth in fast-food jobs report the highest scores on job stress and role conflict, the highest prevalence of young coworkers, and the highest probability of having a young supervisor. Moreover, fast-food employees report the lowest levels of skill utilization and little career potential. 


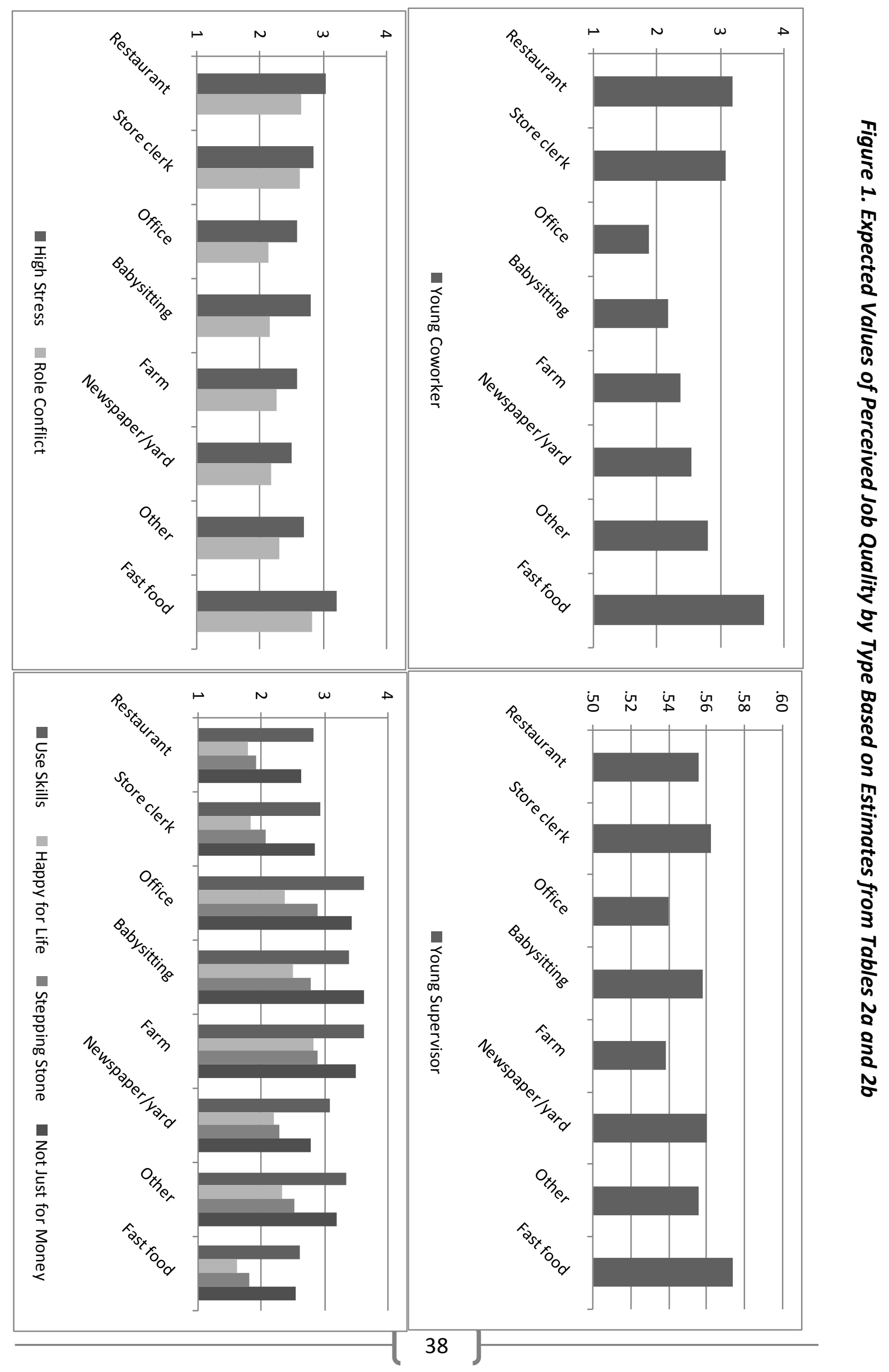


On the other hand, office and clerical work provided the highest quality employment experience for adolescents. Youth employed in these jobs report low levels of job stress and role conflict, as well as high levels of skill utilization and career potential. Adolescent office workers are less likely to have young supervisors, and these jobs allow youth to work with fewer young coworkers compared to all other jobs. In unlisted analyses we compared all jobs to office and clerical positions because these jobs were rated significantly higher on a number of work dimensions. Compared to office and clerical positions, respondents in other jobs had younger coworkers and supervisors, more job stress and role conflict, and less career potential.

It is important to note that the youth employed in farming and agriculture positions reported high skill utilization and low levels of job stress and role conflict. In addition, youth in farm work are more likely than other youth to say they would be happy in this sort of work for the rest of their lives, and they report that they farm for other reasons beyond money. In fact, in unlisted analyses we found that teenagers working in farm and agriculture jobs were significantly more likely to report being happy doing their jobs for the rest of their life. In addition, youth employed in these jobs were not working just for the money, unlike youth in office and clerical jobs. Thus, youth who work in farming consider their jobs to be good in the present moment, and they perceive that their jobs will be good in the future.

\section{Who Works in Good and Bad Jobs?}

In addition to understanding the structure of job quality, it is important to examine characteristics of specific jobs and who is likely to work in these jobs. As shown in Table 3, we estimated a multinomial logistic regression model to predict participation in each of the eight job types. With a reference category of fast-food jobs, coefficients indicate changes in the likelihood of holding a specific job category (relative to having a job in fast food) based upon changes in the predictor variables. This allows us to compare fast-food jobs to the other jobs and identify associations between personal or job characteristics and the range of job types. In general, African Americans and individuals from lower SES backgrounds were significantly more likely to be in fast-food jobs, compared to whites and individuals from higher SES backgrounds. In terms of job characteristics, fast-food workers have some of the most intensive adolescent work schedules; only other types of restaurant work had similar levels of work intensity. The average hourly wages in fast-food jobs are toward the lower end of all the job types; newspaper and odd jobs, babysitting, and farm work pay less whereas other jobs pay more on average. Individuals with lower GPAs and educational expectations are more likely to be in fast-food jobs than most other job types. Preferences for intensive work are also positively related to employment in fast-food and farming jobs. 


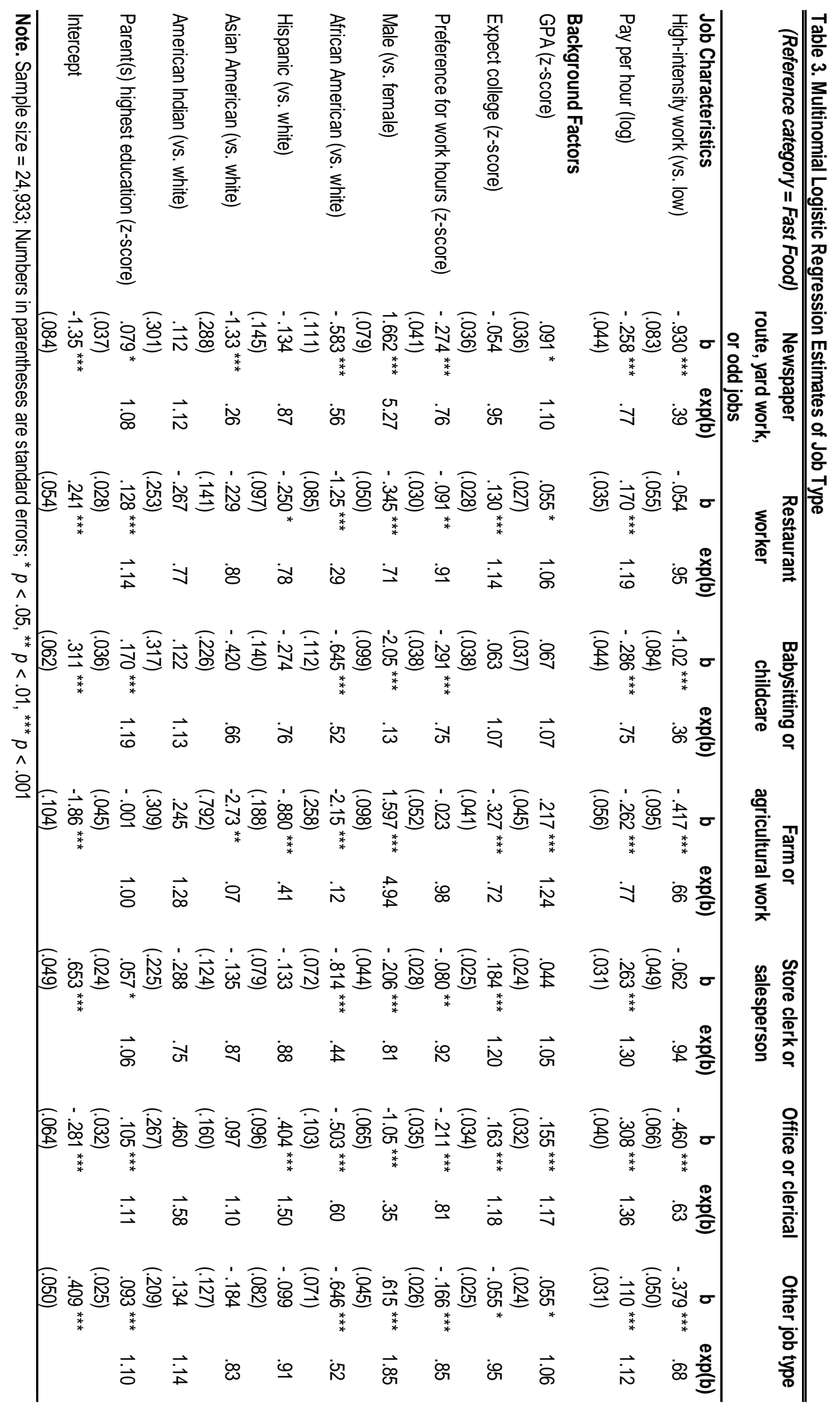


Regarding the "good" jobs, clerical and office jobs entail both high wages and few hours worked per week. Clerical and office jobs are more likely to be held by females, whereas farm and odd jobs are especially likely to be held by males. Hispanic youth are also more likely to be in clerical positions compared to whites, while Asian American and American Indian participation in office jobs are not significantly different from that of white youth. By contrast, white youth are more likely than African-American, Hispanic, and American Indian youth to work in farm jobs. Individuals with higher GPAs and educational expectations are more likely to hold clerical jobs, compared to individuals with lower GPAs and expectations, though restaurant workers also have significantly higher grades and expectations compared to fast-food workers. Individuals with higher GPAs are also more likely to work in farm jobs. However, youth who hold farm jobs have significantly lower educational expectations, as well as a desire for long hours of work, than youth who work in all other types of jobs.

\section{Alternative Specifications}

In other analyses (full results are not shown but are available upon request) we considered alternative specifications of our regression models. First, we examined whether socioeconomic background moderated the effect of job type on perceived job quality. As we reviewed before, the perceived quality of these early work experiences could be different for more and less advantaged youth. In particular, although fast-food work, on average, is associated with poor work quality in this study, youth in poor neighborhoods face limited employment opportunities and may rate these jobs favorably. By contrast, youth who reside in high income neighborhoods may rate even office or clerical positions poorly because they have more opportunities to regain employment if they lose their jobs. However, the inclusion of interaction terms for job type and socioeconomic background did not significantly improve the model fit for any of the outcome measures.

Second, our substantive results were also unchanged by the addition of controls for other behaviors that signify a developmental change to a more mature status, such as how often respondents go out on dates and whether they are currently single (vs. married or divorced). Youth who exhibit problem behaviors, such as delinquency and substance use, may also place more emphasis on paid work than school and subsequently rate the quality of their jobs more favorably than nondelinquent youth. According to precocious development theory [Newcomb and Bentler 1988], adolescent drug users in particular have a higher probability of selecting into situations that are more compatible with substance use, such as moving into their own apartments, quitting school, cohabiting or marrying, and acquiring more adultlike work (i.e., long hours, relatively high pay, adult coworkers and supervisors). In unlisted analyses, we also included three variables for substance use: alcohol use, cigarette use, and marijuana use. The inclusion of controls for substance use did not substantially change our pattern of findings.

Third, the findings from ordinal logistic models predicting perceived job quality by job type were substantively identical to the results of the OLS and binary logistic models presented here. Because the job quality responses do not fit a normal distribution, the error terms in OLS regressions may exhibit heteroscedasticity. Many of the responses were given on ordinal scales, as described above. Accordingly, as alternative specifications we estimated ordinal logistic regression versions of the eight models of job quality by job type. No substantive differences in the results were evident. 
Finally, it should be noted that our substantive results remain unchanged whether our regression results are based upon samples with or without imputed missing values.

\section{Discussion}

Our study, based on national data, is one of the first to demonstrate job stratification among teenage workers. Building upon the work of Mortimer [2003] and Hirschman and Voloshin [2007], we find that early work experiences are likely to vary with respect to important job qualities including the degree of adult supervision, learning opportunities, skill development, work demands, and relevance to future career goals. Results show that the perceived work quality of youth employed in fast-food settings was significantly lower than youth employed in other jobs, even service jobs in other types of restaurants. By contrast, youth employed in office and clerical jobs, as well as farming, reported working with older coworkers and supervisors, less conflict and stress, and greater skill utilization and prospects for future careers relative to adolescents working in other kinds of jobs. Clearly, as this national study demonstrates, adolescent work is characterized as having considerable heterogeneity in job types and qualities.

Although we find some differences in how youth rate different types of jobs, it should also be noted that overall, employed youth were positive about their early work experiences, and that teenager's perceptions of their early work experiences have remained remarkably stable over the past 30 years [Staff and Schulenberg 2010]. For instance, in our analyses employed youth on average experienced minimal job stress and minor interference with family, school, and friends. Employed youth also used their job skills outside of the work context, reported that their jobs were somewhat of a stepping-stone to future work, and said they could be happy doing their jobs for the rest of their lives. Moreover, we found little evidence that most teenagers worked in an age-segregated environment, as only 13 percent of youth reported working with a supervisor under the age of 25, and that "about half" of their coworkers were also teenagers. Overall, less than 5 percent of teenagers worked in jobs where the supervisor was 25 or younger and almost all of the coworkers were teenagers. Moreover, the vast majority of youth working in these age-segregated environments were employed as fast-food workers, store clerks or salespersons, or restaurant workers.

Given these patterns, a recommendation for future research is to attend to the type of job when examining the possible positive and negative effects of paid work on adolescent achievement and adjustment. For example, McNeal [1997] found that youth employed in manufacturing and service jobs were more likely to drop out of high school as their work hours increased than youth who were employed in informal settings (such as farming, babysitting, and doing lawn work). McNeal [1997:217] concluded that while the majority of employed adolescents hold jobs that are detrimental in terms of increasing the likelihood of dropping out of high school, there are some jobs that are either neutral (i.e., no effect on dropout rates) or marginally beneficial. In our study, youth employed in babysitting, lawn care, and newspaper delivery reported low levels of work conflict with school, family, and friends. Informal jobs may provide greater flexibility relative to other types of employment, which may explain why youth employed in informal settings are unlikely to drop out of school even at high work intensities. 
Certain types of jobs may be beneficial in reducing substance use and delinquency, even at high levels of work intensity. As previously reviewed, jobs that offer learning opportunities and do not compromise the student role appear to inhibit deviance, even after controlling for work hours, prior achievements, problem behaviors, and sociodemographic factors [Staff and Uggen 2003]. In our study, youth employed in office and clerical positions report the highest levels of skill utilization and career potential; perhaps these jobs can reduce problem behaviors associated with intensive work. By focusing more on types and qualities of jobs in future research, we can gain a better understanding under what conditions does teenage work provide benefits for and detriments against positive youth development.

Prior research shows that age, gender, race/ethnicity, and SES influence the onset, intensity, and duration of paid work during adolescence. We find that these sociodemographic factors also predict the type and quality of work. In particular, we find that low-SES youth are more likely to work in adultlike jobs than their high-SES counterparts. For instance, low-SES youth are more likely to work with older coworkers and more likely to indicate that they would be happy doing their current job for the rest of their lives than their more advantaged counterparts. This is consistent with ethnographic work, which finds that low-SES youth can benefit from adult interaction in the workplace, even in fast-food jobs. We found little evidence that SES origins moderate the relationship between job type and perceptions of job quality. One reason for the lack of significant findings is that low-SES youth are more likely to drop out of high school than high-SES youth, and our sample included only high school seniors who did not drop out. Perhaps the interaction between job type and family socioeconomic origins would have been statistically significant if we included younger respondents (and thus future dropouts) in our sample. Furthermore, our analyses do not include characteristics of the local labor market or family income to more fully explore the potential moderating role of disadvantaged social origins on work quality.

Finally, some youth work in jobs that involve high levels of injury, and future research should look at more detailed rates of injury in the workplace. In particular, though the small numbers of youth who work in farm jobs rate them favorably, children employed in agriculture have the highest rates of fatal and nonfatal injuries [National Research Council 1998]. The findings on the quality of farming employment in our U.S. sample offer important implications for current national and global farming trends. Fewer U.S. adolescents now seek farm work compared to past generations [Elder and Conger 2000]. This is important considering that our findings and past research demonstrate farming is beneficial for adolescents. Farming can provide adolescents with a greater opportunity for family contact; in addition, farming jobs and farming communities can instill values, competencies, and a sense of responsibility in adolescents, which can put youth on a pathway away from problem behavior and toward future success [EIder and Conger 2000].

Our findings should come as a relief to parents and teachers who may worry about teenage employment today. Our findings indicate most youth rate their jobs favorably, even though some jobs are clearly better than others. "Good" jobs provide opportunities to develop new skills; gain a sense of responsibility and dependability; learn how to balance the demands of work, family, school, and peers; and establish positive vocational identities and work values. Such paid work experiences in adolescence may also involve a supportive supervisor who helps guide the young person to appropriate postsecondary degree programs that match their inter- 
ests and capacities [Call and Mortimer 2001]. These qualities of work may be especially important for youth whose own parents lack work experience and career resources, or youth who have less interest or success in school [Staff and Mortimer 2008]. Even experiences in "bad" jobs during adolescence may give the young person a sense of the extent to which initial jobs represent a good career pathway. Identifying the long-term effects of work hours, job type, and perceptions of early work quality on achievement and vocational development will be the basis of our future work.

\section{References}

Bachman J. [1983]. Premature Affluence: Do high school students earn too much? Econ Outlook USA 10:64-67. Bachman J, Schulenberg J. [1993]. How part-time work intensity relates to drug use, problem behavior, time use, and satisfaction among high school seniors: Are these consequences or merely correlates? Dev Psych 29:220-235.

Bachman J, Staff, J, O'Malley P, Schulenberg J, Freedman-Doan P [2011]. Student work intensity: New evidence on links to educational attainment and problem behaviors. Dev Psych 47:344-363.

Call K, Mortimer J [2001]. Arenas of comfort in adolescence: A study of adjustment in context. Hillsdale, NJ: Lawrence Erlbaum.

Elder G, Conger R [2000]. Children of the land: Adversity and success in rural America. Chicago, IL: University of Chicago Press.

Entwisle D, Alexander K, Steffel Olson L [2000]. Early work histories of urban youth. Amer Soc Rev 65:279-297.

Finch M, Shanahan M, Mortimer J, Ryu S [1991]. Work experience and control orientation in adolescence." Amer Soc Rev 56:597-611.

Hirschman C, Voloshin I [2007]. The structure of teenage employment: Social background and the jobs held by high school seniors. Res in Soc Strat and Mob 25:189-203.

Johnston L, O'Malley P, Bachman, J, Schulenberg J [2011a]. Monitoring the future national survey results on drug use, 1975-2010. Volume I: Secondary school students. Bethesda, MD: National Institute on Drug Abuse.

Johnston L, O'Malley P, Bachman, J, Schulenberg J [2011b]. Monitoring the future national survey results on drug use, 1975-2010. Volume II: College students and adults ages 19-50. Bethesda, MD: National Institute on Drug Abuse.

Kalleberg A, Reskin B, Hudson K [2000] Bad jobs in America: Standard and nonstandard employment relations and job quality in the United States. Amer Soc Rev 65:256-278.

Marsh H, Kleitman S [2005]. Consequences of employment during high school: Character building, subversion of academic goals, or a threshold? Amer Educ Res J 42:331-369.

McNeal R [1997]. Are students being pulled out of high school? The effect of adolescent employment on dropping out. Soc of Ed 70:206-220.

Mortimer J [2003]. Working and growing up in America. Cambridge, MA: Harvard University Press.

Mortimer J, Finch M, Ryu S, Shanahan M, Call K [1996]. The effects of work intensity on adolescent mental health, achievement, and behavioral adjustment: New evidence from a prospective study. Child Dev 67:12431261.

Mortimer J, Harley C, Staff J. [2002]. The quality of work and youth mental health. Work and Occ 29:166-197.

Mortimer J, Staff J. [2004]. Early work as a source of developmental discontinuity during the transition to adulthood. Dev and Psychopath 16:1047-1070.

National Research Council [1998]. Youth at work: Health, safety, and development of working children and adolescents in the United States. Washington, D.C.: National Academy Press.

Newcomb M, Bentler P [1988]. Consequences of adolescent drug use: Impact on the lives of young adults. Newbury Park, CA: Sage.

Newman K [1999]. No shame in my game: The working poor in the inner city. New York: Alfred A. Knopf, Inc. and the Russell Sage Foundation. 
Shanahan M, Finch M, Mortimer J, Ryu S [1991]. Adolescent work experience and depressive affect. Soc Psych Quart 54:299-317.

Staff J, Messersmith E, Schulenberg J [2009]. Adolescents and the world of work. Pp. 270-313 in Handbook of Adolescent Psychology (3rd ed.), edited by R. Lerner and L. Steinberg. New York: John Wiley \& Sons.

Staff J, Mortimer J [2008]. Social class background and the 'school to work' transition. New Dir for Child and Adol Dev 119:55-69.

Staff J, Schulenberg, J [2010]. Millennials and the world of work. J of Bus and Psych 25:247-255.

Staff J, Osgood W, Schulenberg J, Bachman J, Messersmith E [2010]. Explaining the relationship between employment and juvenile delinquency. Crim 48:1101-1131.

Staff J, Schulenberg J, Bachman J [2010]. Adolescent work intensity, school performance, and academic engagement. Soc of Educ 83:183-200.

Staff J, Uggen C [2003]. The fruits of good work: Early work experiences and adolescent deviance. J of Res in Crim and Delinq 40:263-290.

Steinberg L, Cauffman E [1995]. The impact of employment on adolescent development. Annals of Child Dev 11:131-166.

U.S. Department of Labor. [2000]. Report on the youth labor force. Washington, D.C.: U.S. Government Printing Office.

Wright J, Cullen F [2000]. Juvenile involvement in occupational delinquency. Crim 38:863-896. 


\title{
Assessing Adolescent Decision-Making Competence
}

Baruch Fischhoff, PhD, Carnegie Mellon University

\begin{abstract}
Behavioral decision research offers a general approach to studying cognitive aspects of decision making, as well as a platform for studying their interplay with social and affective processes. Applied to any decision, behavioral decision research involves three interrelated tasks: (a) normative analysis, identifying the expected impacts of possible choices; (b) descriptive study, characterizing how individuals view the decision, in terms comparable to the normative analysis; and (c) prescriptive interventions, helping people to bridge critical gaps in their understanding. Applied to adolescents' decisions, behavioral decision research provides analytical and empirical procedures for clarifying the challenges that young people face and their success in addressing them. It recognizes that competence varies by individual and by decision, leading to domain-specific policies and interventions, affording teens as much autonomy as they can manage.
\end{abstract}

\section{Assessing Adolescent Decision-Making Competence}

High stakes ride on society's ability to assess adolescents' decision-making competence [Fischhoff 2008]. If that competence is overestimated, then teens will face choices that are too difficult for them. If it is underestimated, then they will be kept from exercising warranted independence. If teens believe that the boundaries of their autonomy have been drawn wrongly, then they may feel unfairly restricted or unfairly left to fend for themselves.

Behavioral decision research offers a framework for studying decision-making competence, including methods for assessing it, theories for predicting it, and interventions for improving it [Fischhoff 2010; Fischhoff \& Kadvany 2011; Hastie \& Dawes 2002; Kahneman 2011; vonWinterfeldt \& Edwards 1986; Yates 1989]. Behavioral decision research recognizes both individual and situational variability. A given decision might be harder for some people than for others. A given individual might find some decisions harder than others. That variability poses a challenge to teens, who must identify their personal "envelope of competence," circumscribing the decisions that they know how to make. It poses a challenge to adults, who must find the balance between affording teens too much freedom and too little.

Behavioral decision research cannot resolve such policy questions. It cannot say, for example, whether teens can make decisions about interpersonal violence well enough to be adjudicated as adults nor whether teens can make decisions about interpersonal intimacy well enough to assume control of various reproductive decisions. What the research can do is assess how likely teens are to make choices of varying soundness. Whether the benefits of autonomous decision making outweigh its risks is a political-ethical question, not a scientific one. What 
research can do is to clarify the expected costs and benefits of letting teens make various choices.

\section{A Normative Standard}

Behavioral decision research's starting point is a normative analysis, describing a decision precisely enough to identify the choice that a rational actor would make. In this usage, "normative" refers to the procedural norms embodied in the axioms of decision theory. A famous mathematical proof showed that following these seemingly simple rules (e.g., transitivity) leads to choosing the option with the highest expected utility, given an individual's beliefs and values [vonNeumann \& Morgenstern 1947]. Plous [1993] provides a brief introduction; Hastie \& Dawes [2002], vonWinterfeldt \& Edwards [1986], and Yates [1989] provide fuller ones.

From this perspective, social norms are among the things that people might value. A rational choice might reflect just social norms, if people care solely about what other people value. A rational choice might also let social norms be overridden by other concerns or balance conflicting social norms (e.g., those of peers and parents).

Behavioral decision research does not assume that people are rational. Nor does it assume that people must follow (or even know) the axioms, in order to make rational choices. Some decisions are easy enough that even casual analysis leads to the rational choice; some good choices are learned by trial and error. Nor does behavioral decision research assume that people always want to make rational choices. People may prefer to follow their emotions or inviolate moral principles. Nor does behavioral decision research assume that rational choices will also be optimal ones, in the sense of making the greatest expected contribution to people's wellbeing. If people misunderstand their circumstances or themselves, rational choices may not bring the best outcomes.

Normative analysis plays several roles in behavioral decision research. One is facilitating a precise definition of each decision, against which people's performance can be compared. That means identifying people's goals, their options for achieving those goals, and the events that determine the chances of each goal being achieved by each option.

A second role of normative analysis is organizing evidence. Any issue that decision makers might consider must find its way into the normative analysis. It must affect either the definitions of the choice options, the valuation of potential outcomes, or the probabilities of experiencing those outcomes.

The third role of normative analysis is keeping researchers from focusing too narrowly. For example, researchers concerned about a risk behavior (e.g., unprotected sex) naturally see its link to health risks (e.g., sexually transmitted infections), but might neglect teens' other goals (e.g., showing trust in a partner) or obstacles (e.g., sexual coercion). Normative analysis requires a comprehensive view.

Sometimes, quantitative normative analyses are needed (e.g., for assessing the impact of underestimating condom effectiveness by $10 \%$ ). Often, though, qualitative analysis is enough to clarify the decision's structure, identify its critical beliefs and values, and suggest potential problems or interventions [Fischhoff 2005a; Fischhoff et al. 2006]. Once completed, the normative analysis structures the next steps in behavioral decision research: descriptive research, empirically assessing individuals' competence to make the choice, and prescriptive interventions, 
attempting to increase that competence, by closing critical gaps between the normative ideal and the descriptive reality. The next sections consider research on three competencies: assessing beliefs, assessing values, and integrating beliefs and values.

\section{Assessing Beliefs}

When outcomes are certain, decision making is just about values: identifying the most attractive set of outcomes. When outcomes are uncertain, decision makers must predict the outcomes of possible actions. In order to be meaningful, those predictions must be sufficiently precise to be evaluated in the light of experience. That requires a clear description of the event being predicted [Beyth-Marom \& Fischhoff 1997] and a numeric probability of its occurring.

Although people use verbal quantifiers (e.g., likely, rarely), in everyday speech, their meaning can vary widely across people and situations [Budescu \& Wallsten 1995; Schwarz 1999]. Thus, "likely drug side effect" may connote a different probability than "likely Stanley Cup winner." Although eliciting numeric values solves this problem, some researchers believe that it is too demanding for respondents. However, even imperfect measures can be useful, if their strengths and weaknesses are understood. Fortunately, the research on probability elicitation is very extensive, providing guidance on responsible usage [O'Hagan et al. 2006]. Results include:

a) Numeric probability judgments can be as reliable and acceptable as verbal ones. Woloshin et al. [1998] found this pattern when comparing judgments of medical events, elicited with two verbal scales and two numeric scales, each of which had equally spaced options from $0 \%$ to $100 \%$, with one expanding the $0-1 \%$ range with log values from $1 / 100$ to $1 / 1,000,000$ (under a cartoon magnifying glass).

b) People often prefer to provide verbal judgments, but to receive quantitative ones. Receiving quantitative estimates provides useful information, while producing them requires greater effort and accountability [Erev \& Cohen 1990].

c) Absolute values of numeric judgments can vary widely with response mode, while relative values are fairly invariant. For example, absolute values have been found to vary when using odds or probabilities, probabilities or relative frequencies, and individual items or grouped ones [Gilovich et al. 2003; Poulton 1994].

d) Some numeric values are treated specially. For example, people seldom use fractional values [Poulton 1989], a pattern that motivated the log part of Woloshin et al.'s loglinear scale. When uncertain what to say, people sometimes say " 50 " in the sense of "50-50," a vague, non-zero value, rather than a specific numeric probability [Bruine de Bruin et al. 2000].

e) Probability judgments can be deliberately biased, unless honest responses are requested and rewarded. For example, Christensen-Szalanski and Bushyhead [1993] found physicians overestimating the probability of pneumonia, fearing that low-probability cases would be ignored. Forecasters sometimes overstate precipitation probabilities, in order to reduce users' chance of being caught in the rain [Lichtenstein et al. 1982].

f) Probability judgments for knowing the answer to a question are modestly correlated with the probability of being correct [Lichtenstein et al. 1982; Yates 1989]. 
g) People differ in their ability to use probabilities, an ability that correlates with performance on other tasks and with life events that might reflect decision-making competence [Parker \& Fischhoff 2005; Table 4 below; Bruine de Bruin et al. 2007].

Like much psychological research, these studies mostly involve people of at least college age. Jacobs and Klaczynski [2005] offer a collection of articles regarding developmental differences in decision-making processes, while Furby \& Beyth-Marom [1992] and Reyna \& Farley [2006] offer integrative essays. Perhaps a fair summary of the research is that, by mid adolescence, most individuals have approximately adults' imperfect cognitive skills. Of course, having skills is necessary, but not sufficient for relying on them. Nor does it guarantee having the domain-specific knowledge needed to make informed choices [Fischhoff 2008].

Fischhoff et al. [2000] analyzed the construct validity of numeric probability judgments made by a nationally representative sample of 15 and 16-years olds, in the 1997 National Longitudinal Study of Youth (NLSY97). The analyses found, among other things, that teens use the full range of probability values, almost always give $100 \%$ for eating pizza in the next year (on a warm-up question), show no individual-difference tendency to give high or low values, and sometimes seem to say " 50 " in the " $50-50$ " sense. These teens' probability judgments correlate sensibly with their answers to related questions on other NLSY97 modules (created by other researchers). For example, females who reported being sexually active also gave higher probabilities for getting pregnant in the next year and for having a baby by age 20; males showed similar correlations for making someone pregnant and for becoming a father. Teens reporting neighborhood gang activity gave higher probabilities for being arrested in the next year and for dying in the next year or by age 20. Thus, these teens seemed both sensitive to factors affecting their futures and able to express that knowledge in numeric probabilities.

The greater one's faith in a research method, the more seriously one can take the data it produces. For example, the log-linear scale that Woloshin et al. [1998] evaluated was first used by Quadrel et al. [1993], in a study whose results challenged the conventional wisdom that adolescents have a unique sense of invulnerability. Recognizing the extra burden borne by methods producing unexpected results, Quadrel et al. [1993] examined some aspects of construct validity, finding sensible (and similar) usage by teens and adults. Confidence in their results is strengthened by Woloshin et al.'s study and by studies using other methods that also found no unique teen sense of invulnerability [Millstein \& Halpern-Felsher 2002].

That confidence is also strengthened by the NLSY97 finding that adolescents exaggerate their probability of dying soon. This extreme expression of vulnerability appears in the final two rows of Table 1, which shows the 12 NLSY97 questions whose predictive validity could be evaluated, with data from subsequent waves. Teens' median mortality judgments were $10 \%$, for events with a tiny statistical probability $(0.08 \% /$ year). Mean judgments were higher (about $20 \%)$, "inflated" by many 50s, some apparently expressing epistemic uncertainty, rather than numeric probabilities. Although non-numeric 50 s are inappropriate responses, they still provide insight into teens' thinking, meaning perhaps, "I don't know if I'Il live or die" or "I don't want to think about it."

Table 1's other rows show that teens' probability judgments are significantly correlated with these events' probabilities of occurring, as revealed in subsequent waves of the survey (e.g., teens who gave a higher probability for being in regular school a year hence were also 
more likely to be there). Teens' mean probability judgment sometimes approximates the observed rate (row 2), sometimes is optimistic (rows 1, 3, 4), sometimes is pessimistic (rows 9, 10 ), and sometimes has an unclear bias, depending on what teens value (rows 5-8). Because Table 1's occurrence rates reflect self-reports, teens' probability judgments are evaluated in terms of how they interpreted the events.

Table 1 evaluates teens' probability judgments in terms of correspondence tests, comparing them to external real-world events. Those judgments can be also subjected to coherence tests, examining their internal consistency, as defined by probability theory [Fischhoff \& BeythMarom 1983]. Coherence tests include whether the probabilities assigned to an event and its complement sum to 1.0 and whether the probability for an event is strictly greater than that for a subset. Teens' probability judgments often show coherence [Parker \& Fischhoff 2005], but not with Table 1's mortality judgments. There, most teens gave the same probability for dying in the next year and by age 20 (a period of 4.5 years, on average). When the two values differed, one third of teens gave a lower probability to the longer period [Fischhoff et al. 2000]. Thus, mortality judgments are anomalous in both correspondence and coherence terms, suggesting that many teens lack the competence here that they show for other probability judgments. 
Table 1. Predictive validity and accuracy of adolescents' expectations in NLSY97.

\begin{tabular}{|c|c|c|c|c|}
\hline What is the percent chance that you will.. & $\mathrm{N}$ & $\begin{array}{l}\text { Correlation } \\
\text { ( }() \text { with } \\
\text { outcome }\end{array}$ & $\begin{array}{c}\text { Mean re- } \\
\text { sponse (1997) }\end{array}$ & $\begin{array}{c}\text { Observed } \\
\text { outcome rate }\end{array}$ \\
\hline $\begin{array}{l}\text { 1. Be a student in a regular school a year } \\
\text { from now? }\end{array}$ & 3160 & $.64^{* * *}$ & $92.5 \%$ & $79.6 \%$ \\
\hline $\begin{array}{l}\text { 2. Have received a high school diploma by } \\
\text { the time you turn } 20 \text { ? }\end{array}$ & 3077 & $.60^{* * *}$ & $94.5 \%$ & $92.0 \%$ \\
\hline $\begin{array}{l}\text { 3. If you are in school a year from now, ... } \\
\text { work for pay more than } 20 \text { hours a } \\
\text { week? }\end{array}$ & 2492 & $.29^{* * *}$ & $57.7 \%$ & $27.2 \%$ \\
\hline $\begin{array}{l}\text { 4. If you are not in school a year from } \\
\text { now, ... work for pay more than } 20 \\
\text { hours a week? }\end{array}$ & 610 & $.31^{* * *}$ & $80.5 \%$ & $43.9 \%$ \\
\hline $\begin{array}{l}\text { 5. Become pregnant within } 1 \text { year from } \\
\text { now? (female) }\end{array}$ & 844 & $.37^{* * *}$ & $8.9 \%$ & $20.1 \%$ \\
\hline $\begin{array}{l}\text { 6. Get someone pregnant within the next } \\
\text { year? (male) }\end{array}$ & 1553 & $.35^{* * *}$ & $9.4 \%$ & $7.9 \%$ \\
\hline $\begin{array}{l}\text { 7. Become the parent of a baby sometime } \\
\text { between now and when you turn } 20 \text { ? } \\
\text { (female) }\end{array}$ & 1368 & $.38^{* * *}$ & $16.0 \%$ & $25.7 \%$ \\
\hline
\end{tabular}




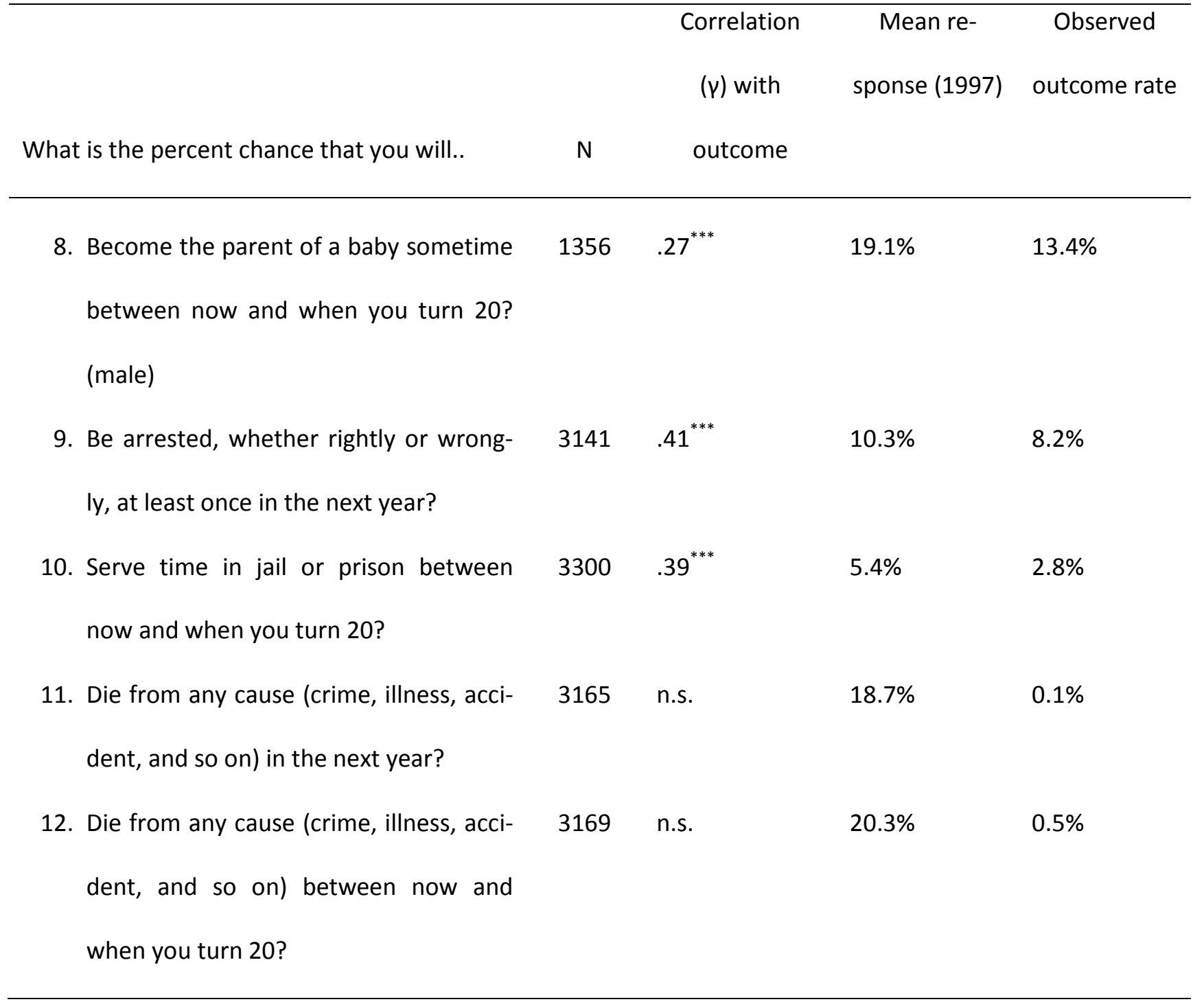

${ }^{* * *} p<.001 ;$ n.s.=not significant

Source: Fischhoff et al. (2010) Note: Complex skip patterns account for the different Ns. 


\section{Assessing Values}

Behavioral decision research has two complementary approaches to assessing the values that individuals hope to realize when making decisions [Fischhoff 1991, 2005a; Lichtenstein \& Slovic 2006]. One approach, rooted in psychophysics, assumes that people know roughly what they want, regarding any question put to them. The second approach, rooted in decision analysis, assumes that people may lack that knowledge, forcing them to derive specific preferences from potentially relevant basic values.

When people have well-articulated preferences, the two approaches converge. People know what they want and express those desires, whenever they are asked clear questions. The approaches diverge, when people lack stable preferences. Perhaps they have not given the topic much thought; perhaps they cannot reconcile conflicting values. In such cases, they don't know what they want, leaving them looking for clues and susceptible to manipulation by how questions are posed. As a result, their expressed values are labile, subject to framing or context effects [Fischhoff 2005a; Kahneman \& Tversky 2000; Lichtenstein \& Slovic 2006; Schwarz 1999].

As an extreme example, consider someone diagnosed with a brain tumor, who must choose between palliative care and aggressive treatment that is equally likely to lengthen or shorten her life. Over time, she might derive specific preferences from her basic values. Or, she might never know what tradeoffs to make between pain and hope. Or, she might shift between positions, depending on how she feels at the moment. In such cases, the psychophysics approach to eliciting values makes little sense. Why ask people what they want, when they don't know?

The alternative value elicitation approach, that of decision analysis, seeks to help people reflect on what they might want [vonWinterfeldt \& Edwards 1986], by presenting a balanced set of potentially relevant perspectives, as identified in the normative analysis. When successful, decision analytic value elicitation deepens people's understanding. However, it can also bias their thinking, if the set of perspectives is not systematically developed and fairly presented [Fischhoff 1991]. Related procedures, facing similar risks, include motivational interviews [Rollnick \& Miller 1995] and deliberative polling [Fishkin 1997]. Both methods also have prescriptive goals: the former hopes that individual reflection will uncover a latent desire for healthy change; the latter hopes that group reflection will uncover latent agreement about public policies.

The values elicited by decision analysis approaches should predict the ones that people express in their lives, when those lives present similarly balanced perspectives. Psychophysics approaches should predict real-life behavior, when lives present the same incomplete set of perspectives as the research question. Comparing the perspectives presented by researchers and by life means looking for regularities, such as how young men shape the values salient to young women in sexual situations, how young men shape the values salient to other young men in conflict situations, and how advertisers shape the values salient to as many people as they can. Some regularities occur naturally; others come from training that makes specific values salient. Pledges (for abstinence, diet, non-violence, etc.) attempt to do that, by making internal cues stronger than external ones.

Value judgments are subject to the same two kinds of performance standard as probability judgments. Correspondence tests ask whether people accept externally prescribed values, such as social norms. Coherence tests ask whether people's values are internally consistent, across 
choices. If a value represents an unambiguous, inviolate principle, then the two tests converge. For example, people opposed to abortion should condemn it in all cases. In more complex situations, though, the tests require normative analyses, showing the roles that specific values play in specific choices. For example, the importance of any value depends on how the decision options vary in that respect. For example, it is not inconsistent to pay attention to money when the options have different monetary outcomes, but to ignore money when the options have similar monetary outcomes. Conversely, ignoring money in the latter case would not represent anti-materialist virtue.

Asking people about specific values can present cognitively challenging tasks, just like asking about specific probabilities. Some of the most demanding tasks ask for values needed by regulatory analyses, such as pricing health services [Tengs \& Wallace 2000] or environmental damages [Mitchell \& Carson 1989]. For example, "Would you be willing to pay $\$ 10 /$ month for a special treatment that would relieve the breathing difficulty due to low level ozone from emissions?") The debate over these tasks raises essential questions regarding the nature of value elicitation [Fischhoff \& Manski 1999].

Although teens rarely participate in policy-related studies, they are often asked questions analogous to one policy concern: How much to discount future outcomes. Economists ask questions like, "How many dollars would you need one year from now, in order to forgo \$100 today?" They would like to use the discount rates implied by the answers in cost-benefit analyses. Unfortunately, those answers vary widely.

Frederick et al. [2002] argued that this variation reflects not just differences in how people value future outcomes, but also differences in how they interpret the questions. Although superficially simple, such questions leave potentially critical details unstated. As a result, respondents must read between the lines in order to complete the task. If they make different inferences about missing details, then they are answering different questions.

Frederick et al. proposed that how people value a future outcome could depend on the seven factors in Table 2. The first is how much they care about the future per se (the usual notion of temporal discounting). Subsequent rows capture other possible reasons for caring less about future outcomes: (2) People are uncertain about getting those outcomes (e.g., because they will have died). (3) People expect the outcome to be worse for reasons not in the description (e.g., the promised produce will be more poorly manufactured). (4) People expect to change in ways that diminish how much they will enjoy the outcome (e.g., losing their sweet tooth). (5) People see a psychological cost to waiting. (6) People will have less time to reminisce about the outcome after getting it. (7) People expect their other assets to change in ways that reduce the outcome's values (e.g., already having similar goods).

Analogous issues could arise when teens consider the relative value of, say, smoking today and enjoying better future health. Teens might care less about their future selves (row 1). However, they also might not expect to live that long, for reasons unrelated to smoking (row 2). Or, teens may expect a future world so degraded that all pleasures are diminished (row 3 ). And so on. Existing research provides a priori grounds for evaluating these options. For example, exaggerated mortality judgments (Table 1) lend credibility to row 2's concerns. However, without well-specified tasks, teens' values can be misunderstood, such as thinking that teens do not care about the future, when they actually do not expect to live to enjoy it. 
Table 2 Possible Reasons for Evaluating Goods Differently at Different Times

\begin{tabular}{|l|l|}
\hline MODEL & CORRESPONDING DESCRIPTION IN WORDS \\
\hline DU (time preference only) & $\begin{array}{l}\text { Future utility should be discounted because we should } \\
\text { care about the later parts of our life (for some, unex- } \\
\text { plained reason) }\end{array}$ \\
\hline DU + probability & $\begin{array}{l}\text { Future utility should be weighted by the probability that } \\
\text { the consequence that gives rise to the utility will actually } \\
\text { occur }\end{array}$ \\
\hline $\begin{array}{l}\text { DU + changes in objective conse- } \\
\text { quence }\end{array}$ & $\begin{array}{l}\text { The objective properties of some coarsely defined conse- } \\
\text { quence may depend on the time at which it occurs }\end{array}$ \\
\hline DU + changes in utility function & $\begin{array}{l}\text { The subjective utility associated with a particular objec- } \\
\text { tive consequence may change over time }\end{array}$ \\
\hline DU + utility from anticipation & $\begin{array}{l}\text { The utility at a given moment may be influenced by the } \\
\text { anticipation of future utility. }\end{array}$ \\
\hline DU + utility from memory & $\begin{array}{l}\text { The utility at a given moment may be influenced by the } \\
\text { recollection of past utility. }\end{array}$ \\
\hline DU + opportunity cost & $\begin{array}{l}\text { Utility depends on the current consumption level, and } \\
\text { the potential consumption level depends on current in- } \\
\text { come \& past investment. }\end{array}$ \\
\hline
\end{tabular}

Source: Frederick, Loewenstein \& O'Donoghue (2002).

\section{Assessing Decision-Making Processes}

Experimental researchers have shown great ingenuity in creating tasks that distinguish among the various rules that people might use, when integrating their beliefs and values (e.g., Weber, 1994; Yates, 1989). Real-world decisions rarely allow the control possible with these artificial tasks. Fortuitously, for predicting behavior, such control is often unnecessary. Many different simple linear (weighted-sum) models can predict many behaviors, about equally well [Goldberg 1968; Dawes \& Corrigan 1974].

The model-building process is straightforward: Take variables that people consider when making a decision (or variables correlated with those variables), standardize them, give them the correct sign (indicating whether they favor a particular choice), and add. The resulting score will predict individuals' propensity to make the focal choice. Expect correlations around 0.3. Weighting the variables can sometimes improve predictions. However, robust weights are hard to find. Regression weights are often unstable because of multicollinearity. Importance weights elicited with rating scales depend on people's limited powers of introspection [Ericsson \& Simon 1994]. As a result, the best research strategy may be to use unit weights $( \pm 1)$. In addition to its simplicity, that strategy keeps researchers from wasting their time, fruitlessly interpreting meaningless variations in weights [Camerer 1980; Hastie \& Dawes 2002].

Because of these problems with weights, simple linear models provide limited insight into decision-making processes. As a result, when behavioral decision researchers want to explain 
(as opposed to predict) behavior, they typically focus on identifying choice rules that people find intuitively appealing. They are particularly interested in rules that violate the normative axioms. Such violations can be revealing about thought processes (which have survived despite being "irrational"), decision-making environments (which are forgiving of such violations), and interventions (which are needed for unforgiving environments).

As an example of such a violation, although decision theory requires evaluating all decision options, people often focus on just one. That leaves the expected outcomes of other options less clear than if they were examined equally well [Beyth-Marom et al. 1993]. A corollary bias is insensitivity to the opportunity costs of choosing a focal option, namely, the other ways to invest those resources. A related corollary is undue commitment to sunk costs, resources already invested in an option. Normatively speaking, previous investments should be ignored, when evaluating future investments. However, people are reluctant just to look ahead, especially when that means realizing losses [Arkes \& Blumer 1985; Kahneman \& Tversky 2000].

Table 3 shows the types of options revealed, when teens described seven recent decisions about specific topics (school, free time, clothing, friendships, health, money, and parents), two recent hard decisions and one pending hard decision. Although the descriptions were often detailed, they typically focused on statements of resolve, like "eat more healthfully" and "stop blaming others." In effect, these decisions re-evaluate a single option, chosen previously, without stating any alternative options. Explicit alternatives were also absent from the next largest category, decisions about whether to do something (e.g., smoke cigarettes). Roughly equal numbers of decisions had two distinct options (e.g., whether to go to school or hang out with friends) or a set of identifiable options (e.g., which class to take, what to wear, with whom to have lunch). Few decisions involved "designing" options (e.g., how to spend free time, what to do about having fought with a friend).

Most of these decisions involved concrete, one-time choices. The main exceptions were the recent decisions about health and money, which often involved policies of some breadth (e.g., what kind of diet or spending pattern to adopt). It is not hard to imagine general policy choices in the other areas (e.g., how to spend free time, how to manage homework, how to keep parents happy). However, teens rarely described them. Although hard decisions provide an opportunity to reflect on big issues, these teens did not report seizing it.

These patterns were echoed in another study, asking young women to describe decisions about sexual activities. Their descriptions were so narrowly focused as to be barely decisions at all. In response, Downs et al. [2004] developed an interactive DVD, hoping to reduce sexually transmitted infections (STIS) by helping young women to see that they had decisions to make. One element of that empowerment was affording cognitive mastery of the domain, by providing decision-relevant information in compact, comprehensible form. A second element was helping users identify decision-making opportunities, by interrupting video narratives in which young men pressed young women for sex, then asking users "What would you do?" A third element was eliciting cognitive rehearsal of refusal strategies, followed by an actress modeling refusal [Bandura 2000]. In a randomized control trial, the intervention outperformed an "ideal usual care" condition (with equal exposure to commercially available materials matched for topic), in terms of attitudes, knowledge, self-reported behavior, and sexual health. A replication is currently in the field, with 3000 young women receiving the intervention under normal clinical conditions. 
Decision theory focuses on evaluating options and is mute regarding their creation. Indeed, it has been criticized for not empowering people to create (or demand) better options [Fischhoff 1992; O'Brien 2000]. In order to create options, people need to understand the processes that affect important outcomes. Downs et al. [2004] used a mental models approach to teach teens about the factors affecting STI risks, focusing on commonly misunderstood facts relevant to formulating decision options (e.g., how risks mount up through repeated exposure, how hard it is for partners to self-diagnose STIs). The mental models approach creates a formal model, summarizing the science regarding the processes shaping key outcomes. Semi-structured, open-ended interviews elicit beliefs on these topics, in their intuitive formulation. These serve as the basis for ecologically valid knowledge tests and interventions. The approach has been applied to informing decisions about many different risks [Fischhoff 2005b; Morgan et al. 2001].

Table 3 Option Structures in Teens' Open-Ended Decision Descriptions

\begin{tabular}{|c|c|c|c|c|c|c|}
\hline \multirow[t]{2}{*}{ Decision } & \multicolumn{6}{|c|}{ Structure } \\
\hline & $\begin{array}{c}\text { To Do } \\
\mathrm{X}\end{array}$ & $\begin{array}{c}\text { Whether } \\
\text { To Do }\end{array}$ & $\begin{array}{c}\text { Two } \\
\text { Choices }\end{array}$ & $\begin{array}{c}\text { Finite } \\
\text { Choices }\end{array}$ & $\begin{array}{l}\text { What To } \\
\text { Do About }\end{array}$ & Missinga \\
\hline \multicolumn{7}{|c|}{ Recent Decisions } \\
\hline School & $36.2 \%$ & $29.0 \%$ & $13.0 \%$ & $13.0 \%$ & $2.9 \%$ & $5.8 \%$ \\
\hline Free Time & 31.9 & 18.8 & 17.3 & 20.3 & 4.3 & 7.2 \\
\hline Clothing & 30.4 & 10.1 & 11.5 & 31.9 & 2.9 & 13.0 \\
\hline Peers & 47.8 & 24.6 & 10.1 & 5.8 & 4.3 & 7.2 \\
\hline Health & 55.0 & 20.2 & 1.4 & 2.9 & 2.9 & 17.4 \\
\hline Money & 52.2 & 11.6 & 10.1 & 4.3 & 10.1 & 11.6 \\
\hline Parents & 30.4 & 23.2 & 18.9 & 4.3 & 8.7 & 14.5 \\
\hline \multicolumn{7}{|c|}{$\underline{\text { Hard Decisions }}$} \\
\hline First Past & 39.1 & 33.3 & 20.2 & - & 5.8 & 1.4 \\
\hline Second Past & 20.2 & 44.9 & 18.8 & 5.8 & 4.3 & 5.8 \\
\hline Current & 2.9 & 44.9 & 23.2 & 13.0 & 13.0 & 2.9 \\
\hline
\end{tabular}

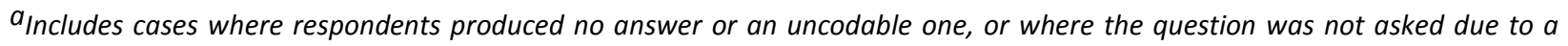
procedural error. These three cases constituted $27 \%, 51 \%$, and $21 \%$ of missing responses, respectively. Source: Fischhoff (1996) 


\section{Cognition in Decision Making}

Behavioral decision research attempts to treat cognitive aspects of decision making in a comprehensive, coherent way. Its normative analyses summarize what is known about the options, the probabilities of achieving valued outcomes, and those outcomes' relative importance. Descriptive analyses characterize decision makers' current beliefs in terms of deviations from the normative analysis. Prescriptive interventions try to bridge the gap between normative ideal and the descriptive reality.

The norms in these normative analyses are typically those of Bayesian decision theory [Edwards et al. 1963; Fischhoff \& Beyth-Marom 1983]. Studies showing non-normative behavior have prompted proposals for revising decision theory, so as to fit human intuitions better, as well as proposals that respect the decision theory norms, but study when less rigorous thinking will suffice [Lopes 1987; Reyna \& Farley 2006; Shafer \& Tversky 1985; Simon 1957]. The Journal of Risk and Uncertainty is one good place to follow this work.

Getting the cognitive part right is necessary, but not sufficient, for a full account of decision making, which also must accommodate social, emotional, and developmental factors [Fischhoff et al. 1998]. Behavioral decision research asks how these factors relate to the normative analyses that define sound decision making, the descriptive accounts that evaluate people's competence, or the prescriptive interventions that try to enhance it.

Social factors fit readily into normative accounts. If people care about social norms, then the expected costs and benefits of complying with them are treated like other outcomes. If social pressures affect how an option is implemented (e.g., if friends might not let friends drive drunk), then that becomes another source of uncertainty when predicting outcomes. If social pressure becomes social coercion, then some actions might become impossible. Descriptive accounts can assess people's awareness of these social effects. Prescriptive interventions can seek to improve people's awareness or change the reality (e.g., Downs et al. 2004).

Emotional effects can also fit into normative analyses, as valued outcomes (e.g., if people want to be angry or sad or happy). They can be captured in descriptive accounts in terms of their effects on each aspect of decision making (defining options, predicting events, determining personal values, integrating beliefs and values). Prescriptive interventions can help people manage their emotions, either by pre-selecting actions (in unemotional conditions) or choosing how to feel (e.g., anger management).

Cognitive appraisal theory [Lerner \& Keltner 2001] offers one such account, predicting the effects of specific emotions on specific judgments. For example, it predicts that anger encourages attributing problems to individuals (rather than to situations) and increases the perceived probability of overcoming problems. Lerner et al. [2003] and Small et al. [2006] demonstrate these effects with terror-related judgments, also finding that nationally representative samples of adults and adolescents responded similarly. Because the study elicited numeric probabilities for well-defined events, it was possible to evaluate the size of emotion effects (as well as their accuracy, given subsequent experience) [Fischhoff et al. 2005]. Over eight events, respondents in an induced anger condition were about $5 \%$ more optimistic than respondents in an induced fear condition. 
The impact of an effect of that size depends on the decision. A close decision might be sensitive to a $5 \%$ shift; a more clear-cut decision might not. Some observers have argued that the close decision to go to war in Iraq was tipped by anger for some people and by fear for others. The wisdom of emotional effects depends on the validity of the cues that emotions provide (e.g., do they overcome unwanted numbing? are they manipulated by others?) [Finucane et al. 2000; Slovic et al. 2005].

Cognitions can also affect emotions. For example, teens who see a $20 \%$ chance of dying in the next year (or think 50-50) might feel frustrated enough to act out or to disassociate themselves from long-term future outcomes (as in row 2, Table 2). The article reporting these exaggerated mortality judgments concludes by speculating that teens take "risks, in part, because they underestimate what is at stake, as a result of overestimating the risk of dying. That is, they take risks not just because of an exaggerated feeling that they are not going to die, but also because of an exaggerated feeling that they are not going to live." [Fischhoff et al. 2000, p. 200].

More generally, any cognitive process that undermines effective decision making may increase the roles of social and emotional factors. For example, Table 3 shows teens considering reduced sets of options. An overly narrow focus could keep teens from identifying good choices or from finding any acceptable choices. As a result, they may drift toward points where choices must be made - perhaps into situations where social and emotional concerns overwhelm cognitive ones. The cognitive rehearsal intervention used by Downs et al. [2004] sought to help young women make decisions prior to experiencing the passion and coercion of intimate encounters.

Thus, teens competent in cognitive aspects of decision making should make better decisions, not only because they can execute those cognitive elements better, but also because cognition gets them further, when making decisions. Table 4 presents results from a study of how cognitive decision-making competencies fit into young people's lives. It shows correlations with an individual-difference measure of decision-making competence (DMC) extracted from a factor analysis of performance on eight tasks, representing basic decision-making skills (e.g., assessing probabilities, applying decision rules). Respondents were 110 18-19 year old males, who, at age 10, had entered a longitudinal study at the Center for Education and Drug Abuse Research (Ralph Tarter, PI), returning every year or two for a day or two of testing, thereby creating an extensive battery of potentially related measures. DMC scores showed good test-retest reliability, as did scores on a version adapted for adults [Bruine de Bruin et al. 2007]. 
The first section shows that DMC scores were correlated with standard measures of verbal and fluid intelligence (Vocabulary and ECF, respectively). The second section shows positive correlations between DMC and "constructive" cognitive styles; these correlations generally remained after partialing out the two intelligence measures, indicating that DMC is independently related to these ways of thinking about the world. The third section shows that DMC is negatively related to several important risk behaviors; again, beyond correlations with intelligence. The fourth section shows that DMC is higher for teens coming from low-risk (LAR) families, higher SES families, and more positive peer environments. (The negative correlation with social support seemed to reflect low DMC teens' more frequent gang membership). As discussed by Parker \& Fischhoff [2005], these results support the construct validity of DMC as a measure of decision-making skills that both cause and reflect important aspects of teens' lives. For example, teens with higher DMC seem to come from families that might both model and reward good decision making. 


\section{Table 4: Correlations between Decision-Making Competence (DMC) and Other Variables}

Semi-partial Correlation, Controlling for

DMC Correlated with

Cognitive ability

Vocabulary

ECF

\section{Overall*}

Cognitive style

Polarized thinking

Self consciousness

Self monitoring

Behavioral coping

\section{Overall}

Risk behavior

Antisocial disorders

Externalizing behavior

Delinquency

In(lifetime \# of drinks)

In(lifetime marijuana use)

In(\# times had sex)

In(\# sexual partners)

\section{Overall}

Social and family influences

Risk status ( $H A R=1 ; \angle A R=0)$
SES
Social support
Positive peer environment

\begin{abstract}
Pearson $r$
\end{abstract}
.50

.48

$p<.0001$
$-.20$

$.14^{\mathrm{b}}$

$.29^{\mathrm{b}}$

$.27^{\mathrm{a}}$

$p<.0001$

$p<.0001$ $-.18^{b}$

$-.28^{\mathrm{b}}$

$-.28^{b}$

$-.22^{b}$

$-.30^{\mathrm{b}}$

$-.30^{\mathrm{b}}$

$-.33^{b}$

$p=.0004$
.28

$p=.0008$

\section{Vocabulary \& ECF}




\section{Conclusion}

Cognition, like emotional and social processes, is, arguably, part of most decisions and all of none. Behavioral decision research provides an integrated approach to studying cognitive aspects of decision making that also accommodates research on non-cognitive aspects. It provides ways to analyze decisions, identify potential problems, and assess the importance of those threats. Its commitment to detail should reduce the risk of simplistic diagnoses. For example, when assessing teens' impulsivity, it encourages considering all the reasons in Table 2, lest one confuse inability to exercise control and choosing to discount future options.

A question that occupies many people concerned about teens' welfare is, "Does information work?" as a way to improve teens' decision making. From a behavioral decision research perspective, there can be no simple answer. In some situations, people would not change their choices, whatever (truthful) information they received. In those cases, information has "worked," leading them to stable decisions [Reyna \& Farley 2006]. Those choices might not please people who disapproved of the values that those decisions embodied; however, the problem would not be how people used information. Stable choices might not even please the people making them, if they wished that they had better options (e.g., those unable to stop smoking or escape abusive relationships).

Information interventions reveal nothing about their recipients' decision-making competence unless they address critical gaps between recipients' information priorities, as identified by normative analyses, and current beliefs, as identified by descriptive studies. Interventions also reveal little, unless performed to professional standards. That means keeping those critical facts from being buried in irrelevant information, including critical facts that recipients already know. That means taking advantage of research into how people process such information and conducting rigorous pretests [Fischhoff et al. 2011].

Unless information interventions are tested fairly, their recipients may be blamed unfairly for ignoring messages that deserved to be ignored, because their content was irrelevant, cluttered, incomprehensible, etc. Unfairly criticizing teens' competence can unfairly undermine their social standing. For example, a pundit recently chose to spin adolescent research as proving "We're perceivers first, not deciders." [Brooks 2007] Any sweeping generalization diminishes the humanity of the individuals being depicted so formulaically. This particular generalization undermines any attempt to inform teens (e.g., sex education, over-the-counter labels on Plan $B$, driver education). Its acceptance would decrease the risk of holding teens responsible for decisions that they lack the competence to make, while increasing the risk of denying them choices that they could handle, were they properly informed.

If one succumbed to the temptation to make sweeping generalizations, but based them on detailed examination of specific decisions, one might conclude that teens do surprisingly well, given the difficulty of the decisions facing them (e.g., intimacy, friendship, drugs, careers, identity, money, appearance). These decisions often pose hard tradeoffs, have unpredictable effects, require mastery of unfamiliar facts, and lack trustworthy information sources. The number of poor decisions that teens make reflects not just their abilities, but also the number and nature of their challenges. Excellent third basemen still make a lot of errors at the "hot corner," relative to other field positions. 
Behavioral decision research's normative, descriptive, and prescriptive research provide an integrated structure for accomplishing tasks addressed by anyone concerned about teens: identifying the critical issues in teens' choices, assessing their current understanding, and helping them do better. It takes advantage of research into cognitive decision-making processes, while clarifying their interface with affective and social processes. It encourages the nuanced assessment of competence that teens deserve.

\section{Acknowledgement}

Chapter preparation supported by National Science Foundation Grant SES 0433152. My thanks go to Wändi Bruine de Bruin, Julie Downs, Irene Belle Janis, Tamar Krishnamurti, and Valerie Reyna.

\section{Questions to Consider for Discussion}

1. How do we think about acceptable risks to young people, considering the need to balance their needs for growth and protection? How do we translate those standards into providing sound environments for young people?

2. How do we resist describing young people in terms of sweeping generalizations (e.g., "the adolescent brain") that undermine respect for the complexity of the situations that they face and their own decision-making processes?

3. How do we help young people to decision-making skills, along with justified feelings of self-efficacy?

\section{References}

Arkes HR, Blumer C [1985]. The psychology of sunk cost. Organizational Behavior and Human Decision Processes 35: $124-140$.

Bandura A [2000]. Self-efficacy. In WJ Perrig \& A Grob (eds.) Control of human behavior, mental processes, and consciousness. Mahwah, NJ: Erlbaum, pp.17-33.

Beyth-Marom R, Austin L, Fischhoff B, Palmgren C, Quadrel MJ [1993]. Perceived consequences of risky behaviors. Developmental Psychology 29: 549-563.

Beyth-Marom R, Fischhoff B [1997]. Adolescents decisions about risk. In: Schulenberg J, Maggs JL, Hurrelmann K, eds. Health risks and developmental transitions during adolescence. New York: Cambridge University Press, pp. 110-135.

Brooks D [2007]. When preaching flops. New York Times. [http://select.nytimes.com/2007/06/22/opinion/22brooks.html]

Bruine de Bruin W, Fischhoff B, Halpern-Felsher B, Millstein S [2000]. Expressing epistemic uncertainty: It's a fiftyfifty chance. Organizational Behavior and Human Decision Processes 81: 115-131.

Bruine de Bruin W, Parker A, Fischhoff B [2007]. Individual differences in adult decision-making competence (ADMC). Journal of Personality and Social Psychology 92: 938-956.

Budescu DF, Wallsten TS [1995]. Processing linguistic probabilities: General principles and empirical evidence. In: Busemeyer JR, Hastie R, Medin DL, eds. Decision making from the perspective of cognitive psychology. New York: Academic Press, pp. 275-318.

Camerer C. [1980]. General conditions for bootstrapping methods. Organizational Behavior and Human Performance 27: 411-422

Christensen-Szalanski J, Bushyhead J [1993]. Physicians' misunderstanding of medical findings. Medical Decision Making 3: 169-175. 
Dawes RM, Corrigan B [1974]. Linear models in decision making. Psychological Bulletin 81: 95-106.

Downs JS, Murray PJ, Bruine de Bruin W, White JP et al. [2004]. An interactive video program to reduce adolescent females' STD risk: A randomized controlled trial. Social Science and Medicine 59: 1561-1572.

Edwards W, Lindman HR, Savage L [1963]. Bayesian statistical inference for psychological research. Psychological Review 70: 193-242.

Erev I, Cohen BL [1990]. Verbal versus numerical probabilities: Efficiency, biases and the preference paradox. Organizational Behavior and Human Decision Processes 45: 1-18.

Ericsson A, Simon HA [1994]. Verbal reports as data. Cambridge, MA: MIT Press.

Finucane ML, Alhakami A, Slovic P, Johnson SM [2000]. The affect heuristic in judgments of risks and benefits. Journal of Behavioral Decision Making 13: 1-17.

Fischhoff B [2010]. Judgment and decision making. Wiley interdisciplinary reviews: Cognitive science. New York: Wiley.

Fischhoff B [2008]. Assessing adolescent decision-making competence. Developmental Review 28: 12-28.

Fischhoff B [2005a]. Cognitive processes in stated preference methods. In: Mäler K-G, Vincent J, eds. Handbook of environmental economics. Amsterdam: Elsevier, pp. 937-968.

Fischhoff B [2005b]. Decision research strategies. Health Psychology 21: S9-S-16.

Fischhoff B [1996]. The real world: What good is it? Organizational Behavior and Human Decision Processes 65: 232-248.

Fischhoff B [1991]. Value elicitation: Is there anything in there? American Psychologist 46: 835-847.

Fischhoff B [1992]. Giving advice: Decision theory perspectives on sexual assault. American Psychologist 47: 577588.

Fischhoff B, Brewer N, Downs JS, eds. [2011]. Communicating risks and benefits: An evidence-based user's guide. Washington, DC: Food and Drug Administration.

Fischhoff B, Bruine de Bruin W, Guvenc U, Caruso D, Brilliant L [2006]. Analyzing disaster risks and plans: An avian flu example. Journal of Risk and Uncertainty 33: 133-151.

Fischhoff B, Bruine de Bruin W, Parker AM, Millstein SG, Halpern-Felsher BL [2010]. Adolescents' perceived risk of dying. Journal of Adolescent Health 46(3): 265-269.

Fischhoff B, Downs J, Bruine de Bruin W [1998]. Adolescent vulnerability: A framework for behavioral interventions. Applied and Preventive Psychology 7: 77-94.

Fischhoff B, Beyth-Marom R [1983]. Hypothesis evaluation from a Bayesian perspective. Psychological Review 90: 239-260.

Fischhoff B, Kadvany J [2011]. Risk: A very short introduction. Oxford: Oxford University Press.

Fischhoff B, Lerner JS, Small DA [2005]. Evolving judgments of terror risks: Foresight, hindsight, and emotion. Journal of Experimental Psychology: Applied 11: 124-139.

Fischhoff B, Manski C, eds. [1999]. Preference elicitation. Boston: Kluwer.

Fischhoff B, Parker A, Bruine de Bruin,W, Downs J, Palmgren C et al. [2000]. Teen expectations for significant life events. Public Opinion Quarterly 64: 189-205.

Fishkin JS [1997]. Deliberative democracy. New Haven: Yale University Press.

Frederick S, Loewenstein G, O’Donoghue T [2002]. Time discounting and temporal preference. Journal of Economic Literature 40: 331-401.

Furby L, Beyth-Marom R [1992]. Risk taking in adolescence: A decision-making perspective. Developmental Review 12: 1-44.

Gilovich T, Griffin D, Kahneman D, eds. [2003]. Judgment under uncertainty II: Extensions and applications. New York: Cambridge University Press.

Goldberg LR [1968]. Simple models or simple processes? Some research on clinical judgments. American Psychologist 23: 483-496.

Hastie R, Dawes RM [2002]. Rational choice in an uncertain world. San Diego: Russell Sage.

Jacobs JE, Klaczynski P, eds. [2005]. The development of judgment and decision making in children and adults. Mahwah, NJ: Erlbaum.

Kahneman D [2011]. Thinking, fast and slow. New York: Ferrar Giroux \& Strauss.

Kahneman D, Tversky A, eds. [2000]. Choice, values, and frames. New York: Cambridge University Press.

Lerner JS, Small DA, Fischhoff B [2003]. Effects of fear and anger on perceived risks of terrorism: A national field experiment. Psychological Science 14: 144-150. 
Lerner JS, Keltner D [2001]. Fear, anger, and risk. Journal of Personality and Social Psychology 81: 146-159.

Lichtenstein S, Fischhoff B, Phillips LD [1982]. Calibration of probabilities. In: Kahneman D, Slovic P, Tversky A, eds. Judgment under uncertainty: Heuristics and biases. New York: Cambridge University Press, pp. 306-339.

Lichtenstein S, Slovic P, eds. [2006]. Construction of preferences. New York: Cambridge University Press.

Lopes L [1987]. Between hope and fear: The psychology of risk. Advances in Experimental Psychology 20: 255-295.

Millstein SG, Halpern-Felsher BL [2002]. Judgments about risk and perceived invulnerability in adolescents and young adults. Journal of Research on Adolescence 12: 399-422.

Mitchell RC, Carson RT [1989]. Using surveys to value public goods. Washington, DC: Resources for the Future.

Morgan MG, Fischhoff B, Bostrom A, Atman C [2001]. Risk communication: The mental models approach. New York: Cambridge University Press.

O'Brien M [2000]. Risk analysis. Cambridge, MA: MIT Press.

O' Hagan A, Buck CE, Daneshkhah A, Eiser JE et al. [2006]. Uncertain judgements: Eliciting expert probabilities. Chichester: Wiley.

Parker A, Fischhoff, B [2005]. Decision-making competence: External validity through an individual-differences approach. Journal of Behavioral Decision Making 18: 1-27.

Plous S [1993]. The psychology of decision making. New York: McGraw-Hill.

Poulton EC [1989]. Bias in quantifying judgment. Hillsdale, NJ: Erlbaum.

Poulton EC [1994]. Behavioral decision research. Hillsdale, NJ: Erlbaum

Quadrel MJ, Fischhoff B, Davis W [1993]. Adolescent (in)vulnerability. American Psychologist 48: 102-116.

Reyna V, Farley F [2006]. Risk and rationality in adolescent decision making: Implications for theory, practice, and public policy. Psychology in the Public Interest 7(1): 1-44.

Rollnick S, Miller WR [1995]. What is motivational interviewing? Behavioral and Cognitive Psychotherapy 23: 325334.

Schwarz N [1999]. Self reports. American Psychologist 54: 93-105.

Shafer G, Tversky A [1985]. Languages and designs for probability judgment. Cognitive Science 9: 309-339.

Simon HA [1957]. Models of man. New York: Wiley.

Small DA, Lerner JS, Fischhoff B [2006]. Emotion priming and attributions for terrorism: Americans' reactions in a national field experiment. Political Psychology 27: 289-298.

Slovic P, Peters E, Finucane ML, MacGregor D [2005]. Affect, risk and decision making. Health Psychology 24(4): S35-S40.

Tengs TO, Wallace A [2000]. One thousand health-related quality- of-life estimates. Medical Care 38: $583-637$.

vonNeumann J, Morgenstern, O [1947]. Theory of games and economic behavior. Princeton: Princeton University Press.

vonWinterfeldt D, Edwards, W [1986]. Decision analysis and behavioral research. New York: Cambridge University Press.

Weber EU [1994]. From subjective probabilities to decision weights. Psychological Bulletin, 115: $228-242$.

Woloshin S, Schwartz LM, Byram S, Fischhoff B, Welch HG [1998]. Scales for assessing perceptions of event probability: A validation study. Medical Decision Making 14: 490-503.

Yates JF [1989]. Judgment and decision making. Englewood Cliffs, NJ: Prentice Hall. 


\title{
Work and its Positive and Negative Effects on Youth's Psychosocial Development
}

\author{
Jeylan Mortimer, PhD, University of Minnesota
}

\begin{abstract}
The combination of schooling and employment is a near-universal teenage experience. Because adolescence is a highly formative and potentially vulnerable period of life, it is important to consider how employment influences adolescent development. Much research shows that teenage employment is associated with problem behaviors, such as drinking, smoking, and various forms of deviance, though whether such behaviors are attributable to employment, or part of a syndrome of "precocious adulthood" that attracts youth to work, remains controversial. Employment is also thought to place adolescents at risk because it threatens educational achievement, limits participation in the academic and extracurricular life of the school, and confronts them with stressors for which they are not yet ready. On the other hand, a job may signify progress in moving toward adulthood for the young person and enhance vocational identity. By providing opportunities for vocational exploration and by teaching generic work and coping skills, employment can promote adaptation to the future adult work role. The temporal investment as well as the quality of work must be considered in assessing its positive or negative impacts on development and socioeconomic attainment. Investigators need to further address the processes through which adolescents enter into various work contexts, and the processes through which employment exerts developmental influence.
\end{abstract}

\section{Introduction}

During adolescence, most young people acquire their first formal jobs; many begin to work informally for pay at younger ages. Given the prevalence of youth work [Manning 1990; Committee on the Health and Safety Implications of Child Labor 1998; U.S. Department of Labor 2000; Staff et al. 2009], most teenagers will be exposed to whatever benefits, or risks, employment has to offer. Because adolescence is a highly formative and potentially vulnerable period of life, it is important to understand the developmental impacts of this experience.

This paper reviews the evidence and controversies surrounding employment's developmental impacts. On the negative side, employment is said to promote problem behaviors like drinking, smoking, and other substance use, getting into trouble at school, and various forms of delinquency. Much concern is expressed about employment's threats to educational achievement. Employment is also considered to be a potent stressor for teenagers who have not yet developed relevant coping skills. In a more positive vein, working is thought (by most youth and their parents) to promote positive character traits, such as self-confidence, responsibility, and independence; to enhance vocational development; and to teach generic occupational and coping skills. Such positive outcomes would likely promote socioeconomic attainment and adaptation to the adult work role. We will see that work may be a source of both negative and positive 
experiences and outcomes; understanding its impact requires consideration of both the teenager's temporal investment in employment and the quality of that work experience.

\section{Negative Effects of Employment}

\section{Problem behavior}

Adolescents who work longer hours more frequently use alcohol, cigarettes and illicit drugs, and report more minor delinquency and school misconduct [Bachman et al. 1986; Bachman and Schulenberg 1993; Schulenberg and Bachman 1993; Greenberger 1984; Greenberger and Steinberg 1986; Mihalic and Elliott 1995; Blum and Rinehart 1997; Steinberg and Dornbusch 1991; Steinberg et al. 1982; Wofford 1988; Wright et al. 1997]. The positive association between adolescent work intensity and alcohol use is one of the most robust findings in the literature [Steinberg et al. 1993; Mortimer et al. 1996a]. There is evidence implicating the quality of youth work as well. The Monitoring the Future studies [Schulenberg and Bachman 1993] at the University of Michigan show that low skill utilization at work is positively associated with high school seniors' cigarette, marijuana, and alcohol use (the latter, only for females). Bachman and Schulenberg [1993] also report that long hours of work are associated with unhealthy lifestyles (less sleep and exercise, skipping breakfast).

Critics of youth work point to developmental risks in the work setting that encourage these problematic behaviors. Acquaintances with older coworkers could introduce adolescents prematurely to alcohol and other substances, and encourage their frequent use. Greenberger and Steinberg [1986] allege that alcohol use reflects the stresses adolescents experience at work and their attempts to restore a positive mood state. Of course, employed teenagers have greater disposable income with which to purchase alcohol, cigarettes and drugs.

Still, investigators debate whether it is working itself that encourages youth problem behavior, or whether youth who engage in such behaviors are more likely to seek employment and to work longer hours [Staff et al. 2009]. According to Bachman and Schulenberg [1993], teenage employment is part of a syndrome of "precocious development" that precipitates a hastened transition to adulthood. Engaging in more "adult-like" ways of handling stress or spending leisure time, as well as working, may be considered means of affirming adult status.

Consistent with the "precocious development" hypothesis, there is mounting evidence that the link between employment and problem behavior is, in fact, spurious. It is clear that teenagers who are disengaged from the educational enterprise are more likely to work long hours. Ninth graders who did not plan to complete college, had low GPA's, and had been held back in school were more likely to work intensively in their senior year [Bachman and Schulenberg 1993]. Time-use diaries from a sample of Seattle youth revealed that prior orientations toward work and school predicted subsequent work hours as well as school performance [Warren 2002]. Students in the St. Paul Youth Development Study (YDS) who had lower educational promise (gauged by educational aspirations, grade point average, perceived intelligence, and intrinsic motivations toward schoolwork) in the ninth grade worked more intensively in the 10th through 12th grades; problem behavior in the ninth grade predicted subsequent sporadic work of high intensity and low duration [Mortimer 2003]. Paternoster and his colleagues [2003] find that intensive hours of work do not affect substance use, delinquency, and school-related misconduct once individual differences in prior deviance are taken into account. Apel et al. 
[2006] also show that movement into intensive formal work does not increase the likelihood of problem behavior. If delinquency precedes involvement in work, the observed associations between paid work and deviance could be spuriously related to preexisting differences between individuals. (In Apel et al.'s study, however, movement into informal work did increase the risk of both delinquency and substance use, compromising educational and other beneficial activities.)

A similar pattern arises when we consider the relationships between employment and educational achievement. Steinberg and Cauffman [1995] allege that adolescent work draws young people away from school and promotes behaviors that interfere with achievement. A longstanding critique of teenage employment is premised on a "zero-sum" model of time use: work has substantial "opportunity costs" because teenage jobs limit time for homework, extracurricular activities in the arts, sports, and school-based clubs, and other engagements designed by adults to promote achievement, exploration of interests, and healthy development [Greenberger and Steinberg 1986; Steinberg and Dornbusch 1991; Marsh 1991; Csikszentmihalyi and Schneider 2000]. Instead, working youth spend their leisure time partying, using drugs and alcohol, and cruising around in cars, because these activities are attractive and compatible with their work schedules [Safron et al. 2001].

But contrary to the "zero-sum" model, time spent in school-related work and extracurricular activities is not compromised when youth limit their involvement in paid work to 20 or fewer hours per week. Moderate hours of employment apparently do not restrict other types of work and leisure, such as homework, school activities, and reading outside of class [Mihalic and Elliott 1997; Schoenhals et al. 1998], as the "well-rounded" adolescent is equally involved in paid work, school, and extracurricular activities [Shanahan and Flaherty 2001]. Paid work may actually "squeeze out" more passive leisure activities, as young people watch less television as work hours increase [Osgood 1999].

Again, preexisting differences may explain the associations between work intensity and academic achievement. Youth who have less involvement and success in conventional adolescent activities-such as going to school and participating in extracurricular sports, clubs, and organizations-are more likely to invest themselves in paid work and to prefer work over school. Studies based on the National Educational Longitudinal Study (NELS88) find no effects of work hours on school performance once pre-existing grades, aspirations, problem behaviors and family social class background are taken into account [Schoenhals et al. 1997; Warren et al. 2000]. Similar findings emerge from the YDS [Mortimer et al. 1996a; Mortimer 2003]. Moreover, recent analyses of NELS data using propensity score matching [Lee and Staff 2007] show that intensive employment has no effect on dropout for those whose backgrounds, attitudes, and behaviors make them strongly inclined to pursue long work hours. This research finds evidence for a causal influence of work hours on dropout only for teenagers who have low to moderate propensity to pursue long hours.

Whereas there has been relatively little investigation of the quality of work and educational outcomes, it is possible that high quality work experiences moderate whatever negative effects high intensity work may entail. When the quality of work is high, there seems to be little association between work intensity and school performance deficits; but when work quality is low, relatively more hours at work is linked with more class cutting and lower grades in school [Barling et al. 1995]. 


\section{Work as stress-promoting}

According to a long-term critique of teenage employment, working places adolescents at risk because they are not yet ready for the stressors they are likely to encounter in the workplace or for the challenges inherent in balancing demanding school and work schedules. The developmental literature points to the dangers inherent in experiencing problems too soon, before the person is ready to handle them effectively [Simmons and Blyth 1987]. Greenberger $[1983,1988]$ depicts young workers as taking on adult responsibilities without adequate coping skills. According to this line of argument, work stressors increase adolescent vulnerability and are "stress sensitizing," lowering thresholds of reactivity and diminishing the effectiveness of coping with similar problems in the future. The experience of overwhelming stressors at work, or failure in managing diverse responsibilities, could foster a general sense of ineffectuality, depressive affect, and low self-esteem. Greenberger [1988] expressed fear that working disrupts bonds with parents, and even close relationships with peers, the social supports that enable youth to successfully cope with problems. Mortimer and Shanahan [1991, 1994], however, find no evidence that this is the case.

Like the realms of problem behavior and educational achievement, investigations of adolescent work and mental health have focused on adolescent investment in employment (hours of work per week). These studies mainly yield null findings [Bachman and Schulenberg 1993; Bachman et al. 1986; Steinberg and Dornbusch 1991; Steinberg et al. 1993]. Similarly, in the YDS, indicators of temporal investment in employment---work status, hours per week, and the cumulative duration and intensity of work during high school---show no consistent relation to adolescent mental health, including depressive affect, self-derogation, and other dimensions (Mortimer et al. 1994; Mortimer and Johnson 1998].

A more promising line of research is based on the premise that the consequences of parttime work for adolescent mental health will depend on its quality. Analyses of longitudinal YDS data, incorporating controls for background and lagged criterion variables, indicate that stressors at work, such as work overload, role conflict, exposure to noxious work conditions (heat, cold), and other negative experiences heighten adolescents' depressed mood, and reduce their self-esteem and self-efficacy [Shanahan et al. 1991; Mortimer et al. 2002a]. Early decisionmaking capacity on the job, suggesting too much autonomy, and the responsibility for things that are beyond one's control, also increase adolescent depressed mood, while the acquisition of useful skills on the job diminish depressive affect [Shanahan et al. 1991; Shanahan 1992].

The quality of work experience has also been found to condition the effects of work hours. When work is of poor quality, long working hours may have particularly deleterious consequences for personal development. Shanahan [1992] reports that both work stress and selfdirection increased depressed mood only among YDS boys working more than the median number of hours in the 10th and 12th grades. Showing a similar pattern, seniors in the Monitoring the Future (MTF) study who described their jobs unfavorably (as not using their skills, unconnected to the future, and "the kind of work that people do just for the money") used cigarettes more frequently as their work intensity increased [Schulenberg and Bachman 1993]. In the MTF, work intensity was found to be less consequential for youth who described their jobs as relevant to their futures. 
Still, the potential psychological benefits of encountering and successfully dealing with difficult situations are well known [Rutter 1985; Masten and Garmezy 1985: Compas 1987; Simmons and Blyth 1987]. Shanahan and Mortimer [1996] proposed a model of "eustress," indicating how stressful experiences can foster successful adaptation, sometimes immediately, but often in the long-term. Primary eustress occurs when positive outcomes, including a sense of challenge, heightened confidence, and the development of coping skills, occur with the experience of stressors. Secondary eustress occurs when earlier stressful experiences heighten the person's adaptive capacity in the face of later stressful encounters. Successful mastery of difficult tasks, even when they are perceived initially as stressful, can heighten thresholds of reactivity to subsequently experienced stressors, strengthen self-efficacy and motivational structures to surmount them, and increase the propensity to select contexts that are ever more challenging yet still controllable. Such outcomes would "steel" the adolescent for future challenges.

Consistent with the secondary eustress hypothesis, we find that adolescent work stressors moderate the deleterious effects of early adult work stressors on mental health four years after high school [Mortimer and Staff 2004]. It is only among those who experience relatively little work stress during adolescence that young adult work stressors diminish self-esteem and selfefficacy and heighten depressed mood. The findings thus suggest that early work stressors heighten youth's resilience. The relatively moderate levels of work stressors reported by a community sample of employed adolescents appear to represent stage-appropriate challenges that enhance preparation for subsequent challenges at work.

\section{Work as Beneficial}

\section{Character-building and positive self-concept formation}

A widespread popular belief posits that adolescent employment has positive developmental consequences. Parents believe that paid work builds character, instills a positive "work ethic," and provides opportunities for growth-inducing experiences that are not available in other settings [Phillips and Sandstrom 1990; Aronson et al. 1996]. Consistent with this view, adolescent employment is positively associated with self-reported dependability, personal responsibility, punctuality and self-reliance [Greenberger and Steinberg 1986; Greenberger 1984]. The role of future worker is a key component of the adolescent future "possible self" [Markus et al. 1990; Johnson and Mortimer 2000]. Just having a job may lead to changed self-concepts and new identities, new expectations of responsibility and independence on the part of parents [Phillips and Sandstrom 1990; Aronson et al. 1996] and high esteem in the eyes of peers [Mortimer and Shanahan 1991].

The ability to function effectively in the work world could signal to the adolescent an immediate capacity to control important outcomes, as well as to function capably as an adult in the future. Employed adolescents may learn to better manage their time as they juggle the multiple activities of worker, student, friend, and family member. Capably handling diverse activities in adolescence could promote a self-image as one who is able to meet the challenges of diverse adult roles [Elder and Caspi 1990]. Consistently, there is evidence that positive experiences in the workplace, signifying the youth's success in the work role, enhance self-efficacy [Call 1996; Call et al. 1995; Call and Mortimer 2001]. Experiences of success and validation of one's role as 
worker (e.g., through the belief that one is paid well for the work one does) are associated with both global and economic self-efficacy [Finch et al. 1991; Grabowski et al. 2001].

\section{Vocational development}

Through their early jobs, adolescents may gain knowledge about the labor force, explore their vocational interests and identities, form occupational values, learn how to behave appropriately in the workplace, and acquire skills that facilitate adaptation to adult work [Mortimer 2003; Mortimer et al. 2002a; Youniss et al. 1999; Vondracek and Skorikov 1997; Skorikov and Vondracek 1997]. Prestigious task forces in the late 1970's emphasized this aspect of paid work [Panel on Youth 1974; Carnegie Council on Policy Studies in Higher Education 1980; and National Commission on Youth 1980]. James Coleman's Panel on Youth suggested that working adults could mentor youth in preparing for future careers, teach them responsibility and independence, and convey the importance of what students were learning in school. Most parents appear to share this perspective [Phillips and Sandstrom 1990; Aronson et al. 1996].

Vocational development, involving the exploration of career interests, work values, and options, intensifies during adolescence and continues into "emerging adulthood" [Meeus et al. 1999]. To make viable occupational choices, young people must understand their own interests and capacities, as well as the affordances and demands of particular lines of work. Vocational exploration may be particularly important in the contemporary United States where most education is not specific to a vocation and institutional bridges between schools and workplaces are lacking [Mortimer and Krueger 2000]. Whereas the increasing prevalence of higher education and the prolonged transition to adult roles during the past few decades has extended vocational exploration to older ages [Mortimer et al. 2002b], adolescents who have greater understanding of their nascent skills, work values, and interests are likely to make better postsecondary educational choices [Schneider and Stevenson 1999].

In formulating a vocational development theory based on self-determination and intrinsic motivation theory [Deci and Ryan 1985], Blustein et al. [1994] describes vocational exploration during adolescence and young adulthood as an agentic process. Those who are able to formulate career goals and mobilize their energies to move toward them are more successful in career establishment [Nurmi et al. 2002]. Zimmer-Gembeck and Mortimer [2007] found that youth who crystallize their vocational decisions during high school or in their early-to-mid twenties are more likely to complete college by their mid-20s than those who exhibit greater indecision or vacillation in their career objectives. Those who were unable or unwilling to articulate occupational goals in response to survey questions were disadvantaged with respect to educational attainment, career establishment and job satisfaction.

Agentic adolescents will select work experiences that enhance their career exploration and further their attainments. Many adolescents initiate a process of selection and optimization of their work environments and career pathways, which continues through the transition to adulthood [Zimmer-Gembeck and Mortimer 2007]. Through their employment, young people begin to gather information about the self, other people, and the world of work. Interviews focused on the subjective process of vocational development show how teens in middle and especially late adolescence begin to formulate their goals for the future (both what they hope to accomplish and what they hope to avoid) in response to the experiences they encounter, both 
positive and negative, in the workplace [Mortimer et al. 2002b; Zimmer-Gembeck and Mortimer 2007].

It is clear from YDS survey data that the quality of work experience is associated with several vocationally-relevant outcomes. Consistent with prior studies (e.g., Kohn and Schooler 1983; Shanahan et al. 1996; Skorikov and Vondracek 1997; Vondracek and Skorikov 1997), those who report more learning opportunities in their jobs come to have higher levels of intrinsic, peopleoriented, and extrinsic occupational rewards [Mortimer et al. 1996b]. Those who invest more in work activity during high school appear to develop more confidence in their capacities as workers, anticipating greater economic efficacy in the future. Even with background variables and lagged economic efficacy controlled, occasional workers and nonworkers, those who invested the least in labor force activity, exhibited less confidence in being able to achieve their economic goals than the most invested workers; sporadic and steady workers manifested levels of efficacy similar to those of the most invested [Mortimer 2003].

\section{Impacts on trajectories of attainment}

Much of our research indicates that adolescents are active agents with respect to their work experiences [Mortimer 2003]. Teenagers whose prior attitudes and resources (measured in the first year of high school) suggest high potential for academic success moderate their subsequent labor force participation. High grades and strong intrinsic motivations toward school promote a steady (high duration, low intensity) work pattern (and lessened the likelihood of "most invested," high duration-high intensity work). Youth who had lower grades, who were more strongly oriented to their peers, and engaged in more problem behavior were more likely to pursue a sporadic work pattern, involving intense (high intensity) but sporadic (low duration) bouts of work. These relationships suggest strategic behavioral patterns in which adolescents assess the likelihood of their succeeding in school (and post-secondary educational pursuits), establish educational goals, and gauge their involvement in the teen labor force accordingly.

As a result, adolescents whose academic orientations and performance and family resources indicate greater payoff from involvement in school choose to be employed, like other adolescents, but they limit their hours of work so as to be able to engage in the full gamut of academic and extracurricular activities, and to have time remaining for friends and family. Steady workers during high school were the most likely to say they wanted to save their earnings for their future educations.

Adolescents with more limited academic potential or family resources make heavier investments in paid work and acquire experiences that will contribute to their human capital development through work, and prepare them for entry to the full-time adult workforce. These youth, less engaged and less successful in the formal educational system, instead look to the workplace as a context for job exploration and human capital development. Youth in the YDS who manifested the most invested pattern of employment were more likely than those who pursued other patterns to say that they began work to learn new skills.

Linkages between work investment patterns and the features of work that youth reported during high school similarly suggest agentic selection processes. If youth who invest heavily in work during high school are expecting to develop their skills and prepare themselves for adult employment through this early participation in the labor force, one would expect that they would report higher quality employment experiences than those who are less invested in em- 
ployment. In fact, those who worked longer hours (the most invested and sporadic workers), reported more learning and advancement opportunities in their jobs than occasional and steady workers and reported relatively high psychological engagement in their work. They also, however, experienced more stressors at work.

In general, the work of the more intensively employed students was more "adult-like;" they worked more hours, had higher earnings, and received more extrinsic and intrinsic rewards. They seemed to be experiencing in a more pronounced way than their less intensively employed counterparts the diverse benefits as well as the drawbacks of work.

Although critics of youth work contend that teenage work diminishes adult socioeconomic standing by disrupting academic achievement, relatively few studies examine long-term outcomes of employment. This lack of attention is unfortunate because the full benefits and costs of youth work may not appear until well after the adolescent period. Using data from the National Longitudinal Survey of Youth (1979 cohort), Carr, Wright, and Brody [1996] and Ruhm [1997] find that intensive work hours during high school increased wages and employment 10 years later but decreased college attendance, especially the completion of 4 or more years of college. While intensive teenage employment was associated with reduced educational standing in early adulthood, limited hours of employment were linked to higher wages and occupational standing from 6 to 9 years after the scheduled date of high school graduation.

Still, Hotz et al. [2002] argue that the effects of prior work status on adult attainments are due to selection processes. For the NLSY79 cohort, employment while attending school does not benefit wages from ages 13 to 28, once differences in school performance, orientations, socioeconomic background, and ability are considered. Their work measures, however, do not incorporate distinct patterns of employment over time, their outcomes do not include educational attainment, and they do not include females.

Much of the most recent YDS research has been directed to determining whether the seemingly strategic patterns of investment in school and work have demonstrable payoffs. We have broached the influence of high school work patterns on long-term attainment processes in two ways: first, by examining post-secondary education, specifically, months of school attendance and receipt of a B.A. degree [Staff and Mortimer 2007]; second, by investigating movement into jobs, self-identified by the respondent as "careers" [Mortimer et al. 2008]. Continuous life history calendar data, collected since 1991 (the expected high school graduation year), enables estimation of discrete-time logit models of the time it takes to get a BA, or to acquire a career, controlling background variables, prior orientations relevant to work and achievement, and time-varying post-secondary schooling, work investments, and family experiences.

What we find provides further confirmation for conceptualizing adolescent employment as a strategic, agentic process. First, those youth who worked steadily during high school (at high duration, low intensity) are found to pursue a similar combination of schooling and working after high school, as they work their way through college. These youth are shown to have a clear advantage in acquiring the highly-coveted bachelor's degree [Staff and Mortimer 2007]. Youth who have little educational promise appear to gain the most advantage in pursuing a steady pattern of work. The most invested (high duration, high intensity) workers, previously exposed to the more "adult-like" demanding, challenging, and engaging work, instead move more quickly toward acquiring career-like employment (Mortimer et al. 2008). Each pattern of work investment thus moves youths toward an outcome that might have been predicted based on 
their earlier goals, resources, and motivations. Importantly, the effects of the high school work patterns are persistent even when these prior orientations and behaviors, implicated in the process of selection to work, are controlled.

In summary, through their choices regarding school and work, both during high school and in the years immediately following, young people can shape their biographical pathways and thereby influence their potential for socio-economic attainment.

\section{Selection and Socialization in the Youth Work Setting: Issues for Consideration}

We have seen that many of the linkages between adolescent work and both negative and positive outcomes are linked to selection processes. Differences between students in their prior rates of deviance and substance use, school performance and orientations toward work and school, as well as family background and demographic characteristics, predate employment and may explain many of the benefits of moderate and high quality work and the negative impact of intensive and poorer quality work. Understanding the developmental significance of adolescent employment requires assessment of both the selection processes through which young people arrive at their occupational destinations, and the socialization processes through which work may exert its influence.

\section{Following are some questions and issues for our group to consider:}

Whereas parents believe that working will make their children more successful in navigating the transition from school to work, do young people share this view and deliberately plan their investment in work accordingly? Do they anticipate and mobilize their job search activities to effect strategies of school and work investment that enhance their educational attainment and career progress?

Second, if socialization does occur in the work setting, how does it happen? For example, we have speculated that the academic attainment of steady workers is mediated by the development of time management skills. Because most college students are employed (about $80 \%$, see Horn et al. 2002), those who have learned how to work while attending high school will likely meet the challenges of combining the college student and worker roles more effectively, enhancing their capacity to obtain the B.A. degree. If the effective balancing of paid work and school is learned during high school and facilitates post-secondary educational attainment, early work could be an integral part of the educational attainment process.

Third, while primary attention has been directed to the temporal features of youth work, we need to know more about the features of work that are most developmentally important. What kinds of job qualities engender what outcomes, and for what types of youth? Evidence with respect to multiple developmental domains indicates that the benefits of employment for adolescents are enhanced when they have higher quality work environments and experiences. Work may be considered to be of high quality for adolescents when it affirms their competence in the work setting, when it promotes psychological engagement and interest, and when it involves positive and cooperative relationships with adults. To assess job quality, analysts have examined a multitude of job characteristics: intrinsic and extrinsic rewards, relations with supervisors and co-workers, and stressors [Mortimer 2003]; earnings [Shanahan et al. 1996]; supervisory work, skill variety, task identity, task significance, autonomy, and job feedback [Mael et al. 1997]; autonomy, role clarity, skill variety, and school-work conflict [Barling et al. 1995]; 
cognitive complexity, physical challenge, motivation, cynicism, opportunities to develop social competence, and stress in the workplace [Stern et al. 1990]; work-related skills and career role models [Flouri and Buchanan 2002]. Which of these are most important? Do the various dimensions come in bundles that are particularly significant? Do they act as substitutes for one another?

Fourth, the potential interactions of youth characteristics with particular qualities of jobs deserve more attention. YDS research indicates that patterns of work investment have different implications for educational attainment for youth with varying levels of educational promise. To develop effective youth work policy, we need to know more about how the youth's own background, motivation, and ambition moderate the developmental impacts of both high and lowquality work experiences.

Finally, recent precipitous declines in opportunities for teenagers to work raise questions about whether youth may be protected from certain employment-related risks but also less likely to receive the benefits from employment that are described in this review. Might other experiences, like unpaid or volunteer work, be assuming some of the functions of paid work in preparing young people for their future roles in the labor force?

\section{Questions to Consider for Discussion}

1) Whereas parents believe that working will make their children more successful in navigating the transition from school to work, do young people share this view and deliberately plan their investment in work accordingly? Do they anticipate and mobilize their job search activities to effect strategies of school and work investment that enhance their educational attainment and career progress?

2) If socialization does occur in the work setting, how does it happen? For example, we have speculated that the academic attainment of steady workers is mediated by the development of time management skills. What other mechanism might explain work's positive and negative impacts?

3) What features of work are most developmentally important? What kinds of job qualities engender what outcomes? The benefits of employment for adolescents appear to be enhanced when they have higher quality work environments and experiences. Work is of high quality for adolescents when it affirms their competence in the work setting, when it promotes psychological engagement and interest, and when it involves positive and cooperative relationships with adults.

4) Least explored are the potential interactions of youth characteristics with particular qualities of jobs. What kinds of jobs are salutary, or detrimental, for what kinds of youth? YDS research indicates that patterns of work investment have different implications for educational attainment for youth with varying levels of educational promise. To develop effective youth work policy, we need to know more about how the youth's own background, motivation, and ambition moderate the developmental impacts of both high and low-quality work experiences. 


\section{References}

Apel, R, Paternoster R, Bushway SD, Brame R [2006]. A job isn't just a job: the differential impact of formal vs. informal work on adolescent problem behavior. Crime Delinquency 52(2): 333-369.

Aronson PJ, Mortimer JT, Zierman C, Hacker M [1996]. Generational differences in early work experiences and evaluations. In: Mortimer JT, Finch MD, eds. Adolescents, work, and family: an intergenerational developmental analysis. Newbury Park, CA: Sage Publications, pp. 25-62.

Bachman JG, Bare DE, Frankie El [1986]. Correlates of employment among high school seniors. Ann Arbor, MI: Institute for Social Research.

Bachman JG, Schulenberg J [1993]. How part-time work intensity relates to drug use, problem behavior, time use, and satisfaction among high school seniors: are these consequences or merely correlates? Dev Psychol 29(2):220-235.

Barling J, Rogers KA, Kelloway EK [1995]. Some effects of teenagers' part-time employment: the quantity and quality of work make the difference. J Organ Behav 16(2): 143-154.

Blum RW, Rinehart PM [1997]. Reducing the risk: connections that make a difference in the lives of youth. Minneapolis, MN: University of Minnesota.

Blustein DL, Pauling ML, DeMania ME, Faye M [1994]. Relation between exploratory and choice factors and decisional progress. J Vocational Behav 44(1):75-90.

Call KT [1996]. The implications of helpfulness for possible selves. In: Mortimer JT, Finch MD, eds. Adolescents, work, and family: an intergenerational developmental analysis. Newbury Park, CA: Sage Publications, pp. 63-96.

Call KT, Mortimer JT [2001]. Arenas of comfort and adolescent stress: evidence from a prospective longitudinal study. Hillsdale, NJ: Lawrence Erlbaum Associates.

Call KT, Mortimer JT, Shanahan M [1995]. Helpfulness and the development of competence in adolescence. Child Dev 66(1):129-138.

Carnegie Council on Policy Studies in Higher Education [1980]. Giving youth a better chance. San Francisco, CA: Jossey-Bass.

Carr RV, Wright JD, Brody CJ [1996]. Effects of high school work experience a decade later: evidence from the National Longitudinal Survey. Sociol Educ 69(1): 66-81.

Committee on the Health and Safety Implications of Child Labor [1998]. Protecting youth at work: health, safety, and development of working children and adolescents in the United States. Washington, DC: National Academy Press.

Compas BE [1987]. Coping with stress during childhood and adolescence. Psychol Bull 101(3):393-403.

Csikszentmihalyi M [1990]. Literacy and intrinsic motivation. Daedalus 119(2):115-140.

Deci EL, Ryan RM [1985]. Intrinsic motivation and self-determination in human behavior. New York: Plenum Press.

Elder GH, Caspi A [1990]. Studying lives in changing society: sociological and personological explorations. In: Rabin Al, Zucker RA, Emmons R, Franks S, eds. Studying persons and lives. New York: Springer Publishing, pp. 201-247.

Finch MD, Shanahan MJ, Mortimer JT, Ryu S [1991]. Work experience and control orientation in adolescence. Am Sociol Rev 56(5):597-611.

Flouri E, Buchanan A [2002]. The role of work-related skills and career role models in adolescent career maturity. Career Dev Q 51(1):36-43.

Grabowski LS, Call KT, Mortimer JT [2001]. Global and economic self-efficacy in the attainment process. Soc Psychol Q 64(2):164-179.

Greenberger E [1983]. A researcher in the policy arena: the case of child labor. Am Psychol 38(1):104-111.

Greenberger E [1984]. Children, family, and work. In: Repucci ND, Weithorn LA, Mulvey EP, Monahan J, eds. Children, mental health, and the law. Beverly Hills, CA: Sage Publications, pp. 103-122.

Greenberger E [1988]. Working in teenage America. In: Mortimer JT, Borman KM, eds. Work experience and psychological development. Boulder, CO: Westview Press, pp. 21-50.

Greenberger E, Steinberg LD [1986]. When teenagers work: the psychological and social costs of teenage employment. New York: Basic Books.

Horn L, Peter K, Rooney K [2002]. Profile of undergraduates in U.S. postsecondary institutions: 1999-2000. Washington, DC: U.S. Department of Education National Center for Education Statistics. 
Hotz VJ, Xu LC, Tienda M, Ahituv A [2002]. Are there returns to the wages of young men from working while in high school? Rev Econ Stat 84(2):221-236.

Johnson MK, Mortimer JT [2000]. Work-family orientations and attainments in the early life course. In: Parcel TL, Cornfield, DB, eds. Work and family: research informing policy. Newbury Park, CA: Sage Publication, pp. 215-248.

Kohn ML, Schooler C [1983]. Work and personality: an inquiry into the impact of social stratification. Norwood, NJ: Ablex Publishing Corporation.

Lee JC, Staff J [2007]. When work matters: the varying impact of work intensity on high school dropout. Sociol Educ $80(2): 158-178$.

Mael FA, Morath RA, McLellan JA [1997]. Dimensions of adolescent employment. Career Dev Q 45(4): 351-368.

Manning WD [1990]. Parenting employed teenagers. Youth Soc 22(2):184-200.

Markus H, Cross S, Wurf E [1990]. The role of the self-system in competence. In: Sternberg RJ, Kolligan Jr. J, eds. Competence considered. New Haven, CT: Yale University Press, pp. 205-226.

Marsh HW [1991]. Employment during high school: character building or subversion of academic goals? Sociol Educ 64(3):172-189.

Masten AS, Garmezy N [1985]. Risk, vulnerability, and protective factors in developmental psychopathology. In: Lahey BB, Kazdin AE, eds. Advances in clinical child psychology. Vol. 8. New York: Plenum Press, pp. 1-52.

Meeus W, ledema J, Helson M, Vollebergh W [1999]. Patterns of adolescent identity development: review of literature and longitudinal analysis. Dev Rev 19(4): 419-461.

Mihalic SW, Elliot D [1997]. Short- and long-term consequences of adolescent work. Youth Soc 28(4):464-498.

Mortimer JT [2003]. Working and growing up in America. Cambridge, MA: Harvard University Press.

Mortimer JT, Finch MD, Ryu S [1994]. Work intensity and the mental health of high school students: a test of three behavioral models. Unpublished paper presented at the 1994 World Congress of Sociology, Bielefeld, Germany.

Mortimer JT, Finch MD, Ryu S, Shanahan MJ, Call K [1996a]. The effects of work intensity on adolescent mental health, achievement, and behavioral adjustment: new evidence from a prospective study. Child Dev 67(3):1243-1261.

Mortimer JT, Harley C, Staff J [2002a]. The quality of work and youth mental health. Work Occupations 29(2), 166197.

Mortimer JT, Johnson MK [1998]. New perspectives on adolescent work and the transition to adulthood. In: Jessor R, ed. New perspectives on adolescent risk behavior. New York: Cambridge University Press, pp. 425-496.

Mortimer JT, Krueger H [2000]. Pathways from school to work in Germany and the United States. In Hallinan M, ed. Handbook of the Sociology of Education. New York: Kluwer Academic/Plenum Publishers, pp. 475-497.

Mortimer JT, Pimentel EE, Ryu S, Nash K, Lee C [1996b]. Part-time work and occupational value formation in adolescence. Soc Forces 74(4):1405-1418.

Mortimer JT, Shanahan MJ [1991]. Adolescent work experience and relations with peers. Unpublished paper presented at the American Sociological Association Annual Meeting, Cincinnati, $\mathrm{OH}$.

Mortimer JT, Shanahan MJ [1994]. Adolescent work experience and family relationships. Work Occupations 21(4):369-384.

Mortimer JT, Staff J [2004]. Early work as a source of developmental discontinuity during the transition to adulthood. Dev Psychopathol 16(4): 1047-1070.

Mortimer JT, Vuolo MC, Staff J, Wakefield S, Xie W [2008]. Tracing the timing of "career" acquisition in a contemporary youth cohort. Work Occupations 35(1):44-84.

Mortimer JT, Zimmer-Gembeck M, Holmes M, Shanahan MJ [2002b]. The process of occupational decision-making: patterns during the transition to adulthood. J Vocational Behav 61(3):439-465.

National Commission on Youth [1980]. The transition of youth to adulthood: a bridge too long. Boulder, CO: Westview Press.

Nurmi JE, Salmela-Aro K, Koivisto P [2002]. Goal importance and related achievement beliefs and emotions during the transition from vocation school or work: antecedents and consequences. J Vocational Behav 60(2): 241-261.

Osgood DW [1999]. Having the time of their lives: All work and no play? In: Booth A, Crouter AC, Shanahan MJ, eds. Transitions to adulthood in a changing economy: no work, no family, no future? Westport, CN: Praeger Publishers, pp. 176-186. 
Panel on Youth of the President's Science Advisory Committee [1974]. Youth: transition to adulthood. Chicago, IL: University of Chicago Press.

Paternoster R, Bushway SD, Brame R, Apel R [2003]. The effect of teenage employment on delinquency and problem behavior. Soc Forces 82(1): 297-335.

Phillips S, Sandstrom KL [1990]. Parental attitudes towards youth work. Youth Soc 22(2):160-183.

Ruhm CJ [1997]. Is high school employment consumption or investment? J Labor Econ 15(4):735-776.

Rutter M [1985]. Resilience in the face of adversity: protective factors and resistance to psychiatric disorder. Br J Psychiatry 147(6):598-611.

Safron DJ, Schulenberg JE, Bachman JG [2001]. Part-time work and hurried adolescence: the links among work intensity, social activities, health behaviors, and substance use. J Health Soc Behav 42(4):425-449.

Schneider B, Stevenson D [1999]. The ambitious generation: America's teenagers, motivated but directionless. New Haven, CT: Yale University Press.

Schoenhals M, Tienda M, Schneider B [1998]. The educational and personal consequences of adolescent employment. Soc Forces 77(2):723-762.

Schulenberg J, Bachman JG [1993]. Long hours on the job? Not so bad for some types of jobs: the quality of work and substance use, affect and stress. Unpublished paper presented at the Biennial Meeting of the Society for Research on Child Development, New Orleans, LA.

Shanahan MJ [1992]. High school work experiences and depressed moods. Unpublished paper presented at the American Sociological Association Annual Meeting, Pittsburgh, PA.

Shanahan MJ, Elder GH, Burchinal M, Conger RD [1996]. Adolescent earnings and relationships with parents: the work-family nexus in urban and rural ecologies. In: Mortimer JT, Finch MD, eds. Adolescents, work, and family: an intergenerational developmental analysis. Newbury Park, CA: Sage Publications, pp. 25-62.

Shanahan MJ, Finch MD, Mortimer JT, Ryu S [1991]. Adolescent work experience and depressive affect. Soc Psychol Q 54(4):299-317.

Shanahan MJ, Flaherty BP [2001]. Dynamic patterns of time use strategies in adolescence. Child Dev 72(2):385-401.

Shanahan MJ, Mortimer JT [1991]. Adolescent work experience and relations with peers. Unpublished paper presented at the American Sociological Association, Cincinnati, $\mathrm{OH}$.

Shanahan MJ, Mortimer JT [1996]. Understanding the positive consequences of psychosocial stress. In: Markovsky B, Lovaglia M, Simon R, eds. Advances in group processes. Vol. 13. Greenwich, CT: JAI Press, pp. 189-209.

Simmons RG, Blyth DA [1987]. Moving into adolescence: the impact of pubertal change and school context. Hawthorne, NY: Aldine de Gruyter.

Skorikov VB, Vondracek FW [1997]. Longitudinal relationships between part-time work and career development in adolescents. Career Dev Q 45(3): 221-235.

Staff J, Messersmith EE, Schulenberg JE [2009]. Adolescents and the world of work. In: Lerner R, Steinberg L, eds. Handbook of adolescent psychology. 3rd ed. New York: John Wiley \& Sons, pp. 270-313.

Staff J, Mortimer JT [2007]. Educational and work strategies from adolescence to early adulthood: consequences for educational attainment. Soc Forces 85(3): 1169-1194.

Steinberg LD, Cauffman E [1995]. The impact of employment on adolescent development. Ann Child Dev 11:131-166.

Steinberg LD, Dornbusch SM [1991]. Negative correlates of part-time employment during adolescence: replication and elaboration. Dev Psychol 27(2):304-313.

Steinberg LD, Fegley S, Dornbusch SM [1993]. Negative impact of part-time work on adolescent adjustment: evidence from a longitudinal study. Dev Psychol 29(2):171-180.

Steinberg LD, Greenberger E, Garduque L, Ruggiero M, Vaux A [1982]. Effects of working on adolescent development. Dev Psychol 18(3):385-395.

Stern D, Stone JR, Hopkins C, McMillion M [1990]. Quality of students' work experience and orientation toward work. Youth Soc 22(2):263-282.

U.S. Department of Labor [2000]. Report on the Youth Labor Force. Washington, DC: U.S. Government Printing Office.

Vondracek FW, Skorikov VB [1997]. Leisure, school, and work activity preferences and their role in vocational identity development. Career Dev Q 45(4): 322-340.

Warren JR [2002]. Reconsidering the relationship between student employment and academic outcomes: a new theory and better data. Youth Soc 33(3):366-393. 
Warren JR, LePore PC, Mare RD [2000]. Employment during high school: consequences for students' grades in academic courses. Am Educ Res J 37(4):943-969.

Wofford S [1988]. A preliminary analysis of the relationship between employment and delinquency/crime for adolescents and youth adults. In: National Youth Survey. Vol.50. Boulder, CO: Institute of Behavioral Science.

Wright JP, Cullen FT, Williams N [1997]. Working while in school and delinquent involvement: implications for social policy. Crime Delinquency 43(2):203-221.

Youniss J, McLellan JA, Su Y, Yates M [1999]. The role of community service in identity development: normative, unconventional and deviant orientations. J Adolesc Res 14(2):248-261.

Zimmer-Gembeck MJ, Mortimer JT [2007]. Selection processes and vocational development: a multi-method approach. Adv Life Course Res 11: 121-148. 


\section{Risk Factors for Nonfatal Work Injury for Young Workers: A Review of Two Relevant Literatures}

F. Curtis Breslin, PhD, Institute for Work and Health

Peter M. Smith, PhD, Centre of Occupational and Environmental Health, Monash University

\section{Introduction}

The inverse relationship between age and non-fatal work injuries is one of the most consistent associations found in occupational health and safety research [Laflamme and Menckel 1995; Salminen 2004]. Depending on the data source, both teenagers and young adults in developed countries have rates of work injury up to two times those of workers over 25 years of age [Breslin et al. 2003; CDC 2001; Dupre 2001; Laflamme and Menckel 1995; Salminen 2004].

Many of the work injuries youth sustain have clear health and economic consequences. For example, 15 to 26 per cent of injured workers under age 18 have reported permanent impairments such as chronic pain, scarring, sensory loss, and loss of range of motion. [Parker et al. $1994 a, b]$. In addition, serious injuries such as fractures and amputations though relatively rare (rate of compensation claims with permanent impairment among working 15 to 19 year olds = 0.59 per 1000 fulltime equivalents (FTEs); [Breslin et al. 2003] are clearly a concern because of the long-term health and disability consequences [Breslin et al. 2003]. Labor market trajectories may also be affected given that 16- to 24-year-olds who sustained a work injury have significantly lower earnings - about $\$ 1,000$ (Canadian dollars) -- in the year after they returned to work than their uninjured counterparts [Breslin et al. 2007c].

This paper reviews the quantitative literatures for two related questions regarding risk factors of work injuries for teenage (15- to 19-years-old) and young adult (20- to 24- years-old) workers: a) What risk factors might account for youth's elevated work-injury rates compared to adult workers; and b) Among young workers, what risk factors are associated with experiencing a work injury? Although the term "risk factor" can have somewhat different meanings in different disciplines, for this paper a risk factor refers to an individual or situational characteristic statistically associated with, although not necessarily causally related to, an increased likelihood of a health event [Stedman 2006], and that is independent of other potential risk factors.

The term, "young worker" has been defined both narrowly and broadly. Policy- makers and researchers -- especially in the U.S. -- define young workers as those less than age 18 because most child labor laws only apply to this age group [NRC 1998]. An alternative definition includes young adults up to age 24 . This broad definition recognizes that many young adults are often in the same labor market niche as adolescents, and young adults are also more likely than older adults to sustain a work injury. In this review, we used the latter definition.

In terms of review scope, studies focusing exclusively on work injuries occurring in agricultural settings were not included because a recent review covered this literature [Reed and Claunch 2000]. Also, this review does not include studies focusing on specific occupational dis- 
eases among young workers, such as asthma or dermatitis. Even though occupational disease is an important topic, published and unpublished reviews of this area exist [Breslin et al. 2006a; Pollack 2001]. In addition, given the chronic course of many diseases, the risk factor issues associated with occupational diseases can be quite different than for acute injuries.

\section{Risk factors and method issues}

There are three methodological aspects of risk factors that are highlighted in this paper for their relevance in interpreting the studies and identifying research gaps (see Figure 1). These dimensions are adapted from a systematic review of observational studies of whiplash injuries [Cote et al. 2001].

\section{Data sources}

Young worker research draws primarily from three data sources: workers' compensation claims, health records, and self-report surveys. Each of these data sources has its advantages and biases. Under-reporting of injuries may be a particular limitation with workers' compensation claims. For example, Shannon and Lowe found that where workers who had sustained injuries that might qualify for compensation, not filing for a claim was more common among those who perceived their injury to be less serious [Shannon and Lowe 2002]. Also, those in temporary jobs or those with multiple jobs did not report the injury. Of these factors, being in a temporary job is common among youth and would make it less likely that they file a claim.

The coverage of work-related injuries through hospital emergency department (ED) records has also been shown to not coincide with injuries reported for workers' compensation [CDC 1998]. Finally, self-report measures may circumvent administrative reporting practices, but recall biases as to the injury date or the interpretation of what is an injury are concerns with this data source. The advantage of an overall review of the relevant studies is that when we see patterns in risk factors from many data sources, this consistency suggests a robustness of the association despite methodological differences.

\section{Relationships between potential risk factors}

The types of relationships between potential risk factors, -- namely confounding, mediation, and moderation -- are important to consider when interpreting the results of the young worker and age-difference literatures. A confounder is a factor that produces a spurious association between the outcome and a predictor [Greenland and Robins 1985]. It does so by being associated with both the predictor and the outcome, without being in the causal pathway between the two. Accordingly, multivariate studies were the focus of this paper because univariate, descriptive statistics leave open the possibility of confounding due to a differential distribution of demographic or other factors. However, estimating the true associations between a variable and an outcome in multivariate analyses has its own set of assumptions, such as that none of the other variables in the model lie in the causal pathway [Greenland et al. 1999]. 
As emphasized in our introduction, identifying a characteristic as a risk factor does not necessarily imply that it is causally related to the likelihood of a work injury. For example, young males show higher rates of acute work injuries than young females. However, the duration and type of hazard exposure, the different ways of carrying out their tasks, and specific physical vulnerabilities to injury may mediate gender differences in the likelihood of work injury (i.e., part of the pathway accounting for observed gender differences) [Messing 1997]. This review reflects the degree to which the methods and analyses of each study were able to rule out potential confounders and characterize possible mediators -- such as hazard exposures -- that underlie the observed association between certain demographic and workplace/job variables with work injury.

A particularly relevant issue for the literature on youth versus adult differences in work injury likelihood is whether age may act as a moderator. A moderator is a variable that changes the relationship between another predictor and the outcome [Baron and Kenny 1986]. A common belief is that cognitive/behavioral/ physiological vulnerabilities unique to youth may make even similar work environments and job tasks more hazardous for youth (i.e., youth specific vulnerabilities). If these youth-specific vulnerabilities had substantial effects and were relatively common among youth, then one would predict that age would moderate the relationship between occupational categories and work injury likelihood. That is, certain occupations would be unusually risky for youth, but there would not be the same elevated risk of work injury among adults in the same occupation. In sum, identifying mediators and ruling out confounding factors are relevant to both risk factor literatures that will be reviewed in this paper. The issue of moderating factors is a potential issue in both literatures, but it is highlighted in this paper in relation to youth's elevated injury risk relative to adult workers.

\section{Type-of-injury dimension}

The type-of-injury dimension refers to the notion of an injury pyramid and its implications for risk factor identification [Institute of Medicine 1999]. The injury pyramid is a visual representation of the levels of injury severity, with less severe injuries being of higher frequency than more severe injuries and fatalities. Different injury severities may have different risk factors. For instance, goods producing industries have higher claim rates (compared to service industries) in jurisdictions where a lost-time claim required three or more days of lost time before a claim could be filed. However, rates of injury between goods and service industries are more similar in jurisdictions where fewer days of lost time from work were needed to qualify for a lost-time claim [Breslin et al. 2005]. Another example on how risk changes by injury severity is that, while youth typically show higher rates of non-fatal injuries such as lost-time claims and ED visits, adult workers typically show higher rates of permanent impairments and fatal occupational injuries [Breslin et al. 2003; Castillo et al. 1994].

The nature of the injuries -- regardless of severity -- is also relevant to interpreting the correlates of an aggregate injury outcome. In a previous review [NRC 1998], claims data showed lacerations/cuts to be the most frequent type of injury, with contusions/abrasions and sprains/strains being the next most common among young workers. Information on the mix of injury types in a study's injury outcome variable is useful for cross-study comparisons, especially if young worker studies identify different injury risk factors. If a study has a particularly unu- 
sual mix of injuries, this may indicate that the samples of young workers may have encountered different sets of hazards. Such differences in hazard exposure to, for example, sharp objects versus heavy lifting may lead to a different set of risk factors being associated with the aggregate injury outcome. That is, many studies make the assumption that risk factors for various acute injuries are similar, but this is an assumption that has not been systematically examined in the young worker literature.

\section{Two questions pertaining to risk factors for work injuries of young workers}

There are two overarching questions pertaining to risk factors for work injuries of young workers: a) What risk factors might account for youth's elevated work-injury rates compared to adult workers? and b) Among young workers, what risk factors are associated with experiencing a work injury?

\section{What risk factors might account for youth's elevated work injury rates compared to adult workers?}

The key reason that youth are considered a special or vulnerable population is that descriptive, population-based data show elevated injury rates for adolescents and young adults. From the two most recent reviews focused on age-related differences in work injuries [Laflamme and Menckel 1995; Salminen 2004], there were 14 population-based studies (e.g., studies reporting on workers' compensation claims across multiple industries) that provided descriptive information on work-injury rates for at least one age group under 25-year-olds. In 10 of these studies, adolescent and young adult workers had higher work-injury rates than their adult counterparts. This elevated risk was more marked and more consistent for young males than for young women (for specific citations, see introduction of [Breslin and Smith 2005]).

Four of these studies showed similar or lower rates for young workers. However, a methodological concern in each of these studies was that the denominators used to calculate the injury rates were based on the number of workers in each age group instead of by the number of hours worked. Because young workers are more likely to work part-time or seasonally, injury rates calculated using the former method underestimate the risk of injury for youth [Castillo et al. 1994; Ruser 1998].

Given the consistent findings of elevated work injury rates for young workers compared to adults, a key focus has been determining the degree to which different jobs (as a proxy for hazard exposure) account for this pattern. Hazard exposures are different for young people because the labor market is strongly segregated by age [NRC 1998]. In many developed countries, young people are over-represented in certain industries, such as food, service or retail sales. The jobs that many young workers hold are low-skilled, and are self-reported as more physically demanding than those jobs held by adults [Breslin and Smith 2005].

To date, only four population-based studies of age-related differences in work injury have included both age and work variables such as type of occupation in a multivariate regression model [Breslin and Smith 2005, 2006; Leigh 1986; Mitchell 1988]. Adjusting for work variables such as job title can be seen as an indirect measure of different hazard exposures between jobs [Cole and Rivilis 2004]. This adjustment provides preliminary information on the extent to 
which youth being concentrated in certain types of jobs can account for the elevated risk of young workers.

In a cross-sectional study using workers' compensation files from nine U.S. states and corresponding Census data (i.e., denominators), Mitchell [1988] found that young workers' elevated claim rates were somewhat reduced when controlling for occupation and industry, but continued to exhibit significant residual risk, suggesting that elevated youth risk is not entirely a reflection of age differences in jobs held.

In another cross-sectional study of Canadian workers [Breslin and Smith 2005], adjusting for job characteristics substantially reduced -- but did not eliminate -- the elevated risk status of adolescent (15 - 19 yrs) and young (20 - 24 yrs) adult male workers. For females, only young (20 - 24 yrs) adult females continued to exhibit an elevated risk of work injury when job characteristics were controlled for.

In a longitudinal survey, a significant inverse relationship between age and the likelihood of work injury was eliminated when work-related factors such as type of job was controlled [Leigh 1986]. Similarly, a multivariate cross-sectional study of workers' compensation claim rates found that the unadjusted relative risk of 15- to 19-year-old workers decreased by 50 per cent (unadjusted $R R=2.56$ ) when factors such as type of occupation and job tenure were controlled (adjusted RR $=1.28$ ) [Breslin and Smith 2006].

Despite many methodological differences among these studies and some variability in findings, most indicate that a substantial part of the elevated injury risk experienced by youth appears to be due to differences in the types of jobs young people and adults hold (and the associated hazard exposures). There may be other work-related variables that affect hazard exposure where youth and adults differ (e.g., organizational factors), but the current literature most consistently focused on and found differences in the types of jobs youth and adults hold.

\section{Explanations for youth's elevated risk even after controlling for work variables}

Two types of explanations may account for the residual elevated risk for youth even after controlling for work-related variables: a) age differences in hazard exposure within jobs; and b) youth-specific vulnerabilities. Each of these will be discussed in more detail below.

\section{Age differences in hazard exposures within jobs}

Multivariate studies of age differences in work injury represent an incomplete evaluation of how youth-specific vulnerabilities may elevate their work injury risk because these studies assume similar hazard exposure within similar occupational categories.

Preliminary evidence of this possibility comes from a study of teenage workers that found a wide discrepancy between job titles and job tasks they performed ([Davis and Frank 1997] cited in [NRC 1998]). For example, a cashier in a fast food restaurant may also regularly be asked to cook or clean. These data are only indirect evidence of age-related hazard differences within an occupation because the variability of tasks of adults in similar occupations is not known. In addition, one set of youth focus groups have reported that youth sometimes experience instances of hazards tasks being shifted onto them by senior workers [Workers' Compensation Board of British Columbia 2001]. These differential task assignments within the same job title may translate into additional hazard exposure for young workers in terms of ergonomic demands and using dangerous equipment/tools. 
Beyond job content, there may be age differences in workplace cultures that ultimately influence hazard exposures in the same job. A young person's typical position as a temporary or part-time worker may translate into less autonomy or control over work tasks. This decreased control may influence injury risk through work intensification [Quinlan et al. 2001]; work pace pressure; frequency of rest breaks; or the ability to vary tasks to reduce injury risks. These hypothesized relationships between workplace culture and hazards are tentative and need to be further explored, especially given the findings by Mortimer ${ }^{1}$ that increased perceived control at work for young people was associated with increased stress.

In sum, the additional hazard exposures not captured by occupational categories may further account for residual risk for young workers and raises the possibility that more refined measures of hazard exposure may lead to even more of youth's elevated risk being accounted for by work-related factors.

\section{Youth-specific vulnerabilities}

There is also the possibility that even the same workplace and job tasks are not experienced the same way by youth and adults because of individual differences. Physical developmental issues may be relevant because "tool design, working surface height, and equipment dimensions are designed for adults and make different demands on the body, with the smaller stature of some teenagers leading to lower physical tolerance and awkward postures [Feldman et al. 2002]." Yet the youth-specific vulnerabilities most frequently discussed are different cognitive functioning and different social-emotional issues between youth and adults.

The media often describes aspects of adolescent cognitive functioning as a major contribution to youth work injury. A typical example from an occupational health and safety trade journal is the following: "The vulnerability of younger workers may arise from their well-known sense of invincibility" [Gordon 2005]. As Fischoff and others have noted [Fischhoff 2007; Furby and Beyth-Marom 1992], however, it appears that by about age 16, an individual has the cognitive capability to appraise risk and use decision heuristics similar to adults. Consistent with this notion, many studies of risk appraisal of health events find no age-related differences [Quadrel et al. 1993; Weinstein 1987]. Also, if cognitive factors were a predominant factor in elevated risk, we would expect to see a gradient where young adults would show less elevated risk (after adjusting for work variables) than adolescents, but more often young adults show as much or greater injury risk than teens [Breslin and Smith 2005].

Complicating the picture, there is some evidence that youth may differ from adults in terms of the salience of potential long-term, in addition to short-term, consequences [Nurmi 1991]. Differences in future time perspective may suggest that certain workplace situations, where long-term consequences influence injury risk but are not salient, may evoke a different response among young workers compared to older workers. The mixed findings on cognitive functioning as a plausible mechanism for youth specific vulnerabilities suggest that an inability to process information relevant to assessing risk among youth is not as pervasive and robust as commonly portrayed in the popular media.

\footnotetext{
${ }^{1}$ See Mortimer J. Work and its Positive and Negative Effects on Youth's Psychosocial Development in Health and Safety of Young Workers: Proceedings of a U.S.-Canadian Series of Symposia, NIOSH 2013. Page 66 in this document.
} 
There are, however, certain findings in the research literature on brain development during adolescent/young adulthood that need to be explored for their relevance to specific vulnerabilities for work injury among youth. Although a detailed review of this literature is beyond the scope of this paper, two key changes in the adolescent brain may be relevant to increased risk of work injury. First, changes in reward sensitivity related to developments in the limbic system are thought to underlie the increased novelty seeking and higher levels of stimulation observed among adolescents [Spear 2000; Steinberg 2004]. Second, the relatively slow development of self-regulatory processes -- such as impulse control, foresight, and planning -- are seen to be linked to the slow maturation of the pre-frontal cortical systems [Spear 2000; Steinberg 2004].

Both of these processes could provide a propensity for different behaviors when engaging in similar job tasks as adults at work (e.g., adherence to safety practices), but possibly through other mechanisms than risk appraisal such as social and motivational issues [Erikson 1964]. Social-motivational issues that are more salient during this life stage include particular needs for affiliation, being attractive to others, achievement and independence. For example, teen's acceptance of parental influence declines during adolescence [Berndt 1979]. This change occurs in conjunction with increased susceptibility to peer influence, which appears to peak at around age 14 [Steinberg and Silverberg 1986]. A related developmental issue is social perspective taking, the ability to understand a situation from another person's point of view. According to Selman [Selman 1980], understanding that other's perspectives are influenced by institutional practices and the social roles they play continues to develop during adolescence. This combination of peer influence and difficulty seeing other's perspectives may make workplace interactions with young people qualitatively different from interactions with adults.

Another important aspect of potential youth specific vulnerabilities is their apparent situation-specific nature. For instance, there is recent research on the specific contexts where youth risk-taking is more likely to occur. Contextual factors influencing risk-driving behaviors among youth have also been demonstrated [Gardner and Steinberg 2005]. In this study, risk in a driving simulation was similar among youth and adults when completing the simulation alone. However, when youth and adults completed the driving simulation in the company of friends, youth showed significantly greater risk-taking tendencies.

General evidence of the modifying effect of the social setting on youth injury risk is also provided by a study examining the relationship between risk-taking behaviors (e.g., recreational drug use, failure to use a bike helmet) and injury among youth 11- to 15-year-olds [Pickett et al. 2002]. There was a clear risk gradient, with youth who reported the most risk-taking behaviors exhibiting an injury rate four times those reporting no high risk-taking behaviors. Importantly, the strength of the behavior-injury association varied by setting with the association being attenuated in school settings compared to home and sports settings. This pattern appears to indicate that more controlled contexts inhibit teen risk-taking, with workplaces potentially akin to school settings in terms of being more controlled due to supervision and co-workers, but with workplaces probably varying on this dimension. Consistent with this notion, a study of a fastfood chain with particularly engineered and organized work processes showed lower than average injury rates among youth [Mayhew and Quinlan 2002]. These work processes were so engineered and controlled that "...there was an almost total removal of all conceptual work from execution of tasks" (page 268). 
Given this combination of cognitive, social, and emotional factors in adolescence and young adulthood, risk appraisal may be less salient or need to be interpreted in the context of the other factors. For instance, one could hypothesize that, consistent with Fischoff ${ }^{2}$, young males are able to accurately appraise the risk, but may still not engage in safe practices due to socialemotional factors (e.g., gender roles)[Harré 2000]. For example, mastery of physical risk has a central position in traditional male gender identity [Kilmartin 1994]. Young males experience pressure to take physical risks at an early age, so as not to be seen as a "sissy" [Kjellberg 1998], or wanting to fit in with their older male co-workers [Breslin et al. 2006d]. Furthermore, mastery of risk can bring with it self-esteem, independence, and peer recognition [Lloyd and Forrest 2001]. These issues particular to the adolescence/young adulthood life stage may lead to, for example, differences in the way workers react to near misses, minor injuries or willingness to engage in certain safety practices.

In sum, the typical discourse in the youth occupational health and safety literature appears to have an implicit assumption that youth-specific vulnerabilities (e.g., cognitive and socialemotional functioning) influence all situations, and an assumption that such vulnerabilities affect all youth to a similar degree. However, studies on adolescent development raise the possibility that social-emotional issues and the motivations arising from them may be more relevant to work injury risk than development aspects of cognitive functioning (e.g., risk appraisal). As noted in the discussion below, this may suggest other targets of intervention besides risk appraisal. Research also indicates that any youth-specific vulnerabilities are highly context dependent. One major implication of this conception is that studies of risk taking in other injury setting may not be generalizable to the work setting. Further, research on young workers reviewed below also suggests that the assumption of vulnerabilities applying to all youth needs to be examined in that specific subgroups of young workers appear to sustain a disproportionate share of the injury burden (e.g., not attending school). Thus, a simple model that developmental factors might be a predominant factor in explaining work injury risk is not tenable and needs to be modified to account for a complex set of research findings and possible mechanisms.

\section{Section summary}

Based on the literature concerning youth's elevated risk of injury compared with adults, the following points are noted:

Based on the few multivariate studies examining this issue, youth's elevated injury risk is substantially reduced (and in one study completely eliminated) after work-related variables such as occupation/industry are controlled. Given the amount of the elevated risk of young workers explained by the types of jobs they hold (and by implication the hazards they are exposed to [Hébert et al. 2003; WHSC 2002]), young workers might be conceptualized as similar to vulnerable adult worker subpopulations such as visible minorities who encounter multiple work-related risk factors due to their lack of work experience or low education level. Such populations are selected into work arrangements that lead to a concentration of risk factors that can lead to adverse health outcomes [Frohlich and Potvin 2008].

\footnotetext{
${ }^{2}$ See Fischhoff B. Assessing adolescent decision-making competence in Health and Safety of Young Workers: Proceedings of a U.S. - Canadian Series of Symposia, NIOSH 2013. Page 46 in this document.
} 
It would be useful to formally evaluate whether age moderates the association between work variables (such as occupational category) and work injury, thereby providing more direct, but preliminary evidence of youth-specific vulnerabilities and their relationship to work injuries.

One possible explanation for any residual elevated injury risk for youth include different hazard exposures within jobs compared to adults. Further exploration of this hypothesis would require more detailed assessments of job- and workplace-related exposures.

Another possible explanation for residual risk for youth are specific vulnerabilities related to cognitive functioning and/or social-emotional functioning. Although research has identified unique aspects of the adolescent brain, research also shows that adolescent risk-taking is sensitive to context. Thus, the simple notions of how developmental factors might affect youth appear untenable.

\section{Among young workers, what risk factors are associated with experiencing a work injury?}

The results of risk factor studies among working youth improve our understanding of why some young workers do and others do not experience a work injury. Such information can help identify particularly vulnerable sub-groups of young workers and assist occupational health and safety (OHS) practitioners and policy-makers in making informed decisions about how to best intervene to reduce injury risk. Given the complexity of the problem, risk factor identification requires a multidisciplinary approach to examine both traditional (occupational, hazard exposure) and non-traditional (social, psychological, economic) risk factors.

Previous reviews of non-fatal occupational injuries among youth in the U.S. summarized studies primarily of workers' compensation claims or emergency department records. These data showed that 16- and 17-year-old workers have higher injury rates than younger adolescents [NRC 1998; Runyan and Zakocs 2000]. In addition, adolescent males exhibited injury rates around twice those of adolescent females [NRC 1998; Runyan and Zakocs 2000]. In terms of work settings, injury rates across studies were found to be elevated in industries such as retail trade, manufacturing, construction, public administration (where park maintenance and other manual tasks were common), and trucking/warehousing [NRC 1998]. One review [NRC 1998] also drew on indirect evidence on adolescent development and workplace policies to support the relevance of other risk factors that had not been specifically correlated with work-injury risk. For example, a finding that 80 per cent of adolescents injured at work reported that no supervisor was present at the time of the injury. Whether this rate of supervision differed between injured and uninjured youth was not provided.

\section{Risk factors among working youth review: Methods overview}

For this paper, a systematic review of risk factors for young workers was updated to include relevant studies published since that review [Breslin et al. 2007a]. Regarding study inclusion criteria, studies were identified that focused on working youth between ages 12 to 24 who engaged in paid work. The studies needed to have examined unintentional, non-fatal work injuries.

In relation to methodological quality, studies were evaluated based on three criteria: a) the study needed to examine work-injury rates or the likelihood of injury (i.e., information on popu- 
lation exposed to possible injury was required); b) the study needed to describe the type or severity of the work injury. Such data on the nature or severity of the work injury provides some indication that the injury measure was assessing nontrivial events and allows for some basis to compare the nature of injury across studies; and c) the study needed to use multivariate analyses that included some combination of individual/demographic characteristics and job/workplace factors as predictors in the regression model.

Studies published between January 1980 and March 2005 were identified through an electronic database search (for details see [Breslin et al. 2006b]). For studies published since then, we searched the archives of SafetyLit, a service that identifies articles published related to injury. Table 1 shows the details of the studies that met these inclusion criteria.

\section{Nature of injuries across studies}

Among the multivariate survey studies reviewed, the outcome was defined as whether any type of injury had occurred at work (sometimes with a specified timeframe). Although many studies provided information on the types of work injury sustained (e.g., cut), no study stratified their multivariate analyses by type of injury.

To examine types of injuries reported between studies, each category of injury reported within a study was rank-ordered, that is the most frequent type of injury was ranked first, the second most frequent was ranked second, etc. (i.e., high frequency ranking). Cuts-lacerations were on average the most frequent type of injury reported across four studies [Breslin et al. 2006b; Driscoll and Hanson 1997; Weller et al. 2003a, 2003b]. Fractures/dislocations and sprains/strains were the next most frequent types of injury. This information on which injuries were most frequent is in line with reports from previous reviews [NRC 1998].

\section{Individual/demographic factors}

Table 2 summarizes the individual/demographic factors that at least two multivariate studies evaluated. Five of eight studies that included gender in their analyses found no independent association of gender when job/workplace factors were controlled (with all but one study showing a significant crude association with gender). This may indicate that when working in similar situations, young males and females exhibit a similar risk. Studies of the fast food industry are consistent with this, showing comparable injury rates for both men and women [Mayhew and Quinlan 2002]. Of note is that the three studies showing residual gender differences tend to be those that included young people in late adolescence and young adulthood. This raises the possibility that jobs and tasks within jobs become more gender differentiated in late adolescence and young adulthood.

Three of five studies examining visible minority status found elevated risk of injury even after controlling for factors such as work setting/industry. The groups at elevated risk were most frequently Hispanic and Black youth. The finding that visible minority status was associated with work injury may occur because this group encounters more hazards at work even within the same job, or due to other social/environmental factors that could contribute to this residual risk that were not controlled. However, the one Canadian study of the five showed visible minorities at significantly lower risk. Given that Canada has a different mix of visible minorities than the U.S. (i.e. in Canada most visible minorities are Asian), this finding may indicate that 
contextual differences and the degree of marginalization minorities experience in the labor market may change their risk of injury.

A positive association between substance use and work injury was found in two studies. However, this association should be explored further before firmer conclusions can be drawn. For example, Shipp and colleagues [Shipp et al. 2005] adjusted for basic demographic factors (e.g., age gender) and only work hours. Thus, whether substance use was independently associated with injury risk, and not a proxy for other personal, socioeconomic, or even workplace factors, is open to question.

Three studies have now examined school status, and two of the three studies found that those youth not in school (with or without a high school diploma) are at an elevated risk for a work injury, even with job/workplace factors controlled. There were indications that those out of school may be encountering a poorer fit between themselves and their work environment compared to their counterparts in school holding the same type of job. For example, those not in school (regardless of high school completion) reported less social support at work. This reduced support could reflect fewer peers as co-workers when working full-time and/or inadequate supervision than their counterparts in school.

Two of the three cross-sectional studies examining length of employment in current job showed a positive association with injury (the fourth, prospective study examining length of employment is discussed below). However, an association between total months on the job and injury in cross-sectional studies obscure the timing of when the injury occurred within the job tenure. That is, length of employment in cross-sectional studies reflects cumulative exposure rather than time varying risk at each month of job tenure (phase specific risk). In studies examining phase specific risk, the findings are mixed. In a longitudinal study of young workers, the month on the job was not associated with risk of a one-week work absence due to injury or illness [Breslin et al. 2007b]. These findings may differ from ecological studies of job tenure and lost-time claim rates [Breslin and Smith 2006] because the former study's outcome reflected a higher level of severity compared to the latter study (where a lost-time claim can be filed after one day of absence in the jurisdiction).

Two cross-sectional studies examined psychosocial traits such as negative affectivity, rebelliousness, impulsivity, and "omnipotence" (e.g., "I honestly think I can do things no one else can")[Frone 1998; Workers' Compensation Board of British Columbia 2001]. Neither study found these traits were significant predictors in their multivariate regressions. However, given the studies' cross-sectional nature, a possible explanation is that the occurrence of a workplace injury might reduce such psychosocial traits post-injury, resulting in smaller differences between groups. This possible explanation underscores the importance of longitudinal studies that clarify the temporal patterning of risk factors and outcomes. A young worker's risk-taking orientation at work was found to be prospectively associated with work injury [Westaby and Lowe 2005]. However, this study did not include occupational variables such as work setting or occupation. Thus, it is unclear whether the risk taking-injury association is due to high risktaking youth holding more hazardous jobs or whether they carry out similar jobs, but in a way that increases risk. 


\section{Workplace and job factors}

The type of work setting or occupation (e.g., restaurant and food service work, respectively) is often used as a proxy for measuring the amount of hazard exposure and dangerous tasks that workers engage in [Punnett and Wegman 2004]. Work setting or occupational categories were associated with the likelihood of a work injury in six of seven studies. In the two studies conducted among junior high and high school students, only restaurant work had an injury risk significantly higher than babysitting. Construction work showed significantly increased risk only among high school students.

A study of Canadian youth found that compared to administrative and clerical jobs, all other occupations demonstrated an increased risk of injury, with process/manufacturing and farming/forestry/fishing jobs showing the highest risk [Breslin et al. 2006b]. The other two Canadian studies showed that physically demanding, manual jobs were associated with higher injury risk than non-manual jobs [Breslin et al. 2007b; Breslin 2008]. The only study that did not find work setting to be predictive also included work hazards as a predictor in a multivariate model, which would be expected to be a more proximal measure of exposure than work setting or occupation (i.e., mediator).

Three studies examined the relationship between the number of work hazards encountered in the workplace (e.g., sharp objects, hot objects) and the likelihood of injury. The number of hazards was positively associated in two of the three studies. The number of hazards was typically the strongest predictor of work injury in these studies (largest standardized parameter estimates), compared to demographic/individual variables and other workplace factors.

Perceived work overload or pace pressure was positively associated with injury risk in all four studies that it was examined. In two studies, perceived work pace pressure contributed to the probability of work injury over and above the strong association between number of work hazards and injury. Barling et al. [Barling et al. 2002] found that work overload indirectly increased work injuries by weakening organizational safety climate (defined as the perception the workers have about the importance that safety has in their workplace)[Zohar 2003].

The number of hours worked per week was positively associated with injury risk in only three of nine studies. However, this lack of consistency in finding an hours-injury association may be a methodological artifact related to whether the job information obtained in the study is the actual job where the injury occurred. For example, studies that used information not only about the person's main job, but about any injury event (sometimes even lifetime prevalence) were less likely to find an association.

Supervisor attributes were assessed in three studies for their association with injury risk. Youth perceptions that the supervisor cared about young workers' safety reduced risk for injury indirectly through an association with organizational safety climate [Barling et al. 2002]. Similarly, youth perceptions that their supervisors viewed risk-taking negatively reduced injury risk indirectly through its effect on youth's perceptions of risk-taking at work [Westaby and Lowe 2005]. In contrast, teen workers' perceptions of how closely their supervisors monitored them did not influence the workers' risk for injury. 


\section{Section summary}

Even though one strength of systematic reviews is their transparency of relevance and quality criteria, this review focused on published studies, with little attention to the non peerreviewed literature. A further limitation is that while basic methodological features were used to screen study quality, those studies meeting the criteria still had a diversity of ways of operationalizing constructs such as job and workplace characteristics.

Based on the literature concerning risk factors of work injury among youth, the following points are noted:

Workplace/job factors showing consistent evidence of an independent association with youth work injury were work setting, frequency of hazard exposure, perceived work overload, and supervisor attitudes to safety.

Individual/demographic factors showing consistent evidence of an independent association with youth work injury were visible minorities (in U.S. studies) and youth who were currently not attending school.

There are a growing number of multivariate studies on this issue, with an additional four 12month prevalence studies [Breslin et al. 2006b; Breslin et al. 2007b; Breslin et al. 2008; Westaby 2005] and two lifetime prevalence of work injury studies [Rauscher et al. 2008; Zierold et al. 2006] above the nine studies identified in a recent systematic review.

\section{Discussion: research issues}

There are several methodological strengths in the literatures related to risk factors and youth work injury. First, there are several data sources such as compensation claims and ED records that allow one to summarize important population-based information on the work injury burden of young workers by demographics, occupation, and industrial categories as well as the nature of the injuries. Second, the literature on risk factors among youth has an increasing number of studies using multivariate analyses, which aid in disentangling the covariation of individual/demographic and job/workplace factors, thereby helping to clarify potential targets of intervention to reduce work injury risk.

\section{Conceptual and methodological gaps}

Even though these literatures show solid progress, there are several needs or gaps that would further improve these literatures' utility in informing OHS interventions and policy. Implicit in these recommendations is a view of what counts as sufficient evidence that a situational or individual characteristic is a risk factor for work injury. Ideally, what counts as evidence should include constructs clearly delineated in a conceptual model, direct measurement of the construct, control for potential confounders, in a rigorous study design.

\section{The need for more theory-driven research}

The awareness that multiple, diverse factors influence young workers' injury risk helps prevent a narrow focus on a single intervention approach. At the macro level, the ecological frameworks [Bronfenbrenner 1979] are essential for providing broad categories of factors and 
for positing important linkages between the social and economic context in which youth work (e.g., family, school) and occupational injury.

Meso-level conceptual models, models that specify interrelationships and pathways broadly alluded to in macro-level frameworks, are particularly needed to guide variable selection and analyses for youth work injury risk. The domains of individual/demographic, job and workplace factors used in previous reviews and the current review of the young worker literature are generally in line with conceptual frameworks employed in other OHS literatures [DeJoy and Southern 1993; Hale and Hovden 1998]. The diversity of etiological factors presents a challenge in that this can lead to a literature that tests only parts of the overall framework, a situation that did occur to a certain extent even in some of the multivariate studies reviewed above. Accordingly, it would be useful if future studies that assessed less established risk factors (e.g., psychosocial variables) would also include more established risk factors, such as hazard exposure or job type.

A useful meso-level conceptual model also includes details of the pathways of influence that identify which factors are proximal (more direct, immediate) determinants in the injury process and which are more distal (e.g., mediation of effects). Proximal determinants of work injury such as exposure to work hazards show strong association with work injury. This finding naturally evokes questions about what workplace, worker, economic, and societal factors lead to some teens being exposed to more hazards than others. In exploring the distal factors that influence the more proximal ones, more potential levers for change can be identified. Accordingly, future studies should specify a model of proximal and distal constructs and test these hypotheses of mediation in their analyses.

A clearer notion of what constitutes a proximal determinant of injury would also be useful in the current etiological literature. Certain studies have included constructs that overlap so substantially with the injury outcome (e.g., coworker injured; [Zierold et al. 2004], that they are more of a proxy for the outcome than a proximal determinant of injury risk. That is, while these proxies for a young worker's injury event may be highly associated with the actual event, such variables provide less information on potential intervention strategies. Accordingly, variables that are essentially proxy outcomes should be distinguished in conceptual models and analyses from proximal determinants of injury risk.

Specific topics where more research is needed include studies collecting information on the benefits of work as well as the potential health hazards of work. To date, no study provides information on whether psychosocial and physical hazards cluster in the same jobs, or whether youth face difficult trade-offs in terms of benefits on working a job, but incurring the risk of work injury. In addition, understanding the relative contribution of risk appraisals (or misappraisals) to work injury, and the extent that workplace factors such as safety climate affect these appraisals (which would be hypothesized to influence behavior) would be a fruitful avenue for future research. 


\section{Expanding uses of administrative data sets containing information on youth work injury}

A previous review [NRC 1998] recommended an expansion of monitoring and surveillance of youth's work patterns (e.g., work hours) and the hazards to which the youth are exposed, and this recommendation is essential in improving the ability of emergency department records and compensation claims to provide information on risk factors for work injury.

In the literature search for the original systematic review of young worker studies, 24 descriptive studies were found that provided breakdowns of work injury rates by demographic (e.g., gender) and industry/occupation [Breslin et al. 2006]. Descriptive studies of youth work injury refer to studies using claims, health records, or self-report that present work-injury rates in univariate or bivariate tables. The descriptive studies published in the early years of this literature were important in terms of documenting the increased work-injury rates young workers experienced compared to adults, and that the risk among youth were differentially distributed by, for example, gender and industry/occupation [NRC 1998].

However, these types of descriptive analyses by standard demographic and industry/occupation variables have limited value at this stage of the youth OHS literature. The limited returns are due to the confounding of demographic and industry/occupation that occurs with these simple breakdowns of rates. Nevertheless, such descriptive studies continue to be conducted and published (e.g., [Horwitz and McCall 2005]). Further, limiting any attempt to identify additional individual and work-related risk factors through compensation claims or health records is the limited type of information collected. For example, these data sources capture only basic job characteristics and demographic information, and variables such as immigrant status or education level, are typically not collected. Accordingly, it is recommended that studies that only descriptively summarize administrative data on young work injuries be avoided.

Despite these disadvantages of administrative data, there are certain types of risk factor issues for which these data sources may provide new information. An advantage of data sources such as claims or health records is that often there is a greater number of data points that can be analyzed compared to primary data collection with surveys. For example, geographic variation of work injuries by regions within a jurisdiction can be usefully explored with such administrative data [Brooks and Davis 1996]. Also, the greater number of observations allow for more refined analyses of a specific type of injury event. In addition, these data sources allow for the injury rates to be broken down further, and regression methods exist that allow for the estimation of risk, adjusting for other factors [Breslin and Smith 2006]. Accordingly, administrative data may be best used as a method for exploring geographic variation in youth injury risk and infrequent injury events or small young worker subgroups.

\section{Use of longitudinal designs and improved measures}

Currently, the majority of the risk factor studies on young worker injuries have a crosssectional design. While providing essential preliminary evidence of association, the retrospective nature of such data does not address possible after effects of sustaining an injury that may obscure associations with a work injury or produce spurious ones. Accordingly, it is essential that future studies consider employing longitudinal designs that allow for the temporal patterning of risk factors and outcomes to be established, and for time-varying risk factors to be assessed more accurately (e.g., hours worked). This would include assessing multiple jobs that 
youth hold over time, and their combined impact on likelihood of a work injury. In addition, this would allow an examination of how risk factors that vary over time affect work-injury risk, which acknowledges the dynamic nature of the injury process in a way that cross-sectional studies cannot capture.

Another key methodological issue is the measures used to assess risk factors and injury outcomes. The knowledge gap in hazard exposure within job categories and in potential mediators of injury risk noted above suggest that measures be developed that provide specific information on exposures that go beyond the job title. It can be difficult to efficiently cover the range of hazards that young workers may encounter given the variability of job tasks and workplaces they encounter (data cited in [NRC 1998]. However, such assessments would avoid the problem of misclassification and within job title variability, which can lead to reduced exposureoutcome links [Messing and Stellman 2006]. Relevant exposure measures include physical hazards, workplace safety climate, and organizational procedures.

For measures of job/workplace factors as well as psychosocial characteristics of the worker, it would be useful to provide evidence of the reliability and validity of these possible risk factors. A related issue specific to research questions on youth versus adult worker differences is that efforts must be made so that terms or variables used have similar meanings for all age groups [Messing and Stellman 2006]. For example, the same work arrangement (e.g., part-time, temporary work) may translate into different levels of job satisfaction, job security and possibly safety attitudes for youth than for adults.

\section{Discussion: recommendations}

Many young people in North America engage in paid employment [Usalcas 2005], and some benefits of youth employment have been documented [Mortimer 2003]. Nevertheless, descriptive epidemiological studies show that a substantial portion of youth sustain injuries that are preventable and have the potential to continue to affect their work life. Several substantive recommendations appear to follow from the preliminary evidence presented in the paper:

The consistency and strength of work setting and hazard exposure, both for explaining youth-adult work injury risk and for explaining injury risk just among youth, provide further empirical support for continuing to prioritize safety measures that either eliminate hazards youth encounter on their jobs, or for reducing youth's presence in those jobs/workplaces.

The same evidence that suggests that work-related factors account for much of the elevated risk of youth compared to adults also implies that developmental factors have a limited contribution to work injury risk. Within that limited contribution, indirect evidence raises the possibility that the social-emotional aspects of the adolescent/young adulthood life stage may be more relevant than cognitive functioning issues (e.g., risk misappraisal). This pattern suggests that interventions focusing on peer pressure and social norms (e.g., gender roles) and their relationship to workplace safety may be a useful supplement to traditional education that emphasizes safety knowledge and statistics aimed at changing risk appraisals.

To assist in providing evidence-based prevention of youth work injuries, sensitivity to age differences is necessary and includes more than comparing injury rates by age group, or an exclusive focus on youth-only samples. It requires a more detailed examination of the workplace

reality for youth, and improving the quality of information on both potential risk factors and 
outcomes. In addition, a better understanding of risk factors will require a multidisciplinary approach from the health, engineering, labor economics, and other social sciences to further delineate and explore the established and new factors underlying the burden of injury among young people, as well as the factors that select them into certain types of jobs and work arrangements.

Figure 1. Relevant methodological dimensions when assessing risk factors.

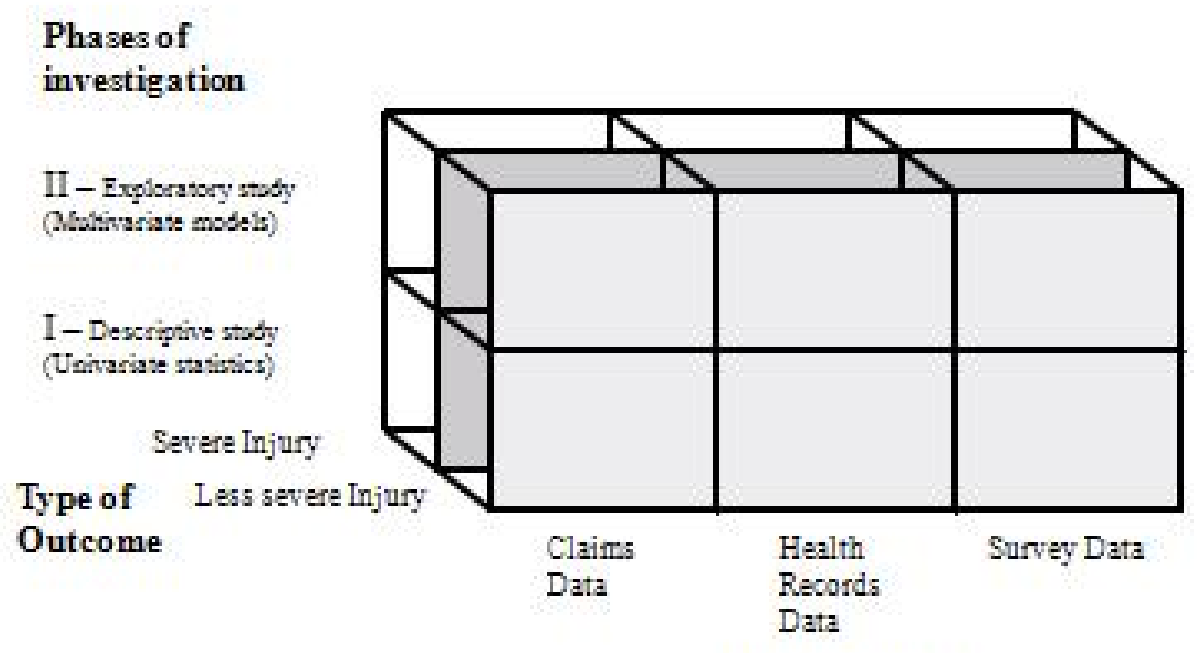

Data Source 


\begin{tabular}{|c|c|c|c|c|c|}
\hline Author (year) ${ }^{\text {ref }}$ & $\begin{array}{l}\text { Time period } \\
\text { Jurisdiction }\end{array}$ & $\begin{array}{l}\mathbf{N} \\
\text { Data source }\end{array}$ & $\begin{array}{l}\text { Age } \\
\text { (years) }\end{array}$ & $\begin{array}{l}\text { Recruitment method } \\
\text { Recruitment rate }\end{array}$ & Outcome definition \\
\hline Evensen (2000) & $\begin{array}{l}1996 \\
\text { North Carolina, } \\
\text { USA }\end{array}$ & $\begin{array}{l}117 \text { who worked in the } \\
\text { last } 4 \text { months ( } 61 \% \\
\text { male) } \\
\text { Source: phone survey }\end{array}$ & $14-17$ & $\begin{array}{l}\text { Respondents from a previous survey } \\
\text { targeting a representative sample of } \\
\text { teen workers were recontacted } \\
\text { Recruitment rate: } 207 \text { of } 238 \text { eligible } \\
\text { teens were interviewed }\end{array}$ & $\begin{array}{l}\text { Ever been injured in current job by: a fall, } \\
\text { burned, hit by vehicle, assaulted/ shot, } \\
\text { cut, heavy lifting, falling object, shot? } \\
\text { Sum of individual injury items (range } 0 \text { to } \\
\text { 7). }\end{array}$ \\
\hline Frone (1996) & $\begin{array}{l}1996 \\
\text { New York, USA }\end{array}$ & $\begin{array}{l}319 \text { who currently } \\
\text { worked for pay at least } \\
5 \text { h/week and a full- } \\
\text { time student ( } 40 \% \\
\text { male) } \\
\text { Source: self- adminis- } \\
\text { tered questionnaire }\end{array}$ & 16-19 & $\begin{array}{l}\text { Recruitment through advertisements at } \\
\text { three colleges and } 37 \text { high schools } \\
\text { Recruitment rate: not reported }\end{array}$ & $\begin{array}{l}\text { Average frequency (never to very often) } \\
\text { of seven types of work injuries during the } \\
\text { preceding } 9 \text { months: strains/ sprains, } \\
\text { cuts or lacerations, burns, bruises/ con- } \\
\text { tusions, fractured bone, dislocated joint, } \\
\text { or other injuries. }\end{array}$ \\
\hline $\begin{array}{l}\text { Workers' Com- } \\
\text { pensation } \\
\text { Board of British } \\
\text { Columbia } \\
\text { (2001) }\end{array}$ & $\begin{array}{l}2000 \\
\text { British Colum- } \\
\text { bia, Canada }\end{array}$ & $\begin{array}{l}\text { All those employed } \\
\text { within past } 12 \text { months, } \\
33 \text { males who had a } \\
\text { compensation claim } \\
\text { within past year, } 36 \\
\text { males who had at least } \\
\text { two traffic accident } \\
\text { insurance claims, } 76 \\
\text { males who had neither } \\
\text { type of claim } \\
\text { Source: self- adminis- } \\
\text { tered questionnaire }\end{array}$ & $18-22$ & $\begin{array}{l}\text { Convenience sample from lists of } \\
\text { claimants from the province's Workers' } \\
\text { Compensation Board and the prov- } \\
\text { ince's car insurance corporation The } \\
\text { control group with neither type of claim } \\
\text { was recruited by phone } \\
\text { Recruitment rate: not reported }\end{array}$ & $\begin{array}{l}\text { Number of injuries in current job from a } \\
\text { list of } 10 \text { mechanisms of injury (e.g., cut } \\
\text { by something sharp). }\end{array}$ \\
\hline Driscoll (1997) & $\begin{array}{l}1993 \\
\text { Canberra, Aus- } \\
\text { tralia }\end{array}$ & $\begin{array}{l}997 \text { ( } 83 \% \text { males) } \\
\text { Source: self- } \\
\text { administered } \\
\text { questionnaire }\end{array}$ & $\begin{array}{l}\text { Mean } \\
\text { age } 20.2\end{array}$ & $\begin{array}{l}\text { All first- to third-year students at the } \\
\text { Canberra Institute of Technology en- } \\
\text { rolled in a formal apprenticeship pro- } \\
\text { gram were given the questionnaire } \\
\text { Recruitment rate: not reported }\end{array}$ & $\begin{array}{l}\text { Occurrence of injuries during the school } \\
\text { year occurring in the school/ workplace } \\
\text { where at least one of the following oc- } \\
\text { curred: the loss of at least one shift, re- } \\
\text { ceived hospital treatment, received su- } \\
\text { tures to a wound. }\end{array}$ \\
\hline
\end{tabular}




\begin{tabular}{|c|c|c|c|c|c|}
\hline Author (year) ${ }^{\text {ref }}$ & $\begin{array}{l}\text { Time period } \\
\text { Jurisdiction }\end{array}$ & $\begin{array}{l}\mathbf{N} \\
\text { Data source }\end{array}$ & $\begin{array}{l}\text { Age } \\
\text { (years) }\end{array}$ & $\begin{array}{l}\text { Recruitment method } \\
\text { Recruitment rate }\end{array}$ & Outcome definition \\
\hline Barling (2002) & $\begin{array}{l}\text { Time period not } \\
\text { reported } \\
\text { Large city in } \\
\text { Canada }\end{array}$ & $\begin{array}{l}164 \text { currently em- } \\
\text { ployed ( } 51.3 \% \text { male) } \\
\text { Source: self- } \\
\text { administered } \\
\text { questionnaire }\end{array}$ & $14-24$ & $\begin{array}{l}300 \text { surveys were distributed to local } \\
\text { high schools, colleges, and a downtown } \\
\text { community center } \\
\text { Recruitment rate: } 85 \% \text { of distributed } \\
\text { surveys were returned }\end{array}$ & $\begin{array}{l}\text { Average frequency (never to frequently) } \\
\text { of experiencing seven types of work inju- } \\
\text { ries during the past year: strains/sprains, } \\
\text { cuts/lacerations, burns, bruises/ contu- } \\
\text { sions, fractured bone, dislocated joint, } \\
\text { serious muscle/ back pain, blisters. }\end{array}$ \\
\hline Zierold (2004) & $\begin{array}{l}2001 \\
\text { Wisconsin, USA }\end{array}$ & $\begin{array}{l}3189 \text { who worked dur- } \\
\text { ing past summer }(48 \% \\
\text { male) } \\
\text { Source: self- } \\
\text { administered } \\
\text { questionnaire }\end{array}$ & $10-14$ & $\begin{array}{l}\text { Teachers in five school districts and one } \\
\text { large urban school administered survey } \\
\text { Recruitment rate: } 5499 \text { of the } 10,366 \\
\text { students in the participating middle } \\
\text { schools completed the survey (53\%) }\end{array}$ & Occurrence of injury during summer job. \\
\hline Breslin (2008) & $\begin{array}{l}2000-2001 \\
\text { Canada, exclud- } \\
\text { ing Northwest } \\
\text { Territories }\end{array}$ & $\begin{array}{l}12,506 \text { who worked } \\
\text { during the last } 12 \\
\text { months ( } 51.8 \% \text { male) } \\
\text { Source: structured in- } \\
\text { terviews }\end{array}$ & $15-24$ & $\begin{array}{l}\text { Secondary analysis of The Canadian } \\
\text { Community Health Survey (CCHS), a } \\
\text { large, population based sample survey } \\
\text { of persons aged } 12 \text { and older, living in } \\
\text { private dwellings in Canada } \\
\text { Recruitment rate: } 130,837 \text { respondents } \\
\text { of all ages from } 125,159 \text { households } \\
\text { with a person response rate of } 91.9 \%\end{array}$ & $\begin{array}{l}\text { Occurrence of injury at a job or business } \\
\text { in the last } 12 \text { months serious enough to } \\
\text { limit their normal activities and received } \\
\text { medical attention from a health profes- } \\
\text { sional within } 48 \text { hours of the injury. }\end{array}$ \\
\hline Breslin (2007) & $\begin{array}{l}\text { 1993-2003 } \\
\text { Canada, exclud- } \\
\text { ing Northwest } \\
\text { Territories and } \\
\text { Yukon }\end{array}$ & $\begin{array}{l}17,041 \text { who were em- } \\
\text { ployed ( } 50.9 \% \text { male) } \\
\text { Source: structured in- } \\
\text { terviews }\end{array}$ & $16-24$ & & $\begin{array}{l}\text { Occurrence of a work disability absence } \\
\text { for } 1 \text { week or longer due to a work- } \\
\text { related illness or disability. }\end{array}$ \\
\hline
\end{tabular}




\begin{tabular}{|c|c|c|c|c|c|}
\hline Author (year) ${ }^{\text {ref }}$ & $\begin{array}{l}\text { Time period } \\
\text { Jurisdiction }\end{array}$ & $\begin{array}{l}\mathbf{N} \\
\text { Data source }\end{array}$ & $\begin{array}{l}\text { Age } \\
\text { (years) }\end{array}$ & $\begin{array}{l}\text { Recruitment method } \\
\text { Recruitment rate }\end{array}$ & Outcome definition \\
\hline Breslin (2006) & $\begin{array}{l}\text { 2000-2001 } \\
\text { Canada, exclud- } \\
\text { ing Northwest } \\
\text { Territories }\end{array}$ & $\begin{array}{l}\text { 14,541 who worked } \\
\text { during the last } 12 \\
\text { months ( } 51.6 \% \text { male) } \\
\text { Source: structured in- } \\
\text { terviews }\end{array}$ & $15-24$ & $\begin{array}{l}\text { Secondary analysis of The Canadian } \\
\text { Community Health Survey (CCHS), a } \\
\text { large, population based sample survey } \\
\text { of persons aged } 12 \text { and older, living in } \\
\text { private dwellings in Canada } \\
\text { Recruitment rate: } 130,837 \text { respondents } \\
\text { from } 125,159 \text { households with a person } \\
\text { response rate of } 91.9 \%\end{array}$ & $\begin{array}{l}\text { Occurrence of injury at a job or business } \\
\text { in the last } 12 \text { months serious enough to } \\
\text { limit their normal activities and received } \\
\text { medical attention from a health profes- } \\
\text { sional within } 48 \text { hours of the injury. } \\
\text { Mechanisms of injury. }\end{array}$ \\
\hline Westaby (2005) & $\begin{array}{l}\text { Time period not } \\
\text { reported, } \\
10 \text { US states }\end{array}$ & $\begin{array}{l}2542 \text { who were em- } \\
\text { ployed ( } 67 \% \text { male) } \\
\text { Source: self- } \\
\text { administered ques- } \\
\text { tionnaire }\end{array}$ & $12-21$ & $\begin{array}{l}\text { Members of the National Future Farm- } \\
\text { ers of America (FFA), a youth organiza- } \\
\text { tion completed the survey in the con- } \\
\text { text of FFA classroom activities } \\
\text { Recruitment rate: Of } 180 \text { invited chap- } \\
\text { ters of the FFA, } 117 \text { agreed to partici- } \\
\text { pate, a } 65 \% \text { group response rate. }\end{array}$ & $\begin{array}{l}\text { The number of times injured at work in } \\
\text { the past three months that required } \\
\text { medical attention. }\end{array}$ \\
\hline Weller (2003a) & $\begin{array}{l}\text { May } 1995 \\
\text { Texas (South), } \\
\text { USA }\end{array}$ & $\begin{array}{l}1608 \text { who reported } \\
\text { working in the past } 6 \\
\text { months ( } 55 \% \text { male) } \\
\text { Source: self- } \\
\text { administered ques- } \\
\text { tionnaire }\end{array}$ & $\begin{array}{l}10^{\text {th }}- \\
12^{\text {th }} \\
\text { graders }\end{array}$ & $\begin{array}{l}\text { Of the } 23 \text { high schools, larger schools } \\
\text { had a randomly selected subset of clas- } \\
\text { ses surveyed. In schools with fewer } \\
\text { than } 200 \text { students, all students were } \\
\text { surveyed } \\
\text { Recruitment rate: } 3565 \text { of } 7221 \text { eligible } \\
\text { students }\end{array}$ & Ever injured while working \\
\hline Weller (2003b) & $\begin{array}{l}\text { May } 1995 \\
\text { Texas (South), } \\
\text { USA }\end{array}$ & $\begin{array}{l}3008 \text { who reported } \\
\text { working for pay } \\
\text { Source: self- } \\
\text { administered } \\
\text { questionnaire }\end{array}$ & $\begin{array}{l}6^{\text {th }}-8^{\text {th }} \\
\text { graders }\end{array}$ & $\begin{array}{l}\text { Of the } 27 \text { middle schools, larger schools } \\
\text { had a randomly selected subset of clas- } \\
\text { ses surveyed. In schools with fewer } \\
\text { than } 200 \text { students, all students were } \\
\text { surveyed } \\
\text { Recruitment rate: } 7302 \text { of } 8757 \text { eligible } \\
\text { students }\end{array}$ & $\begin{array}{l}\text { Ever injured while working and injury } \\
\text { medically attended }\end{array}$ \\
\hline
\end{tabular}




\begin{tabular}{|c|c|c|c|c|c|}
\hline Author (year) & $\begin{array}{l}\text { Time period } \\
\text { Jurisdiction }\end{array}$ & $\begin{array}{l}\mathbf{N} \\
\text { Data source }\end{array}$ & $\begin{array}{l}\text { Age } \\
\text { (years) }\end{array}$ & $\begin{array}{l}\text { Recruitment method } \\
\text { Recruitment rate }\end{array}$ & Outcome definition \\
\hline Shipp (2005) & $\begin{array}{l}\text { May } 1995 \\
\text { Texas (South), } \\
\text { USA }\end{array}$ & $\begin{array}{l}3265 \text { who reported } \\
\text { having ever worked for } \\
\text { pay ( } 50.5 \% \text { male) } \\
\text { Source: self- } \\
\text { administered ques- } \\
\text { tionnaire }\end{array}$ & $\begin{array}{l}9^{\text {th }}-12^{\text {th }} \\
\text { graders }\end{array}$ & $\begin{array}{l}\text { Of the } 23 \text { high schools, larger schools } \\
\text { had a randomly selected subset of clas- } \\
\text { ses surveyed. In schools with fewer } \\
\text { than } 200 \text { students, all students were } \\
\text { surveyed } \\
\text { Recruitment rate: not reported }\end{array}$ & $\begin{array}{l}\text { Occurrence of injury while working for } \\
\text { pay }\end{array}$ \\
\hline $\begin{array}{l}\text { Rauscher } \\
(2008)\end{array}$ & $\begin{array}{l}1999 \\
\text { Massachusetts } \\
\text { USA }\end{array}$ & $\begin{array}{l}1430 \text { who reported } \\
\text { having ever worked for } \\
\text { pay ( } 53.3 \% \text { male) } \\
\text { Source: self- } \\
\text { administered ques- } \\
\text { tionnaire }\end{array}$ & $14-18$ & $\begin{array}{l}\text { Teachers administered the survey to } \\
\text { students in grades } 9 \text { through } 11 \\
\text { Recruitment rate: Of } 2776 \text { students, an } \\
\text { overall response rate of } 77 \% \text { is estimat- } \\
\text { ed }\end{array}$ & $\begin{array}{l}\text { Ever been injured while working by any } \\
\text { of the following injuries: back injury, any } \\
\text { other muscle injury, burn, cut, broken } \\
\text { bone, electric shock, other. }\end{array}$ \\
\hline Zierold (2006) & $\begin{array}{l}2003 \\
\text { Wisconsin, USA }\end{array}$ & $\begin{array}{l}3574 \text { who reported } \\
\text { working during the } \\
\text { school year } \\
\text { Source: self- } \\
\text { administered ques- } \\
\text { tionnaire }\end{array}$ & 14-18 & $\begin{array}{l}\text { Teachers in } 5 \text { school districts adminis- } \\
\text { tered the survey to students } \\
\text { Recruitment rate: Of } 8085 \text { students, } \\
6810 \text { completed the survey }(84 \%)\end{array}$ & $\begin{array}{l}\text { Occurrence of injury. Occurrence of se- } \\
\text { vere injury affecting normal activity for } \\
\text { longer than } 3 \text { days. }\end{array}$ \\
\hline
\end{tabular}




\begin{tabular}{|c|c|c|c|c|c|c|c|c|c|c|c|c|c|c|c|c|}
\hline \multirow[b]{2}{*}{ Factors } & \multicolumn{10}{|c|}{ Outcome: time period of 12 months or less or linked to current job } & \multicolumn{5}{|c|}{ Outcome: ever injured at work } & \multirow[b]{2}{*}{ Total } \\
\hline & 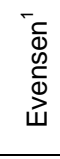 & $\stackrel{\text { @ }}{\stackrel{0}{0}}$ & 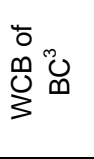 & $\begin{array}{l}\overline{\bar{O}} \\
. \mathscr{W} \\
\bar{\square}\end{array}$ & $\begin{array}{l}\stackrel{+}{\circ} \\
\stackrel{.}{\bar{\Xi}} \\
\infty \\
\infty\end{array}$ & 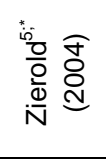 & 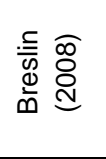 & 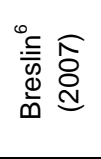 & 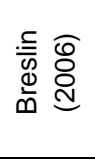 & $\begin{array}{l}\frac{\overrightarrow{0}}{\sqrt{0}} \\
\frac{0}{0} \\
3\end{array}$ & 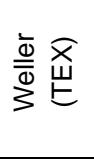 & 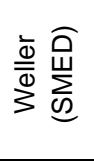 & 气气 & 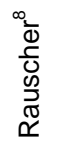 & 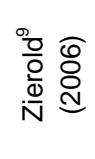 & \\
\hline \multicolumn{17}{|l|}{$\begin{array}{l}\text { Demographic } \\
\text { Individual factors }\end{array}$} \\
\hline Gender & 0 & 0 & & & & 0 & + & 0 & + & & + & 0 & & & & $00000+++$ \\
\hline Age & & 0 & & & & 0 & 0 & 0 & + & & 0 & 0 & & & & $000000+$ \\
\hline Race/visible minority & & & & & & + & & & - & & 0 & + & & & + & $0+++-$ \\
\hline Psychosocial traits & & 0 & 0 & & & & & & & + & & & & & & $00+$ \\
\hline Substance use & & + & & & & & & & & & & & + & & & ++ \\
\hline $\begin{array}{l}\text { Not in school/ low ed- } \\
\text { ucation level }\end{array}$ & & & & & & & + & + & + & & & & & & & +++ \\
\hline Length of employment & 0 & + & & + & & & & 0 & & & & & & & & $00++$ \\
\hline Socio-economic status & & & & & & & & & 0 & & 0 & 0 & & + & & $000+$ \\
\hline \multicolumn{17}{|l|}{ Work- related factors } \\
\hline Work setting/ Industry & 0 & & & + & & & + & + & + & & + & + & & & & $0++++++$ \\
\hline No. \& types of hazards & + & + & 0 & & & & & & & & & & & & & $0++$ \\
\hline Duration of work hours & 0 & 0 & 0 & & & 0 & 0 & + & + & & + & 0 & & & & $000000+++$ \\
\hline Workload/ workplace & + & + & + & & $+{ }^{* *}$ & & & & & & & & & & & ++++ \\
\hline Shift & 0 & & 0 & & & 0 & 0 & & & & & & & & & 0000 \\
\hline Supervisor behaviors & & 0 & & & + & & & & & + & & & & & & $0++$ \\
\hline Co-worker behaviors & & 0 & & & & & & & & & & & & & & 0 \\
\hline Population density & & & & & & + & & 0 & 0 & & & & & & & $00+$ \\
\hline $\begin{array}{l}\text { (+) positive association with he } \\
{ }^{1} \text { Evensen also examined task } \\
{ }^{2} \text { Frone also examined job bore } \\
{ }^{3} \text { WCB of BC also examined pe } \\
{ }^{4} \text { Barling also examined perceiv } \\
\text { 5 Zierold also examined no jobs } \\
{ }^{6} \text { Breslin (2007) also examined } \\
{ }^{7} \text { Shipp adjusted for work hours } \\
{ }^{8} \text { Rauscher controlled for work } \\
{ }^{9} \text { Zierold also examined work p } \\
{ }^{*} \text { combined two studies; **indire }\end{array}$ & $\begin{array}{l}\text { utcon } \\
\text { y (0) } \\
(+) \text {, ro } \\
\text { d risk } \\
\text { fety c } \\
\text { safety } \\
\text { er of } \\
\text { le, se } \\
\text { y dura } \\
(0)\end{array}$ & $\begin{array}{l}\text { nbig } \\
\text { b (jo } \\
\text { te, sa } \\
\text { ing }( \\
\text { (0), } \\
\text { nicit } \\
\text { hou }\end{array}$ & $\begin{array}{l}\text { ociation; } \\
\text { 0), work/ } \\
\text { fety) (0) } \\
\text { related } \\
\text { formed } \\
\text { ation lev } \\
\text { orked per }\end{array}$ & $\begin{array}{l}\text { inver } \\
\text { hool } \\
\text { ents, } \\
\text { legal } \\
(-) \\
\text { veek, } \\
\text { ess }\end{array}$ & $\begin{array}{l}\text { associ } \\
\text { lict (0) } \\
\text { ty con } \\
\text { ts (0), }\end{array}$ & $\begin{array}{l}\text { tion. } \\
\text { job dissati } \\
\text { ciousness } \\
\text { sked to do }\end{array}$ & ction (0) & pressio & ), co-wo & njure & ar miss & & & & & \\
\hline
\end{tabular}




\section{References}

Barling J, Loughlin C, Kelloway EK [2002]. Development and test of a model linking safety-specific transformational leadership and occupational safety. J Appl Psychol 87(36):488-96.

Baron RM, Kenny DA [1986]. The moderator-mediator variable distinction in social psychological research: conceptual, strategic, and statistical considerations. J Pers Soc Psychol 51(6):1173-82.

Berndt T [1979]. Developmental changes in conformity to peers and parents. Dev Psychol 15:608-16.

Breslin FC [2008]. Educational status and work injury among young people: refining the targeting of prevention resources. Can J Public Health 99(2):121.

Breslin FC, Smith P [2005]. Age-related differences in work injuries: a multivariate, population-based study. Am J Ind Med 48(1):50-6.

Breslin FC, Smith P [2006]. Trial by fire: a multivariate examination of the relation between job tenure and work injuries. Occup Environ Med 63(1):27-32.

Breslin FC, Day D, Tompa E, Irvin E, Bhattacharyya S, Clarke J, Wang A [2006a]. Systematic review of risk factors for work injury among youth. Summary. Toronto: Institute for Work \& Health.

Breslin FC, Day D, Tompa E, Irvin E, Bhattacharyya S, Clarke J, Wang A [2007a]. Non-agricultural work injuries among youth. A systematic review. Am J Prev Med 32(2):151-62.

Breslin FC, Day D, Tompa E, Irvin E, Bhattacharyya S, Clarke J, Wang A, Koehoorn M [2006b]. Systematic review of factors associated with occupational disease among young people. Toronto, ON: Institute for Work \& Health.

Breslin C, Koehoorn M, Smith P, Manno M [2003]. Age related differences in work injuries and permanent impairment: a comparison of workers' compensation claims among adolescents, young adults, and adults. Occup Environ Med 60(9):E10.

Breslin FC, Pole JD, Tompa E, Amick BC, III, Smith P, Johnson SH [2007b]. Antecedents of work disability absence among young people: a prospective study. Ann Epidemiol 17(10):814-20.

Breslin FC, Polzer J, MacEachen E, Morrongiello B, Shannon H [2006d]. Workplace injury or "part of the job"?: towards a gendered understanding of injuries and complaints among young workers. Soc Sci Med 64(4):78293.

Breslin FC, Smith P, Mustard CA, Zhao S [2006b]. Young people and work injuries: an examination of jurisdictional variation within Canada. Inj Prev 12:105-10.

Breslin FC, Tompa E, Zhao R, Amick B, Pole J, Smith P, Wang A [2007c]. Work disability absence among young workers leads to earnings losses in the following year. Scand J Work Envir Health 33(3):192-7.

Bronfenbrenner U. [1979]. The ecology of human development: Experiments by nature and design. Cambridge, MA: Harvard University Press.

Brooks DR, Davis LK [1996]. Work-related injuries to Massachusetts teens, 1987-1990. Am J Ind Med 29(2):153-60.

Castillo DN, Landen DD, Layne LA [1994]. Occupational injury deaths of 16- and 17-year-olds in the United States. AJPH 84(4):646-9.

CDC (Centers for Disease Control and Prevention) [1998]. Surveillance for nonfatal occupational injuries treated in hospital emergency departments - United States. MMWR 47(15):302-6.

CDC (Centers for Disease Control and Prevention) [2001]. Work-related injuries and illnesses associated with child labor - United States, 1993. MMWR 45:464-8.

Cole DC, Rivilis I [2004]. Individual factors and musculoskeletal disorders: a framework for their consideration. J Electromyogr Kinesiol 14(1):121-7.

Cote P, Cassidy JD, Carroll L, Frank JW, Bombardier C [2001]. A systematic review of the prognosis of acute whiplash and a new conceptual framework to synthesize the literature. Spine 26(19):E445-E458.

Davis L, Frank E [1997]. Work-related injuries to Massachusetts adolescents: findings from the Massachusetts SENSOR program. Morgantown, West Virginia. Paper presented at the National Occupational Injury Symposium.

DeJoy DM, Southern DJ [1993]. An integrative perspective on worksite health promotion . J Occup Med 35(12):1221-30.

Driscoll T, Hanson M [1997]. Work-related injuries in trade apprentices. Aust N Z J Public Health 21(7):767-72.

Dupre D [2001]. Accidents at work in the EU 1998-1999. Eurostat. No. KS-NK-01-016-EN-I. 
Erikson E. [1964]. Childhood and society, 2nd ed. New York: Norton.

Evensen CT, Schulman, MD, Runyan, CW, Zakocs, RC, Dunn, KA [2000]. The downside of adolescent employment: hazards and injuries among working teens in North Carolina. J Adoles 23:545-60.

Feldman DE, Shrier I, Rossignol M, Abenhaim L [2002]. Work is a risk factor for adolescent musculoskeletal pain. J Occup Environ Med 44(10):956-61.

Frohlich KL, Potvin L [2008]. Transcending the known in public health practice: the inequality paradox: the population approach and vulnerable populations. AJPH 98(2):216-21.

Frone MR [1998]. Predictors of work injuries among employed adolescents. J Appl Psychol 83(4):565-76.

Furby L, Beyth-Marom R [1992]. Risk taking in adolescence: a decision-making perspective. Dev Rev 12:1-44.

Gardner M, Steinberg L [2005]. Peer influence on risk taking, risk preference, and risky decision making in adolescence and adulthood: an experimental study. Dev Psychol 41(4):625-35.

Gordon S [2005]. Starting young . Can Occup Saf May-June.

Greenland S, Pearl J, Robins JM [1999]. Causal diagrams for epidemiologic research. Epidemiology 10(1):37-48.

Greenland S, Robins JM [1985]. Confounding and misclassification. AJE 122(3):495-506.

Hale AR, Hovden J. [1998]. Management and culture: the third age of safety. A review of approaches to organizational aspects of safety, health and environment. In: Feyer AM, Williamson A, editors. Occupational injury - risk, prevention and intervention. London: Taylor and Francis, pp. 129-65.

Harré N [2000]. Risk evaluation, driving, and adolescents: a typology. Dev Rev 20:206-26.

Hébert F, Gervais M, Duguay P, Champoux D, Massicotte P [2003]. Les jeunes: Contraintes du travail et risques. October 2003, Montréal, Canada. Presentation at the 2nd meeting of the Canadian Association of Research on Work and Health.

Horwitz IB, McCall BP [2005]. Occupational injury among Rhode Island adolescents: an analysis of workers' compensation claims, 1998 to 2002. J Occup Environ Med 47(5):473-81.

Institute of Medicine (Committee on Injury Prevention and Control DoHPaDP. [1999]. Reducing the burden of injury: advancing prevention and treatment. Washington, DC: National Academy Press.

Kilmartin C. [1994]. The masculine self. Toronto: Maxwell Macmillan Canada.

Kjellberg A. [1998]. Men are gendered also. In: Kilbom A, Messing K, Thorbjörnson C, editors. Women's health at work. Solna, Sweden: Arbetslivinstitutet. pp. 279-307.

Laflamme L, Menckel E [1995]. Aging and occupational accidents: a review of the literature of the last three decades. Saf Sci 21:145-61.

Leigh JP [1986]. Individual and job characteristics as predictors of industrial accidents. Accid Anal and Prev 18(3):209-16.

Lloyd T, Forrest S [2001]. Boy's and young men's health: literature and practice review. London: National Health Service: Heath Development Agency.

Mayhew C, Quinlan M [2002]. Fordism in the fast food industry: pervasive management control and occupational health and safety risks for young temporary workers. Sociol Health IIIn 24(3):261-84.

Messing K [1997]. Women's occupational health: a critical review and discussion of current issues. Women Health 25(4):39-68.

Messing K, Stellman J [2006]. Sex, gender, and women's occupational health: the importance of considering mechanism. Environ Res 101:149-62.

Mitchell OS [1988]. The relation of age to workplace injuries. Mon Labor Rev (July):8-13.

Mortimer JT. [2003]. Working and growing up in America. Cambridge, MA: Harvard University Press.

NRC (National Research Council. Committee on the Health and Safety Implications of Child Labor) [1998]. Protecting youth at work: health, safety, and development of working children and adolescents in the United States. Washington, DC: National Academy Press/National Research Council.

Nurmi J [1991]. How do adolescents see their future? A review of the development of future orientation. Dev Rev 11:1-59.

Parker DL, Carl WR, French LR, Martin FB [1994a]. Characteristics of adolescent work injuries reported to the Minnesota Department of Labor and Industry. Am J Public Health 84(4):606-11.

Parker DL, Carl WR, French LR, Martin FB [1994b]. Nature and incidence of self-reported adolescent work injury in Minnesota. Am J Ind Med 26:529-41.

Pickett W, Garner MJ, Boyce WF, King MA [2002]. Gradients in risk for youth injury associated with multiple-risk behaviors: a study of 11,329 Canadian adolescents. Soc Sci Med 55:1055-68. 
Pollack SH [2001]. Adolescent occupational exposures and pediatric-adolescent take-home exposures. Pediatr Clin North Am 48(5):1267-89.

Punnett L, Wegman D [2004]. Work-related musculoskeletal disorders: the epidemiologic evidence and the debate. J Electromyogr Kinesiol 14:13-23.

Quadrel MJ, Fischhoff B, Davis W [1993]. Adolescent (in)vulnerability. Am Psychol 48(2):102-16.

Quinlan M, Mayhew C, Bohle P [2001]. The global expansion of precarious employment, work disorganization, and consequences for occupational health: a review of recent research. Int J Health Serv 31(2):335-414.

Rauscher KJ Myers DJ (2008). Socioeconomic disparities in the prevalence of work-related injuries among adolescents in the United States. J Adoles HIth 42(1): 50-7.

Reed DB, Claunch DT [2000]. Nonfatal farm injury incidence and disability to children: a systematic review. Am J Prev Med 18(4)(Suppl):70-9.

Runyan CW, Zakocs RC [2000]. Epidemiology and prevention of injuries among adolescent workers in the United States. Annu Rev Public Health 21:247-69.

Ruser J [1998]. Denominator choice in the calculation of workplace fatality rates. Am J Ind Med 33:151-6.

Salminen S [2004]. Have young workers more injuries than older ones? An international literature review. J Safety Res 35:513-21.

Selman R. [1980]. The growth of interpersonal understanding: developmental and clinical analyses. New York: Academic Press.

Shannon HS, Lowe GS [2002]. How many injured workers do not file claims for workers' compensation benefits? Am J Ind Med 42(6):467-73.

Shipp EM, Tortolero SR, Cooper SP, Baumler EG, Weller NF [2005]. Substance use and occupational injuries among high school students in South Texas. Am J Drug Alcohol Abuse 31:253-65.

Spear L [2000]. The adolescent brain and age-related behavioral manifestions. Neurosci Biobehav Rev 24:417-63.

Stedman TL. [2006]. Stedman's Medical Dictionary, 28th edition. Maryland, USA: Lippincott Williams \& Wilkins.

Steinberg L [2004]. Risk taking in adolescence: what changes, and why? Ann N Y Acad Sci 1021:51-8.

Steinberg L, Silverberg S [1986]. The vicissitudes of autonomy in early adolescence. Child Dev 57:841-51.

Usalcas J [2005]. Youth and the labor market. Ottawa: Statistics Canada. No. 75001 XIE.

WHSC ( Workers Health and Safety Centre) [2002]. Opinion poll on workplace health and safety conditions in Ontario. Toronto: Workers Health and Safety Centre.

Weinstein N [1987]. Unrealistic optimism about susceptibility to health problems: conclusions from a communitywide sample. J Behav Med 10:481-500.

Weller NF, Cooper SP, Basen-Engquist K, Kelder SH, Tortolero SR [2003a]. The prevalence and patterns of occupational injury among south Texas high school students. Tex Med 99(8):52-7.

Weller NF, Cooper SP, Tortolero SR, Kelder SH, Hassan S [2003b]. Work-related injury among south Texas middle school students: prevalence and patterns. South Med J 96(12):1213-20.

Westaby J, Lowe J [2005]. Risk taking orientation and injury among youth workers: examining the social influence of supervisors, coworkers, and parents. J Appl Psychol 90:1027-55.

Workers' Compensation Board of British Columbia [2001]. Young workers and risk factors for workplace accidents . Vancouver, BC: Workers' Compensation Board of British Columbia.

Zierold KM, Anderson H [2006]. Severe injury and the need for improved safety training among working teens. Am J Health Behav 30(5): 525-32.

Zierold KM, Garman S, Anderson H [2004]. Summer work and injury among middle school students, aged 10-14 years. Occup Environ Med 61(6):518-22.

Zohar D. [2003]. Safety climate: conceptual and measurement issues. In: Quick JC, Tetrick LE, editors. Handbook of occupational psychology. 1st ed. Washington, DC: American Psychological Association, pp. 123-42. 


\section{Tracking Work-Related Injuries among Young Workers: An Overview of Surveillance in the United States}

Letitia Davis, ScD, EdM, Massachusetts Department of Public Health

Beatriz Pazos Vautin, MPH, Massachusetts Department of Public Health

\section{Introduction}

In this white paper, we provide an overview of surveillance of work-related injuries among youths less than 18 years of age (also referred to as teens or young workers) in the United States. We begin with brief discussions of public health surveillance, in general, and occupational health surveillance, in particular. We then review the major surveillance systems used to track fatal and nonfatal injuries among working teens. Discussions of surveillance systems typically focus on "numerator data" used for case ascertainment. However, surveillance also requires information on the population at risk - in this case teen employment data - to generate injury rates. Employment data sources ("denominator data") used in conducting surveillance of work-related injuries to teens are also briefly discussed. This paper is meant to serve as a stimulus for discussion of gaps in surveillance of work-related injuries to teens and strategies for improvement.

Surveillance of injuries to youths employed in agriculture poses unique challenges, in part, because of the blurred distinction between work and home life on family farms. Since 1996, the National Institute for Occupational Safety and Health (NIOSH) has undertaken a number of initiatives to improve surveillance of all injuries to children in agriculture. These initiatives, listed in Appendix Davis-I, are beyond the scope of this report.

\section{Public Health Surveillance}

Public health surveillance is the ongoing systematic collection, analysis, and interpretation of health data essential to the planning, implementation, and evaluation of public health practices, closely integrated with the timely dissemination of these data to those who need to know [CDC 2012]. It is often referred to as the "cornerstone of public health practice" that provides the foundation on which to build successful prevention programs. Several aspects of this definition merit elaboration. Surveillance is systematic; it is carried out using consistent methods over time. It is often continuous but may also be periodic. However, it should not be confused with one time survey research efforts. Surveillance also involves interpretation of findings. It is not sufficient to simply generate data tables. It is incumbent on the surveyor to apply epidemiologic skills to interpret surveillance findings for data users. Thirdly, and perhaps most importantly, surveillance carries with it a responsibility for public health action. While the precise boundary between surveillance and intervention is subject to debate, it is widely accepted that the final link in the surveillance chain is the application of the data to prevention. At a minimum, the surveyor must have working relationships with those in positions to influence policy 
and implement programs and should provide surveillance findings to these data users in a format that meets their needs. Others have gone so far as to say that it is incumbent on the surveyor to follow-up to assure that effective action has been taken [Thacker and Berkleman 1992].

It is useful to make a distinction between case-based and population-based surveillance. Case-based surveillance involves the ongoing and rapid identification of identifiable cases for purpose of case follow-up. It is the approach generally used in conducting surveillance of communicable diseases and is related to the concept of a sentinel health event - a single health event is a sentinel or warning sign that our prevention system has failed and intervention is warranted [Rutstein et al 1983]. Follow-up may include interventions (e.g. efforts to control spread of disease, eliminate injury risks) and/or collection of additional data to augment the descriptive epidemiology of the condition under surveillance. Data from a case-based system may or may not be complete or representative. Population-based surveillance, on the other hand, involves collection of representative data that can be used to monitor trends in a defined population over time, locale, and population characteristics. It may involve collecting data on all cases (a census) or a representative sample. The data may be anonymous - i.e. do not necessarily contain individual (or in the domain of occupational health surveillance - employer) identifiers. Case- and population-based approaches to surveillance are not mutually exclusive. In our experience conducting surveillance at the state level, we have found that the most useful surveillance systems have attributes of both. These systems can be used to identify sentinel cases for follow-up and, at the same time, generate representative summary data to guide broader based prevention efforts. Arguably, it is the combination of case stories and statistics that is often most compelling in influencing public health policy [Derickson 1992].

\section{Occupational Health Surveillance}

Surveillance by definition involves the collection of "health data." In the domain of occupational health, surveillance may involve collecting data on work-related health outcomes, such as work-related injuries, illnesses or deaths, or health and safety hazards, such as exposures to hazardous chemicals or the presence of unguarded equipment. Hazard surveillance is often considered optimal because it should allow for identification of risks before injuries or illnesses occur. In the United States, however, hazard surveillance efforts, outside of those undertaken internally by some of the larger employers, are generally quite limited. It would also be possible to conduct surveillance of worker or corporate health and safety behaviors, such as use of respirators or the presence of workplace health and safety programs, but systems are not currently in place to track health and safety behaviors. The existing national and state occupational health surveillance systems collect data on occupational health outcomes. This paper therefore focuses on surveillance systems in place that document health outcomes - predominantly work-related injuries - among teens. Young workers are also at risk of work-related illness, yet many, if not most work-related illnesses are diseases of long latency that do not appear until years after initial exposure to workplace hazards. (Note that acute chemical poisonings, such as carbon monoxide poisoning, are considered injuries in the epidemiologic literature.)

There is no comprehensive system for surveillance of work-related injuries and illnesses in the United States. In the late 1980s, several national studies identified serious problems with 
the national surveillance efforts and called for improvements [Pollack and Keimieg 1987; Keystone Center 1989]. Since that time, a comprehensive surveillance system for fatal occupational injuries has been established. Surveillance of nonfatal injuries, however, remains fragmented with significant gaps. As will be discussed, there is continuing and growing concern about undercounting of nonfatal injuries and about the possibility that undercounting may systematically vary by worker, establishment, or industry characteristics. These potential systematic biases are not well understood.

\section{Goals of Tracking Work-related Injuries to Teens}

Information about where and how young workers are injured on the job is essential to target, design and evaluate prevention efforts, ranging from regulatory and educational activities to the development of new safer technologies and public policies to promote safe work for youths. Surveillance provides this information, allowing us to set priorities for allocation of limited prevention resources, to design relevant interventions, such as amendments to child labor laws, and to monitor progress in meeting injury reduction goals. Surveillance can also play a critical role in mobilizing action to address the young worker health and safety problems. Surveillance is important at both the national and state levels. National data are essential to inform national prevention priorities and programs. However relying on national statistics can obscure dangers that may be specific to a particular state. State data help identify the specific occupations, industries and communities in which workplace hazards faced by teens need to be addressed. In addition, state surveillance systems can also pinpoint specific workplaces in which young workers are at risk and intervention is necessary. Publication of state data can also be a powerful means of attracting the attention and gaining support of local policy makers and the public [MDPH and EDC 2005]. In sum, the potential goals of conducting surveillance of workrelated injuries among teens are many (Table 1 ) and vary according to surveillance system and geographic area under surveillance. 
Table 1. Goals of Tracking Work-related Injuries among Young Workers

- To document the overall magnitude of the problem: How many teens are injured? At what rate? What is the human and economic impact of these injuries?

- To identify the industries and occupations where intervention is most needed: What industries and occupations have the highest injury rates? The highest numbers of teen injuries? The most severe injuries?

- To identify individual workplaces where intervention is warranted

- To characterize the populations (defined by age, gender, race/ethnicity) at risk that merit special attention

- To characterize the most common types of injuries, causes of injuries and known risk factors that need to be addressed.

- To identify potential, previously undocumented risk factors that require further etiologic research, e.g. lack of training/supervision

- To identify new or emerging risks for young workers

- To evaluate the effectiveness of intervention efforts

- To mobilize support for prevention activities

\section{Surveillance of Fatal Occupational Injuries}

There are two main sources of data on fatal occupational injuries among young workers in the United States. The Census of Fatal Occupational Injuries provides population-based data on fatalities at the national and state levels. The Fatality Assessment and Control Evaluation program provides in depth information about the circumstances surrounding fatal incidents for a sample of young worker deaths.

\section{Census of Fatal Occupational Injuries}

The Census of Fatal Occupational Injuries (CFOI), begun in 1992, is a cooperative effort of the Bureau of Labor Statistics (BLS) in the U.S. Department of Labor and the states to develop a complete and accurate annual census of all fatal occupational injuries [BLS 2012a]. For a death to be counted, the deceased must have been working for pay, compensation or profit at the time of the event, engaged in a legal work activity, or present at the site of the incident as a requirement of his or her job. Because no single source of data provides an exhaustive count of all workplace fatalities, CFOI uses multiple sources, such as death certificates, Occupational Safety and Health Administration (OSHA) records and news media reports, to identify and document work-related deaths. At least two or more source documents are required for each death to independently substantiate that the incident was work-related.

CFOI counts are considered a complete or nearly complete ascertainment of work-related injury deaths. However, an accurate count still depends on recognition in individual cases that the deceased was working at the time of the fatal incident. Youths are typically not thought of as workers, therefore, it is reasonable to assume that some deaths of children and adolescents may not be identified as work-related and are not captured by CFOI. This would be most likely when deaths involve young workers on family farms and in family businesses where the bound- 
aries between work and family life are blurred. Conversely, there is the possibility of including fatalities among youth at family operated businesses that are not work-related because the youth was in a work environment due to its proximity to the home environment but not working. The potential under or over count of young worker fatalities, while likely small, has not been formally evaluated.

CFOI provides national (Table 2) and state level data annually on the numbers and rates of deaths by age groups. ${ }^{1}$ Because the Current Population Survey (CPS) employment statistics used to calculate rates in these annual reports exclude workers under 16 years of age, annually published rates are limited to workers 16 years of age or older. Prior to 2008, these annually published rates were calculated using the number of employed persons in the denominator (i.e. deaths per 100,000 workers). Because teen workers typically work part time or temporary jobs, these rates underestimate the risk per hour worked for younger workers. (See denominator discussion below.) Since 2008, rates published by CFOI have been calculated using 100,000 full time employees equivalents (FTEs) as the denominator.

${ }^{1}$ State level data are reported by state in which the fatal incident occurred. 
Table 2. Numbers and rates* of fatal occupational injuries among workers less than 18 years of age, United States, 2005-2010

\begin{tabular}{|c|c|c|c|c|c|c|c|c|c|c|c|c|}
\hline \multirow[t]{2}{*}{ Age (years) } & \multicolumn{2}{|c|}{2005} & \multicolumn{2}{|c|}{2006} & \multicolumn{2}{|c|}{2007} & \multicolumn{2}{|c|}{2008} & \multicolumn{2}{|c|}{2009} & \multicolumn{2}{|c|}{2010} \\
\hline & $\#$ & Rate & $\#$ & Rate & $\#$ & Rate & $\#$ & Rate & $\#$ & Rate & $\#$ & Rate \\
\hline$\leq 15$ & 23 & -- & 11 & -- & 18 & -- & 11 & -- & 13 & -- & 16 & -- \\
\hline $16-17$ & 31 & 1.4 & 21 & .9 & 20 & .9 & 23 & 2.5 & 14 & $\mathrm{n} / \mathrm{a}$ & 18 & 3.0 \\
\hline Total & 54 & -- & 31 & -- & 38 & -- & 34 & -- & 27 & -- & 34 & -- \\
\hline
\end{tabular}

Source: Census of Fatal Occupational Injuries, available at: http://www.bls.gov/iif/oshcfoi1.htm. Date accessed July 13, 2012.

*2005-2007 rates are based on number of deaths per 100,000 workers. 2008-2010 rates are based on number of deaths per 10,000 FTEs.

In a 2005 BLS special report based on CFOI data, national rates including rates for workers 15 years of age and taking hours of work into account were provided (Figure 1.) [Windau and Meyer, 2005]. Rates for workers 15 years of age were found to be higher than rates for workers aged 16-17 years during the 1994-2004 period and to have increased during this period whereas rates for workers 16-17 years of age decreased (not shown). These findings underscore the need to examine age specific patterns. Denominator data necessary to compute rates for teens less than 15 years of age are not available. 
One of the pressing policy questions in this area of safe youth employment is whether young workers are being fatally injured in jobs that are currently prohibited for youths, indicating a need for better law enforcement, or in jobs that are legally allowed, indicating a need for new regulations. Notably, CFOI does not collect specific information about whether the deaths of young workers occurred in circumstances violating child labor laws, although in some cases this can be implied from available data elements, e.g. time of incidents. Violations of safety laws are likewise not documented in CFOI. ${ }^{2}$

\section{Fatality Assessment Control and Evaluation (FACE) Program}

The National Institute for Occupational Safety and Health's (NIOSH) FACE program aims to prevent fatal occupational injuries by identifying risk factors and developing and disseminating prevention recommendations. FACE is a collaborative effort of NIOSH staff (in-house program) and a subset of states (currently nine) that have NIOSH funding to conduct surveillance and intervention activities following the FACE model. FACE provides in-depth information about targeted fatal incidents collected through on-site, research-oriented field investigations. Each fatality investigation results in a FACE report describing the fatal event that includes recommendations to prevent similar incidents. These reports and related alerts are disseminated widely to industry, labor, manufacturers and other stakeholders. National targets for FACE investigations vary over time. ${ }^{3}$ Young worker deaths were included as a target from 1999 through 2009. Many of the subsequent investigations identified common risk factors, including employment in violation of hazardous orders in child labor laws and lack of health and safety training. Because additional investigations were not generating significant new information about other needed prevention strategies, starting in 2010, NIOSH narrowed its focus to young worker deaths in which the hazards involved are not already covered by the hazardous orders. Since 1999, 106 FACE investigations of young worker deaths have been completed and are available on the NIOSH website [NIOSH 2012].

FACE serves as an important case-based complement to the population-based CFOI data on young worker deaths. It provides in-depth information about the circumstances leading to young worker deaths that is used to develop prevention recommendations and that has generated hypotheses about potential risk factors that merit further etiologic research, e.g. the role of supervision. FACE reports also serve as compelling case studies that augment the CFOI statistics. Aggregate FACE data are informative (e.g. the \% of young worker deaths investigated that occurred in jobs prohibited by child labor laws) but not necessarily representative as not all young worker deaths are investigated [Higgins et al. 2002]. Despite the limitations in using aggregate FACE data, FACE is widely recognized as a flagship NIOSH program that has had demonstrable impact in reducing workplace injury risks.

\footnotetext{
${ }^{2}$ For fatal incidents investigated by the Occupational Safety and Health Administration (OSHA), safety violations related to fatal incidents are documented in the OSHA Integrated Management Information System (IMIS) database.

${ }^{3}$ In 2012, national targets include falls in residential and commercial construction, machine related fatalities, immigrant worker deaths, deaths involved in energy production, deaths of foreign-born workers, and young worker deaths in which hazards involved are not covered by child labor laws.
} 


\section{Surveillance of Nonfatal Injuries}

There are two main sources of national population-based data on nonfatal work-related injuries to youths, the annual Survey of Occupational Injuries and IIInesses (SOII) and the National Electronic Injury Surveillance System- Occupational Supplement (NEISS-Work). These are valuable sources of information, yet, as described below, each captures only part of the picture, and each is subject to undercounting injuries. Additional data sources have been used for surveillance of work-related injuries to teens in some states. Several of the state approaches to surveying injuries among young workers are also discussed below.

\section{Survey of Occupational Injuries and IIInesses}

The official source of statistics on nonfatal work-related injuries and illness in the United States is the annual Survey of Occupational Injuries and IIInesses (SOII). Like CFOI, the SOII is a collaboration of the federal BLS and the states. Information is collected through a survey mailed to a stratified random sample of private sector employers ( $n \sim 190,000)$ who are required to provide information on all work-related injuries and illness that meet the OSHA record-keeping requirements. These include injuries that result in loss of consciousness, one or more days away from work, restricted worker activity, transfer to another job, or medical treatment beyond simple first aid. Excluded from the SOll are the self-employed, household workers and workers on farms with fewer than 11 employees ${ }^{4}$.

The SOIl provides national and state estimates ${ }^{5}$ of the numbers and rates of occupational injuries and illnesses overall and by industry. More detailed data on injury by worker and injury characteristics, including age, are available only for the injuries and illnesses resulting in one or more days away from work. The most recent SOll estimates of the number of young worker injuries are included in Table 3. Note that standard BLS tables include data for workers 16-17 years of age in the 16-19 year age group; however, data for individual ages can be obtained from the BLS-SOII custom reports [BLS 2012b].

\footnotetext{
${ }^{4}$ Prior to 2008, national illness and injury estimates based on the SOll excluded public sector workers. Since 2008, the national estimates have included data on state and municipal workers from all states.

${ }^{5}$ State level estimates are available for about 42 states that participate in SOII. For those states that do not participate, BLS collects data from a sample of establishments to generate national estimates. The number of participating states varies slightly from year to year.
} 
Table 3. Estimated number of occupational injuries and illnesses involving days away from work among workers 14-17 years of age, United States, private industry, 20052010

\begin{tabular}{ccccccc}
\hline Age (years) & $\mathbf{2 0 0 5}$ & $\mathbf{2 0 0 6}$ & $\mathbf{2 0 0 7}$ & $\mathbf{2 0 0 8}$ & $\mathbf{2 0 0 9}$ & $\mathbf{2 0 1 0}$ \\
\hline 14 & 20 & 20 & 120 & -- & -- & 60 \\
15 & 60 & 160 & 270 & 130 & 150 & 140 \\
16 & 2,780 & 2,720 & 1,660 & 1,790 & 1,060 & 980 \\
17 & 4,860 & 4,730 & 4,210 & 4,320 & 3,140 & 2,790 \\
Total & 7,720 & 7,630 & 6,260 & 6,240 & 4,350 & 3,970 \\
\hline
\end{tabular}

Source: Survey of Occupational Injuries and IIIness, available at http://data.bls.gov/cgi-bin/dsrv Date accessed July 17, 2012.

The SOII has a number of limitations that need to be taken into account in interpreting the data on work-related injuries to teens. Given the groups of workers excluded from the survey, it has been estimated that it misses at least $11 \%$ of working teens [CDC 1996]. It is has long been recognized that the SOll does not capture most occupational illnesses among all age groups, and there is mounting evidence that work-related injuries are substantially undercounted. Estimates of the undercount range widely from $20 \%$ to $70 \%$. [Ruser 2008; Rosenman et al. 2006; Boden and Ozonoff 2008].

Systematic biases in undercounting, by age, for example, are not well understood. Because most young people work only part-time, they may sustain injuries that do not interfere with scheduled work but would have prevented them from working had they been scheduled to work in the days following the injury. Technically, these injuries should be recorded on OSHA logs, but it is reasonable to assume that these injuries would be less likely to be recorded than injures sustained by full-time adult workers. The SOII is also subject to sampling error. At the state level, in all but the most populous states, the sample size is too small to obtain detailed data on injuries to young workers by industry, occupation, nature of injury or event.

Another significant limitation is that the SOII has not until recently provided rates of injuries sustained by teens. Prior to 2006, injury/illness rates based on SOll data routinely reported by BLS were generated using data on hours of employment provided by the employers participating in the survey. This information is not broken down by age, precluding computation of age specific rates. Since 2006, BLS has annually published national rates by age and other demographic characteristics, using data on employment and hours worked from external sources [Pierce 2008]. As shown in Figure 2, data on workers aged 16-17 are included in the 16-19 year age group. Rates by age are available by nature of injury, type of event and source [BLS 2012b]. 
Figure 2. Estimated incidence rates of nonfatal occupational injuries and illness involving days away from work by age group, United States, private sector, 2010

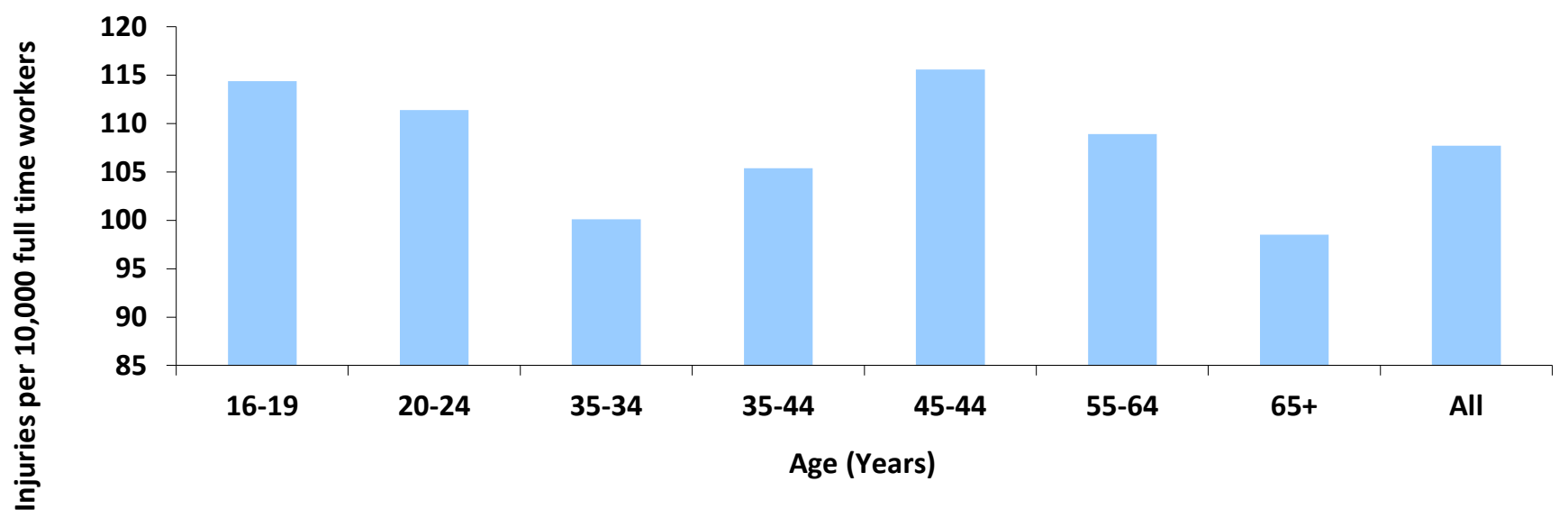

Source: Survey of Occupational Injuries and Illnesses available at www.bls.gov/news.release/archives/osh2_11092011.pdf Date accessed July 17, 2012

\section{National Electronic Injury Surveillance System-Occupational Supplement}

NIOSH collects information on nonfatal occupational injuries and illnesses through a national probability-based sample of U.S. hospital emergency departments (EDs). The work-related injury data collection known as NEISS-Work is an occupational supplement to the Consumer Product Safety Commission's (CPSC) National Electronic Injury Surveillance System (NEISS). ${ }^{6}$ Work-related cases are identified by chart review conducted at the participating hospitals. An injury/illness is considered work-related if it occurred while the patient was working for pay or other compensation, working on a farm or volunteering for an organized group. NIOSH uses these data to obtain demographics of the injured workers, and a description of the injury event. National estimates of ED-treated work-related injuries and illnesses can be made, as well as estimates for injuries and illnesses to special populations (e.g., children, women, AfricanAmericans), injury events (e.g., falls), and types of injuries (e.g., eye injuries). Approximately $95 \%$ of the NEISS-Work cases are injuries.

An inherent limitation of NEISS-Work is that it captures only those injuries treated in emergency departments, which have been estimated to represent about one third of all workplace injuries requiring medical treatment among workers of all ages [CDC 1998]. Furthermore, for children and adolescents, ED staff may not think to ask about the work-relatedness of an injury or may not note work-relatedness in the medical records. As discussed below, youths who are covered on their parents' insurance may be less likely than adults to file for workers' compensation, one of the data elements looked at in medical records to identify work-related cases. Small sample size is also a limitation. Additionally, limited resources have precluded NIOSH's routine coding and analysis of industry and occupation data collected by NEISS-Work. However, $\mathrm{NIOSH}$ is beginning to code industry, although not routinely yet.

\footnotetext{
${ }^{6}$ NEISS-Work uses a 67-hospital subset of the CPSC's larger hospital collection network. CPSC's data collection focuses on product- and recreation-related injuries and illnesses and excludes work-related cases. The number of participating hospitals in NEISS and NEISS-Work can vary from year to year.
} 
As shown in Table 4, NEISS-Work national estimates of the numbers of injuries among workers 15-17 years of age treated in EDs are much higher than the estimates of injuries to young workers (aged 14-17 years) based on the SOII (Table 3). Differences in scope of the survey (worker populations covered and case definitions) and sampling error explain part of the discrepancy. For example, not all workers treated in EDs necessarily lost a day or more of work. SOll findings for 2010 indicate that median lost time for injuries/illnesses resulting in days away from work was lowest among the young age groups [BLS 2011]. One follow-up study based on interviews with injured youths identified by NEISS-Work, found that $68 \%$ of them experienced limitations in their normal activities for a least one day, however, these cases may not have lost a day or more of work [Knight et al. 1995].

Table 4. Estimated number of emergency department-treated injuries/illness among workers 15-17 years of age, United States by year, 1998-2009

\begin{tabular}{lccccc}
\hline \hline Year & $\begin{array}{c}\text { Number of } \\
\text { Injuries }\end{array}$ & $\mathbf{9 5 \% ~ C l}$ & Year & $\begin{array}{c}\text { Number of } \\
\text { Injuries }\end{array}$ & $\mathbf{9 5 \%} \mathbf{C l}$ \\
\hline 1998 & 73,700 & 14,500 & 2004 & 50,200 & 11,000 \\
1999 & 80,400 & 16,900 & 2005 & 51,600 & 13,400 \\
2000 & 74,600 & 17,200 & 2006 & 52,600 & 14,500 \\
2001 & 60,300 & 12,400 & 2007 & 48,600 & 12,600 \\
2002 & 54,500 & 10,900 & 2008 & 37,800 & 11,400 \\
2003 & 51,000 & 10,400 & 2009 & 26,600 & 6,700 \\
\hline \hline
\end{tabular}

Source: National Electronic Injury Surveillance System-Occupational Supplement

NEISS-Work also provides important national surveillance findings on nonfatal occupational injury rates by age. Work-related injury rates for workers 15-17 years of age have consistently been found to be between $60 \%-70 \%$ higher than the rates for workers of all ages and second only to rates for workers 18-24 years of age (Figure 3) [CDC 1998; CDC 2006; CDC 2007; NIOSH 2003]. The estimated injury rates for workers $15-17$ years of age over time are shown in Figure 4. 
Figure 3. Estimated rates* of work-related nonfatal injuries and illnesses treated in hospital emergency departments, by age group, 2009

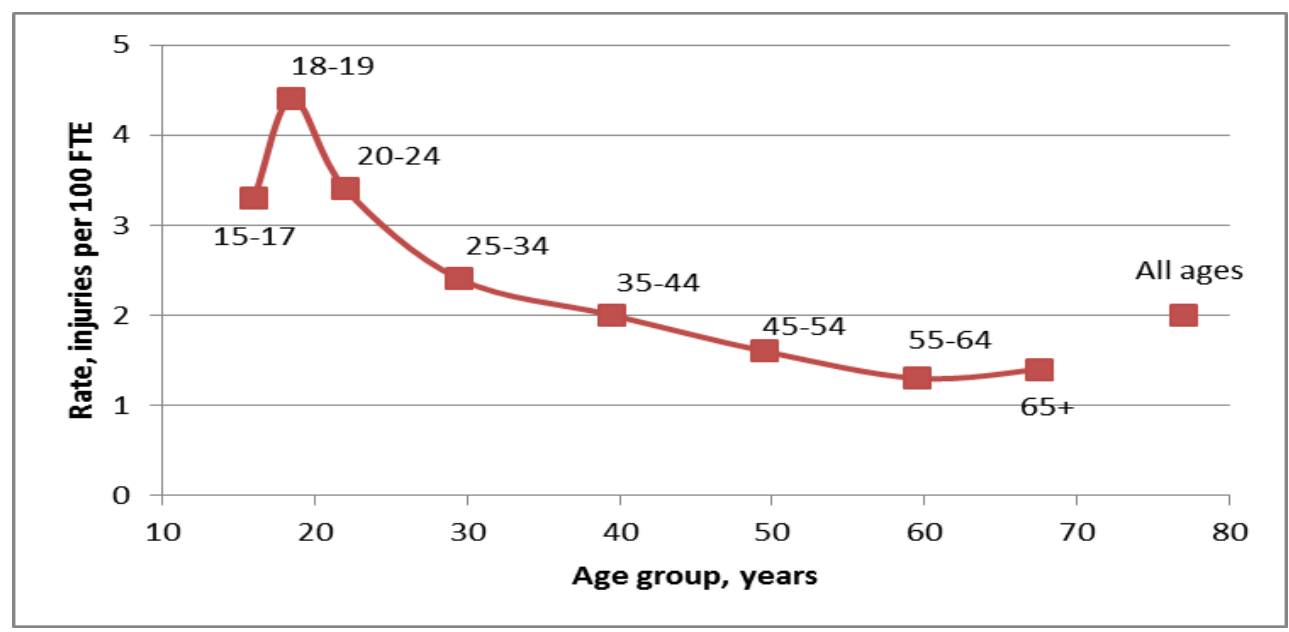

Source: National Electronic Injury Surveillance System-Occupational Supplement *Numbers of injuries and illnesses per 100 full time workers; standard errors range from 10-15\% (not shown).

Figure 4. Estimated rate* of work-related nonfatal injuries and illnesses treated in hospital emergency departments, 15-17 year-olds, 1998-2009

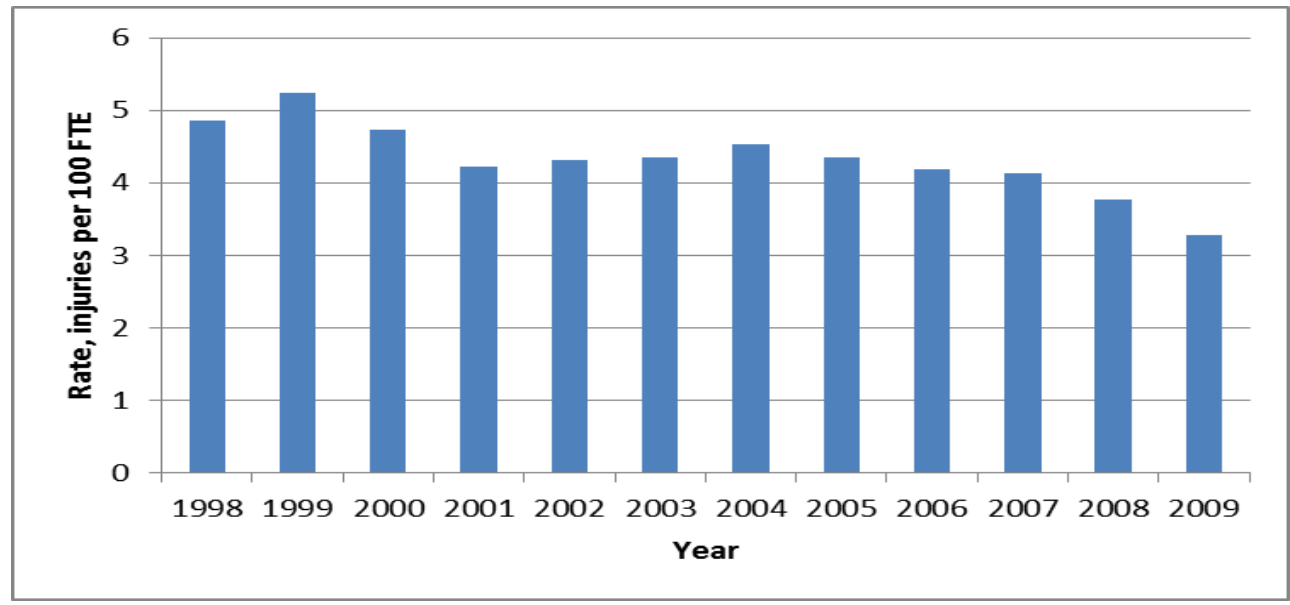

Source: National Electronic Injury Surveillance System-Occupational Supplement

*Numbers of injuries and illnesses per 100 full time workers; standard errors range from 10-15\% (not shown). 


\section{State-based Surveillance}

State-based surveillance of work-related injuries to teens provides important opportunities to identify local concerns and to link data collection with active intervention in the workplace and the community. The most comprehensive system using multiple data sources has been implemented, with NIOSH support, in Massachusetts (See box.) Other states have made use of state workers' compensation data to document injuries to working teens [Banco et al. 1992; Bellville et al. 1993; Miller and Kaufman 1998; Cooper et al. 1999; Horwitz and McCall 2005; McCall et al. 2007; Walters et al. 2010; Mujuru and Mutambudzi 2007]. Changes in information technology continue to lead to new injury data sources in states, such as statewide emergency department data, that offer new opportunities for tracking injuries to young workers at the state level.

\section{Massachusetts Teens at Work: Injury Surveillance and Prevention Project}

Since 1992, the Massachusetts Department of Public Health, with funding provided by NIOSH, has tracked work-related injuries to workers less than 18 years of age using multiple data sources. The surveillance system is designed both to identify sentinel cases for worksite follow-up and to generate summary data to inform broad-based prevention efforts. Workers' compensation claims for injuries resulting in more than five lost work days, together with statewide inpatient hospitalization data and emergency department data are used to identify cases. Follow-up interviews are conducted with a sample of injured teens both to triage cases for worksite follow-up and to learn more about factors leading to the injuries. Summary data have been used to promote a wide range of prevention efforts ranging from changes in the child labor laws, to technological interventions to reduce hazards and educational initiatives to protect working teens [MDPH and EDC 2005].

\section{Workers' Compensation Data}

Workers' compensation (WC) records can be an important, readily available source of information about nonfatal teen injuries at the state level. WC systems and the data they collect vary markedly from state to state, and the data cannot be compiled or compared across states. Some state WC data bases, for example, include all cases for which either medical and/or lost wage claims that meet the eligibility requirements have been filed. In many states, just the lost wage claim data are available for analysis. Eligibility requirements (i.e. number of lost work days) varies markedly by state. Self-employed workers, including, for example, news carriers in Massachusetts, are not covered by WC. It also is well recognized that many injured workers who are covered by WC never apply, and there is some evidence that teens injured on the job are less likely to file claims than injured adults [Brooks and Davis 1996; Fingar et al. 1992]. Despite these limitations, states have been able to use WC data on young worker injuries effectively to raise awareness about the problem and identify state prevention priorities. 


\section{Hospital Data}

Most states collect and maintain data on all inpatient hospitalizations (CSTE 2005). In recent years a growing number of states have developed similar statewide data bases on all emergency department visits [CDC 2008a]. While these state data sets have been developed primarily for administrative purposes, they can be a useful source of population-based information about work-related injuries among teens. These data sets do not include explicit information about work-relatedness of the health conditions for which the patient is treated, and it is necessary to rely on designation of workers' compensation as payer to identify work-related cases. Several studies suggest that this designation captures approximately $80 \%$ of the work-related injury cases [Sorok et al. 1993; Davis et al. 2012] These hospital based data sets likely provide the best information about injury diagnoses, and in states where the data have External Cause of Injury codes, they can also provide information about cause of injury. However, these data sources do not include information about industry or occupation. They can be used to provide useful information about the extent of the problem and types of injuries experienced by young workers, but are of limited usefulness in targeting industry or occupation specific interventions at the state level.

One recent study in Massachusetts in which medical records were reviewed for a sample of work-related injuries among workers of all ages treated in EDs found that these records contained information on employer name for over $80 \%$ the injury cases [Davis et al. 2012]. The option of including employment information in these large administrative data sets is an important policy consideration. An even more pressing issue for the occupational health community interested in surveillance is the ongoing effort to include information about employment and work-relatedness of health conditions in electronic health records [IOM 2011].

\section{Youth Risk Behavior Survey}

A potentially useful source of self-reported data on young worker injuries at both the national and state levels is the Youth Risk Behavior Survey (YRBS) that monitors priority healthrisk behaviors and the prevalence of obesity and asthma among youth and young adults. The YRBS, a collaboration of CDC and state education and health agencies, collects information through national, state and local school-based surveys of students in grades 9-12 [CDC 2008b]. Questions about work and work-related injuries are not currently included in the national survey, although states do have the option of adding state specific questions.

Some states conduct additional surveys to collect information about the health of youth [Weller et al. 2003]. Massachusetts, for example, conducts the Massachusetts Youth Health Survey (YHS) in conjunction with the YRBS. The YHS collects data from a sample of middle and high schools throughout the state. In 2009 the Massachusetts Department of Public Health included questions about work and work-related injuries on the YHS; $18 \%$ of middle school students reported having a paid job other than babysitting or yard work in the past year. Approximately $5 \%$ of these students reported being injured badly enough to seek medical care. Among high school students, $49 \%$ reported having a paid job of whom $4 \%$ reported being injured badly enough to seek medical care [MDESE and MDPH 2010]. 


\section{Denominator Data}

Data on teen employment are necessary to calculate rates of injuries among young workers. The number of workers employed is often used as the denominator in calculating occupational injury rates. However, for groups who typically work part-time, such as teens, "hours worked" (which is usually expressed as "full-time equivalents") is a more appropriate denominator. As noted above, failure to take the number of hours worked into account can result in underestimates of the risk of injury for part-time employees [Ruser 1998].

Official estimates of employment in the United States are derived from the Current Population Survey (CPS) a monthly survey of about 60,000 households nationwide conducted by the Census Bureau for the BLS. It provides a comprehensive data set on the labor force, employment, unemployment, and persons not in the labor force. Data on industry, occupation, weeks worked, and hours worked per week are available for people 15 years of age and older. Notably, the U.S. Department of Labor's definition of the labor force excludes people under the age of 16. Even though data are collected on 15 year olds, those data are not used in the official estimates, nor are they included in most of the published tables. In all but the most detailed tables, data for workers 16 and 17 years of age are aggregated with those for older age groups.

Finding data on teen employment for injury surveillance purposes at the state level is challenging. While the CPS provides reliable data for computing teen injury rates based on both employees and FTEs by industry and occupation at the national level, the sample size in many states is too small to provide reliable estimates of teen employment at any level of detail. Historically, the data collected on the long form of the decennial Census has been a source of more reliable detailed state level data but the Census is conducted only every ten years and youth employment patterns may vary in the interim. In 2005, the Bureau of Census introduced the American Community Survey (ACS). The ACS is a monthly survey of about 3 million households that has replaced the decennial Census long form and provides estimates of demographic, housing, social, and economic characteristics every year for all states. ACS is fully implemented and provides more reliable data on the number of teens employed at the state, county and census track levels. However, due to the way the questions are asked in the ACS, it does not provide reliable data on hours of teen employment throughout the year (i.e. teen FTE estimates). The standard ACS data tables currently available do not include employment information for 15 year olds but such information is available in the ACS micro-data [US Census Bureau 2012].

\section{Conclusion}

Surveillance of fatal occupational injuries among young workers is comprehensive, and includes both population- and case-based approaches. Minor improvements could be made to improve collection of some important data elements in CFOI and to improve standard CFOI data reports for workers less than 18. Research to assess systematic over or under count of young worker deaths in CFOI particularly those in family businesses and on family farms might also be carried out.

Surveillance of nonfatal injuries among young workers is much more problematic. While differences in the scope of the SOII and NEISS preclude comparisons, the substantial disparity in the estimated numbers of cases underscores the need for surveillance research to better un- 
derstand the scope of the problem. While both data sources point to relatively higher risk among young workers compared to workers of all ages, reliable national or state data on teen injury rates by industry or occupation necessary to focus prevention activities are not routinely available. Data on risks of teens versus adults in the same jobs are consequently also not available. Recent efforts by BLS to publish nonfatal injury/illness rates by age and other worker characteristics are to be applauded but interpreting these findings in light of concerns about underreporting in this system and comparisons with the NEISS-Work counts is challenging. Surveillance research to better understand the undercount and systematic biases in undercounting by age is needed. BLS should also be encouraged to publish data for the "under 18" age group in standard reports.

While not addressed explicitly in this review, better information on severity of nonfatal injuries sustained by teens (as well as older workers) is needed. Cuts and lacerations experienced by young workers, for example, are often viewed as not serious. Yet findings based on an albeit small number of interviews conducted by the Massachusetts surveillance system indicate that $14 \%$ of teens with such injuries anticipate long term loss of sensation and $7 \%$ anticipate long term loss of motion. The number of days of lost work, used in the SOll as the indicator of severity, likely underestimates severity of injuries experienced by part-time or temporary workers.

Additionally, it is well recognized that low income minority and immigrant workers, including young minority and immigrant workers, are more likely employed in the most hazardous jobs [Baron and Wilson 2011]. Emergency department data from Massachusetts have consistently revealed that Hispanic teens have a higher rate of ED visits for work-related injuries compared to white teens [MDPH 2012]. Better surveillance information on race and ethnicity of workers with nonfatal injuries is also needed to document and address occupational health disparities among workers of all ages. While the SOll collects data on race and ethnicity that is recorded in the OSHA logs, employers are not required to record this information, and it is available in the SOII for only about two-thirds of cases. OSHA should consider making race and ethnicity information mandatory data elements as they are in other federal health surveys as set forth in the Affordable Care Act [Public law 111-148].

Notably, this review has focused on surveillance of work-related injuries to U.S. workers under age 18. Yet workers ages 18-24, who are no longer protected under child labor laws, are also at high risk of nonfatal injuries. Future surveillance activities targeting young workers should be expanded to include workers in this age group as they are in many other countries.

Finally it is important to recognize that surveillance of nonfatal occupational injuries at both the national and state levels is hampered by lack of resources. Stakeholder input to NIOSH through its National Occupational Health Research Agenda process and from program reviews conducted by the National Academy of Sciences have called for improved surveillance and surveillance research [IOM 2009]. This is an opportune time to recommend new initiatives to improve tracking work-related injuries among young workers.

Acknowledgements: Thanks to Dawn Castillo, Larry Jackson, and John Myers at NIOSH for their input and review of this manuscript. 


\section{References}

Banco L, Lapidus G, Braddock M [1992].Work-Related injury among Connecticut minors. Pediatrics 89:957-960.

Baron S, Wilson S [2011]. Occupational and environmental health equity and social justice, in Levy Bs, et al., eds. Occupational and environmental health: Recognizing and preventing disease and injury. 6th edition, New York: Oxford University Press, pp. 69-97.

Belville R, Pollack SH, Godbold JH, Landrigan PJ [1993]. Occupational injuries among working adolescents in New York State. J Am Med Assoc 269:2754-2759.

Boden LI, Ozonoff Al [2008]. Capture-recapture estimates of non-fatal workplace injuries and illnesses. Annals of Epidemiology 18(6):500-06.

Brooks D, Davis L, Gallagher SS [1993]. Work-related injuries among Massachusetts children: A study based on emergency department data. Am J of Ind Med 24:313-314.

Brooks DR, Davis LK. Work-related injuries to Massachusetts teens, 1987-1990. AJIM 1996 29(2):153-60.BLS [2011] Bureau of Labor Statistics homepage. Survey of Occupational Injuries and Illnesses, 2010. Date accessed July 17, 2012.

BLS [2012a] Bureau of Labor Statistics Injuries, Illnesses, and Fatalities Program, Census of Fatal Occupational Injuries homepage [http://www.bls.gov/iif/oshfat1.htm].

BLS [2012b] Bureau of Labor Statistics Nonfatal cases involving days away from work: selected characteristics (2003 forward) [http://data.bls.gov/cgi-bin/dsrv?ch].

CDC (Centers for Disease Control and Prevention) [1996]. Work-related injuries and illness associated with child labor, United States, 1993. MMWR 45(22): 464-468.

CDC (Centers for Disease Control and Prevention) [1998]. Surveillance for nonfatal occupational injuries treated in hospital emergency departments--United States, 1996. MMWR 47(15):302-6.

CDC (Center for Disease control and Prevention) [2006]. Nonfatal occupational injuries and illnesses among workers treated in hospital emergency departments - United States, 2003. MMWR 55(16):449-52.

CDC (Centers for Disease Control and Prevention) [2007]. Nonfatal occupational injuries and Illnesses in the United States, 2004. MMWR 56(16):393-397.

CDC (Centers for Disease Control and Prevention) [2008a]. Strategies to improve external cause-of-injury coding in state-based hospital discharge and emergency department data systems. MMWR 57(RR01):1-15.

CDC (Centers for Disease Control and Prevention) [2008b] Youth Risk Behavior Surveillance, United States, 2007. MMWR 57(SS-4):1-131.

CDC (Centers for Disease Control and Prevention) [2012]. CDC's vision for public health surveillance in the 21st Century. MMWR 61 (Suppl; July 27, 2012):1-40.

Cooper SP, Burau KD, Robison TB, Richardson S, Schnitzer PG, Fraser J Jr. [1999]. Adolescent occupational injuries: Texas, 1990-1996. Am J of Ind Med 35:43-50.

CSTE (Council of State and Territorial Epidemiologists) [2005]. Putting Data to Work: Occupational Health Indicators from Thirteen Pilot States for 2000.

Davis LK, Hunt PR, Hackman HH, McKeown LN, Ozonoff VV [2012]. Use of statewide electronic emergency department data for occupational injury surveillance: A feasibility study in Massachusetts. Am J Ind Med 55(4): 344-52.

Derickson A [1992]. Making human junk: Child labor as a health issue in the progressive era. Am J Public Health 92(9):1280-1290.

Fingar AR, Hopkins RS, Nelson M [1992]. Work-related injuries in Athens county, 1982-1986: A comparison of emergency department and workers' compensation data. J Occup Med 34:779-787.

Higgins D, Tierney J, Hanrahan L [2002]. Preventing youth worker fatalities: the Fatality Assessment and Control Evaluation (FACE) Program. AAOHN 50(11):508-514.

Horwitz IB, McCall BP [2005].Occupational injury among Rhode Island adolescents: An analysis of workers' compensation claims, 1998 to 2002. J Occup Environ Med 47:473-481.

IOM (Institute of Medicine) and National Research Council [2009]. Traumatic Injury Research at NIOSH. Committee to Review the NIOSH Traumatic Injury Research Program. Rpt. No. 6. Review of Research Programs of the National Institute for Occupational Safety and Health. Washington, DC: the National Academies Press. 
IOM (Institute of Medicine) [2011]. Incorporating occupational information in electronic health records: Letter report. Washington, DC: The National Academies Press.

Keystone Center: The Keystone National Policy Dialogue on Work-Related IIIness and Injury Recordkeeping, Final Report, 1989.

Knight EB, Castillo DN, Layne LA [1995]. A detailed analysis of work-related injury among youth treated in emergency departments. Am J Ind Med 27:793-805.

MDESE (Massachusetts Department of Elementary and Secondary Education) and MDPH (Massachusetts Department of Public Health) [2010]. Health and Risk Behaviors of Massachusetts Youth, 2009. [http://www.doe.mass.edu/cnp/hprograms/yrbs and www/mass.gov/dph].

MDPH (Massachusetts Department of Public Health) and EDC (Education Development Center) [2005]. Protecting Young Workers: A Guide for Building a State Surveillance System for Work-Related Injuries to Youths. [http://www.mass.gov/eohhs/gov/departments/dph/programs/health-stats/ohsp/injuries-workersunder-18/].

MDPH (Massachusetts Department of Public Health) [2012]. Teens at Work: Work Related Injuries to Teens in Massachusetts, 2005-2009. [http://www.mass.gov/eohhs/gov/departments/dph/programs/healthstats/ohsp/injuries-workers-under-18/].

McCall BP, Horwitz IB, Carr BS [2007]. Adolescent occupational injuries and workplace risks: An analysis of Oregon workers' compensation data 1990-1997. Journal of Adolescent Health 41:248-55.

Miller ME, Kaufman JD [1998]. Occupational injuries among adolescents in Washington state, 1988-1991. Am J Ind Med 34:121-132.

Mujuru P, Mutambudzi, M [2007]. Injuries and seasonal risks among young workers in West Virginia--a 10-year retrospective descriptive analysis. American Association of Occupational Health Nurses 55(9):381-387.

Pollack ES, Keimieg DG, eds. [1987]. National Academy of Sciences, Panel on Occupational Safety and Health Statistics: Counting Injuries and Illnesses in the Workplace, Proposal for a Better System. Washington, DC: National Academy Press.

NIOSH [2003]. NIOSH alert: Preventing Deaths, Injuries and Illness of Young Workers. By Mardis Al and Pratt SG. Cincinnati, OH: U.S. Department of Health and Human Services, Centers for Disease Control and Prevention, National Institute for Occupational Safety and Health, DHHS (NIOSH) Publication No. 2003-123.

NIOSH [2012]. Fatality Assessment and Control Evaluation (FACE) Program [http://www.cdc.gov/niosh/face/]. Date accessed: July 2012.

Pierce, Brooks [2008]. Methods underlying new workplace injury and illness rates by demographic group, in Compensation and Working Conditions, Bureau of Labor Statistics.

Rosenman KD, Kalush A, Reilly MJ, Gardiner JC, Reeves M, Luo Z [2006]. How much work-related injury and illness is missed in the current national surveillance system? J Occup Environ Med 48(4):357-65.

Rutstein DD, Mullan RJ, Frazier TM, Halperin WE, Melius JM, Sestito JP [1983]. Sentinel health events (occupational): A basis for physician recognition and public surveillance. Am J Public Health. 73(9):1054-62.

Ruser JW [1998]. Denominator choice in the calculation of workplace fatality rates. Am J Ind Med 33(2):151-156.

Ruser J [2008]. Examining evidence on whether BLS undercounts workplace injuries and illnesses. Monthly Labor Review 131(8):20-32.

Sorok GS, Smith E, Hall HZ [1993]. An evaluation of New Jersey's hospital discharge database for surveillance of several occupational injuries. Am J Ind Med 23:427-437.

Thacker S and Berkleman R [1992]. History of public health surveillance. In: Halperin and E Baker eds. Public Health Surveillance. New York: W. Van Nostrand Reinhold Publishers, pp.1-15.

US Census Bureau [2012]. American Community Survey [www.census.gov/acs/www/data documentation/data main].

Walters JK, Christensen KA, Green MK, Karam LE, Kincl LD [2010]. Occupational injuries to Oregon workers 24 years and younger: An analysis of workers' compensation claims, 2000-2007. Am J Ind Med 53(10):984-994.

Weller N, Cooper S, Tortolero SR, Kelder SH, Hassan S [2003]. Work-Related injury among South Texas middle school students: Prevalence and patterns. Southern Medical Journal 96(12):1213-1220.

Windau J, Meyer S [2005]. Occupational injuries among young workers. Monthly Labor Review 128(10):11-23. 


\section{Appendix Davis-I: National Institute for Occupational Safety and Health (NIOSH) Child Agricultural Injury Prevention Initiative}

\section{Fatality Surveillance}

As part of the larger Childhood Agricultural Injury Prevention Initiative, NIOSH conducts surveillance of all fatal injuries to youths less than 20 years old that occur on farms by using four separate fatality data sources: 1) Bureau of Labor Statistics (BLS) Census of Fatal Occupational Injuries surveillance data (CFOI); 2) National Center for Health Statistics (NCHS) Vital Statistics Mortality (VSM) surveillance data; 3 ) death certificates from state vital statistics registrars; and 4) NIOSH Fatality Assessment and Control Evaluation (FACE) fatality investigations.

CFOI: CFOI is a census of all occupational fatalities occurring in the U.S. These data are compiled by BLS from all 50 states, the District of Columbia, and New York City using multiple data sources (e.g., death certificates, newspaper clippings, corner reports, police reports). CFOI records include information on the age of the victim, the industry in which the victim was employed at the time of death, and the victim's occupation at the time of death. By using the industry information in the CFOI, occupational farming related deaths can be identified regardless of whether the death occurred on a farm or not. There are no age limitations placed on whether a death is included in the CFOI system, which allows for the identification of occupational deaths to youth of all ages.

VSM: VSM is a census of all deaths occurring in the U.S. as reported through death certificates filed with state Vital Statistics Offices to NCHS. VSM data are coded using the International Classification of Disease for location and underlying external cause of death. Location of Injury is used to identify all unintentional fatalities that occurred on farms regardless of workrelatedness. Farm-related deaths identifiable through the VSM data include those sustained doing chores, paid work, or recreational activities such as hunting or swimming. Farm deaths that occur in the farm house or home premises are not identifiable because death certificate coding rules denote the location of these deaths as "home." Intentional deaths and transportation events are not identifiable as having occurred on a farm because the location variable is not coded for these events.

Death Certificates: NIOSH collects death certificates from all 50 states, excluding the District of Columbia and New York City that meet the following criteria: 1) location of Injury denoted as "Farm;" 2) age of the victim less than 20 years; and 3) the immediate, contributing, or underlying cause of death having a ICD-9 code E-800-E999, or ICD-10 code V01-Y98. The main difference between the death certificate data collected by NIOSH and the NCHS VMS is the inclusion of on-farm motor vehicle and intentional deaths by the NIOSH surveillance effort. 
FACE: The Fatality Assessment and Control Evaluation (FACE) project uses a case-based surveillance approach to: identify work environments which place workers at high risk for fatal injury; identify potential risk factors; and formulate and disseminate prevention strategies to those who can intervene in the workplace. Investigation findings and prevention recommendations are incorporated into health communication documents for broad dissemination and are used by employers to increase worker safety, by manufacturers to modify machinery and equipment to increase worker safety, and by the Occupational Safety and Health Administration (OSHA) and other organizations in the promulgation of safety standards and compliance directives. Youth less than 18 years of age, including teens working on farms, are a target population of the FACE program.

\section{Nonfatal Injury Surveillance}

NIOSH conducts surveillance of nonfatal injuries to youths less than 20 years old that occur on farms by using three separate data sources: 1) Consumer Products Safety Commission (CPSC) National Electronic Injury Surveillance System (NEISS); 2) U.S. Department of Labor (USDOL) National Agricultural Worker Survey (NAWS); and 3) NIOSH Childhood Agricultural Injury Survey (CAIS).

NEISS: NEISS collects nationally representative, timely, nonfatal occupational injury surveillance data by using a sample of U.S. hospital emergency departments (EDs). NIOSH funds CPSC to identify work-related cases from a subsample of EDs in the NEISS system. NIOSH uses these data to obtain demographics of the injured workers, and a description of the injury event. National estimates of all work-related traumatic injuries can be made, as well as estimates for injuries to special populations (e.g., children, women, African-Americans), injury events (e.g., falls), and types of injuries (e.g., eye injuries). NIOSH uses NEISS to identify farm-related youth injuries through the use of the location code included in the surveillance system.

NAWS: NAWS is a personal interview survey of 3,400 predominantly migrant and seasonal farm workers across the United States each year. In 1999, the NIOSH pilot tested the use of a farm injury module within NAWS. The module was asked of all farm workers in the NAWS sample, including workers under age 20. Workers were asked about occupational injuries that occurred to them on a farm in the last 12 months. In addition, NAWS provides demographic and work profiles for all farm workers participating in the survey. Initial results from NAWS led NIOSH to provide USDOL additional funds to collect the injury module in the 2002-2004 NAWS. NIOSH continued funding the NAWS injury module for the years 2008-2010. These data are currently being analyzed.

CAIS: CAIS is a survey-based surveillance system of farm operators conducted for NIOSH by the U.S. Department of Agriculture (USDA), National Agricultural Statistics Service (NASS). CAIS covers youths who live on, work on, or visit farms in the United States. Each round of CAIS is based on a telephone survey of 50,000 farm operations selected at random across the United States. Farm operators are asked about the total number of nonfatal injuries that occurred to 
youths under age 20 on their farms in the preceding calendar year. Details about all injuries are collected for positive responses. Demographic data on farm household youths and youths directly hired to work on the farm are also collected. To date, CAIS data have been collected for calendar years 1998, 2001, 2004, 2006, and 2009. The sixth CAIS survey will be collected in 2012. To address a lack of coverage of minority farming operations (both racial minorities and Hispanics) in the CAIS, NIOSH has collaborated with NASS to conduct the same injury survey specifically for minority farm operations (M-CAIS). To date, M-CAIS data have been collected for calendar years 2000, 2003, and 2008. The fourth M-CAIS is scheduled to be collected in 2014.

\section{Hazard Surveillance}

NIOSH conducts hazard surveillance of farming operations through the NIOSH Farm Hazard Survey (FHS). The FHS is a telephone survey of 25,000 farm operators conducted for NIOSH by USDA, NASS. The first FHS was conducted in 2006, with the second round collected in 2011. Farm operators were asked questions about safety and health issues associated with their farm. These issues ranged from questions about farm tractor use, Roll-over Protective Structure (ROPS) use on tractors, guarding and shielding on machinery used on the farm, use of hearing protection and other protective equipment by the farm operator, and chemical exposures to the farm operator in the previous year. Information on the number of youth living on the farm is included in the FHS, which allows for assessing farm hazards these youth may be exposed to.

* Acknowledgements: Thanks to John Myers of the Division of Safety Research at NIOSH who prepared this summary on NIOSH surveillance of young worker injuries in agriculture. 


\title{
Prevalence of Working Conditions Associated with Adolescent Occupational Injury in the U.S.: A Review of the Literature
}

\author{
Kimberly J. Rauscher, MA, ScD, West Virginia University \\ Carol W. Runyan, MPH, PhD, Colorado School of Public Health
}

\section{Introduction}

For millions of US adolescents work is a part of daily life. In 2011, 1.3 million 16- and 17year-olds held formal, paying jobs [BLS 2011].

Substantial numbers of young people under the age of 16 also work [DOL 2000; Kruse and Mahoney 2000]. While the large majority of these youth return home safely at the end of each workday, others are not as fortunate. Even though adolescent workers are protected by numerous safety regulations and child labor laws, each year hundreds of thousands of workers under the age of 18 suffer from preventable work-related injuries [NIOSH 2006; NIOSH 2003] and one dies every eight days from an injury sustained on the job [BLS 2010]. And, as reported by $\mathrm{NIOSH}$, an average of 42 deaths among 15-17 year olds were recorded for the period 19982007 [CDC 2010].

The literature on the epidemiology of adolescent work-related injury (WRI) is limited in comparison to that of adult workers, yet a solid knowledge base has been formed by over 20 years of research. Much of this work has been descriptive, documenting the nature, severity and sources of these injuries as well as the presence of hazardous working conditions associated with injury (e.g., use of particular equipment, working alone at night, the lack of health and safety training and supervision) [Greenberger and Steinberg 1986; Runyan et al. 2007; Delp et al. 2002; Zierold and Anderson 2006a; Runyan et al. 2006; Rauscher et al. 2011; Rauscher et al. 2012].

Some analytic studies have gone farther identifying both individual and work-based risk factors for adolescent WRI. In addition to characteristics such as age, gender, race and socioeconomic status [Rauscher and Myers 2008; Zierold and Anderson 2006b, 2006c; Belville et al. 1993; Brooks and Davis 1996; Horwitz and McCall 2005; Layne et al. 1994; Miller and Kaufman 1998], several work-based factors have been identified as putting adolescents at increased risk for WRI.

Among these are: working with equipment or tools [Zierold and Anderson 2006b; Frone 1998; Parker et al. 1994; Evensen et al. 2000; Brooks et al 1993; Mardis and Pratt 2003], working at a fast pace [Frone 1998; Evensen et al. 2000; Breslin et al. 2007] and working without proper supervision [Frone 1998]. All have been identified as risk factors for adolescent WRI. In addition, surveillance data have demonstrated that work in particular industries and occupations [Zierold and Anderson 2006b; Belville et al. 1993; Brooks and Davis 1996; Horwitz and McCall 2005; Layne et al. 1994; Miller and Kaufman 1998; Weller et al. 2003; Banco et al. 1992; McCall et al. 2007; Schober et al. 1988] and working without health and safety training [MDPH 
2007; Knight et al. 1995] are associated with non-fatal adolescent occupational injuries. Working at night, cash handling and customer interaction have also been shown to be associated with increased risk of crime related assaults and fatalities [NIOSH 2003; Richardson and Windau 2003; Windau and Toscano 1994; Davis 1987; NIOSH 1995], particularly in retail and service settings [Moracco et al. 2000; Loomis et al. 2001; Peek-Asa et al. 2001; Jenkins 1996].

Evidence regarding the prevalence of these work-based risks is sparse, yet what is available indicates that many of today's youth are working under conditions that may put them at risk of injury. Below we outline the evidence for adolescent work-related injury risk factors and report on their prevalence as demonstrated in the literature.

\section{Equipment/Tool Use}

Evidence of Association: Several studies have demonstrated that using equipment or tools is associated with increased WRI risk among adolescents even after controlling for hours of work [Parker et al. 1994], and other correlates such as age, gender, personality traits, substance use, and a variety of work-quality related variables [Frone 1998]. Further evidence reveals that working with dangerous equipment and doing hazardous tasks better predicts WRI than does work setting (e.g. grocery, food service). After adjusting for individual characteristics, work schedules and a number of working conditions, Evensen et al. found that the amount of hazardous equipment use continued to predict WRI while work setting was no longer significant among youth working in retail settings [Evensen et al. 2000]. One recent study also showed that motor vehicles were responsible for $43 \%$ of all fatalities in North Carolina between 1990 and 2008 [Rauscher et al. 2011].

Prevalence: Despite child labor laws meant to prohibit youth from using dangerous equipment or tools, typical teen work settings contain a wide variety of such hazards. Studies characterizing the adolescent workplace show the following: 19\% of young workers report using equipment they feel is dangerous; nearly half report using power equipment/tools; about onethird drive motor vehicles, use ladders or scaffolding, and forklifts; one-quarter use food slicers or fryers; and 17\% operate heavy machinery [Runyan et al. 2007; Zakocs et al. 1998; Dunn et al. 1998]. One study of injured adolescent workers found that over one-third were working with equipment that contributed to their injuries--half of which was power-driven machinery [Knight et al. 1995]. More recent studies show that youth continue to be exposed to a variety of dangerous equipment and tools. In a study of young construction workers in North Carolina, upwards of two-thirds reported using sledgehammers, handsaws, box cutters, and power drills [Rauscher et al. 2012].

\section{Fast Paced Work}

Evidence of Association: Being required to work at a rushed or fast pace has also been shown to increase young workers' risk of injury [Frone 1998; Evensen et al. 2000; Breslin et al. 2007]. One study in particular showed that work pace remained a strongly significant predictor of WRI after controlling for age, gender, work setting, job tenure, night work, weekly hours, hazard exposures and tasks variability [Evensen et al. 2000]. In interviews with youth with inju- 
ries treated in emergency department, $32 \%$ of the youths reported they were working quickly at the time of injury [Frone 1998; Breslin et al. 2007].

Prevalence: Few data exist on how many adolescents have jobs where they are required to work at a fast pace, but interviews with teens in the retail industry showed that 39\% "always" or "often" felt rushed at work [Zakocs et al. 1998]. Runyan et al.'s (2007) national study of teens working in the retail and service sector showed that $43 \%$ of respondents reported that at least once a day they felt rushed to get their work done. Given the widespread employment of youth in food service and grocery stores [DOL 2000; NRC 1998] where fast, efficient customer service is crucial and work tasks are often timed [Garson 1988; Tannock 2001; Leidner 1993], it is reasonable to say that a good number of teens are working under conditions that require them to rush.

This is supported by Greenberger and Steinberg in their seminal work in the 1980's, When Teenagers Work, in which they reported that most teens work in jobs where they are under "a great deal of time pressure and are expected to repeat a limited number of highly routinized tasks, quickly, efficiently, and without having to think very much about what they are doing" ( $p$. 67) [Greenberger and Steinberg 1986], In the more recent 2004 Youth Jobs Study conducted by Rauscher et al., where 279 youth residing in Massachusetts were surveyed, $73 \%$ of respondents reported that they feel they are required to work "very fast" in their jobs [Rauscher et al. in press].

\section{Lack of Adequate Supervision}

Evidence of Association: While evidence is very limited, working without supervision has been shown to be associated with adolescent WRI in at least one study [Frone 1998]. Using survey data from working adolescents, Frone demonstrated that supervisor monitoring and injury were negatively correlated [Frone 1998]. Although data on this relationship is sparse, health and safety experts, academics as well as NIOSH scientists suggest that young worker injuries often occur in the absence of adequate supervision [NIOSH 2003; NRC 1998; Runyan and Zakocs 2000]. Limited surveillance data support this assertion, however, Knight et al. found that among youth with work injuries treated in emergency departments $80 \%$ reported there was no supervisor present at the time of injury and $23 \%$ said they were working alone when they were injured [Knight et al. 1995]. A recent North Carolina study using medical examiner records showed that $35 \%$ of young worker fatalities occurred while the youths were working entirely alone [Rauscher et al. 2011].

Prevalence: Multiple surveys characterizing the youth workplace show a lack of supervision of adolescent workers [Runyan and Zakocs 2000; Runyan, et al. 2007]. Greenberger and Steinberg showed that teenage workers spend about $78 \%$ of their time outside "the immediate vicinity of an adult" and only about $12 \%$ of their time near a supervisor [Greenberger and Steinberg 1986]. More recent findings indicate lack of supervision is still a major problem in the teen workplace. Results from Rauscher's Youth Job Study [Rauscher et al. in press], show that over $51 \%$ of teenagers reported that they work free from close supervision, while Runyan and colleagues found, in a national study of teens working in retail and service sector jobs, that over one quarter of working youth do so with no adult supervisor present at least one day a week [Runyan et al. 2007]. 
Runyan et al.'s study also showed that only $25 \%$ of working youth have supervisors that check on them once a day to see that they are doing their jobs correctly while $23 \%$ have supervisors that check on them at least once a week, but not every day. Likewise, a study of teens working in the construction industry in North Carolina, Runyan, et al. (2006) reported that most of the teens worked in settings with few employees on site; $54 \%$ indicating the business had fewer than six employees "usually present" at the worksite. Though most respondents indicated their work was checked more than once a day and that they were "told what to do and how to do it," nearly $20 \%$ of the respondents stated that they had worked completely alone, without being in hearing or sight distance of other workers.

\section{Lack of Health and Safety Training}

Evidence of Association: Evidence is limited on the effect of not having safety training and its relationship to WRI, yet two studies using surveillance data found that over half of workinjured adolescents did not have any health and safety training [MDPH 2007; Knight et al. 1995].

Prevalence: Research characterizing the work experiences of youth shows that between 33 and 45 percent of young workers have not received health and safety training [Runyan et al. 2007; Delp et al. 2002; Zierold and Anderson 2006a; Zakocs et al. 1998]. Data on the lack of training in one's rights as a worker is much more variable with one survey showing about $75 \%$ [Delp 2002] and another showing 28\% [Zierold and Anderson 2006a] of young workers having no training on these rights. Though almost all teens working in construction in North Carolina reported receiving some form of training related to safety, $45 \%$ indicated they had received fewer than 4 hours of such training [Runyan et al. 2006]. A large majority (84\%) of these youth reported having worked on tasks or under conditions that violated at least one state or federal child labor law [Runyan et al. 2006].

A companion study of 50 Latino teens working in construction jobs in North Carolina revealed that a quarter received no safety training at all and approximately a quarter received less than one hour of training [O'Connor et al. 2005]. Language barriers can often present challenges to training workers, and with a growing Latino population in the US, attention to providing language-appropriate training is in even greater need than before.

Several studies report information about training young workers to deal with potentially threatening situations related to workplace violence. Combining similar data collected in the mid-1990s from five sites, Runyan et al., noted that percentages varied widely among teens who reported having been trained to deal with angry customers (35-76\%), to deal with a robbery (34-53\%) and to deal with sexual harassment (21-33\%) [Runyan et al. 2005]. Runyan's national study revealed that $60 \%$ had been trained to deal with an angry customer, $41 \%$ in what to do in the event of a robbery, and $63 \%$ in sexual harassment situations. In addition, approximately $60 \%$ reported they had been trained what to do if they were threatened or assaulted [Runyan et al. 2007].

It is important to point out that unless asked specifically about safety training topics, surveyed youth may report that they have indeed received safety training when in fact what they have received is job training [Zierold and Anderson 2006a]. Thus, results from youth surveys may underestimate the problem of working without safety training. 


\section{Work in Particular Industries and Occupations}

Evidence of Association: Working in particular industries increases young workers' injury risk yet it is difficult to say exactly which industries are the most dangerous as industry rankings by injury rates differ depending on the study and its data source [Runyan and Zakocs 2000]. For example, one study using emergency department data ranked retail, manufacturing and construction as the industries with the three highest injury rates [Layne et al. 1994]. Other studies that used workers compensation data showed manufacturing to have either the first [Belville et al. 1993], second [Brooks and Davis 1996; Layne et al. 1994] or third [Horwitz and McCall 2005; Banco et al. 1992] highest injury rate and showed the retail industry to rank either first [Schober et al. 1988] or second [Banco et al. 1992]. In several cases, agriculture had the highest [Schober et al. 1988] or second highest [Belville et al. 1993; Horwitz and McCall 2005] injury rates.

Other studies have pointed to high rates in "personnel supply services" - indicating adolescent involvement as temporary workers in what is likely a wide variety of settings that are not differentiated in the data [Horwitz and McCall 2005; McCall et al. 2007]. In a survey of high school students where establishment type was compared, adjusted odds ratios for WRI showed that those working in restaurants (3.2), construction (3) and factories or offices (2.9) had the highest injury risks compared to those working in informal settings as babysitters (the referent group) [Weller et al. 2003]. Several fatality studies have shown that the majority of deaths among youth occur in construction and agriculture [Dunn and Runyan 1993; Rauscher et al. 2011].

When looking at differences in injury rates within particular occupations, studies reveal the same issues in determining their rankings as exist with trying to rank industries [Belville et al. 1993; Horwitz and McCall 2005; Banco et al. 1992; McCall et al. 2007]. A few consistencies do appear, however, with youth working as unskilled laborers or production workers often having the highest rates of injury [Belville et al. 1993; Horwitz and McCall 2005,McCall et al. 2007] and waiters/food counter workers having the second highest rates [Horwitz and McCall 2005; Banco et al. 1992].

A few cautions about interpreting rates of young worker injury by industry and occupation are in order. First, calculating actual rates per full time equivalent workers, no matter the job or industry, is difficult given that most teen workers do not work full time [DOL 2000]. Second, because teens change jobs more frequently than adults and may hold several different jobs at once, comparing injury rates between the industries and occupations in which youth are injured should be done with some caution [Runyan and Zakocs 2000; Runyan et al. 2005]. Lastly, when analyzing teens' risks of injury, it may be more useful to examine work tasks rather than occupations. This is because adolescents often work in jobs where they do a variety of tasks that do not conform to a neat definition of a particular "occupation." For example, adolescents often work in fast food restaurants where they may cook food, unload trucks, clean the bathrooms, mow the grass, and work as a cashier [Runyan and Zakocs 2000; Runyan et al. 2005].

Prevalence: Employment in some of these high risk industries and occupations is common among youth. Several reports using government data [NRC 1998] show that the majority of youth under 18 , approximately $60 \%$, work in the retail industry where they work mainly in eat- 
ing and drinking establishments (30\%). Roughly $25 \%$ work in the service industry, chiefly in recreation and private households. Other high risk industries such as manufacturing (4\%) or construction (3\%) are far less frequently populated by young workers. The most common occupational categories in which youth work are service (39\%) (e.g., food preparation) and sales (27\%) (e.g., cashier) [DOL 2000].

\section{Late Night Work, Cash Handling, and Customer Interaction}

Evidence of Association: Little research has examined the risks associated with working late at night, cash handling, and customer interactions in adolescent populations. One recent study showed that $17 \%$ of young worker fatalities occurred after dark and two-thirds of homicides were committed in the course of a robbery [Rauscher et al. 2011]. Another showed that among youth who experienced workplace violence in the form of either physical or verbal assaults, customers were responsible for 31 and 55 percent of those assaults, respectively [Rauscher 2008].

Other studies have demonstrated that cash handling, working late at night and with customers and cash, are associated with increased risk of crime related assaults and fatalities among adult workers [NIOSH 2003; Richardson and Windau 2003; Windau and Toscano 1994; Davis 1987; NIOSH 1995], particularly in retail and service settings [Moracco et al. 2000; Loomis et al. 2001; Peek-Asa et al. 2001; Jenkins 1996] so it is likely that there are similar risks to youth who work under these conditions.

Prevalence: Data from studies of adolescent workers indicate that adolescents are employed in these risky conditions, suggesting cause for concern. Teens are overwhelming employed in the retail industry [DOL 2000, NRC 1998], which is a particularly risky industry for workplace violence [Peek-Asa et al. 1999; Janicak 1999]. Young retail workers report high rates of customer aggression [Tucker and Loughlin 2006]. Using survey data collected from workers between ages 14-17 from five sites in the U.S., Runyan et al., found that $10-12 \%$ of respondents reported working alone at night, with as many as a third reporting having worked after 10pm (this figure increases with the age of the adolescent) [Runyan et al. 2005]. A survey of NC Teens showed that $65 \%$ of respondents had worked between $7 \mathrm{pm}$ and $11 \mathrm{pm}$ and $14 \%$ had worked between $11 \mathrm{pm}$ and 7am [Evensen et al. 2000]. Evensen et al. reported that $70 \%$ of retail employees had worked after $7 \mathrm{pm}$ on a school night and $10 \%$ had worked between 11pm and 5am [Evensen et al. 2000]. In more recent work on teens in retail and service settings, Runyan et al. discovered that approximately $52 \%$ worked after $9 \mathrm{pm}$ and $10 \%$ worked after $11 \mathrm{pm}$ on a school night [Runyan et al. 2007].

\section{Adolescent WRI Risk Across Industry and Occupations}

Limited evidence exists as to how the above WRI risk factors are distributed across the

range of industries and occupations in which many teens are employed. Below we present what is known on this topic. 


\section{Variations in Equipment Use}

In terms of equipment/tool use, one study of young retail workers found that those employed in eating and drinking establishments were more likely than those employed in grocery stores or other retail stores to use equipment that they felt was dangerous [Zakocs et al. 1998]. Compared to grocery store or other retail store workers, food service workers have been shown to have greater exposures to the types of hazards associated with cuts and burns [Evensen et al. 2000]. Grocery store workers, however, have more exposures to fall hazards than workers in food service or other retail stores [Evensen et al. 2000]. A more recent study showed that young retail workers were somewhat more likely than service industry workers to report using power-driven equipment [Rauscher et al. 2008]. Those working in service, however, were somewhat more likely to report driving a motor vehicle and using heavy equipment but far more likely to report using a forklift ( $52 \%$ vs. $20 \%$ ) than were retail workers [Rauscher et al. 2008].

\section{Variations in Fast Work Pace}

Fast paced work was shown in one study to differ between workers in food service, grocery stores and other retail settings [Evensen et al. 2000]. In focus groups with workers in these establishments, being rushed was a common theme discussed by food service and grocery store workers but rarely brought up by youth who worked in other retail settings [Zakocs et al. 1998]. In their earlier work, Greenberger and Steinberg also found that teens employed in food service jobs worked under the greatest degree of time pressure while skilled laborers generally worked under less time pressure than teens in other jobs [Greenberger and Steinberg 1986].

\section{Variations in Supervision}

While evidence of differences in supervision by industry is scant, several studies have addressed supervisory conditions in varied settings. One study of the entire population of North Carolina teens permitted to work in construction one summer $(n=187)$, showed that most (54\%) reported having worked on construction sites with few employees working on site, with $20 \%$ saying they had worked completely alone, without being in sight or hearing distance of other workers [Runyan et al. 2006]. A similar lack of supervision has been found in retail and service industries. Among a national sample of teens working in these two industries, $26 \%$ reported that they had worked without an adult supervisor present at least one day a week and $10 \%$ worked alone in either the daytime or at night [Runyan et al. 2007].

\section{Variations in Health and Safety Training}

Several studies show that receipt of health and safety training varies by industry. Within the retail industry, training on how to avoid injury is most likely to be given to those working in food service followed by those working in grocery stores and then to those in retail stores [Zakocs et al. 1998]. Another study found that training across these settings was fairly similar (restaurants-74\%, grocery stores-72\%, department stores-77\%) yet was much higher than that reported among youth working in other settings including lumber yards (47\%), lumber mills (34\%), or tree-trimming/cutting operations (49\%) [Zierold and Anderson 2006a]. Workers in tree-trimming and manufacturing were the least likely to be given training in worker rights while those in hotels/motels were the most likely to receive this training, followed by those 
working in grocery stores and restaurants [Zierold and Anderson 2006a]. While not specific to safety, per se, clerical workers and skilled laborers receive eight times the amount of on-the-job training as that received by food service workers, and twice that received by store clerks, according to Greenberger and Steinberg [Greenberger and Steinberg 1986].

\section{Variations in Late Night Work, Cash Handling and Customer Interaction}

We have found little research that has investigated how youths' exposure to working late at night, cash handling, and customer interaction vary by industry and occupation. One study of child labor violations did find that that the percentages of those who worked beyond the latest hour allowed at night was higher among those working in the service industry (22\%) than among those in the retail industry (9\%) [Rauscher et al. 2008]. Based on the nature of the business transacted in retail settings, we can expect that youth working in this industry sector are more likely to be exposed to cash handling and customer interaction than in many other jobs, yet many occupations in the service industry also involve customer or client interaction. Clearly, more research is needed in this area so that we may better understand how these risks differ for youth working in different settings.

\section{Discussion}

As indicated throughout this paper, the data used to understand adolescent work exposures and risk factors for injuries are sparse. The studies that do exist vary in covering different ages of adolescents and different types of work settings and industries. Definitions of injury and exposure are not uniform. As a result, comparisons of results across studies must be done with caution. Despite these limitations, it is clear that US adolescents are exposed to multiple types of hazards that can lead to work-related injury. These hazards include work practices such as work pace, inadequate supervision and training, as well as equipment use, working late at night, and working in settings where cash handling and customer interaction are common. Adolescents for whose language or cultural norms differ from the mainstream in the US require special attention, but the evidence to guide intervention with this population is even more limited.

There is much room for further investigation of the differences between work environments in which adolescents experience the most injuries and those where injuries are less common. Research should examine both the presence of physical hazards in the work environment and the social factors (e.g., supervision and training practices) that can influence worker safety, as well as the interactions between them.

Future investigations of work hazards and injury risk factors should differentiate the opportunities to enhance policies themselves as well as to improve the implementation and enforcement of existing policies. To the extent possible, investigators should try to anticipate changing work patterns that may accompany shifts in the labor pool and job market. Quality data should be obtained to assess both the benefits and risks of work by young people and compare with the benefits and risks of other activities in which they spend time, keeping in mind the overall goal of facilitating healthy and safe physical and psycho-social development. 


\section{References}

Banco L, Lapidus G, Braddock M [1992]. Work-related injury among Connecticut minors. Pediatrics 89(5 Pt 1):957960.

Belville R, Pollack SH, Godbold JH, et al. [1993]. Occupational injuries among working adolescents in New York state. JAMA 269(21):2754-2759.

BLS [2000]. Report on the youth labor force. Washington, DC: U.S. Department of Labor, Bureau of Labor Statistics [http://www.bls.gov/opub/rylf/rylfhome.htm].

BLS [2003-2009]. Census of fatal occupational injuries database. Washington, DC: U.S. Department of Labor, Bureau of Labor Statistics. [http://www.bls.gov/iif/oshcfoi1.htm]

BLS [2011]. Labor force statistics from the current population survey. Washington, DC: U.S. Department of Labor, Bureau of Labor Statistics [http://www.Bls.Gov/cps/cpsaat03.Htm].

BLS [2012]. Labor force statistics from the current population survey. Washington, DC: U.S. Department of Labor, Bureau of Labor Statistics [http://www.bls.gov/cps/].

Breslin F, Day D, Tompa E, et al. [2007]. Non-agricultural work injuries among youth: A systematic review. Am J Prev Med 32(2):151-162.

Brooks DR, Davis LK [1996]. Work-related injuries to Massachusetts teens, 1987-1990. Am J Ind Med 29(2):153160.

Brooks DR, Davis LK, Gallagher SS [1993]. Work-related injuries among Massachusetts children: A study based on emergency department data. Am J Ind Med 24(3):313-324.

CDC (Centers for Disease Control and Prevention) [2003]. Notice to readers: NOISH alert; preventing deaths, injuries and illnesses of young workers. Washington, DC: US Department of Health and Human Services. DHHS (NIOSH) 2003-128.

CDC (Centers for Disease Control and Prevention) [2010]. Occupational injuries and deaths among younger workers --- United States, 1998-2007. MMWR 59(15):449-455.

Davis H [1987]. Workplace homicides of Texas males. Am J Public Health 77(10):1290-1293.

Delp L, Runyan CW, Brown M, et al. [2002]. Role of work permits in teen workers' experiences. Am J Ind Med 41(6):477-482.

Dunn KA, Runyan CW [1993]. Deaths at work among children and adolescents. American journal of diseases of children 147(10):1044-1047

Dunn KA, Runyan CW, Cohen LR, et al. [1998]. Teens at work: A statewide study of jobs, hazards, and injuries. J Adolesc Health 22(1):19-25.

Evensen CT, Schulman MD, Runyan CW, et al. [2000]. The downside of adolescent employment: Hazards and injuries among working teens in North Carolina. Journal of adolescence 23(5):545-560.

Frone MR [1998]. Predictors of work injuries among employed adolescents. J Appl Psychol 83(4):565-576.

Garson B [1988]. The electronic sweatshop. New York: Penguin.

Greenberger E, Steinberg L [1986]. When teenagers work: The psychological and social costs of adolescent employment. New York: Basic Books.

Horwitz IB, McCall BP [2005]. Occupational injury among Rhode Island adolescents: An analysis of workers' compensation claims, 1998 to 2002. JOEM / American College of Occupational and Environmental Medicine 47(5):473-481.

Janicak CA [1990]. An analysis of occupational homicides involving workers 19 years old and younger. JOEM / American College of Occupational and Environmental Medicine 41(12):1140-1145.

Jenkins E [1996]. Workplace homicide: Industries and occupations at high risk. Occupational Medicine: State of the Art Reviews 11(2):219-225.

Kelloway EK, Barling J, Hurrell JJ [2006]. Handbook of workplace violence. Thousand Oaks, CA: Sage Publications, Inc. $\mathrm{p} 696$.

Knight EB, Castillo DN, Layne LA [1995]. A detailed analysis of work-related injury among youth treated in emergency departments. Am J Ind Med 27(6):793-805.

Kruse DL, Mahoney D [2000]. Illegal child labor in the United States: Prevalence and characteristics. Industrial and Labor Relations Review 54(1):17-40.

Laraque D, Barlow B, Durkin M [1999]. Prevention of youth injuries. J Natl Med Assoc 91(10):557-571. 
Layne LA, Castillo DN, Stout N, et al. [1994]. Adolescent occupational injuries requiring hospital emergency department treatment: A nationally representative sample. Am J Public Health 84(4):657-660.

Leidner R [1993]. Fast food, fast talk: Service work and the routinization of everyday life. Berkeley: University of California Press

Loomis D, Wolf S, Runyan C, et al. [2001]. Homicide on the job workplace and community determinants. Am J Epidemiol 154(5):410-417.

Mardis AL, Pratt SG [2003]. Nonfatal injuries to young workers in the retail trades and services industries in 1998. JOEM / American College of Occupational and Environmental Medicine 45(3):316-323.

McCall BP, Horwitz IB, Carr BS [2007]. Adolescent occupational injuries and workplace risks: An analysis of Oregon workers' compensation data 1990-1997. J of Adolesc Health 41(3):248-255.

Miller ME, Kaufman JD [1998]. Occupational injuries among adolescents in Washington state, 1988-1991. Am J Ind Med 34(2):121-132.

Moracco KE, Runyan CW, Loomis D, et al. [2000]. Killed on the clock: A population-based study of workplace homicide, 1977-1991. Am J Ind Med 37(6):629-636.

National Research Council [1998].Committee on the Health and Safety Implications of Child Labor. Protecting youth at work: Health, safety and development of working children and adolescents in the United States. Washington, DC: National Academy Press. Institute of Medicine; 1998.

NIOSH [2006]. NIOSH safety and health topic: Young worker safety and health. Centers for Disease Control and Prevention [http://www.cdc.gov/niosh/topics/youth].Notice to readers: NOISH alert; request for assistance in preventing deaths and injuries of adolescent workers. MMWR 44(35):652.

Occupational Health Surveillance Program [2007]. Teens at work. Work-related injuries to teens in Massachusetts, 2000-2004. Boston, MA: Massachusetts Department of Public Health

O'Connor T, Loomis D, Runyan C, et al. [2005]. Adequacy of health and safety training among young Latino construction workers. JOEM 47(3):272-277.

Parker DL, Carl WR, French LR, et al. [1994]. Nature and incidence of self-reported adolescent work injury in minnesota. Am J Ind Med 26(4):529-541.

Peek-Asa C, Erickson R, Kraus JF [1999]. Traumatic occupational fatalities in the retail industry, United States 19921996. Am J Ind Med 35(2):186-191.

Peek-Asa C, Runyan CW, Zwerling C [2001].The role of surveillance and evaluation research in the reduction of violence against workers. Am J Prev Med 20(2):141-148.

Rauscher KJ [2008]. Workplace violence against adolescent workers in the US. Am J Ind Med 51(7):539-544.

Rauscher KJ, Myers D [2008]. Socioeconomic disparities in the prevalence of work-related injuries among adolescents in the US. J of Adolesc Health 42(1):50-57.

Rauscher KJ, Myers D, Runyan CW, Schulman M [2012]. Young worker safety in construction: Do family ties and workgroup size affect hazard exposures and safety practices? Work-a Journal of Prevention Assessment \& Rehabilitation 42:549-558.

Rauscher KJ, Runyan CW, Radisch D [2011]. Work-related fatalities among youth ages 11-17 in North Carolina, 1990 - 2008. Am J Ind Med 54:136-142.

Rauscher KJ, Runyan CW, Schulman M, et al. [2008]. Child labor law violations in the US retail and service industries: Findings from a national survey of working adolescents. Am J Public Health 98(9):1693-1699.

Rauscher KJ, Wegman DH, Wooding J, Davis L, and Junkin, R. Adolescent Work Quality: A View from Today's Youth. Journal of Adolescent Research. Unpublished

Richardson S, Windau J [2003]. Fatal and nonfatal assaults in the workplace, 1996 to 2000. Clinics in Occupational and Environmental Medicine 3(4):673-689.

Runyan C, Vladutiu C, Rauscher KJ, et al. [2008]. Teen workers' exposures to occupational hazards and use of personal protective equipment. Am J Ind Med 51(10): 735-740.

Runyan CW, Bowling JM, Schulman M, et al. [2005]. Potential for violence against teenage retail workers in the United States. J Adolesc Health 36(3):267.e261-267.e266.

Runyan CW, Dal Santo J, Schulman M, et al. [2006]. Work hazards and workplace safety violations experienced by adolescent construction workers. Arch Pediatr Adolesc Med 160(7):721-727.

Runyan CW, Schulman M, Dal Santo J, et al. [2007]. Work-related hazards and workplace safety of us adolescents employed in the retail and service sectors. Pediatrics 119(3):526-534. 
Runyan CW, Schulman M, Ta M [2005]. Adolescent employment: Relationships to injury and violence. American Public Health Association.

Runyan CW, Zakocs RC [2000]. Epidemiology and prevention of injuries among adolescent workers in the United States. Annu Rev Public Health 21:247-269.

Schober SE, Handke JL, Halperin WE, et al. [1988]. Work-related injuries in minors. Am J Ind Med 14(5):585-595.

Tannock S [2001]. Youth at work. The unionized fast-food and grocery workplace. Philadelphia, PA: Temple University Press.

Weller NF, Cooper SP, Basen-Engquist K, et al. [2003].The prevalence and patterns of occupational injury among south Texas high school students. Tex Med 99(8):52-57.

Windau J, Toscano G [1994]. Workplace homicides in 1992. Fatal workplace injuries in 1992: A collection of data and analysis. Report 870. Washington, DC: US Department of Labor, Bureau of Labor Statistics.

Woolf A, Alpert HR, Garg A, et al [2001]. Adolescent occupational toxic exposures: A national study. Arch Pediatr Adolesc Med 155(6):704-710.

Zakocs RC, Runyan CW, Schulman MD, et al. [1998]. Improving safety for teens working in the retail trade sector: Opportunities and obstacles. Am J Ind Med 34(4):342-350.

Zierold KM, Anderson H [2006a]. The relationship between work permits, injury, and safety training among working teenagers. Am J Ind Med 49(5):360-366.

Zierold KM, Anderson HA [2006b]. Severe injury and the need for improved safety training among working teens. American Journal of Health Behavior 30(5):525-532.

Zierold KM, Anderson HA [2006c]. Racial and ethnic disparities in work-related injuries among teenagers. J Adolesc Health 39(3):422-426.

Zierold KM, Welsh EC, McGeeney TJ [2012]. Attitudes of teenagers towards workplace safety training. J Community Health 37(6):1289-95. 


\title{
A Review of the Research on How Work-Based Injury Risks are Distributed across Youth's Jobs in Canada
}

\author{
Peter M. Smith, PhD, Monash Centre for Occupational and Environmental Health \\ F. Curtis Breslin, PhD, Institute for Work and Health
}

\section{Introduction}

The objective of this portion of the paper is to review the research describing the distribution of risk factors for work-related injury across age groups in Canada. In particular, we wish to outline differences in the working conditions for labor market participants aged 15 to 24 , relative to other labor market participants (i.e. those 25 years and older). Our focus on work-based risks is guided by previous research that demonstrates that differences in the labor market experiences of young workers - in both their working conditions (e.g. unskilled work), and their employment patterns (e.g. movement in and out of short tenure work) - are a primary determinant in explaining the higher incidence of work-related injuries among this age group compared to older workers [Breslin and Smith 2005; Breslin and Smith 2006].

\section{Defining and Identifying Risk Factors}

The previous review paper in this collection, on the risk factors for young workers by Breslin, defines a risk factor as "a characteristic [that is] statistically associated with, although not necessarily causally related to, an increased likelihood of morbidity or mortality that is independent of other potential risk factors". It is important to note that causality is not required under this definition to define a work characteristic as a risk factor, allowing us to use crosssectional research in our review, rather than having to rely on the small number of studies that have examined predictors of work injury using a longitudinal framework. Also missing from this definition is clarity around the required strength of the association, and if the factor under investigation should be modifiable or not [Beck 1998; Burt 2005]. For the purpose of this review we will cover work-related variables that have been statistically associated with work-related injury, assessed through either self-report or administrative data sources (e.g. hospitalization or workers' compensation claims). We have sought to include factors that are positively or negatively associated with work injury. That is, in some cases having a particular work-based factor (e.g. safety training) might be associated with decreased risk of injury. We will also assume that all risk factors covered are potentially modifiable given they are work-based. However, the extent to which workplaces share this view, in particular when changes will impact on a business's profitability is debatable [Eakin 2000].

There are two primary criteria that allow one to identify work-based factors associated with work-related injuries that are distributed differentially across age groups. The first is to examine the distribution of a known risk factor. That is, there have been previous studies linking a risk factor to work place injuries, and a subsequent study has examined the distribution of this risk 
factor across age groups. The second of these criteria is by observing the effect of mediation in a statistical regression model. These relationships can be observed in studies examining the probability of injury across age groups. In these studies, if the inclusion of the work-based factor in a regression model attenuates the excess risk of work injury among younger workers, then we can assume that the variable in question is both associated with age and is associated with the likelihood of work injury [Baron and Kenny 1986].

Therefore, in this review we will summarize work-based factors that meet the following two criteria: a relationship between that factor and work injury had been established (either positive or negative); and, Canadian data are available describing prevalence of the work-based factor across age groups, including $15-24$ year olds.

\section{A Framework to Group Work-based Risk Factors}

Work-based risk factors can be classified in a variety of ways. For the purpose of this review we have classified work-based risks into those that operate at: the individual (worker) level; the job (occupational) level; and the level of the workplace [Runyan and Zakocs 2000]. Worker level characteristics include items such as physical characteristics of workers, psychological factors such as perceptions of invincibility or lack of experience. Job level characteristics include aspects related to the availability of work (e.g. temporary employment) and those related to the nature of work (e.g. workplace hazards or physical demands). Workplace level factors include level of unionization in the workplace, training given to workers, the industry in which the workplace operates and the size of the workplace.

\section{Individual Factors}

Individual factors that may place younger workers at increased risk of injury include lack of training and supervision, inexperience, as well as possible differences in risk perception. Job experience is directly related to the length of time an individual has been in a job. Data from Ontario respondents to the $\mathbf{2 0 0 0}$ Labor Force Survey shows that young workers are more likely to be in their first month of employment compared to older workers. In any month during the year just over $8 \%$ of $15-19$ year olds and almost $5 \%$ of $20-24$ year olds are in their first month of employment, compared to $1 \%$ of workers over 25 years of age [Breslin and Smith 2006]. This difference in job tenure is partially driven by the higher quit rates among younger workers [Morissette et al. 1992] as they move from one entry level job to another. However, job transitions continue for younger workers, even as they gain education. Data from the Survey of Labor and Income Dynamics reporting that workers younger than 25 years of age with bachelor's education have more job transitions than older workers, with younger men with degrees in humanities having, on average, more than two job transitions over a four year period [Giles and Drewes 2001]. In sum, young workers are much more likely to be in their first month of a job than older workers. And the first month of a job is a time when the work injury risk is four times greater than the risk of injury after being in a job for more than 12 months.

Similar to others [Runyan and Zakocs 2000], we were unable to locate research evidence documenting differences in developmental characteristics (e.g. body frames, perceptions of invincibility) between young workers and older workers, or potential mediating effects these fac- 
tors have in the relationship between age and risk of work injury. We are only aware of one study that has specifically examined the relationship between developmental factors such as negative affectivity, rebelliousness, and impulsivity with risk of work injury [Frone 1998]. This paper found that each of these factors were not associated with increased risk of injury once working conditions had been accounted for. We have summarized our views on the relative importance of developmental characteristics relative to occupational and workplace characteristics elsewhere [Breslin and Smith 2010]. Analyses of the 2000 General Social Survey demonstrates that $22 \%$ of $15-24$ year old male workers reported higher levels of stress due to perceived increased risk of injury at work, compared to $12 \%$ of men aged over 55 years, with this elevated probability remaining after adjustment for differences in occupations [Williams 2003]. Another study reported only minimal differences across age groups in the percent of workers who perceived their health and safety were at risk because of their jobs [Brisbois 2003]. Taken together, this suggests that differences in risk perception between younger and older workers are minimal in Canada, with - if anything - risk perception (in the form of elevated perceived stress) being more prevalent among younger workers.

\section{Job Factors}

Many occupational level factors have been associated with increased risk of work-related injury. These include: precarious or temporary employment which is thought to increase injury risk via work intensification, disorganization among workers, and lack of knowledge and compliance with workplace safety regulations [Quinlan et al. 2001; Quinlan 2004]; employment in occupations which are associated with higher levels of physical demands (manual occupations) [Breslin and Smith 2005; Smith and Mustard 2004]; and holding multiple jobs [Wilkins and Mackenzie 2007].

In addition, particular self-reported work characteristics have been associated with higher probability of work injury. These include: perceived physical demands at work [Breslin and Smith 2005]; reporting that job tasks involve doing heavy work or carrying heavy loads [Wilkins and Mackenzie 2007]; having a decreased ability to use skills or having reduced authority to make decisions over the way work is done [Koehoorn et al. 2006]; having work that is fast paced or requires increased concentration [Cole et al. 2005; Nakata et al. 2006]; or the combination of low job control and high psychological demands - referred to as high strain work [Rugulies and Krause 2005]. However, it should be noted that most of the studies linking low control, high demands and job strain to work injury have used musculoskeletal injuries or repetitive movement injuries as their primary outcomes, and have not examined the types of injuries more common among younger workers such as cuts and burns [Breslin et al. 2003].

Young workers in Canada have unique employment patterns compared to other Canadian labor market participants. Data from the Canadian Labor Force Survey documents workers aged $15-24$ years of age have consistently had higher unemployment rates than older workers since data was first collected in 1976 [Statistics Canada 2006]. In addition youth often combine work with schooling, with almost $40 \%$ of full-time students continuing to work during school months [Statistics Canada 2006; Marshall 2007]. Further, 15 to 24 year olds have the highest percentage of involuntary part-time work (working part-time, but wanting to work full-time) [Statistics Canada 2006]. Combined with their higher unemployment rate, this need for full-time work 
may result in younger workers being more likely to accept employment, and stay, in occupations with a high level of risk.

In relation to the job-level risks described above, data from the 2005 Labor Force Survey documents that $30 \%$ of 15 - 24 year olds are in temporary employment relationships, compared to less than $10 \%$ of workers aged 25 to 54 years of age [Statistics Canada 2006]. Youth are also more likely to hold multiple jobs compared to workers aged 25 to 54 years of age [Statistics Canada 2006]. Self-reported data from the 2002 Canadian Community Health Survey documents that workers aged 15 to 24 years of age have higher perceived physical exertion and are more likely to be in high-strain (low control and high demands) and passive (low control and low demands - also referred to as monotonous) work, than those aged 40 to 54 years of age [Shields 2006; Park 2007], although no differences were noted on other measures such as supervisory support.

\section{Workplace Factors}

Factors at the workplace level that may increase risk of injury include the industry in which the workplace operates; the amount of safety training that the workplace provides; the size of the workplace; and the percent of unionization in the workplace. For example, over the 1990's lost-time claim rates in Ontario were highest in agriculture, manufacturing, transport, construction and retail trade industries [Breslin et al. 2007]. The provision of health and safety training early in employment may help to orientate new workers to the hazards and safety procedures in their new workplace, possibly reducing the length of time it takes for them to adapt to their new surroundings, and reducing workplace injuries [Heath 1991; Burke et al. 2006; Mayhew and Quinlan 2002]. In small workplaces occupational health and safety practices may not be as organised, which might lead to increased risks of injury, in addition to compensation after injury and return to work [Lentz and Wenzl 2006; Champoux and Brun 2003; Hasle et al. 2009]. Data from the US Census Bureau and Bureau of Labor Statistics have reported that industries with a higher number of small firms have higher fatality rates [Lentz and Wenzl 2006]. The same report also found that in the mining industry, larger firms had lower fatality rates. While there are no data examining differences in injury rates among unionized and non-unionized employees, unionization has been associated with better access to fair compensation, and having protections at work to reduce hazards, which may reduce injury risk [Williams et al. 2007].

Workplace based safety training may be particularly important for young workers. Providing safety training that covers not only how to operate equipment, but what to do when work becomes unsafe or how to refuse unsafe work may be particularly important given their lack of previous experience in the labor market, or knowledge of occupational health and safety legislation [Kosny 2005; Gray 2002; Angus Reid Group 2000]. Despite the possible importance of training, Canadian data from the Workplace and Employee Survey suggests that young workers are no more likely to receive safety, orientation or equipment training (either on-the-job and in a classroom) than other workers. Only $23 \%$ of young men (15- $24 \mathrm{yrs}$ ) and $20 \%$ of young women in their first year of a new job reported receiving any safety, orientation or equipment training in the previous 12 months [Smith and Mustard 2007].

Other than safety training, we found limited Canadian data reporting on differences in workplace level factors across age groups in Canada. With the only other information we were 
aware of documenting that young workers were less likely to be employed in workplaces that offer either non-wage benefits (e.g. dental plan, supplemental medical insurance), or access to personal and family support programs (such as counseling, fitness services) [Lowe 2007]. We therefore undertook an analysis of the 2007 Canadian Labour Force Survey to examine current occupation and workplace characteristics of relevance among labor force participants in Canada. The results of this analysis are presented in Table 1.

Table 1: Work-based risk factors by age group. Canadian 2007 Labour Force Survey

\begin{tabular}{|c|c|c|c|c|}
\hline & $15-19$ yrs & $20-24$ yrs & $25-55$ yrs & $55+$ yrs \\
\hline \multicolumn{5}{|l|}{ Employment patterns } \\
\hline Unemployed & $14.3 \%$ & $8.3 \%$ & $4.8 \%$ & $4.6 \%$ \\
\hline Self Employed & $2.4 \%$ & $3.4 \%$ & $14.9 \%$ & $27.2 \%$ \\
\hline At school full-time & $55.3 \%$ & $18.1 \%$ & $1.3 \%$ & $0.1 \%$ \\
\hline Temporary Employment & $35.2 \%$ & $23.9 \%$ & $9.2 \%$ & $11.5 \%$ \\
\hline Underemployed* & $6.7 \%$ & $6.5 \%$ & $3.4 \%$ & $3.4 \%$ \\
\hline In $1^{\text {st }}$ month of employment & $7.2 \%$ & $4.5 \%$ & $1.3 \%$ & $0.9 \%$ \\
\hline \multicolumn{5}{|l|}{ Job level characteristics } \\
\hline Multiple Jobs & $5.1 \%$ & $7.3 \%$ & $4.9 \%$ & $3.8 \%$ \\
\hline Working full-time & $30.7 \%$ & $72.7 \%$ & $90.1 \%$ & $80.7 \%$ \\
\hline Manual Occupations & $45.6 \%$ & $42.3 \%$ & $30.1 \%$ & $30.4 \%$ \\
\hline Mixed Occupations & $30.5 \%$ & $25.9 \%$ & $22.3 \%$ & $26.6 \%$ \\
\hline Non-Manual Occupations & $23.9 \%$ & $31.8 \%$ & $47.5 \%$ & $43.0 \%$ \\
\hline \multicolumn{5}{|l|}{ Workplace level characteristics } \\
\hline Less than 20 employees & $47.4 \%$ & $41.7 \%$ & $29.9 \%$ & $33.9 \%$ \\
\hline $\begin{array}{l}\text { Covered by a union or colle } \\
\text { tive bargaining agreement }\end{array}$ & $11.4 \%$ & $17.4 \%$ & $34.7 \%$ & $36.8 \%$ \\
\hline Agriculture & $2.8 \%$ & $1.2 \%$ & $0.8 \%$ & $0.9 \%$ \\
\hline Construction & $3.7 \%$ & $7.4 \%$ & $5.5 \%$ & $4.9 \%$ \\
\hline Transport & $1.1 \%$ & $2.9 \%$ & $5.2 \%$ & $6.1 \%$ \\
\hline Manufacturing - durables & $2.6 \%$ & $5.3 \%$ & $8.4 \%$ & $7.5 \%$ \\
\hline Retail trade & $36.2 \%$ & $20.2 \%$ & $9.9 \%$ & $11.0 \%$ \\
\hline
\end{tabular}

As demonstrated in Table 1, workplace based factors with differential age distributions across Canadian labor market participants include employment in small workplaces, coverage in a union or collective bargaining agreement, and employment in retail trade and construction, with younger workers being more likely to be employed in retail trade and construction (with different distributions for workers less than 20, compared to those 20 to 24 years of age) and smaller 
workplaces compared to older workers. Younger workers were less likely to be covered by a union or collective bargaining agreement.

Also included in Table 1 are updated figures on previous work-based risk factors covered in this paper. In 2007, compared to older workers, younger workers in Canada were still more likely to be unemployed, working in temporary jobs, working part time but wanting full-time work, combining school and work, working in multiple jobs, working in manual (physically demanding) occupations, and being in the first month of a new job. As the research covered in this chapter has suggested, each of these factors is associated with an increased risk of work injury. Table 1 also reports the majority of younger workers (15 - 19 years of age) are attending school fulltime, while we cannot comment on the protective effect of schooling at older age groups, there is evidence that attending school in youth aged 15 to 24 years of age is associated with decreased risk of injury among younger workers in Canada, even after adjustment for hours worked [Breslin et al. 2006].

\section{Research Gaps}

There are current gaps in the research examining the work-based risks of younger workers compared to adults. The first relates to the measurement of work-based risk factors. While there are some characteristics that we have reported that are fairly objectively measured (e.g. multiple jobs, being in the first month of employment), other characteristics may be affected by self-reporting bias; and others may not be accurate enough to detect specific differences that result in elevated risk of injury among young workers.

In relation to self-reported bias, younger age groups might be more likely to under-report the risks or physical demands of their occupations. Possible reasons for this are because younger workers fear being perceived as too inexperienced; or because they calibrate (or compare) levels of self-reported physical demands differently due to their increased participation in other physically demanding activities such as sports. In relation to accuracy of measures, groupings such as manual occupations or temporary work may not pick up specific differences associated with age within these broad groupings. For example, tasks assigned to young workers may be very different than to older workers, even within the same occupational group, or young workers may not fit into safety or protective equipment designed for an older male workforce similar to what Karen Messing has reported for occupational tasks differences between men and women [Messing 1998].

In this portion of the paper we have only described work-based variables that are differentially distributed across age groups, and are related to an increased risk of work injury, which may in turn account for part of the excess risk of work injury among younger workers. It is also possible that particular work-based variables might be associated with an increased risk among $15-24$ year olds, relative to older workers. That is, the relationship between the work-based variable and risk of injury is stronger among younger workers, and weaker (or non-existent) among older workers. Evidence of this relationship would enable targeted approaches for these risk factors to be implemented specifically among younger workers. However, given the limited amount of research testing a moderation hypothesis, this is a fertile area for future research, but beyond the scope of the current review. 
Our review offers some specific areas to examine to understand youth's elevated risk. These include replicating and extending work on adult workers on the mechanisms underlying contingent work in samples of young workers. In addition, given the concentration of young workers in small businesses, more specific dimensions of small business employment which lead to higher risk of injuries among young workers should be explored. Finally detailed research on hazard exposure and knowledge acquisition in the first year of job tenure would provide useful information on the nature of the risk encounters by new workers.

\section{Conclusions}

Our review has demonstrated that young workers in Canada are faced with numerous workbased risks. At the individual level these risks include job-related inexperience, with young workers being more likely to be in the first month of their current job than older workers. At the workplace level younger workers in Canada are more likely to be in temporary work, involuntarily working part-time, working multiple jobs, working in physically demanding occupations, and having lower job control. At the workplace level young workers are more likely to be employed in a small workplace and not to be members of a union. Despite these risks young workers are no more likely to be given safety or orientation training than older workers.

Taken together, these patterns suggest that young workers occupy a niche in the labor market that is typified by a combination of low skill jobs and working arrangements located within workplaces that are not conducive to occupational health and safety and injury prevention. As a result we feel that more needs to be done at the workplace level to protect younger workers as they transition from school into full-time work. While it is unrealistic to expect complete changes in the types of occupations and workplaces in which young workers are employed, more can be done within occupations and workplaces to protect young workers. For example, Mayhew and Quinlan [2002] have reported that in a fast food retail chain in Australia, a tightly controlled system involving orientation, on-the-job training, supervision, and mandatory completion of safety checklists, resulted in lower than expected injury rates among young workers, although over $90 \%$ of the workforce were casually employed. We suggest that more effort should be focused on environmental (e.g. removing hazards) and organizational (enforced safety policies and practices). If all Canadian workplaces and occupations were made safer, young workers -

given their vulnerable position in the current labor market - would be one of the groups who would benefit the most.

\section{Acknowledgments}

While completing this work Peter Smith was supported by a New Investigator Award through the Canadian Institutes of Health Research. Data used in this paper were made available through University of Toronto, Data Library Service and Statistics Canada's data liberation initiative. Approval for the secondary data analyses was obtained through the University of Toronto, Health Sciences I Ethics committee. Thanks to Ms Sara Morassaei for help with revising and editing the manuscript. 


\section{References}

Angus Reid Group. Young workers and workplace injuries. Vancouver: Worksafe British Columbia; 2000.

Baron RM, Kenny DA [1986]. The moderator-mediator variable distinction in social psychological research: Conceptual, strategic, and statistical considerations. J Pers Soc Psychol 51:1173-82.

Beck JD [1998]. Risk revisited. Community Dent Oral Epidemiol 26:220-5.

Breslin FC, Koehoorn M, Smith PM, Manno M [2003]. Age related differences in work injuries and permanent impairment: A comparison of workers' compensation claims among adolescents, young adults, and adults. Occup Environ Med 60:e10.

Breslin FC, Smith PM [2005]. Age-related difference in work injuries: A multivariate, population-based study. Am J Ind Med 48:50-6.

Breslin FC, Smith PM [2006]. Trial by fire: A multivariate examination of the relation between job tenure and work injuries. Occup Environ Med 63:27-32.

Breslin FC, Smith PM, Mustard CA, Zhao R [2006]. Young people and work injuries: An examination of jurisdictional variation within Canada. Inj Prev 12:105-10.

Breslin FC, Tompa E, Mustard C, Zhao R, Smith P, Hogg-Johnson S [2007]. Association Between the Decline in Workers' Compensation Claims and Workforce Composition and Job Characteristics in Ontario, Canada. Am J Public Health 97:453 -- 5.

Breslin FC, Smith P [2010]. A commentary on the unique developmental considerations of youth: integrating the teenage cortex into the occupational health and safety context [commentaries]. International Journal of Occupational and Environmental Health 16:225-9.

Brisbois R [2003]. How Canada stacks up: the quality of work - an international perspective. Ottawa: Canadian Policy Research Networks.

Burke MJ, Sarpy SA, Smith-Crowe K, Chan-Serafin S, Salvador RO, Islam G [2006]. Relative effectiveness of worker safety and health training methods. Am J Public Health 96:315-23.

Burt BA [2005]. Concepts of risk in dental public health. Community Dent Oral Epidemiol 33:240-7.

Champoux D, Brun JP [2003]. Occupational health and safety management in small size enterprises: an overview of the situation and avenues for intervention and research. Safety Science 41:301-18.

Cole DC, Ibrahim S, Shannon HS [2005]. Predictors of work-related repetitive strain injuries in a population cohort. Am J Public Health 95:1233-7.

Eakin JM [2000]. Commentary on promoting the determinants of good health in the workplace. In: Poland BD, Green LW, Rootman I, eds. Settings for health promotion: Linking theory to practice. Thousand Oaks, CA: Sage Publications; p.166-74.

Frone MR [1998]. Predictors of work injuries among employed adolescents. J Appl Psychol 83:565-76.

Giles P, Drewes T [2001]. Liberal arts degrees and the labor market. Perspectives on Labor \& Income 13:27-33

Gray GC [2002]. A socio-legal ethnography of the right to refuse dangerous work. Studies in Law, Politics, and Society 24:133-69.

Hasle P, Kines P, Andersen LP [2009]. Small enterprise owners' accident causation attribution and prevention. Safety Science 47:9-19.

Heath ED [1991]. Identifying those worker populations that are at higher levels of risk. Am Ind Hyg Assoc J 52:A211-A-2.

Koehoorn M, Demers PA, Hertzman C, Village J, Kennedy SM [2006]. Work organization and musculoskeletal injuries among a cohort of health care workers. Scand J Work Environ Health 32:285-93.

Kosny A [2005]. 7 things you'd better know! Governing youth risk at work. Canadian Review of Social Policy 66-78.

Lentz TJ, Wenzl TB [2006]. Small business with high fatality rates: assessment of hazards and their prevention. Journal of Occupational and Environmental Hygiene 3:D8-D14.

Lowe GS [2007]. 21st century job quality: achieving what Canadians want. Ottawa: Canadian Policy Research Networks.

Mayhew C, Quinlan M [2002]. Fordism in the fast food industry: pervasive management control and occupational health and safety risks for young temporary workers. Sociology of Health \& Illness 24:261-84.

Marshall K [2007]. The busy lives of teens. Perspectives on Labor \& Income 8:5-15.

Messing K [1998]. Women workers and their working conditions. In: One-eyed Science: Occupational health and women workers. Philadelphia: Temple University Press, pp.1-11. 
Morissette R, Picot G, Pyper W [1992]. Workers on the move: Quits. Perspectives on Labor \& Income

Nakata A, Ikeda T, Takahashi M, et al. [2006]. Impact of psychosocial job stress on non-fatal occupational injuries in small and medium-sized manufacturing enterprises. Am J Ind Med 49:658-69.

Park J [2007]. Work stress and job performance. Perspectives on Labor \& Income 8:5-17.

Quinlan M, Mayhew C, Bohle P [2001]. The global expansion of precarious employment, work disorganization, and consequences for occupational health: A review of recent research. Int J Health Serv 31:335-414.

Quinlan M [2004]. Workers' compensation and the challenges posed by changing patterns of work: evidence from Australia. Policy and Practice in Health and Safety 2:25 -- 52.

Rugulies R, Krause N [2005]. Job strain, iso-strain, and the incidence of low back and neck injuries. A 7.5-year prospective study of San Francisco transit operators. Soc Sci Med 61:27-39.

Runyan CW, Zakocs RC [2000]. Epidemiology and prevention of injuries among adolescent workers in the United States. Annu Rev Public Health 21:247-69.

Shields M [2006]. Stress and depression in the employed population. Health Rep 17:11-29.

Smith PM, Mustard CA [2004]. Examining the associations between physical work demands and work injury rates between men and women in Ontario, 1990-2000. Occup Environ Med 61:750-6.

Smith PM, Mustard CA [2007]. How many employees receive safety training during their first year of a new job? Inj Prev 13:37-41.

Statistics Canada [2006]. The Canadian labor market at a glance: 2005. Ottawa: Statistics Canada, Labor Statistics Division.

Wilkins K, Mackenzie SG [2007]. Work injuries. Health Rep 18:1-18.

Williams C [2003]. Sources of workplace stress. Perspectives on Labor \& Income 4:23-30.

Williams RM, Westmorland MG, Shannon HS, Amick III BC [2007]. Disability management practices in Ontario health care workplaces. Journal of Occupational Rehabilitation 17:153 -- 65. 


\section{The Unique Developmental Considerations of Youth-Related Work Injuries}

May Sudhinaraset, Johns Hopkins Bloomberg School of Public Health

Robert W. Blum, MD, PhD, Johns Hopkins Bloomberg School of Public Health

This paper was subsequently published in the International Journal of Occupational and Environmental Health (Maney Publishing), which holds the copyright. The publisher has granted access through the following link:

http://www.ingentaconnect.com/content/maney/oeh/2010/00000016/00000002/art00012

Sudhinaraset M, Blum RW [2010]. The unique developmental considerations of youth-related work injuries. International Journal of Occupational and Environmental Health, 16(2): 195-201. 


\section{State of the Art in Young Worker Safety Interventions in the United States}

Susan S. Gallagher, MPH, Tufts University

Sara Rattigan, MS, Massachusetts Department of Public Health

\section{Introduction}

Most youth in the United States have been employed by the time they reach the age of high school graduation [CHSICL, 1998]. It has been suggested that working affects both the academic achievement and the social development of youth. There is also a wealth of data suggesting that young workers have a high rate of injury on the job and are inadequately protected from occupational injury [CHSICL 1998; Runyan and Zakocs 2000; Suruda et al. 2003; Mardis and Pratt 2003]. Many of the research articles that provide a descriptive epidemiology of injury to teen workers also offer recommendations for prevention. The National Occupational Research Agenda (NORA) Intervention Effectiveness Team emphasized that development, implementation and evaluation of effectiveness are central elements to preventing work-related injury and illness [Goldenhar et al. 2001]. Yet not a lot is known about what interventions have been implemented and/or evaluated for this population.

As requested for the Symposium on Young Worker Health and Safety Interventions and Knowledge Mobilization Strategies, this paper examines past interventions to protect working youth in the U.S. It aims to:

1) Review existing program and policy interventions designed to improve safety for young workers by type, scope, target audience and approach (e.g., education, engineering, enforcement);

2) Identify gaps in the knowledge base on effective interventions for improving young worker safety;

3) Identify challenges to and recommendations for improving the evidence supporting young worker safety program and policy interventions; and

4) Consider strategies for knowledge mobilization about young worker health and safety.

\section{Methods}

We surveyed published literature from 1989 through 2008 (20-year period) that referenced interventions related to young worker safety. Young workers were defined as 21-years-old or less. The search was supported by the Tufts University Hirsch Health Sciences Library and was conducted through the OVID and PubMED databases. The following search terms were chosen: adolescent/young worker, safety, occupational safety, industrial safety, injury, injury prevention, agriculture, young/adolescent worker safety education, young/adolescent worker safety 
regulation, young/adolescent worker regulation/law enforcement, young/adolescent worker protective equipment, young/adolescent worker labor laws, and young/adolescent farm worker safety.

Websites of federal agencies with some relationship to young workers were also searched. These included: National Institute for Occupational Safety and Health (NIOSH), the U.S. Department of Labor (DOL), and the Division of Adolescent and School Health (DASH) at the Centers for Disease Control and Prevention (CDC).

In addition, an email request was sent out to the Young Worker Safety and Health Network's list serve [YWSHN 1997] and the State and Territorial Injury Prevention Directors Association [STIPDA 1992] Injury Exchange (now called the Safe States Exchange), an online community designed to facilitate networking, relationship building, and information exchange between all STIPDA members. We hoped to use a snowball technique to identify descriptions of unpublished young worker interventions in the U.S. in any type of setting, or unpublished evaluations of program effectiveness, e.g. program reports. No responses were received from STIPDA and approximately 10 were received through the Young Worker list serve. The latter method resulted in one additional publication.

The search yielded a total of 64 articles initially identified as relevant. We identified three additional articles in reviewing the reference lists of articles found during the search, for a total of 67. Twenty-six of these were deemed not applicable because they reported on general injury occurrences among young workers, or only provided recommendations without any specific intervention reference or description. Articles that were published earlier than 1989, later than 2008, and/or in countries other than the U.S. were omitted as were duplicate articles identified. The remaining 41 articles were sorted according to Figure 1.

Figure 1. Young worker intervention literature search results.

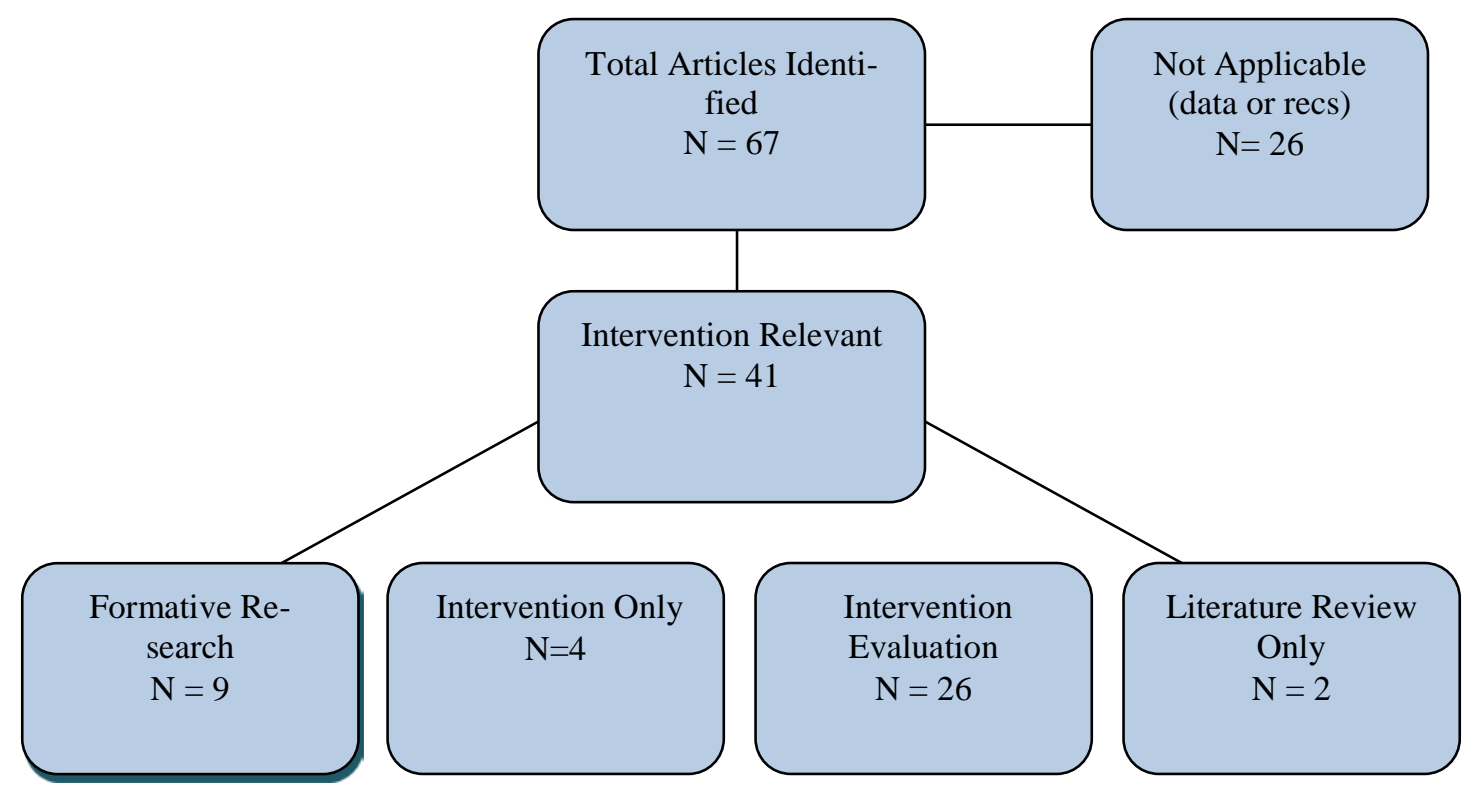


Search results were then reviewed and assigned by content into a classification scheme composed of 13 variables. See Appendix Gallagher-I for detailed definitions. Variables included those listed in the white paper solicitation by the symposium principal investigators and others added by the co-authors. They included the following:

- Funder of the research to track sources of support

- Publication year to track trends in intervention development and research

- State where study conducted to assess geographic distribution

- Availability of full text

- Industry setting for the intervention

- Type of intervention (education, engineering, enforcement)

- Scope of the intervention (formative research, intervention, literature review)

- Target audience

- Age range of workers

- Objectives of the study

- Level of the ecological model addressed

- Evidence base, if any, of the research

- Research results, both positive and negative

- Additional notes on the article, including limitations specific to the article or to worker safety interventions overall.

\section{Overview of what is currently being done to protect working youth in the U.S.}

\section{Background - Importance of maintaining diversity of strategies}

It has long been established in the field of injury prevention that it is important to combine efforts and maintain a diversity of strategies to: alter unsafe behaviors; change social norms; convince policy makers to take action through education; make the physical environment and/or consumer products less hazardous through engineering and design changes; and regulate compliance with safety standards through passage of regulations/legislation and enforcement/litigation [Haddon and Baker 1981]. Providing effective protection in the workplace for adolescents, therefore, also requires a mix of these strategies. Some of these include: equipment design and other passive safety features; job-specific safety training by the employer; adequate supervision; matching required job skills with adolescent development; informing parental attitudes about young workers; general training about hazards and risk avoidance in the workplace; and better public information and education about aspects of child labor laws and their enforcement.

Note that we also examined interventions by the five level socio-ecological model, used in public health as a framework to develop interventions and better understand the effects of potential prevention strategies [Sallis and Owen 2002]. This model considers the complex interplay between the individual, interpersonal (family, significant others, peers), organizational, community, and policy levels. The interdependence outlined in this model emphasizes that health improvement or risk reduction is not always about individual behavior per se, but rather individual outcome, through whatever level it can best be achieved. 
Effective interventions are often implemented within and across levels to reduce individual and collective health risks [Sallis and Owen 2002; Stokols 1996]. When applied to young worker safety, the socio-ecological model draws attention to areas in need of change other than young worker attitudes and behavior. It provides leverage to show movement toward the long-term goal of young worker behavior change through means of change in other populations or policies first. This approach is more likely to sustain prevention efforts over time than any onedimensional effort.

Figure 2. Socio-ecological model [Sallis and Owen 2002].

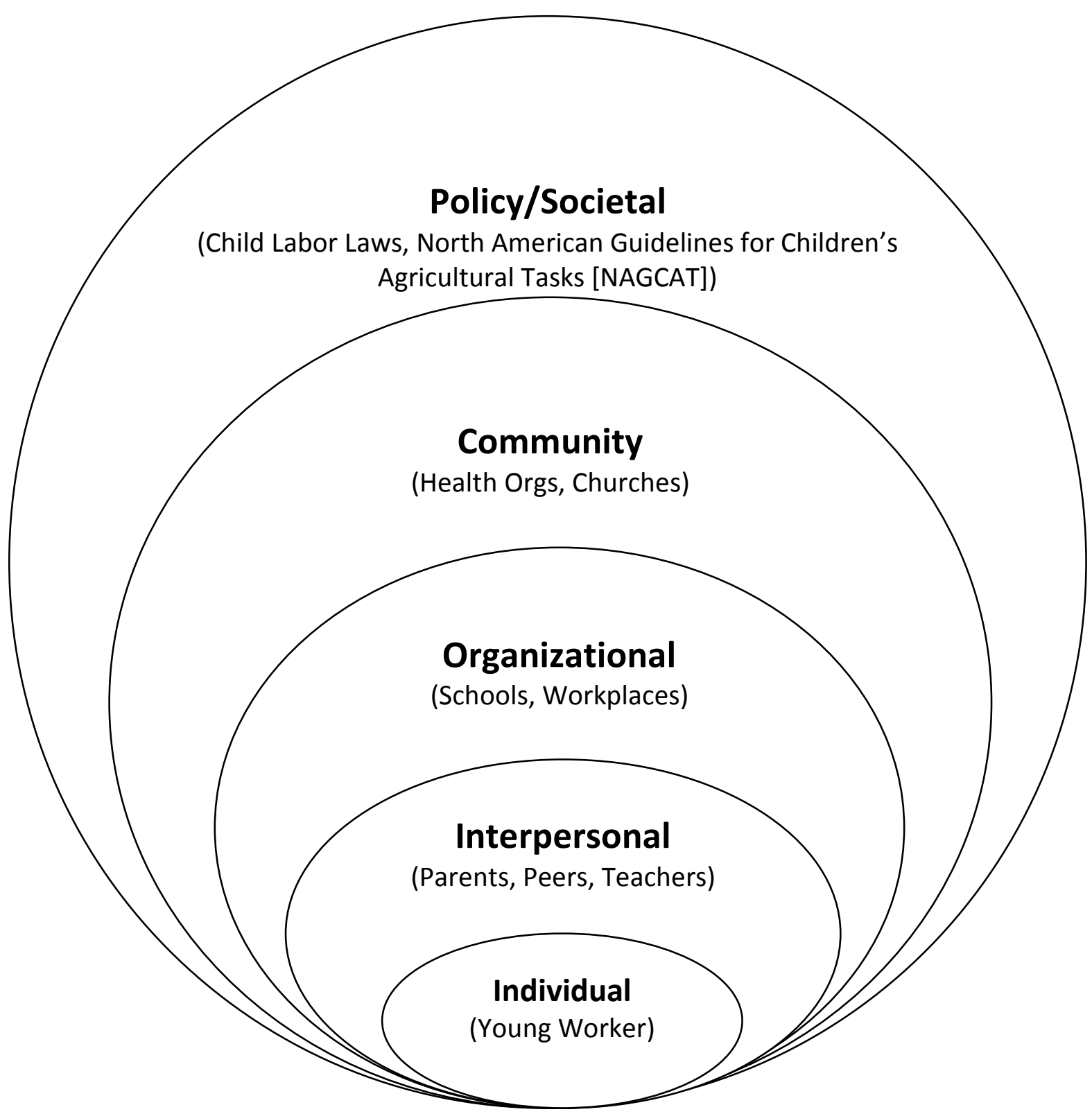


Individual level interventions directly target young workers in trying to influence their beliefs about and attitudes toward worker health and safety and injury prevention, as well as promoting positive behavior change. The interpersonal level targets a population with whom young workers interact personally in order to promote positive behavior change in young workers; this could include teachers or site managers, as well as peers and parents. The organizational level speaks to the impact of institutional frameworks on young worker safety, such as schools or places of employment.

Interventions at the community level make use of how community entities interact with each other and the local population to influence health and safety behavior in young workers. This is an important level because the more support one has, the stronger the intervention will be, whether in terms of financial support, policy support, or peer support. An example of community power might be involving local health care providers in educational or policy efforts that keep workers safer on the job, because these efforts in turn will keep their patients healthier overall.

Finally, the public policy level represents the influence and instruction from a societal level on young worker safety. The Occupational Safety \& Health Administration [OSHA], the North American Guidelines for Children's Agricultural Tasks [NAGCAT], the Fair Labor Standards Act [FLSA] and many other child labor-related laws and policies are housed within this level. Laws are critical because they are enforceable, which increases the likelihood of positive behavior change by decreasing the benefits of non-compliance.

Prevention strategies should include a continuum of activities that address multiple levels of the model, are developmentally appropriate and are conducted across the lifespan. A visual of this might be a regulation implemented at the policy level that is supported at the community level, enforced at the organizational level, and encouraged at the interpersonal level to lead to safer practices in the workplace, which in turn results in lowered risk to the individual.

Following is a summary of the intervention-related information collected from a review of the 41 relevant articles identified. Young worker ages covered in the intervention literature ranged from eight to 21 years with the majority being teens 14- to 17-years-old or high school age. A few of these studies also included older workers.

\section{Published studies of existing program and policy interventions}

\section{Funders}

NIOSH was the primary funder and provided full or partial funding for $61 \%$ of the 41 identified studies. $49 \%$ of studies received full funding from NIOSH. In $22 \%$ of the studies, the funder could not be determined. The remaining funders included two foundations; two universitybased centers (University of North Carolina and University of Texas); a state agency (WA); the National Center for Injury Prevention and Control (NCIPC) at the CDC; the National Institute of Environmental Health Sciences (NIEHS) at the NIH; two Canadian agencies (one governmental); and miscellaneous organizations. Six of the studies cited more than one funder.

\section{Year of Publication}

There has been a steady increase in the number of published intervention studies since 1989 with a maximum number of six identified in each 2005 and 2006 . No studies were identi- 
fied from 1989 through 1992. There were seven studies published from 1993-1999, 16 from 2000-2004, and 18 from 2005-2008.

\section{State}

The U.S. states most represented throughout the studies were those in the Western (24\%), Midwestern (22\%), and Southern (22\%) regions of the country. Specifically, California and lowa independently appeared in five studies each (12\%); Kentucky and Mississippi appeared in the same four studies (10\%); and North Carolina, Washington and Wisconsin each appeared in three studies (7\%). Seven of the studies, or $17 \%$, were conducted in Eastern states.

Of the 41 studies reviewed, 11 (27\%) were conducted at a national level and, of those, three included Canadian regions. Not including national papers, only three were multi-state studies. The state was not able to be identified in two studies (approximately $5 \%$ ).

\section{Industry}

Agriculture was the primary industry cited for the intervention studies, comprising $51 \%$ of the work settings. Five percent each involved the construction industry and the retail and service sectors. The remaining $39 \%$ were not specific to any particular industry setting.

\section{Target Audience}

Within the 41 studies a variety of target audiences were identified, and 10 studies involved more than one target audience (Table 1). The majority of interventions targeted youth directly (54\%), followed by teachers (17\%) and parents (12\%). Six of the studies focused specifically on Latino youth, either working youth (4) or students (2). Community organizations, employers, health care providers and policy makers were least often mentioned as targets.

Table 1. Target audience for the intervention by sector.

\begin{tabular}{|l|l|l|l|}
\hline Target Audience & $\begin{array}{l}\text { Agriculture } \\
\text { Studies } \\
(\mathrm{n}=21)\end{array}$ & $\begin{array}{l}\text { Non-agriculture } \\
\text { Studies } \\
(\mathrm{n}=20)\end{array}$ & $\begin{array}{l}\text { Total Studies } \\
(\mathrm{n}=41)\end{array}$ \\
\hline Students/working youth & 12 & 10 & 22 \\
\hline Teachers/instructors & 3 & 4 & 7 \\
\hline Parents/family members & 4 & 1 & 5 \\
\hline Employers & 2 & 2 & 4 \\
\hline Health care providers & 2 & 1 & 3 \\
\hline Schools & 1 & 2 & 3 \\
\hline Community organizations & 2 & 1 & 3 \\
\hline Policy makers/stakeholders & 1 & 2 & 3 \\
\hline No specific audience & 2 & 4 & 6 \\
\hline
\end{tabular}

\section{Type of Approach - Education, Enforcement, or Engineering}

Education was the primary approach used in the intervention studies. When used in isolation, it accounted for $44 \%$ of the intervention studies; in combination with enforcement, education was employed in $63 \%$ of the studies. Enforcement was the sole approach in $21 \%$ of the in- 
tervention studies, and when used in combination with education accounted for $41 \%$. Education and enforcement were the only two approaches used together in combination and accounted for eight studies (20\%). Engineering was used as the approach in only two (5\%) studies, and three studies were not able to be categorized by approach because the focus was a literature review or perceptual study.

Table 2. Intervention approach by socio-ecological level.

\begin{tabular}{|l|l|l|l|}
\hline Socio-Ecological Level & $\begin{array}{l}\text { Single Level } \\
(\mathrm{n}=26)\end{array}$ & $\begin{array}{l}\text { Multiple Levels } \\
(\mathrm{n}=13)\end{array}$ & $\begin{array}{l}\text { Total } \\
(\mathrm{n}=39)\end{array}$ \\
\hline Individual & 5 & 4 & 9 \\
\hline Interpersonal & 2 & 4 & 6 \\
\hline Organizational & 5 & 5 & 10 \\
\hline Community & 6 & 3 & 9 \\
\hline Policy & 8 & 4 & 12 \\
\hline
\end{tabular}

* Note: Two literature review studies were not included in the socio-ecological model analysis.

\section{Type of Approach - Socio-Ecological Level}

The majority of the studies (63\%) employed a single level of the socio-ecological model (Table 2). Studies that employed more than one level accounted for $32 \%$, with the majority of those involving two levels. Overall, policy dominated as the most included approach within the socio-ecological model, while the interpersonal level (e.g. parents, teachers, peers) was least often the area of focus.

\section{Scope of Interventions}

Twenty-six studies (63\%) were classified as evaluations of interventions, policies or programs. Formative research to develop or improve interventions, policies or programs was the primary focus of nine studies (22\%) that did not include an intervention component. Four studies were identified as descriptions of existing interventions, policies or programs without any evaluation, and two studies were literature reviews of current interventions, policies or programs.

\section{Objective of the Study}

Just over half (54\%) of the studies had a single objective. These were best classified, in order of frequency, as knowledge change (5), policy change (5), organizational change (3), injury change (prevention/reduction) (3), attitude change (2), curriculum change (2), and behavior change (1). Studies with more than one objective (39\%) usually involved a combination of knowledge, attitude and/or behavior change. Taking into account both single and multiobjective studies, knowledge change still dominated (10), followed by attitude change (9), policy change (8), organizational change (8), behavior change (6) and curriculum change (3). Four studies [Banco, et al, 1997; Gadomski, et al, 2006; Marlenga et al., 2006; Zierold and Anderson, 2006] specifically stated injury change as a measurable objective, three of which were combined with policy change (2) and behavior change (1). 


\section{Study Design - Evidence Base}

The largest category of study design was the cross sectional survey with 15 articles or $37 \%$ of all the identified studies. Some of the studies also included a second method, focus groups. Quasi-experimental design was the method used in 10 studies (24\%), followed by four randomized control trials (RCTs) (10\%), four retrospective case series (10\%), an observation study, and a focus group study. Six studies were purely descriptive and included literature reviews or trend reports.

\section{Evidence of Effectiveness}

A number of young worker safety interventions showed promising evidence-based results, which should be noted as building blocks for future intervention development or existing intervention improvement. These 12 studies are summarized in Table 3 by their objective and represent 17 areas where positive change was in evidence.

Table 3. Interventions with some evidence of effectiveness.

\begin{tabular}{|c|c|c|c|c|}
\hline Objective & $\begin{array}{l}\text { Target Audi- } \\
\text { ence }\end{array}$ & Industry & Design & Author \\
\hline \multicolumn{5}{|c|}{ INJURY REDUCTION } \\
\hline NAGCAT & Youth & Agriculture & $\mathrm{RCT}$ & Gadomski . 2006 \\
\hline Box cutters & Youth & Retail & RCT & Banco et al. 1997 \\
\hline \multicolumn{5}{|c|}{ BEHAVIOR CHANGE } \\
\hline NAGCAT & Parents & Agriculture & $\mathrm{RCT}$ & Marlenga et al. 2002 \\
\hline NAGCAT & Parents & Agriculture & Observation & Zentner et al. 2005 \\
\hline AgDARE $^{1}$ & Youth & Agriculture & Quasi Experiment & Reed and Kidd 2004 \\
\hline AgDARE & Youth & Agriculture & Quasi Experiment & Reed et al. 2003 \\
\hline Work Permits & Youth & All & Observation & Delp et al. 2002 \\
\hline \multicolumn{5}{|l|}{ ORG CHANGE } \\
\hline Box cutters & Supermarkets & Retail & $\mathrm{RCT}$ & Banco et al. 1997 \\
\hline \multicolumn{5}{|l|}{ POLICY CHANGE } \\
\hline NAGCAT & $\begin{array}{l}\text { Farm Manag- } \\
\text { ers }\end{array}$ & Agriculture & $\mathrm{RCT}$ & Gadomski et al. 2006 \\
\hline Worker Permits & Youth & All & Observation & Delp et al. 2002 \\
\hline Worker Permits & Youth & All & Observation & $\begin{array}{l}\text { Zierold and Anderson } \\
2006\end{array}$ \\
\hline \multicolumn{5}{|l|}{ KNOWLEDGE } \\
\hline $\begin{array}{l}\text { Farm Safety Day } \\
\text { Camps }\end{array}$ & Youth & Agriculture & Quasi Experiment & McCallum et al. 2005 \\
\hline $\begin{array}{l}\text { English as a } 2^{\text {nd }} \\
\text { Language } \\
\text { Curriculum }\end{array}$ & Latino Youth & Agriculture & Quasi Experiment & Teran et al. 2008 \\
\hline
\end{tabular}

${ }^{1}$ Agriculture Disability Awareness and Risk Education. 


\begin{tabular}{|l|l|l|l|l|}
\hline $\begin{array}{l}\text { Youth @ Work: } \\
\text { Talking Safety }\end{array}$ & Youth & All & Quasi Experiment & Bush and Miara 2008 \\
\hline ATTITUDES & Youth & Agriculture & Quasi Experiment & Reed et al. 2001 \\
\hline AgDARE & Youth & Agriculture & Quasi Experiment & Reed and Kidd 2004 \\
\hline AgDARE & Agriculture & Quasi Experiment & Teran et al. 2008 \\
\hline ESL Curriculum & Youth &
\end{tabular}

\section{Injury reduction}

Two RCTs showed positive change in preventing injuries among young workers. In the first, farms in which lay educators visited and reviewed the North American Guidelines for Children's Agricultural Tasks (NAGCAT) had a longer time to occurrence of a NAGCAT-preventable injury among young workers, in comparison to farms that had no review of the guidelines [Gadomski et al. 2006]. The second showed that supermarkets providing protective safety cutters for employee use had far fewer employee injuries, when compared to control and experimental groups, both using regular case cutters and one exposed to safety training [Banco et al. 1997]. The Banco study also found that intervention supermarkets saved a significant amount of money as a result of fewer employee injuries, an incentive for wider organizational implementation of the protective cutters.

\section{Behavior change}

Five interventions showed a positive change in behavior. Two of these targeted parent behavior through dissemination of NAGCAT. In one case parents who received tailored delivery of NAGCAT were more likely (50\%) to be using the guidelines 15 months later than a control group [Marlenga et al. 2002]; and in another case, 90\% of parents who had been exposed to NAGCAT reported having made one or more NAGCAT-recommended changes on their farm (although most were in how a job was done, and not a purchase of protective equipment). Two of the three behavior-change promising interventions resulted from the AgDARE program, a schoolbased agricultural safety curriculum, developed by two public health nurses: the first showed an increase in protective behaviors among an intervention group of students, observed for performance of certain tasks seven to fourteen months after training [Reed et al. 2003], however not in as many areas as desired. In another evaluation in which AgDARE and non-AgDARE students were visited between 11 and 20 months after intervention, 76\% of those visited showed one or more positive safety behavior changes in performing farm tasks since participating in the program; those visited were also more likely than the control group to engage in safety behaviors not covered by the AgDARE curriculum [Reed and Kidd 2004]. The final behavior-change intervention was based at the policy level, and found through survey results that students without work permits were more likely to perform hazardous tasks than those with permits [Delp et al. 2002].

\section{Policy change}

Three interventions showed positive effects of policy. The first was in the Gadomski study [Gadomski et al. 2006] in which farms receiving NAGCAT materials were less likely to violate certain age-minimum NAGCAT recommendations than control farms. Two different survey- 
based studies found that young workers without permits were less likely to receive safety training than those with permits [Delp et al. 2002; Zierold and Anderson 2006].

\section{Knowledge and attitude change}

Six occurrences-three each-of knowledge and attitude changes were also shown across multiple interventions. The AgDARE program, which involves nurse participation in addition to school teacher instruction, has shown twice in controlled studies that it can significantly increase positive attitudes among students toward farm safety, including their perceived ability to prevent farm injury [Reed et al. 2001; Reed and Kidd 2004]. The other intervention showing significant attitude change was a high school-based English as a Second Language (ESL) curriculum addressing agricultural safety, for predominately Spanish-speaking students, in which a non-equivalent comparison group was used as a control [Teran et al. 2008]. The attitudes of the ESL participants improved regarding their ability to protect themselves, and their perceptions of the dangers of pesticide exposure. The Teran study also found that ESL participants showed greater knowledge about laws and hazards, as well as solutions and resources for problem reporting, than students not exposed to the curriculum. It should also be noted that there was great enthusiasm for the ESL curriculum from the whole community.

The other two increases in knowledge occurred in another high school-based educational program and a safety day camp for younger children (8 to 13 years old). The Farm Safety Day Camps found, through pre-tests and post-telephone interviews, an increase in knowledge and decrease in risk behaviors (based on knowledge) among youth [McCallum et al. 2005]. The Youth @ Work: Talking Safety program, which addresses general worker safety and injury prevention, is a formative research-based, pre-tested curriculum that showed an increase in knowledge about hazard control, young worker rights, and emergency preparedness, based on pre- and post-tests [Bush and Miara 2008].

\section{Agriculture vs. Other Industries}

Of all 17 incidences of positive changes resulting from interventions, 11 (attributed to eight studies), or nearly 65\%, are within the agriculture setting. Only six (attributed to a total of four studies) represent other industries, and of these only two incidences within one study (box cutter) targets a specific non-agricultural industry.

\section{Study Design}

Of the 17 incidences of positive change, only 29\% (representing 3 studies) were determined through RCTs, the strongest and preferred study design. The majority (47\%) resulted through quasi-experimental designs (six studies total), still worthy of note, and the fewest (24\%) through observational studies ( 3 studies total), the least preferred method for reliability.

\section{Evidence of Ineffectiveness}

In addition to the evidence of effective interventions, several studies showed poor outcomes. These should also be considered for future intervention development and are summarized below in Table 4. 
Table 4. Interventions with limited or no evidence of effectiveness.

\begin{tabular}{|l|l|l|l|l|}
\hline Objective & $\begin{array}{l}\text { Target Au- } \\
\text { dience }\end{array}$ & Industry & Design & Author \\
\hline INJURY REDUCTION & Youth & Agriculture & Retro Case Series & Marlenga et al. 2006 \\
\hline Act 455 (WI) & All & Observation & $\begin{array}{l}\text { Zierold and Anderson } \\
2006\end{array}$ \\
\hline Worker Permits & Youth & Agriculture & RCT & Lee et al. 2004 \\
\hline KNOWLEDGE & Youth & Agriculture & Observation & Zentner et al. 2005 \\
\hline Partners Program & Agriculture & RCT & Lee et al. 2004 \\
\hline ATTITUDES & Parents & A & \\
\hline NAGCAT & Youth & Agrith &
\end{tabular}

\section{Lack of injury reduction}

Two interventions that aimed to show a reduction in young worker injuries did not. The first, related to the relationship of worker permit and young worker performance, is of particular interest: despite two studies demonstrating that young workers with permits are more likely to receive safety training [Delp et al. 2002; Zierold and Anderson 2006], the Zierold study also found that among the same group of workers, those with permits were just as likely as those without to be injured on job or experience near misses. Another injury prevention initiative involved implementation of a law (Act 455 in Wisconsin) that required tractor drivers under age 16 to complete a certification course [Marlenga et al. 2006]. Unfortunately, there was no significant change in tractor crashes among youth or when youth were considered at fault, or occurring on public highways, post Act 455 . The lack in injury reduction was attributed to: an incomplete certification curriculum, a lack of attention to increasing the number of tractors equipped with ROPS, and a lack of enforcement of the Act, suggesting a policy alone is not enough to significantly reduce tractor-related crashes.

\section{Lack of knowledge and attitude change}

The other less than desirable outcomes occurred in the areas of knowledge and attitude. One nationally implemented rural youth health and safety initiative, called the Partners Program, designed to promote positive student attitudes, by building leadership skills and sustainable community partnerships, failed to affect safety knowledge or attitudes, leadership, or selfconcept and self-reported injuries among young farm workers, either short- or long-term when compared to control groups [Lee et al. 2004]. The evaluation team noted two contributors to the lack of significant results: lack of any testing of adapted curriculum materials, and inconsistent implementation among intervention groups, again emphasizing the importance of formative research and pretesting that likely contributed to the positive knowledge results of Youth @ Work: Talking Safety [Bush and Miara 2008]. The other study noting poor attitude outcome occurred in the same study that showed positive behavior change among parents that were actively exposed to NAGCAT; but in terms of attitude, parent perceptions of general farm hazards did not translate into the perception that their children were at high risk for injuries [Zentner et 
al. 2005]. While this is not a desirable outcome, it does draw attention to the fact that behavior change may be possible without attitude change.

\section{Agriculture vs. Other Industries}

Of all five incidences of evidence noting unsuccessful efforts, four (attributed to three studies), or $80 \%$, are based in agriculture. Only one incident is related to all industries, and none target a specific industry outside of agriculture.

\section{Study Design}

Of the five incidences with negative intervention-related findings, two (40\%) were from studies using an RCT design (representing one study) and another two used an observational design (representing two studies). The fifth was based on a retrospective case series design, and none were quasi experimental, largely differing from the positive change incidence results.

\section{Moving forward: Current gaps and challenges to address}

\section{Gaps in the knowledge base on effective interventions}

There is a large disconnect between the body of available data on work-related injuries and risk factors for youth workers, and the application of the data for safety interventions.

With the exception of agriculture, there is a notable absence of interventions that address the industry sectors in which youth are employed.

Most interventions target students or working youth at the individual level of the socioecological model. Interventions that specifically target other audiences in a position to support safety among working youth, such as parents, health care providers, schools, employers and community organizations, are minimal.

Diverse populations of youth (e.g. non-English speaking, Latino workers, etc.) are growing in the U.S. [US Census Bureau 2010 and 2011], but there are few youth worker interventions that specifically address these populations.

Despite intervention approaches being distributed among the different levels of the socioecological model, many of these focus on a single level instead of building momentum across levels, which limits effectiveness.

With the exception of two studies [Kidd et al. 2003; Salazar MK et al. 2004], theory is not incorporated into the design of the young worker interventions. Health communication and health behavior theory should be employed in designing targeted interventions, especially those with the goal of individual knowledge, attitude or behavior change. See Appendix Gallagher-II for an example of one theory, the Transtheoretical Model/Stages of Change.

Engineering/technological solutions for identified problems and adjustment in equipment use and job design to better meet the needs of young workers appear to be limited in the literature

Enforcement of policies and regulations is seldom the subject of studies related to policy intervention.

Studies are not in evidence that aim to motivate young workers to be receptive to the use of protective equipment or other simple preventive measures that help to eliminate hazards. For example, young workers resist wearing seat belts in tractors equipped with ROPS, do not avoid 
excessively noisy equipment when wearing ear plugs, and do not avoid dust conditions when wearing masks [Reed, Westneat and Kidd, 2003], due to a false sense of protectiveness.

Employers have been identified as a key contributor to the safety of young workers, either through providing training and protective equipment, or implementing and enforcing guidelines aimed at reducing injuries on the job. There is a lack of interventions that target employers as a means to positive change in young worker safety.

Formative research prior to/in conjunction with the implementation of intervention research is lacking.

There are very few studies with injury reduction set as a measurable objective. Knowledge, attitude, policy and behavior change are the goals of most interventions. Additionally, studies seldom evaluate the translation of knowledge and attitude changes into behavior change.

RCTs and quasi-experimental studies comprise less than one-third of the study designs.

\section{Challenges and recommendations in improving the intervention evidence base}

- Expand the resources to conduct intervention studies of high quality. Cultivate relationships with new funders and obtain more funding from non-NIOSH sources

- Move beyond interventions for youth in agricultural settings to other industries in which many youth are also employed (e.g. retail and service).

- In addition to targeting individual youth, encompass other levels of the socio-ecological model as the audiences.

- In addition to educational approaches, propose a mix of strategies within requests for proposals.

- Use existing data to develop, implement and evaluate interventions. Paucity of data on the circumstances for nonfatal and fatal injury is not the reason for the current state of affairs.

- Work to bring employers on board. Reaching employers continues to be a challenge, but identifying the most effective way of communicating with them, either through more targeted messaging or incentive offerings, is critical to the improvement of young worker safety across the country.

- Change societal norms around young worker safety to support the country's future workforce and overall health. Begin assessing how to transform societal views around recognizing young workers as having a right to and deserving safer working environments and adequate training. A large part of this is improving how to build a political will.

- Widely apply and put into practice more evidence-based interventions. Although knowledge to implement evidence-based strategies exists, the popular and political will to do so has not been marshaled. Multiple audiences need to be reached with communication tailored to meet the specific perceptions and needs of each, such as in a marketing campaign.

- Convince those in the field to think outside of the box and partner with other disciplines to design more effective interventions. For example, pairing ergonomic specialists with child development specialists could enhance engineering or environmental changes for youth workers; pairing behavioral scientists or health communication specialists with occupational safety researchers could result in more tailored interventions that are theory-based or include effective two-way communication, as opposed to one-way directional dissemination of information. 
- Engage the health care community as a partner. Health and public health agencies need to assume some responsibility for preventing injuries to young workers. They need to be coaxed to the table with labor and education agencies. For example, there could be more emphasis on the prevention of adolescent injuries in school-based clinics and other youthserving programs overseen by the public health sector. Before this can happen, the health care community needs to understand the extent of the problem and its role in addressing it; labor and education agencies need to include them and understand the unique role they play in reaching disadvantaged populations.

- Use technology more effectively. Particularly among adolescent and young adult populations, it is critical to understand modern technologies and make better use of them in initiatives directly and indirectly involving young people.

\section{Conclusion}

Work-related injuries among youth offer a good example of insufficient progress in implementing prevention strategies. The literature has identified many factors and occupational settings that contribute to the high rate of injuries to working youth. It has also identified many recommendations for prevention; yet, attempts to implement and evaluate interventions for young workers have been limited. Most that exist focus on educating youth about hazards in the workplace, often through school curriculum, or focus on youth working in agricultural settings. Adults such as parents, employers and policy makers are in a position to address the safety of youth workers, but are rarely targeted in intervention. The emphasis has remained on educating youth and has not fully encompassed the diversity of strategies that are needed.

Today there are effective prevention measures that have not been uniformly applied to improve the safety of young workers; we must weave them in to our existing efforts. Continued progress demands application of theory when designing interventions; an effective balance of education, engineering and enforcement approaches; consideration of the levels of the socioecological model as a framework for intervention; and stronger experimental designs. While there will be challenges along the way, that we can clearly identify gaps in young worker interventions to date provides promise that we will have greater success in moving forward.

\section{References}

Banco L, Lapidus G, Monopoli J, Zavoski RT [1997]. The Safe Teen Work Project: a study to reduce cutting injuries among young and inexperienced workers. Am J Ind Med 31(5):619-622.

Beyer D [1993]. Current trends in state child labor legislation and enforcement. Am J Ind Med 24(3):347-350.

Bush D, Miara C [2008]. Youth @ Work: Talking Safety: summary of content and evaluation efforts. Berkley, CA: The Labor Occupational Health Program. Waltham, MA: Educational Development Center. Unpublished.

Bush D [2007]. Involving youth in public health and policy: The Young Worker Leadership Academy. Unpublished paper presented at the American Public Health Association Annual Meeting, Washington, DC, November 5.

Carrabba JJ, Field WE, Tormoehlen RL [2000]. Effectiveness of the Indiana 4-H tractor program at instilling safe tractor operating behaviors and attitudes in youth. J Agric Saf Health 6(3): 179-189.

Chapman LJ, Schuler RT, Wilkinson TJ, Skjolaas CA [1995]. Farm-work hazard prevention efforts by school-based agricultural education instructors. Am J Ind Med 28(4):565-577. 
CHSICL (Committee on the Health and Safety Implications of Child Labor), National Research Council and Institute of Medicine [1998]. Protecting youth at work: health, safety and development of working children and adolescents in the United States. Washington, DC: National Academies Press.

DASH. Website for the Division of Adolescent and School Health, Centers for Disease Control and Prevention. [http://www.cdc.gov/healthyyouth/]. Date accessed: May 2009.

Delp L, Runyan CW, Brown M, Bowling MJ, Jahan SA [2002]. The role of work permits in teen worker experiences. Am J Ind Med 41(6):477-482.

DOL. Website for the U.S. Department of Labor. [http://www.dol.gov/]. Date accessed: May 2009.

Elkind PD, Pitts K, Ybarra SL [2002]. Theater as a mechanism for increasing farm health and safety knowledge. Am J Ind Med 42(2)(Suppl):28s-35s.

Gadomski A, Ackerman S, Burdick P, Jenkins P [2006]. Efficacy of the North American Guidelines for Children's Agricultural Tasks. Am J Public Health 96(4):722-7.

Goldenhar LM, LaMontagne AD, Katz T, Heaney C, Landsbergis P [2001]. The intervention research process in occupational safety and health: An overview from the NORA Intervention Effectiveness Research Team. J Occup Environ Med 43(7):616-622.

Haddon W, Baker SP [1981]. Injury control. In: Clark D, MacMahon B, eds. Preventive and community medicine. Boston: Little Brown Co. Inc., pp. 109-140.

Hartling L, Brison RJ, Crumley ET, Klassen TP, Pickett W [2004]. A systematic review of interventions to prevent childhood farm injuries. Pediatrics 114(4):e483-96.

Higgins DN, Tierney J, Hanrahan L [2002]. Preventing young worker fatalities: The Fatality Assessment and Control Evaluation (FACE) Program. AAOHN 50(11):508-14.

Kidd P, Reed D, Weaver L, Westneat S, Rayens MK [2003]. The transtheoretical model of change in adolescents: implications for injury prevention. J Safety Res 34(3):281-288.

Lee BC, Westaby JD, Berg RL [2004]. Impact of a national rural youth health and safety initiative: results from a randomized controlled trial. Am J Public Health 94(10):1743-9.

Linker D, Miller ME, Freeman KS, Burbacher T [2005]. Health and safety awareness for working teens: developing a successful statewide program for educating teen workers. Fam Community Health 28(3):225-238.

Mardis AL, Pratt SG [2003]. Nonfatal injuries to young workers in the retail trades and services industries in 1998. Journal of Occup Environ Med 45(3):316-323.

Marlenga B, Berg RL, Linneman JG, Brison RJ, Pickett W [2007]. Changing the child labor laws for agriculture: impact on injury. Am J Public Health 97(2)276-282.

Marlenga B, Brison RJ, Berg RL, Zentner J, Linneman J, Pickett W [2004]. Evaluation of the North American Guidelines for Children's Agricultural Tasks using a case series of injuries. Inj Prev 10(6):350-357.

Marlenga B, Doty BC, Berg RL, Linneman JG [2006]. Evaluation of a policy to reduce youth tractor crashes on public roads. Inj Prev 12(1):46-51.

Marlenga B, Pickett W, Berg RL [2002]. Evaluation of an enhanced approach to the dissemination of of the North American Guidelines for Children's Agricultural Tasks: a randomized controlled trial. Prev Med 35(2):150159.

Mazur JM, Cole HP, Reed D, Claunch D [2005]. Instructional practices at Farm Safety 4 Just Kids (FS4JK) safety day camps. J Agric Saf Health 11(2):257-64.

McCallum DM, Conaway MB, Drury S, Braune J, Reynolds SJ [2005]. Safety-related knowledge and behavior changes in participants of farm safety day camps. J Agric Saf Health 11(1):35-50.

McCauley LA, Sticker D, Bryan C, Lasarev MR, Scherer JA [2002]. Pesticide knowledge and risk perception among adolescent Latino farmworkers. J Agric Saf Health 8(4):397-409.

Miara C, Gallagher S, Bush D, Dewey R [2003]. Developing an effective tool for teaching teens about workplace safety. Am J Health Educ 34(5)(Suppl):30s-34s.

Miller ME, Handleman E, Lewis C [2007]. Protecting young workers: coordinated strategies to help raise safety awareness. Prof Saf June:38-45.

Moehling CM [1999]. State child labor laws and the decline of child labor. Explor Econ Hist 36(1):72-106.

Murphy DJ, Kiernan NE, Chapman LJ, Goldenhar L [1996]. An occupational health and safety intervention research agenda for production agriculture: Does safety education work? Am J Ind Med 29(4):392-396.

NAGCAT. North American Guidelines for Children's Agricultural Tasks, Marshfield Clinic Research Foundation. [http://www.nagcat.org/nagcat/]. Date accessed: June 2009. 
NIOSH [1999]. Promoting safe work for young workers: A community-based approach. By Bush D, González-Arroyo M, Stock L, Delp L, Miara C, Dewey R, Sinclair RC, Ortega MJ. Cincinatti, OH: U.S. Department of Health and Human Services, Centers for Disease Control and Prevention, National Institute for Occupational Health, DHHS (NIOSH) Publication No 99-141.

NIOSH. Website for the National Institute for Occupational Safety and Health, Centers for Disease Control and Prevention. [http://www.cdc.gov/niosh/]. Date accessed: May 2009.

O'Connor T, Loomis D, Runyan C, Abboud dal Santo J, Schulman M [2005]. Adequacy of health and safety training among young Latino construction workers. J Occup Environ Med 47(3):272-7.

OSHA. Occupational Safety and Health Administration, U.S. Department of Labor. [http://www.osha.gov/]. Date accessed: June 2009.

Prochaska JO, Redding CA, Evers KE [2002]. The transtheoretical model and stages of change. In: Glanz K, Rimer BK, Lewis FM, eds. Health behavior and health education: theory, research, and practice. $3^{\text {rd }}$ ed. San Francisco: Jossey-Bass, pp. 99-120.

Reed DB, Browning SR, Westneat SC, Kidd PS [2006]. Personal protective equipment use and safety behaviors among farm adolescents: gender differences and predictors of work practices. J Rural Health 22(4):314320.

Reed DB, Kidd PS, Westneat S, Rayens KM [2001]. Agricultural Disability Awareness and Risk Education (AgDARE) for high school students. Inj Prev 7(1)(Suppl):i59s-i63s.

Reed DB, Kidd PS [2004]. Collaboration between nurses and agricultural teachers to prevent adolescent agricultural injuries: the Agricultural Disability Awareness and Risk Education Model. Public Health Nurs 21(4):32330.

Reed DB, Westneat SC, Kidd P [2003]. Observation study of students who completed a high school agricultural safety education program. J Agric Saf Health 9(4):275-83.

Runyan CW, Dal Santo J, Schulman M, Lipscomb H, Harris TA [2006]. Work hazards and workplace safety violations experienced by adolescent construction workers. Arch Pediatr Adolesc Med 160(7):721-7.

Runyan CW, Zakocs RC [2000]. Epidemiology and prevention of injuries among adolescent workers in the United States. Annu Rev Public Health 21:247-69.

Salazar MK, Napolitano M, Scherer JA, McCauley LA [2004]. Hispanic adolescent farmworkers' perceptions associated with pesticide exposure. West J Nurs Res 26(2):146-166.

Sallis JF, Owen N. Ecological Models of Health Behavior[2002]. In: In: Glanz K, Rimer BK, Lewis FM, eds. Health behavior and health education: theory, research, and practice. $3^{\text {rd }}$ ed. San Francisco: Jossey-Bass, pp. 462484.

Schulte PA, Stephenson CM, Okun AH, Palassis J, Biddle E [2005]. Integrating occupational safety and health information into vocational and technical education and other workforce preparation programs. Am J Public Health 95(3):404-11.

Shipp EM, Cooper SP, del Junco DJ, Bolin JN, Whitworth RE, Cooper CJ [2007]. Pesticide safety training among farmworker adolescents from Starr County, Texas. J Agric Saf Health 13(3):311-21.

STIPDA (State and Territorial Injury Prevention Directors Association) [1992]. Injury Exchange online community. [http://www.stipda.org/displaycommon.cfm?an=1\&subarticlenbr=180]. Date accessed: May 2009.

Stokols D [1996]. Translating social ecological theory into guidelines for community health promotion. Am J Health Promot 10(4):282-298.

Suruda A, Philips P, Lillquist D, Sesek R [2003]. Fatal injuries to teenage construction workers in the U.S. Am J Ind Med 44(5):510-514.

Teran S, Strochlic R, Bush D, Baker R, Meyers J [2008]. Reaching teen farm workers with health and safety information: an evaluation of a high school ESL curriculum. J Agric Saf Health. 14(2):147-62.

US Census Bureau [2010]. Language use in the United States: 2007: American community survey reports. By Shin HB, Kominski RA. US Department of Commerce, Economics and Statistics Administration, US Census Bureau, Publication No ACS-12. [http://www.census.gov/prod/2010pubs/acs-12.pdf]. Date accessed: July 30, 2012.

US Census Bureau [2011]. The Hispanic population 2010: 2010 census briefs. By Ennis SR, Ríos-Vargas M, Albert NG. US Department of Commerce, Economics and Statistics Administration, US Census Bureau, Publication Mo C2010BR-04. [http://www.census.gov/prod/cen2010/briefs/c2010br-04.pdf]. Date accessed: July 30, 2012. 
YWHSN (Young Worker Safety and Health Network) [1997].youthwrk@listserv.oit.unc.edu, University of North Carolina Injury Prevention Research Center. [http://www.osha.gov/SLTC/teenworkers/networkmembers.html]. Date accessed: May 2009.

Zakocs RC, Runyan CW, Schulman MD, Dunn KA, Evensen CT [1998]. Improving safety for teens working in the retail trade sector: opportunities and obstacles. Am J Ind Med 34(4):342-350.

Zentner J, Berg RL, Pickett W, Marlenga B [2005]. Do parents' perceptions of risks protect children engaged in farm work? Prev Med 40(6):860-6.

Zierold KM and Anderson $\mathrm{H}$ [2006]. The relationship between work permits, injury, and safety training among working teenagers. Am J Ind Med 49(5):360-366.

\section{Resources}

California Resource Network for Young Workers' Health and Safety [2009]. [http://www.youngworkers.org/]. Date accessed: June 2009.

CDC (Centers for Disease Control and Prevention) [2001]. School health guidelines to prevent

CDC (Centers for Disease Control and Prevention) [2001]. School health guidelines to prevent unintentional injuries and violence. MMWR 50 (No. RR-22) (work-related injuries pages 8-9)

Christoffel T, Gallagher SS [2006]. Injury prevention \& public health: practical knowledge, skills and strategies. $2^{\text {nd }}$ edition. Sudbury, MA: Jones and Bartlett Publishers.

CSN (Children's Safety Network), OHSP-MDPH (Occupational Health Surveillance Program, Massachusetts Department of Public Health) [1995]. Protecting Working Teens: A Public Health Resource Guide. Newton, MA: Education Development Center.

NAS (National Academy of Sciences) [2002]. Speaking of health: assessing health communication strategies for diverse populations. Washington, DC: National Academy of Sciences, Institute of Medicine, Board on Neuroscience and Behavioral Health.

NIOSH [2005]. Working Together for Safety: A State Team Approach to Preventing Occupational Injuries to Young People. By Education Development Center, Inc. Cincinnati, Ohio: U.S. Department of Health and Human Services, Centers for Disease Control and Prevention, National Institute for Occupational Health, DHHS (NIOSH) Publication No 2005-134.

NIOSH [2007]. Youth@Work: Talking Safety. Cincinnati, Ohio: U.S. Department of Health and Human Services, Centers for Disease Control and Prevention, National Institute for Occupational Health, DHHS (NIOSH) Publication No 2007-136.

unintentional injuries and violence. MMWR 50(RR-22):8-9. US Department of Labor. YouthRules! Website. [http://www.youthrules.dol.gov/]. Date accessed: June 2009. 


\section{Appendix Gallagher-I: Classification Scheme Variables and Subcategories}

Articles were assigned to 13 classification scheme variables in order to identify themes.

1. Funder: Entity that provided support for the published research or intervention.

- Variable (dependent on intervention)

2. Year: Year the article was published.

- Variable (Year range: 1989 to 2008)

3. State: The state within the United States in which the study or research was conducted.

- Variable

4. Text: The degree of literature available for review.

- Full Text

- Abstract

- In Press

5. Work Setting: The occupational field for which the intervention was developed.

- Agriculture

- Construction

- Retail and Service

- All

6. Type: Which of the three $E^{\prime} s$ the intervention is based in.

- Education

- Enforcement

- Engineering

7. Scope: The aim of the intervention.

- Formative Research: Research necessary to develop or improve effective interventions, policies or programs

- Intervention: Description of an existing intervention, policy or program

- Intervention Evaluation: Evaluation of an existing intervention, policy or program

- Literature Review: A review of current interventions, policies or programs

8. Target Audience: The group or entity the intervention was developed to create change in.

- Young Workers

- Hispanic/Latino Young Workers

- Parents

- Farms 
- High Schools

- Child Labor Laws

- Training Programs

- Variable Entities (e.g. supermarkets, community organizations)

9. Worker Age: Age of worker behavior for which behavior change/injury reduction is desired.

- 17 and under

- High School

- All

- Variable (specific to intervention)

10. Objectives: Goal of intervention or research article.

- Knowledge Change

- Attitude Change

- Behavior Change

- Curriculum Change

- Organizational Change

- Policy Change

- Other (specific to intervention)

11. Socio-Ecological Level: Level under which the intervention falls.

- Individual: Targets young worker directly.

- Interpersonal: Targets population with which young worker interacts.

- Organizational: Targets institution that impacts young worker performance.

- Community: Targets groups within the community in which young worker lives/works.

- Policy: Targets policies that have potential to protect or affect young worker safety.

12. Evidence Base: Type of design that provides scientific legitimacy to intervention.

- Cross-Sectional Survey

- Controlled Trial

- Observational Study

- Quasi-Experimental Design

- Randomized Controlled Trial

- Retrospective Case Series

- Survey

- Other Variable Design (e.g. focus groups, theory, pre-testing)

- None

13. Results: Results of the intervention or research.

- Variable (specific to intervention objectives)

14. Notes: Questions and important issues raised based on the intervention or research.

- Variable (specific to the intervention) 


\section{Appendix Gallagher-II: Transtheoretical Model/Stages of Change Theory}

The Transtheoretical Model (TM), or Stages of Change theory [Prochaska et al. 2002], seems the most relevant for the development and evaluation of young worker safety and injury prevention interventions [Kidd et al. 2003]. It allows interventions to do more than focus on knowledge and attitude change, and then leap to behavior change. It is comprised of five stages of behavior that lead to continued performance of the desired behavior:

- Pre-contemplation

- Contemplation

- Preparation

- Action

- Maintenance

The beauty of TM is that it can demonstrate movement toward the desired behavior in concrete increments, and fills in the gray area currently lacking between the black and white of knowledge/attitude and behavior. Interventions that use TM become theory based, and also have greater means to show positive results, both of which are important to potential funders.

For example, it may not be effective to model safe protective behaviors for young workers who do not consider themselves at risk for injury: one might first introduce the youth to the idea of workplace safety in order to raise awareness (or knowledge); once they are contemplating worker safety, the next step to move them to intend (or prepare) to practice safe work habits might be sharing strategies and benefits; once they have intention and are ready to prepare for safe work practices, modeled behaviors will better resonate and be more effective.

After young workers have moved from pre-contemplation to preparation, they are ready to put what they have learned into action, and once action (or the desired behavior) is demonstrated, it is hoped it will be maintained. However, the model also provides guidance on how to proceed if the target audience falls backward from maintenance: for example, if a group of young workers stop performing a certain behavior, they may need a refresher at the preparation level.

Each stage of change is measurable progress towards achieving behavior change (and can be claimed as such in grant progress reports, etc.). 


\section{A State of the Art Review of Knowledge Mobilization and Dissemination Practices Related to Occupational Safety and Health}

Peter Levesque, PhD, Knowledge Mobilization Works

\section{Define knowledge mobilization (KMb) and dissemination as used within both the U.S. and Canada.}

The field of Knowledge Management (KM), Knowledge Mobilization (KMb), and Knowledge Transfer (KT) is in a period of growth and development. As with any domain under construction, there is significant confusion about terminology and overlaps in meaning. There is however, a growing body of literature and practice that is creating some stability of meaning and interpretation for sectors such as health, education, and business.

Knowledge Mobilization Works defines knowledge mobilization $(\mathrm{KMb})^{1}$ as "the complex process of making knowledge ready for service or action to build value." (Summarized by Figure 1.) This definition is grounded in theories of social construction and based on the premise that "information and knowledge are quintessentially human creations, and we will never be good at managing them unless we give people a primary role" [Davenport 1997].

This conceptualization is further supported by the work of Brown: "knowledge usually entails a knower" [Brown 2002]. He emphasizes the fundamental differences between data ${ }^{2}$, information $^{3}$ and knowledge ${ }^{4}$. Knowledge always has a social life.

The term knowledge mobilization emerged in Canada from the Social Sciences and Humanities Research Council of Canada (SSHRC) in 2001 as part of its strategy to shift from a granting agency to a "knowledge council". The foundation for KMb was based on two premises: that leading edge information is not enough to ensure Canada's place in a rapidly changing world and, information has more power and value when combined with analysis and action to create knowledge. The conclusion was that this translates into economic, social, and cultural benefits for Canadians. The core concepts of knowledge mobilization are complexity (rather than complicated), emergence, iterative creation, and value production from exchange mechanism. The

\footnotetext{
${ }^{1}$ The acronym KMb is used for knowledge mobilization to differentiate it from knowledge management that uses KM. KM has developed a strong emphasis on technology led by information systems specialists. KMb emphasizes complexity, emergence, and the social relationships found in networks and learning communities.

${ }^{2}$ Simple observations of states of the world: easily structured, easily captured on machines, often quantified, and easily transferred.

${ }^{3}$ Data endowed with relevance and purpose: requires unit of analysis, needs consensus on meaning, human mediation necessary.

${ }^{4}$ Valuable information from the human mind - includes reflection, synthesis, and context: hard to structure, difficult to capture on machines, often tacit [rather than explicit], hard to transfer.
} 
summary framework (Figure 2 ) shows relationships between content ${ }^{5}$, context $^{6}$, capacity ${ }^{7}$ and culture $^{8}$. These aspects are linked to one another through synchronous (same time) as well as asynchronous (self-selected time) conversation channels.

Knowledge mobilization is one among many terms used to define the processes leading to more effective and perhaps more efficient access, utilization, implementation, and evaluation of knowledge from many sources including research findings.

In Canadian healthcare, the dominant term is knowledge translation (KT). The Canadian Institutes of Health Research (CIHR) defines KT as: "a dynamic and iterative process that includes synthesis, dissemination, exchange and ethically-sound application of knowledge to improve the health of Canadians, provide more effective health services and products and strengthen the health care system"[CIHR 2009].

It is recognized that KT is complex and occurs both at the end of the grant (dissemination and communication of findings via traditional academic and disciplinary channels, customized reports and informational artifacts tailored to specific audiences), as well as being an ongoing process that is integrated into all aspects of research [CIHR 2009].

As part of their "knowledge to action" process, CIHR maintains a portfolio of programs and resources to support knowledge translation, commercialization, innovation and industry. They define synthesis, dissemination, and exchange as follows [CIHR 2009]:

Synthesis - the contextualization and integration of research findings of individual research studies within the larger body of knowledge on the topic. A synthesis must be reproducible and transparent in its methods, using quantitative and/or qualitative methods. It could take the form of a systematic review, follow the methods developed by the Cochrane Collaboration, result from a consensus conference or expert panel or synthesize qualitative or quantitative results. Realist syntheses, narrative syntheses, meta-analyses, meta-syntheses and practice guidelines are all forms of synthesis. Resources related to synthesis are available.

Dissemination - involves identifying the appropriate audience and tailoring the message and medium to the audience. Dissemination activities can include such things as summaries for / briefings to stakeholders, educational sessions with patients, practitioners and/or policy makers, engaging knowledge users in developing and executing dissemination/implementation plan, tools creation, and media engagement.

Exchange - refers to the interaction between the knowledge user and the researcher, resulting in mutual learning. According to the Canadian Health Services Research Foundation (CHSRF), the definition of knowledge exchange is "collaborative problem-solving between researchers and decision makers that happens through linkage and exchange. Effective knowledge exchange involves interaction between knowledge users and researchers and results in mutual learning through the process of planning, producing, disseminating, and applying existing or new research in decision-making." KT is summarized by the Knowledge to Action cycle (Figure 3).

\footnotetext{
${ }^{5}$ Data, information, and knowledge produced by researchers as well as co-created with stakeholders.

${ }^{6}$ Behavior and work processes, politics, technology, and disciplinary priorities.

${ }^{7}$ Human, fiscal, and time resources available and adaptable to emerging opportunities.

${ }^{8}$ Values, norms, beliefs, and mental models.
} 
Figure 1: Knowledge Mobilization Works (KMbW) value production model

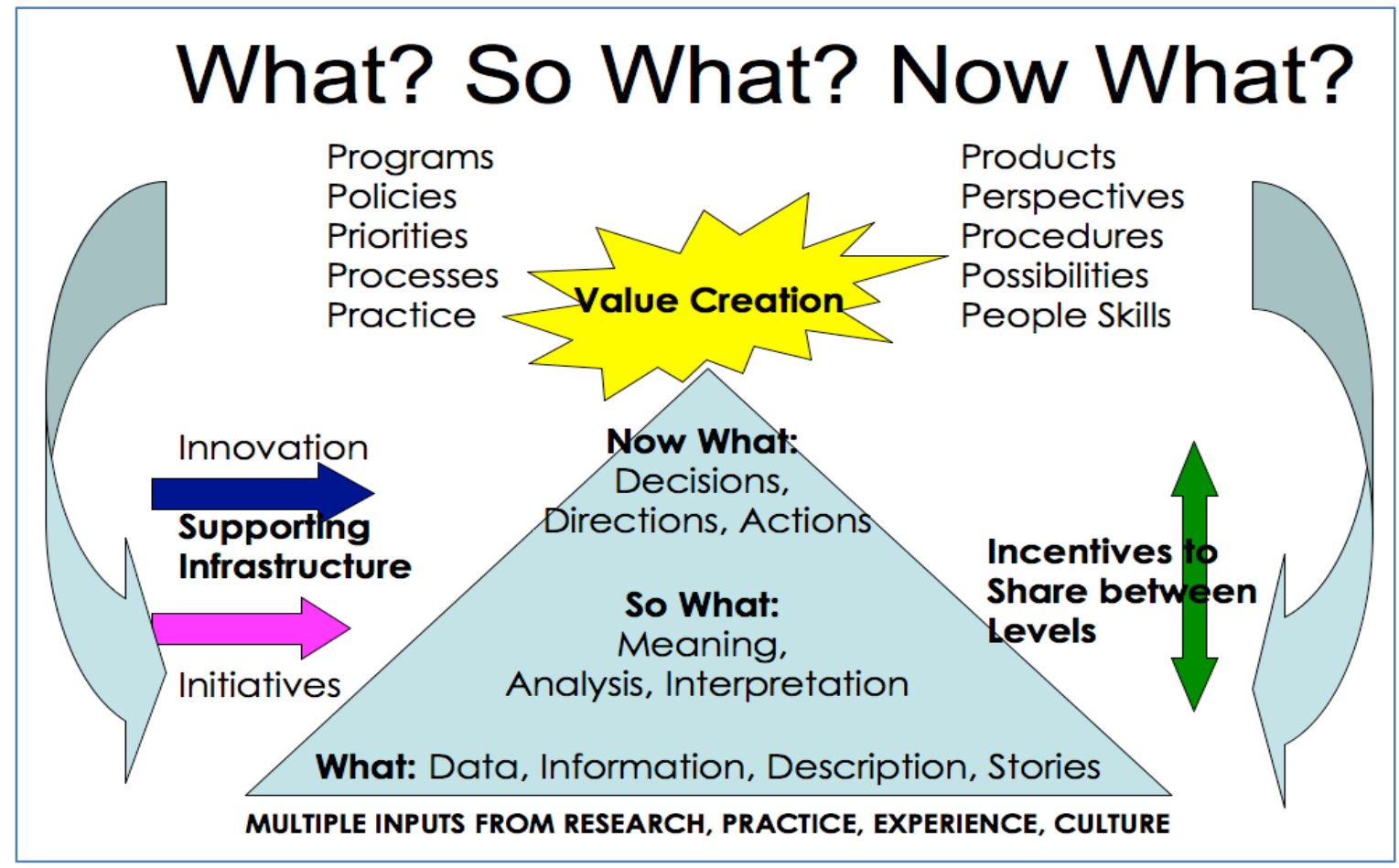

Figure 2: Core concepts for knowledge ecology

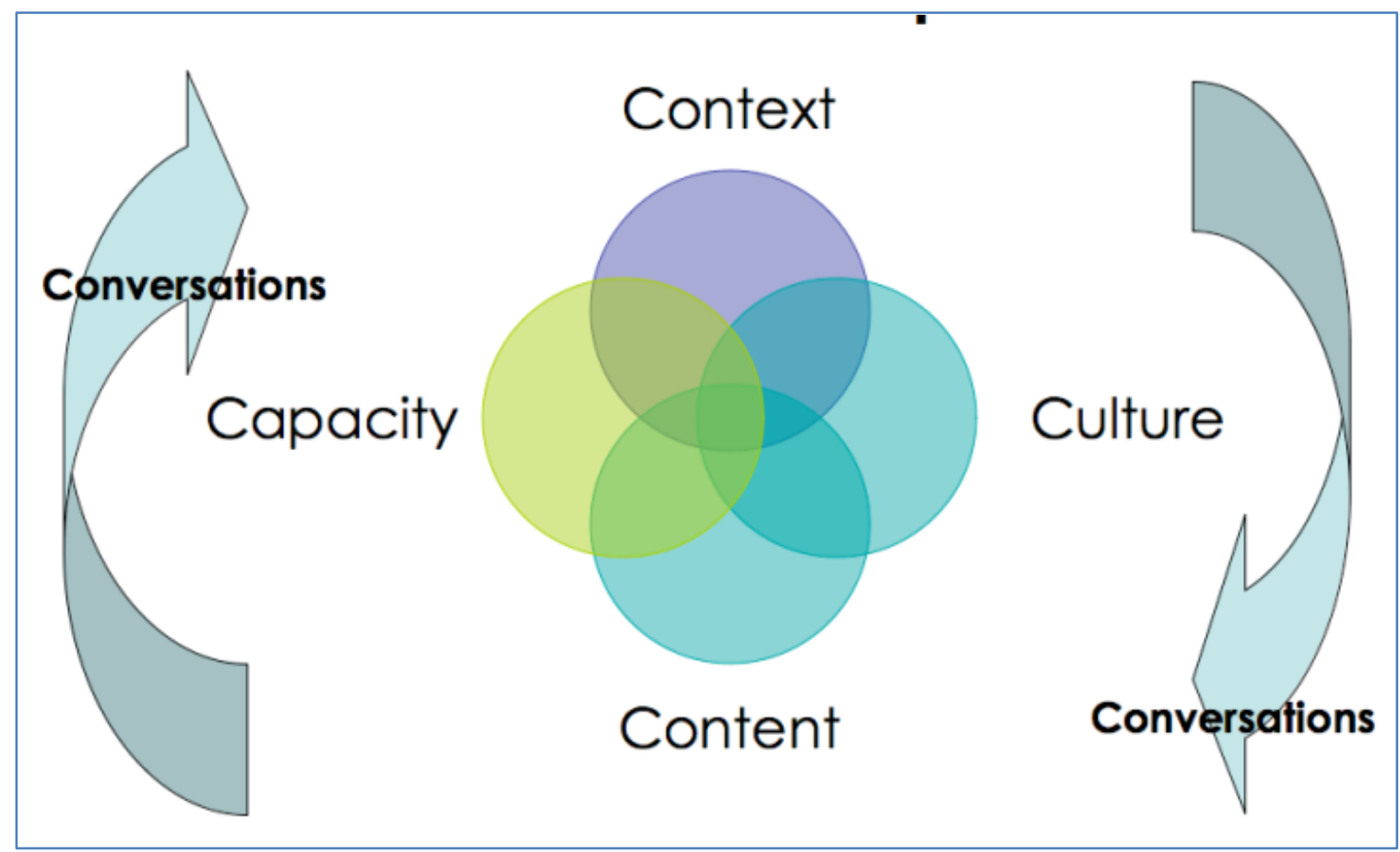


Figure 3: Knowledge to action process

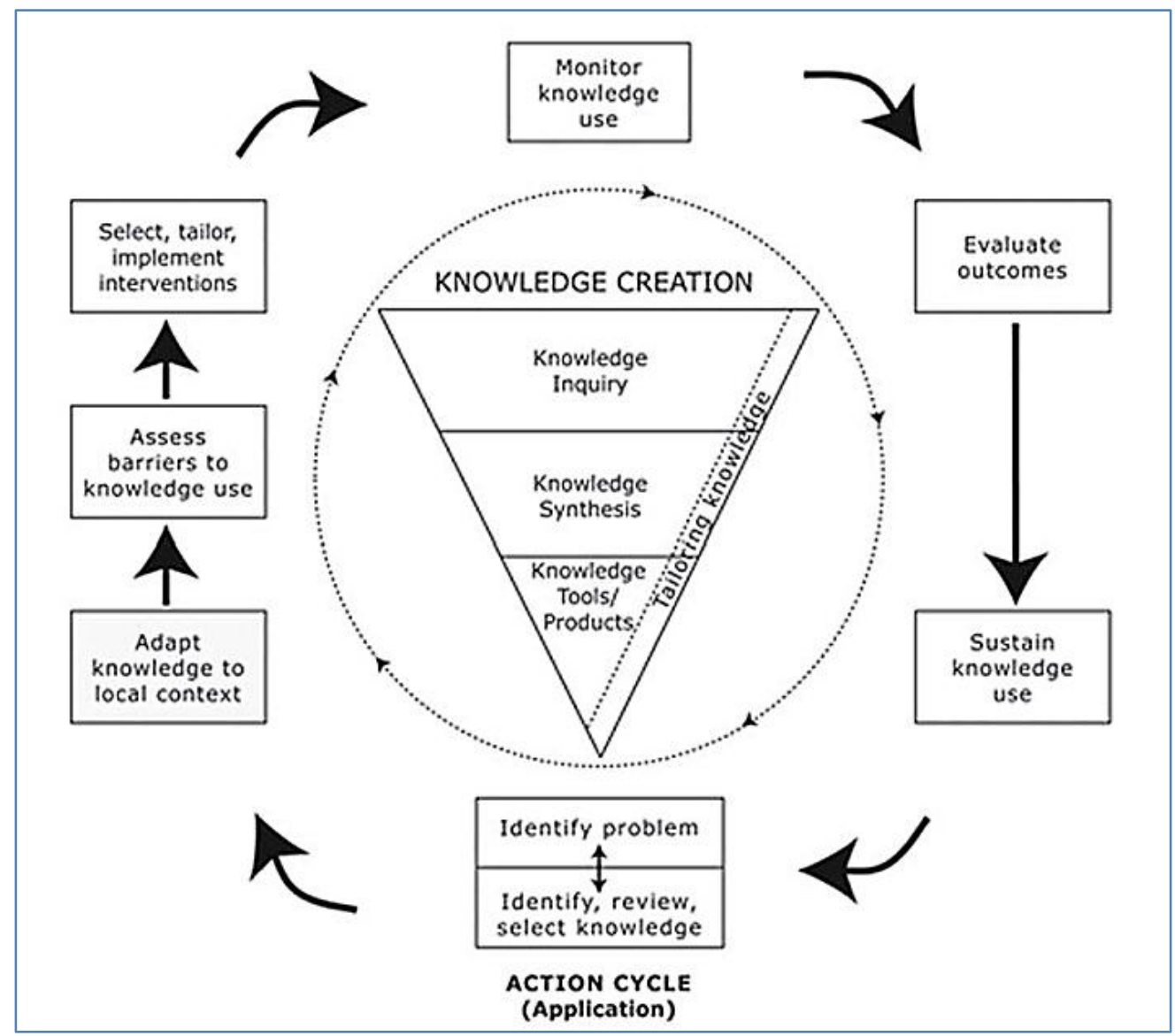

The global research and implementation leaders of $\mathrm{KMb} / \mathrm{KT}$ have historically been based in either Canada or the United Kingdom. The United States has been the global leader on the Knowledge Management (KM) front but the foci have been more business and government process related. The emphasis on information management and technology has not translated easily into intensive human services sectors such as health, social services, and education. There appears to be some significant movement towards recognizing that technology is likely a smaller part of the equation than many product/service vendors have argued.

The U.S. National Institute on Disability and Rehabilitation Research (NIDRR) defines knowledge translation as: providing the tools though which to ensure that people with disabilities become fully integrated and participating members of society. NIDRR's Knowledge Translation efforts ensure the widespread distribution, in usable formats, of practical scientific and technological information generated by research, demonstration, and related activities. NIDRR's challenge is to reach diverse and changing populations; to present research results in many different and accessible formats; and to use technology appropriately [NRIC 2009].

The U.S. Agency for Healthcare Research \& Quality (AHRQ) Knowledge Transfer/Implementation (KT) program consists of projects that disseminate products, tools, and research of the AHRQ to specific target groups and help implement them [AHRQ 2009].

The U.S. National Center for the Dissemination of Disability Research (NCDDR) suggests the following definition of KT: The collaborative and systematic review, assessment, identification, 
aggregation, and practical application of high-quality disability and rehabilitation research by key stakeholders (i.e., consumers, researchers, practitioners, and policymakers) for the purpose of improving the lives of individuals with disabilities [Tetroe 2007].

\section{Identify evidence about the success of alternative $K M /$ dissemination practices, with emphasis on the occupational health and safety domain.}

When assessing research evidence, the starting point should always be to go from highest level of certainty to lowest level of certainty. The Centre for Evidence-based Medicine at University of Oxford states that systematic reviews (with homogeneity) have the highest level of certainty [OCEM 2009].

The current evidence does not provide clear conclusions about the success of $\mathrm{KMb} /$ dissemination practices, with emphasis on the occupational health and safety domain, mostly due to the lack of available studies. There are no systematic reviews specifically on knowledge mobilization/dissemination (or similar terminology) for occupational health and safety in the Cochrane Library.

The Institute for Work and Health provides a series of four page summaries of reviews related to occupational health and safety but does not provide evidence on the effectiveness of the strategies and resources provided.

Presented below are a few examples of relevant reviews available:

Intervention review: Workplace interventions for preventing work disability [van Oostrom et al. 2009], summarized:

...that there is moderate-quality evidence to support the use of workplace interventions to reduce sickness absence among workers with musculoskeletal disorders when compared to usual care. However, workplace interventions were not effective to improve health outcomes among workers with musculoskeletal disorders. Considering all the types of work disability together, the results showed low-quality evidence that workplace interventions are more effective than usual care in reducing absence from work because of sickness. Unfortunately, no conclusions could be drawn regarding interventions for people with mental health problems and other health conditions due to a lack of studies. In conclusion, care providers could implement workplace interventions in guiding workers disabled with musculoskeletal disorders if the main goal is return to work.

Intervention review: The effectiveness of occupational health and safety management system (OHSMS) interventions: A systematic review [Robson et al. 2007], summarized:

...the studies' results were generally positive. There were some null findings but no negative findings. In spite of these promising results, the review concluded that the body of evidence was insufficient to make recommendations either in favor of or against OHSMSs.

There are however, some promising case studies compiled by the CIHR [2006]. These include:

\section{Knowledge translation through research-based theatre}

$\mathrm{KT}$, a quintessentially collaborative, cross-disciplinary exercise, can only be effective if there is something concrete in it for all partners. 


\section{The Agricultural Health and Safety Network}

The Network increased from five to 154 rural municipalities, and from 1,000 to 26,000 farm families, representing more than half of all farms in Saskatchewan, since 1988.

The Quebec Network for Work Rehabilitation: The challenge of knowledge translation and implementing a program in clinical practice

Implementing a complex, evidence-based rehabilitation program within an organization requires involvement from all personnel, particularly from those who will be directly responsible for undertaking the interventions.

\section{Interprovincial knowledge translation in occupational health and safety}

KT capacity within the entire social system or network can make the difference between success and failure of the translation.

\section{Translating research knowledge to stakeholders: The case of forklift safety}

Experience has shown that when researchers know more about realities in the field, research results are often more effective.

There also seems to be a growth of organizations and initiatives dedicated to disseminating research findings on occupational health and safety but the evidence to support their activities appears to be "under construction".

\section{Identify best practices in KMb/dissemination, even if evidence is not yet clear.}

\section{1) Active rather than passive:}

Davis et al. [2003] compare how continuing medical education (CME), continuing professional development (CPD), and knowledge translation promote the implementation of evidenced-based research into practice. The article notes that the passive education embraced by the CME and CPD models do not change physicians' behavior. The authors posit that knowledge translation is more effective in producing change and present specific ways in which knowledge translation is different from CME and CPD as justification for their position.

\section{2) Use logic models and/or roadmap}

Fielden et al. [2007] advocate using a logic model for planning and implementing partnerships to bridge the gap between knowledge and practice. The authors describe the development of a community-academic research partnership to address issues regarding vulnerable populations. The article notes the advantage of logic models in establishing common purpose and vision; however, the authors also report the challenges of such relationships due to issues of trust, power, commitment, motivation, and accountability. The authors suggest how to address the issues raised.

Harmsworth and Turpin [2000] document a step-by-step workbook for research teams to use in developing an effective plan for dissemination of their findings. The authors focus attention on what is to be disseminated, identification of the target populations, establishment of 
reasonable timeframes, and venue of dissemination. The authors note that effective dissemination involves the recipient to participate in the awareness, understanding or action dictated by the new knowledge.

\section{3) Link users and researchers}

Gold and Taylor [2007] describe their methodology and results in evaluating the Integrated Delivery Systems Research network (IDSRN) program of the U.S. Agency for Healthcare Research and Quality (AHRQ). The authors conducted interviews and reviewed program documents as well as analyzed projects and case studies. The results supported the concept of linking researchers with users of the research in a team-based approach. Further, IDSRN provided a mechanism to address issues in an expedited manner. The results noted weaknesses in the administrative structure of IDSRN, which resulted in its reorganization into ACTION (Accelerating Change and Transformation of Organizations and Networks).

\section{4) External validation}

Green and Glasgow [2006] recommend that external validity should be included in the planning process, thus making the research relevant to the people who will use the outcomes for setting policy or for decision making on an individual level.

\section{5) Adopt a knowledge ecology and/or systems thinking approach}

Brown [1999] argues that an organization is a knowledge ecology; it is fundamentally dynamic and gains robustness through diversity. But ecologies cannot be designed; they can only be nurtured. The key to nurturing these ecologies is finding the balance between spontaneity and structure. People need both the latitude to improvise and the business processes to apply their knowledge. Thus, creative leaders must learn to be bold yet profoundly grounded. It's easy to be conservative and grounded, or to be radical and impulsive. It's hard to be both grounded and radical (and the literal meaning of the word -- "going to the root" -- suggests exactly the right approach). That is the discipline of knowledge creation.

\section{6) Aggregate when possible}

The use of reviews, whether systematic or realist, reduces the amount of literature the must be read, assesses the consistency of findings across studies, and widens the ability to generalize individual studies across participants and settings. The single study is often not the unit of transfer, translation, or mobilization.

\section{7) Adopt open access}

Open access (OA) [IDRC 2009] allows us to reach a wider audience. Recent studies in computer science, astronomy and physics find a clear correlation between online availability and the citation count of an article. While access might not be the only condition for citation, it is certainly a necessary one. A second advantage is OA's potential for speeding up research progress and productivity. As each one of us is not only a writer but also a reader, we benefit from greater availability of scientific articles. With more and more of our knowledge going into the public domain, we can eventually render the marketplace a non-factor in research dissemination. 


\section{8) Engage with boundary spanners}

Informal ties that connect actors across formally defined organization boundaries generally are a better determinant of individual exploration performance than the extent to which actors have informal ties that bridge disconnected elements of the social structure. It is argued that internal cross-specialization ties - ties that cross formally defined areas of specialization - are the most important mechanism by which an actor accesses information and resources from different knowledge domains. Nevertheless, to successfully mobilize such resources across formal organizational boundaries, individuals benefit from having strong indirect ties in their internal networks [Løvås and Mors 2007].

Knowledge mobilization, knowledge translation, and dissemination should be about deriving the most value from the knowledge available to support the outcomes in populations of concern or interest. Evidence of effective practice in occupational safety and health is in its early stages of development. There are however, leaders and facilitators in a range of instructional, organizational, and governmental settings willing to create a systematic approach to understand what works to close the research to practice gap.

\section{References}

AHRQ (Agency for Healthcare Research \& Quality) [2009]. AHRQ's Knowledge Transfer/Implementation Program. [http://www.ahrq.gov/news/ktint.htm]. Date accessed: July 31, 2012.

Brown JS [1999]. Sustaining in the ecology of knowledge. Leader-to-Leader 12(Spring):31-36.

Brown JS [2002]. The Social Life of Information. Cambridge: Harvard Business School Press, p. 119.

Bridging the Know-Do Gap: A Resource for Researchers

[http://www.idrc.ca/EN/Resources/Publications/Pages/IDRCBookDetails.aspx?PublicationID=851] Date accessed: July 31, 2012.

(CIHR) Canadian Institutes of Health Research [2006]. Moving Population and Public Health Knowledge Into Action: Occupational and workplace health. [http://www.cihr-irsc.gc.ca/e/30750.html]. Data accessed: July 31, 2012.

(CIHR) Canadian Institutes of Health Research [2009]. About Knowledge Translation. [http://www.cihrirsc.gc.ca/e/29418.html]. Date accessed: July 31, 2012

(CIHR) Canadian Institutes of Health Research [2009]. More About Knowledge Translation at CIHR. [http://www.cihr-irsc.gc.ca/e/39033.html]. Date accessed: July 31, 2012.

Davenport TH [1997]. Information ecology: mastering the information and knowledge environment. Oxford: Oxford University Press, p. 3.

Davis D, Davis ME, Jadad A, Perrier L, Rath D, Ryan D, Sibbald G, Straus S, Rappolt S, Wowk M, Zwarenstein M [2003]. The case for knowledge translation: Shortening the journey from evidence to effect. BMJ 327:3335.

Fielden SJ, Rusch ML, Masinda MT, Sands J, Frankish J, Evoy B [2007]. Key considerations for logic model development in research partnerships: A Canadian case study. Eval Progam Plann 30:115-124.

Gold M, Taylor EF [2007]. Moving research into practice: Lessons from the US Agency for Healthcare Research and Quality's IDSRN program. Implement Sci 2(9):1-28.

Green LW, Glasgow RE [2006]. Evaluating the relevance, generalization, and applicability of research: Issues in external validation and translation methodology. Eval Health Prof 29(1):126-153.

Harmsworth S, Turpin S, TQEF National Co-ordination Team [2000]. Creating an effective dissemination strategy: An expanded interactive workbook for educational development projects. 
[http://www.innovations.ac.uk/btg/resources/publications/dissemination.pdf]. Date accessed: July 31, 2012.

IDRC (International Development Research Centre) [2009]. The Knowledge Translation Toolkit: Bridging the KnowDo Gap: A Resource for Researchers. [http://www.idrc.ca/EN/Resources/Publications/Pages /IDRCBookDetails.aspx?PublicationID=851\}. Date accessed: July 31, 2012.

Løvås B, Mors M [2007]. Boundary Spanners and Brokers: Disentangling the Effects of Formal and Informal Boundaries on Exploration Performance. Unpublished paper presented at the annual meeting of the American Sociological Association, New York City, NY, Aug 10.

NRIC (National Rehabilitation Information Center) [2009]. Introduction to the NIDRR Program Directory. [http://www.naric.com]. Date accessed: July 31, 2012.

OCEM (Oxford Centre for Evidence-based Medicine) [2009]. Levels of Evidence. [http://www.cebm.net/index.aspx?o=1025]. Date accessed: July 31, 2012.

Robson LS, Clarke JA, Cullen K, Bielecky A, Severin C, Bigelow PL, Irvin E, Culyer A, Mahood Q [2007]. The effectiveness of occupational health and safety management system interventions: A systematic review. Saf. Sci. 45(3):329-353.

Tetroe J [2007]. Knowledge translation at the Canadian Institutes of Health Research: a primer. Focus, Technical Brief No. 18. National Center for the Dissemination of Disability Research. [http://www.ncddr.org/kt/products/focus/focus18/]. Date accessed: July 31, 2012.

van Oostrom SH, Driessen MT, de Vet HCW, Franche RL, Schonstein E, Loisel P, van Mechelen W, Anema JR [2009]. Workplace interventions for preventing work disability. Cochrane Database of Systematic Reviews: Reviews 2009(2). [http://www.mrw.interscience.wiley.com/cochrane /clsysrev/articles/CD006955/frame.html] Date accessed: July 31, 2012. 


\section{Evaluating Interventions to Prevent Injuries to Young Workers}

Harry Shannon, PhD, McMaster University

\section{Introduction}

Previous papers in this series of workshops have covered several issues on work safety in young workers. Breslin and Smith [2012] reviewed the risk factors for young workers; in particular, they explored why young workers have higher injury rates than adult workers, and among young workers, what risk factors are linked to experiencing a work injury. Two papers described the data collection systems that include information on injuries and other health risks in young workers in the United States ${ }^{1}$ and in Canada [Koehoorn 2007].

Jeremy Staff ${ }^{2}$ discussed the transition and adaptation to work of youth, drawing on previous literature and new analyses of an ongoing U.S. study; of particular concern was whether and under what conditions work has positive or negative effects on young workers. Mortimer's related review [2012] examined whether work during teen years has a positive or negative effect on psychosocial development, and if any such relationships are moderated by the time spent at work and the quality of work.

Those papers provide the backdrop for my paper. Given that there appears to be broad consensus that injury rates are higher in young workers than in adults, particular efforts have been made in recent years to improve safety in this vulnerable group. Yet, as I will show, we do not know how successful these interventions have been. There is a dearth of proper evaluation ${ }^{3}$ of work safety measures in general, and almost nothing that I have found on specific interventions for young workers, with the notable exception of the agricultural sector in the United States.

The lack of solid evidence is not surprising. Good evaluations are not easy to do in the messy world of work; and when interventions adopt a variety of measures in the expectation that at least some of them will 'work', sorting out the relative and combined effects may be almost impossible. Yet if we are to make progress in improving work safety, we must try to do these evaluations. This paper outlines approaches to achieve this aim. I will draw heavily on a document I co-authored [NIOSH 2001], which in turn used well-established principles of evaluation. A more basic introduction to evaluating work safety measures was produced by the Intervention Effectiveness Research Team of the National Occupational Research Agenda (NORA)

\footnotetext{
${ }^{1}$ Davis L and Vautin B. Tracking Work-Related Injuries among Young Workers: An Overview of Surveillance in the United States, Health and Safety of Young Workers: Proceedings of a U.S.-Canadian Series of Symposia, NIOSH 2013. Page 105 in this document.

${ }^{2}$ Staff J. et al. Identifying Good and Bad Jobs in Adolescence in Health and Safety of Young Workers: Proceedings of a U.S.Canadian Series of Symposia, NIOSH 2013. Page 26 in this document.

${ }^{3}$ Several terms may be used, sometimes synonymously, sometimes to make a distinction: e.g., intervention research or program evaluation, even surveillance. I will simply refer to 'evaluation'.
} 
and is a useful starting point for those with no background in the area [NIOSH 2004] ${ }^{4}$. The (U.S.) National Safety Council has developed a presentation outlining these issues [National Safety Council 2004].

The paper will show the importance of rigorous evaluation, and outline briefly what we know about effective work safety interventions. I will note some specific challenges in applying the methods to measures targeted at young workers, list several types of interventions ${ }^{5}$, describe what are known as threats to validity in evaluation studies, and then show what needs to be done to demonstrate the effectiveness (or lack thereof) of safety interventions.

\section{Definition of a young worker}

As Breslin and Smith [2012] noted, there are various definitions of a 'young worker'. They distinguished between teenagers (15 to 19 year olds) and young adults (between 20 and 24 years' old). Legislation may be different again, for example, in determining the applicability of child labor laws. Davis and Vautin [2012: Tables 2 and 3] showed data on occupational injuries that included a category workers even younger than 15 . Children on farms live on a worksite and often do some work well before they are teens. Given the concern about the role of work and number of hours on the job in relation to school performance and other social behaviors and development (as in the papers by Staff and Mortimer), one might make a distinction not based solely on age, but on whether work is part-time because the young person's main role is as a student. Stages of mental and physical development might also be used to account for ability to perform certain tasks safely.

In general, though, these distinctions are not relevant to this paper. A precise definition is not required. However, for some issues it is important to appreciate the differences and how they may need to be taken into account in an evaluation. I will note these when relevant.

\section{Importance of rigorous evaluations}

Occupational safety suffers from the "it's obviously a good idea" syndrome, believing that "common sense" tells us that a particular safety measure will be beneficial. I will briefly describe some occasions on which this was shown not to be true.

Saari [1998] reported a safety poster campaign in shipyards. The posters were widely accepted, and viewed positively by the workforce. On this occasion, though, there was a control group, and injury rates were no different in the poster areas than in the control settings. Saari wryly noted: "If a careful evaluation of accidents had not been made, the campaign would have been promoted as an effective program." [Saari, 1998:184]

Daltroy and colleagues introduced an educational program to reduce back injuries in postal workers. They wanted to use a design known as a randomized trial - which includes a comparison group that did not receive the program. They had great trouble persuading the management and unions to do this. The workplace parties argued that the intervention was very likely

\footnotetext{
${ }^{4}$ Two other useful papers on evaluation that cover topics beyond those in this paper are Zwerling et al. [1997] which deals with occupational injuries, and Doll et al. [2003] which is not limited to occupational settings.

${ }^{5}$ Issues I will not discuss include how new interventions are developed, administrative issues such as who should be involved in the evaluation, or what should be included in a report of the evaluation.
} 
to be successful, so they should not withhold it from some workers; but the parties eventually agreed to the trial. There was indeed a reduction in back injury rates in the intervention group but a similar decrease in the comparison group too. [Zwerling 2001]

A more disturbing example is the following ${ }^{6}$. A railway company introduced a policy that maintenance and repair workers had to wear earmuffs and hard hats at all times. This, of course, seemed to be a reasonable approach, but the company did not take the time to evaluate its effectiveness - and also did not listen to concerns from employees that they could not hear noises in the environment. At one point, a railway carriage came loose and started to move down a slope. A worker who saw this reportedly telephoned the crew who were working on the railway line further down the hill. However, apparently because they were wearing earmuffs, those workers did not hear the phone ringing, and were not aware of the danger. They did not move off the tracks and as a result, four of them were killed. Thus an intervention that "obviously" made sense proved to be disastrous. [Clark 2004]

There are other reasons for doing good evaluations. By providing high-quality evidence, we can encourage others to adopt useful measures, or avoid spending time, effort and money on ineffective interventions. Otherwise, it remains doubtful that effective prevention will be implemented. Indeed, we can argue there is an ethical imperative to make widely known the best methods to prevent work injuries.

\section{What is successful in work safety}

Hale and Hovden [1998] note three types of approaches to improving work safety. The first is application of technical measures; the second the use of selection, training and motivation of workers; and the third - most recent - entails management systems to improve health and safety. Given the decline in work injuries, especially fatalities, during the twentieth century, these methods - or at least some combinations of them - have clearly been effective. Yet despite proclaimed targets of zero injuries, people still die or suffer disability because of incidents at work. To further reduce the number, we need solid evidence on effective measures.

Such evidence is lacking for many safety measures. For example, a special issue of the American Journal of Preventive Medicine [2000; 18(4S)] on systematic reviews of strategies to prevent occupational injuries looked at a range of specific measures and targets, for example, falls prevention in construction, interventions to prevent eye injuries, and roll-over protective structures to reduce farm tractor fatalities. A primary finding of most reviews was that there was a very limited number of good quality studies, so the research base needs to be improved before the question can be answered. A more recent meta-analysis of behavior-based safety approaches stated the main finding should be interpreted cautiously, because of the "poor to marginal' methodological quality of the studies included [Tuncel et al. 2006]. Even a systematic review published last year found just a few eligible evaluations of construction safety interventions, and those were of relatively poor quality [Lehtola et al. 2008].

A literature search found very little published work evaluating an intervention aimed specifically at young workers. Banco and colleagues [1997] found some improvement in laceration injury rates (and costs) when young workers in a supermarket chain were provided with a new type of case cutter. As well, McCloskey [2008] has pointed to the declines of injury rates in

\footnotetext{
${ }^{6}$ The details are admittedly sketchy and based on an early newspaper report.
} 
young workers in the provinces of Ontario and Manitoba as some indication that programs may be working. He did note the need for more evaluation of preventive programs, stating that 'virtually nothing is known about the effectiveness of individual components' of such programs. [McCloskey 2008:48]

As noted above, an exception to the paucity of papers in this area is agricultural work. There have been a reasonable number of evaluation reports on the North American Guidelines for Children's Agricultural Tasks (NAGCAT) and a synthesis was recently published by Marlenga et al. [2012]. An earlier review of all types of interventions by Hartling et al. [2004] had included some of the same studies. Finally, Reed and colleagues conducted several evaluations of the Agricultural Disability Awareness and Risk Education (AgDARE) program for high school students [e.g., Reed et al. 2001]. These evaluations used a range of methods, with greater or lesser degrees of rigor (see section 7.2). In the current context it is worth noting that the results were variable - some reports suggesting a specific safety benefit from the intervention, while others found little or no effect.

\section{Issues specific to young workers}

Many of the hazards at work apply equally to all workers regardless of age (or any other characteristic). Yet the high rates among young workers have prompted particular concerns. Breslin and Smith [2012] reviewed the evidence, and suggested several potentially relevant aspects. The increase in risk for young workers might be because of the types of occupation or industry in which they are employed. The relationship between work variables and work injury might be moderated by age. The hazard exposures for young workers might be different than for adults even within jobs. Youth may be vulnerable because of cognitive or social/emotional functioning (a developmental issue). Some of these may guide safety measures aimed specifically at young workers, and may be important to keep in mind when we evaluate those measures.

\section{Specific interventions for young workers}

\subsection{General types of intervention.}

I interpret the term 'safety intervention' broadly. It is simply an attempt to change how work is done to improve safety, i.e., reduce the risk of injury. We can group work safety interventions into three main types: a) engineering - changing the physical work environment; b) behavioral - focussing on what the individual worker does, and attempting to influence it via motivation and education; and c) administrative - a wide category that can include development or adoption of health and safety management systems in the company or legislative and enforcement approaches. These imply that the intervention can focus on the individual, the work group, the company or the jurisdiction.

\subsection{Some programmes currently in place}

In North America, there are various organizations responsible for promoting work health and safety. Sue Boychuk and Sue Gallagher have reviewed these in some detail, so I will simply refer to my quick (and far from comprehensive) scan of some of the web sites. The sites all de- 
scribe special programmes for young workers (although they differ in their definitions of a young worker). The Ontario Workplace Safety \& Insurance Board (WSIB) has several links at http://www.wsib.on.ca/en/community/WSIB/ArticleDetail?vgnextoid=220948db92e0c210VgnV CM100000469c710aRCRD [Date accessed: 23 July 2012]. Some information is produced directly by the WSIB, and some by the provincial Ministry of Labour. Programs focus on education about hazards of work, and rights (and responsibilities) of workers and companies. The YWAP Young Worker Awareness Program - for example, states its purpose as: "To give you the health and safety awareness you need to protect yourself and your fellow workers. The Ministry site states that the information is for young and new workers - the latter are included presumably because there are many immigrants from places where laws and policies on occupational health and safety are very different. Another link is to a Guide for Parents, which encourages discussion within families about potential hazards and how to deal with them. Other approaches include posters and television advertisements.

In the United States, similar material is available via the NIOSH website http://www.cdc.gov/niosh/topics/youth/ [Date accessed: 23 July 2012]. As well, resources are provided for high school classroom use. Each state has its own site.

In summary, the programs include much information that applies to all workers, not just young workers. As might be expected, they make heavy use of electronic media. They appear to focus on the workers themselves; I am unaware of programs that, e.g., increase inspection rates at worksites that employ many young workers. Our challenge is to evaluate these programs, so we can identify the best prevention approaches.

\section{Establishing Effectiveness}

\subsection{Process or outcome evaluation}

Preventive measures are designed to reduce the rate of injuries. However, in some circumstances, the type of injury one is trying to prevent is relatively uncommon. From a statistical viewpoint, this means it could take a long time and/or require a large number of workers involved before any benefits are detectable. Under these circumstances, an evaluator may not wait for a final answer based on injuries. Rather, some other measure may be chosen that could be seen as a surrogate for injuries.

A process evaluation may simply explore whether the program was implemented as intended. Measures used include, for example, the proportion of workers who attend training sessions, or the number of safety pamphlets distributed. Training sessions may also include a brief 'test' and performance on the test can check if workers have understood the material presented.

The evaluation may also measure an 'intermediate' outcome. Thus if a campaign encourages use of personal protective equipment (PPE), the change in the proportion of times workers are observed using appropriate PPE could be measured. A 'logic model', that outlines theoretically the steps whereby an intervention is expected to reduce injuries, can guide decisions about which process and intermediate outcomes ${ }^{7}$ could be examined.

Use of either of these outcomes, though, begs the question as to whether they are indeed precursors of improved injury rates. They may well be, but ideally this should be properly estab-

\footnotetext{
${ }^{7}$ The definitions of process and intermediate outcomes vary. Readers may see the terms used a little differently.
} 
lished. This requires demonstrating that changes in process and intermediate outcomes are indeed followed by changes in injury incidence, the 'true' or 'final' outcome measure.

\subsection{Study designs}

There are several methods used in evaluation. The list below begins with the weakest type of design, and progresses to the strongest.

- Non-experimental study: This is the most basic type. It could simply look at conditions or some indicator of safety following an intervention (sometimes called an "after only" design). A somewhat more sophisticated approach is the Before-After design. As the name implies, this measures an indicator of safety both before the intervention and after to look for differences.

- Quasi-experimental study: This method entails using a comparison group, which does not receive the intervention, or receives only a minimal intervention. The safety indicator may be measured only after the intervention. The indicator may also be measured twice in each group - both before and after the intervention.

- Experimental study: This approach is conducted by allocating individuals (or work groups or companies) to receive or not receive the intervention using randomization (chance).

\subsection{Threats to validity in non-experimental studies}

The aim of a rigorous evaluation is to ensure that the result is unbiased, that is, it is not distorted by problems with the methods of the study. Non-experimental studies - those without a comparison group - are the most susceptible to such threats to validity. I now describe briefly some of the threats that can arise in such designs. (See also Table 1)

History threat: Sometimes other events occur at the same time as the intervention of interest, for example, publicity in the media about work hazards or changes in the broader economy. If these events affect the outcome, it will be impossible to separate its effect from the safety measure being evaluated. Clearly it is impossible to control such outside events, but a careful record of them may allow some assessment of how much impact they may have had on the study results.

Instrumentation / reporting threat: The method of measuring an outcome might appear to be the same, but could change over time. For example, as part of a program to reduce 'repetitive strain injuries', a workplace may encourage full reporting of early symptoms. Even if the intervention is effective, increased reporting may produce an apparent - and spurious - increase in the rate of cases. This problem can be avoided by ensuring that the measurement method indeed remains constant over the duration of the study.

Regression-to-the-mean threat: Even when work conditions remain the same, there will be random fluctuation in the number of injuries from, say, month to month. Typically, if a company has a high rate in one month, the rate may well fall in the next month without any special action. If action is taken, it may appear to have led to a subsequent decrease in injuries, but we 
cannot rule out regression to the mean. A similar problem would arise if a Ministry of Labour inspection policy targets workplaces in the previous year that have had high injury rates. In some cases, the company's high rate will be a chance occurrence, and improvement in the following year will not be a result of inspections. It may not be possible to avoid this threat to validity, but we could look at the longer term pattern of injury rate in each company. If the rate is high year after year, then we would be more justified in attributing a drop to the intervention.

Testing threat: Taking a measurement before an intervention may affect the outcome measurement afterwards. For example, asking workers how often they use the established procedures on the job could prompt greater awareness of the procedures and higher scores at the post-intervention measurement, regardless of the effect of the intervention. While this might be the desired result, we would not be able to separate the effects of the initial test and the intervention. In this sense, the test is part of the intervention.

Placebo threat: Medical trialists have long believed in the need for a placebo as a comparison with the active drug being tested. It is thought that even an inactive drug can have physiological effects resulting from the psychological response to being given the placebo. Such an effect could conceivably affect injuries, or at least reporting of injuries, if, say, pain is the outcome of interest.

'Hawthorne effect' threat: A series of experiments from 1924 to 1932 at the Hawthorne works factory near Chicago appeared to find that productivity improved regardless of the experimental condition, i.e., the changes that were made by the researchers (see, for example, http://en.wikipedia.org/wiki/Hawthorne effect. Date accessed: 23 July 2012). While there has since been doubt cast on the conclusions reached, whether the term should continue to be used, and the exact definition, the notion is that people respond well when attention is paid to them. This has obvious implications for a workplace intervention, and whether a special intervention might lead to reduced (reporting of) injuries because of the intervention itself, or the simple fact that there was any intervention. As with the testing threat, this outcome is desirable anyway. Yet if the same effect could be achieved with a cheaper or simpler intervention, we want to determine this.

Early enthusiasm threat: When a program is first introduced, those responsible may be particularly keen to show it works, and devote extra attention to training, etc. As time goes by, the enthusiasm diminishes to a 'steady-state' level, leading to a reduced impact. If we thought this threat was a possibility, we could follow the program for a longer period to determine if the initial benefits are maintained.

Maturation threat: Reductions in injury rates may occur as workers gain more experience and/or more training. This is particularly likely with young workers, since their work experience is very limited. If such a drop coincided with the implementation of some safety measure, we could falsely conclude that the measure was effective. (This threat is related to the history threat.) 
Dropout threat: Young workers, especially students, are almost by definition temporary workers - they often spend a relatively short time with any given employer. If the workplace begins a program, workers who leave will not show any benefits; similarly replacement workers will not be exposed to the whole program, and possible benefits of the intervention will be underestimated. Alternatively, a program might find that those who continued in the program reported a lower injury rate in the year after the program than had been reported in the year before. But if a substantial proportion of those in the program 'dropped out' - either not completing the program or not reporting their post-program injury experience - we could not be sure we were properly estimating the program effect, since the dropouts would be included in the preprogram estimate of injury rate.

We may be able to deal partially with this threat if we examine carefully the characteristics of the dropouts and those who complete the study, and we could compare before and after rates just for those who completed the study. However, this would limit our ability to generalize our results to a broader range of workers.

Inadequate power threat: If a study is small, even a sizable effect may be declared statistically non-significant. The study is said to have low (statistical) power. This can be avoided by calculating an adequate sample size before the study begins. As well, when several evaluations of the same intervention have been done, we might pool the results through a meta-analysis.

In summary, there are many threats to validity that exist if we simply conduct a Before-After study. I now describe approaches to improving the design to reduce or eliminate these threats.

\subsection{Improvements in the study design}

Add a control group: The single most useful improvement that can be made to a nonexperimental design is to include a control (comparison) group. To the extent that this comparison is similar to the intervention group, this removes many of the threats to validity noted above. (Some others remain, and these will be described below.) For example, with young workers, the maturation threat is removed if we compare one group of new workers with another, since we would expect a similar degree of maturation in either group. If a difference between groups remains, we have more confidence that it is a result of the intervention.

Take more measurements before and after the intervention: It is possible that there is a downward trend in the injury rate over time. Thus the rate would be lower after the intervention, compared with before, even with a useless intervention. By examining several periods before and after the intervention, the trend can be examined - if the drop following the intervention is particularly large, it is more reasonable to attribute it to the intervention. This approach is called an 'interrupted time series'.

Introduce the intervention at different times in the groups: If it really is not feasible to withhold the intervention, it may still be possible to stagger its introduction in different groups. That is, the first group gets the intervention early on; a second group gets it some while later; and so 
on. This is particularly effective in removing the history threat. The potential effect of other events can be taken into account.

Reverse the intervention: Some interventions may have immediate, and only short-term, effects - e.g., personal protective equipment (PPE). If an intervention that apparently has an effect on injury rate is removed and the effect is reversed, we can have more confidence that the changes were due to the intervention. There are of course ethical concerns with such an approach. As well, it will not work with many interventions, such as training, that we hope have a lasting impact.

Measure multiple outcomes: We can strengthen our conclusions by adding more outcomes. One is to measure an 'intermediate' outcome. A program to reduce eye injuries by use of goggles should see an increase in such use before the reduction in eye injuries. If this did not happen, we could not attribute the reduction to the use of goggles. Management will certainly want to know if productivity was affected; and those planning to apply the intervention elsewhere would like to know how acceptable it was to the workplace parties.

A second possibility is to measure an additional outcome which we do not expect will be affected by the intervention. In the example of goggle use, we would not expect hand injuries to be affected; if they showed a similar reduction as eye injuries, we might suspect some other force was at work.

\subsection{Threat to validity in quasi-experimental studies}

Bias due to confounding: The major potential problem with quasi-experimental studies is whether the comparison group is truly similar to the intervention group. There are all sorts of reasons why it may not be: in a study aimed at changing individual behavior, the workers who participate or volunteer in the program are likely different in their attitudes to safety than those who do not. This would also apply to managers and workplaces that agree to adopt certain methods to improve health and safety. Even if we account for some of the 'confounders' that differ between the groups, we cannot rule out the possibility that unmeasured, or even unknown, confounders bias the estimate of the intervention's effect.

\subsection{Experimental designs}

We can limit the impact of confounders by randomization - we allocate participants to groups in a formally unbiased way (such as tossing a coin) and then treat the groups in identical fashion apart from the intervention. If this can be done, it is the strongest design possible. In practice, it may be difficult to do a randomized trial - as noted earlier, there may be resistance from the workplace parties, or ethical concerns about withholding a potentially beneficial intervention. Still, these barriers can be overcome, with the promise of more reliable evidence at the end of the study.

The study must still be carefully conducted. Even with randomization there are still threats to validity. 
Diffusion (contamination) threat: If workers within a company are randomized to an educational program or control, they are likely to discuss the information provided among themselves. The control group will not be 'pure'. It might be possible to randomize work groups (rather than individuals) to reduce this problem. (If this is done, adjustments to the sample size and statistical analysis are required.) The general principle is that the groups should be as separate as possible.

Rivalry or resentment threat: Workers in the control group might react to not receiving the intervention. They could stop reporting injuries to make their safety performance look good. Or the opposite could occur - they might 'over-report' injuries to show they need the program also. This problem can be avoided if the groups are in different locations. (This implies randomizing teams of workers, not individuals.)

\subsection{Qualitative methods}

The approaches described above are quantitative. Yet if an intervention does not appear to work, it might still be useful. It may be that it was not implemented as intended, something that a quantitative "black box" evaluation could not identify. Qualitative methods, including indepth interviews and focus groups, can explore these issues, and provide rich detail on what really happened. As well, we may not be able to measure all (intermediate) outcomes, especially those that are hard to quantify, yet some understanding of their role is important. If the qualitative and quantitative approaches yield similar results, the conclusions are strengthened. If the results differ, we should explore why.

\subsection{Summary}

Experimental or quasi-experimental designs are vastly preferable to non-experimental ones. While there are often practical difficulties, experimental studies are in principle optimal, and should be attempted where possible.

There are other methodological issues - selecting the study sample, deciding on sample size, choosing proper measurement methods, analyzing the data, etc. Readers are referred to NIOSH [2001], or a text on evaluation research methods, for more details.

\section{Examples of how interventions might be evaluated}

I will now outline how two types of interventions might be assessed. The descriptions will necessarily be brief and somewhat vague, but I hope to show that good evaluations are feasible if we are willing to try.

Intervention 1: Program to reduce back pain in young workers: Many young workers are employed in the fast food industry, and conduct a range of tasks, including heavy lifting. Back pain was the most common complaint in a study of young workers [Breslin et al. 2007:787]. Suppose a fast food chain decides to try to reduce back problems by education on lifting technique.

The first decision is to determine the study design. We could conduct a randomized trial among workers by listing all employees in the appropriate age range and allocating them to receive either the educational program or something minimal, maybe being given a simple pam- 
phlet. If we know boys do more lifting than girls, we could restrict the study to males. To avoid the diffusion bias, though, we would be better randomizing outlets, not individuals, an approach that is possible in this example.

Regarding measurement of the outcome, we can look at the back injury rate in the two groups. Also, we can look at back pain via a questionnaire, since young workers may not report all injuries [Breslin et al. 2007]. There is a role for measuring an intermediate outcome, namely lifting technique. This would be difficult, since a worker might use the approved technique only with the observer present. An even earlier intermediate outcome would be whether the workers understood the material presented - they could be asked to demonstrate how to lift before and after the program to ensure they had understood correctly. (Of course, any benefit is predicated on whether the technique really does reduce risk - we are assuming it does.)

There are some problems we would likely face. For example, turnover in this industry may be high, which could lead to dilution of any effect if new workers did not receive the training. To prevent this we would encourage the employer to incorporate the program into training for new workers in the intervention outlets. Finally, we would want to avoid the rivalry / resentment threat. Since research ethics require participants in such projects to provide informed consent, we could not keep from them information on the trial. Instead, we might promise the comparison group that they will receive the program if the trial shows it to be effective.

Intervention 2: Social Marketing Program to Teach Young Workers about Workplace Health and Safety:

Several programs in Ontario (described above) aim to increase young workers' awareness of health and safety. This includes knowing their rights under the legislation. One such campaign includes posters, TV advertisements, etc. to show that those who thought "it couldn't happen to me" can suffer severe life-changing events.

Evaluation of this type of program is more difficult. Since the program attempts to change the knowledge, attitudes, and behavior of a whole population, there is no realistic comparison group. (We might consider one from a different jurisdiction, but since most provinces and states have programs aimed at young workers, this would not be useful.) We are limited to a before-after comparison.

The obvious comparison is the injury rate in young workers before and after the program. One concern about this is the denominator - we need to know how many young people are in the workforce and since many are part-time, we must also find out the number of hours they work per week. Both number employed and time at work could change depending on the state of the economy, and need to be taken into account. We could do a survey of youth asking them about their knowledge of such issues as their rights under health and safety legislation. As well, we could conduct (qualitative) in-depth interviews with a sample of young workers asking about, e.g., whether they were aware of the program, what they understand about their rights as employees, whether they have exercised those rights, etc. Similarly, interviews with employers could ask about their knowledge of the program and whether they have changed the conditions at their company for young workers. One complication is that there might be some 'latency' before the program could be expected to have its effect - societal attitudes would not change overnight. This would require careful consideration of when to measure the outcome. Unfortunately, this would risk encountering the history threat. If the program had not yet been 
implemented, interviews could be conducted both before and after it occurred. In this case, the qualitative data may well be far more useful than any quantitative results.

(I should note that this methodology would still be labeled 'low quality' in most reviews. Mustard and Bielecky [2007] would have done so in their review of social marketing campaigns. They found several such campaigns that were evaluated using randomized controlled trials, but none of the campaigns were aimed at whole populations. Rather, most used direct mail or workplace posters that could keep control groups blinded to the intervention.)

These two examples outline the evaluation procedures. In practice, of course, many more details must be worked out. Still the examples show that one can conduct evaluations of two diverse types of intervention.

\section{Conclusion}

Even with improvements over time and implementation of a variety of programs, there are still many occupational injuries in young workers (and indeed in workers in general). There is little solid evidence on the degree of success of the programs. This paper has described various issues in evaluating these interventions, and I would not want to minimize the difficulties in practice of doing evaluations using high quality designs - the hypothetical example of Intervention 2 in the previous section used only a weak methodological approach. Yet if we want to use limited resources wisely to obtain the maximum possible benefit, we need to conduct more and better evaluations than have been done. In this way, we will be able to identify which programs work, and just how effective they are - essential steps to reducing the burden of injuries in young workers. 
Table 1. Some threats to validity in before-after evaluations with no comparison group

\begin{tabular}{|c|c|}
\hline $\begin{array}{l}\text { Threat to internal } \\
\text { validity }\end{array}$ & Description of threat \\
\hline History & $\begin{array}{l}\text { Some other influential event(s), which could affect the outcome, } \\
\text { occurs during the intervention }\end{array}$ \\
\hline $\begin{array}{l}\text { Instrumenta- } \\
\text { tion/Reporting }\end{array}$ & $\begin{array}{l}\text { Validity of measurement method changes over course of the in- } \\
\text { tervention }\end{array}$ \\
\hline $\begin{array}{l}\text { Regression-to-the- } \\
\text { mean }\end{array}$ & $\begin{array}{l}\text { Change in outcome measure might be explained by a group with } \\
\text { a one-time extreme value naturally changing towards a normal } \\
\text { value }\end{array}$ \\
\hline Testing & $\begin{array}{l}\text { Taking measurement (e.g. test) could have an effect on the out- } \\
\text { come }\end{array}$ \\
\hline Placebo & $\begin{array}{l}\text { Intervention could have a non-specific effect on the outcome, } \\
\text { independent of the key intervention component }\end{array}$ \\
\hline Hawthorne & $\begin{array}{l}\text { Involvement of outsiders could have an effect on the outcome, } \\
\text { independent of the key intervention component }\end{array}$ \\
\hline Early enthusiasm & $\begin{array}{l}\text { The instructors or others may show greater enthusiasm when a } \\
\text { program is first implemented than they do later }\end{array}$ \\
\hline Maturation & $\begin{array}{l}\text { Intervention group develops in ways independent of the inter- } \\
\text { vention (e.g. aging, increase experience, etc.), possibly affecting } \\
\text { the outcome }\end{array}$ \\
\hline Dropout & $\begin{array}{l}\text { The overall characteristics of the intervention group change due } \\
\text { to some participants dropping out, possibly affecting the out- } \\
\text { come }\end{array}$ \\
\hline Inadequate power & $\begin{array}{l}\text { If a study is small, even substantial effects will not be statistically } \\
\text { significant, so a useful intervention will be discarded. }\end{array}$ \\
\hline
\end{tabular}

Source: NIOSH, 2001

\section{References}

Banco L, Lapidus G, Monopoli J, Zavoski R [1997]. The safe teen work project: a study to reduce cutting injuries among young and inexperienced workers. Am J Indust Med 31:619-622.

Breslin FC, Polzer J, MacEachen E, Morrongiello B, Shannon H [2007]. Workplace injury or "part of the job"?: towards a gendered understanding of injuries and complaints among young workers. Soc Sci Med 64:78293.

Breslin FC, Smith PM [n.d.]. White Paper 1: Risk factors for nonfatal work injury for young workers: a review of two relevant literatures. Unpublished document.

Clark A [2004]. Rail deaths: victim warned of safety fears, says widow. The Guardian (online): [http://www.guardian.co.uk/society/2004/feb/17/health.transportintheuk] Date accessed: 23 July 2012.

Doll L, Bartenfield T, Binder S [2003]. Evaluation of interventions designed to prevent and control injuries. Epidem Rev 25:51-59.

Hale AR, Hovden J [1998]. Management and culture: the third age of safety; a review of approaches to organizational aspects of safety, health and environment. In: Feyer A-M, Williamson A, eds. Occupational injury risk, prevention and intervention. London: Taylor \& Francis. 
Hartling L, Brison RJ, Crumley ET, Klassen TP, Pickett W [2004]. A systematic review of interventions to prevent childhood farm injuries. Pediatrics 114(4):e483 -e496.

Koehoorn M [2007]. White Paper 2: Data collection systems used in the United States and Canada to understand the injury and other health risks of work. Part 1 - the Canadian perspective. Unpublished document.

Lehtola MM, van der Molen HF, Lappalainen J, Hoonakker PLT, Hsiao H, Haslam RA, Hale AR, Verbeek JH [2008]. The effectiveness of interventions for preventing injuries in the construction industry: a systematic review. Am J Prev Med 35:77-85.

Lipscomb J, Dement JM [2009]. A counterview on data quality and the systematic review process for occupational injury interventions: are we missing the forest for the trees [letter to the editor]? Am J Prev Med 36:377378.

Marlenga B, Lee BC, Pickett W [2012]. Guidelines for children's work in agriculture: implications for the future. Journal of Agromedicine 17(2):140-148.

McCloskey E [2008). The health and safety of young people at work: a Canadian perspective. Int J Workplace Health Management 1: 41-49.

Mortimer J [n.d.]. Work and its positive and negative effects on youth's psychosocial development. Unpublished document.

Mustard C, Bielecky A [2007]. A review of evaluations of social marketing campaigns in occupational injury, disease or disability prevention. Toronto: Institute for Work \& Health.

National Safety Council [2004]. Safety intervention evaluation: a systematic approach. [http://www.acgih.org/events/ControlBand/Thomas Safetylntervention.pdf] Date accessed: 23 July 2012.

NIOSH [2001]. Guide to evaluating the effectiveness of strategies for preventing work injuries: How to show whether a safety intervention really works. By Robson LS, Shannon HS, Goldenhar LM, Hale AR. Cinncinnati, OH: U.S. Department of Health and Human Services, Centers for Disease Control and Prevention, National Institute for Occupational Safety and Health, DHHS (NIOSH) Publication No. 2001-119.

NIOSH [2004]. Does it really work: how to evaluate safety and health changes in the workplace. By Intervention Effectiveness Research Team. Cinncinnati, OH: U.S. Department of Health and Human Services, Centers for Disease Control and Prevention, National Institute for Occupational Safety and Health, DHHS (NIOSH) Publication No. 2004-135.

Reed DB, Kidd PS, Westneat S, Rayens MK [2001]. Agricultural disability awareness and risk education (AgDARE) for high school students. Inj Prev 7(Suppl I):i59-63.

Saari J [1998]. Safety interventions: international perspectives. In: Feyer A-M, Williamson A, eds. Occupational injury - risk, prevention and intervention. London: Taylor \& Francis.

Tuncel S, Lotlikar H, Salem S, Daraiseh N [2006]. Effectiveness of behavior based safety interventions to reduce accidents and injuries in workplaces: critical appraisal and meta-analysis. Theor Issues Ergonomics Sci 7:191-209.

Zwerling [2001]. Book review. A review of a guide to evaluating the effectiveness of strategies for preventing work injuries: how to show whether a safety intervention really works. J Safety Res 32:501-503.

Zwerling C, Daltroy LH, Fine LJ, Johnston JJ, Melius J, Silverstein BA [1997]. Design and conduct of occupational injury intervention studies: a review of evaluation strategies. Am J Indust Med 32:164-179. 


\title{
Setting an Agenda for Advancing Young Worker Safety in the U.S. and Canada
}

\author{
Carol Runyan, MPH, PhD, Colorado School of Public Health \\ University of North Carolina Injury Prevention Research Center (at the time of this project) \\ John Lewko, PhD, Centre for Research in Human Development Laurentian University \\ Kimberly Rauscher, MA, ScD, West Virginia University School of Public Health \\ University of North Carolina Injury Prevention Research Center (during part of this project)
}

Note: This paper presents the summary of the fourth symposium session. It was published in Public Health Reports, May-June 2012 Volume 127 and is provided here with the permission of the journal. It is also available online: http://www.publichealthreports.org/issueopen.cfm?articlelD $=2838$

\begin{abstract}
Scholars and practitioners from multiple perspectives, including developmental science, sociology, business, medicine, and public health, have considered the implications of employment for young people. We summarize a series of meetings designed to synthesize information from these perspectives and derive recommendations to guide research, practice, and policy with a focus on young worker safety and health. During the first three meetings, participants from the United States and Canada considered invited white papers addressing developmental issues, public health data and findings, as well as programmatic advances and evaluation needs. At the final meeting, the participants recommended both research and policy directions to advance understanding and improve young worker safety.
\end{abstract}

More than 17.6 million workers younger than 25 years of age are employed annually in the United States.1 In Canada, nearly three million young people aged 15-24 years (65\%) were working in 2010.2,3 The U.S. recorded 3.6 deaths per 100,000 young workers (younger than 25 years of age) in the period 1998-2007, with an additional 7.9 million nonfatal injuries treated in emergency departments. In Canada in 2009, there were 35 fatalities among workers younger than 25 years of age, and 33,837 experienced nonfatal injuries requiring time away from work.5 Both the U.S. and Canada have laws at the federal and state or provincial levels to regulate the employment of young people. In the U.S., the Fair Labor Standards Act protects workers younger than 18 years of age by limiting the types of jobs they can hold and their work hours. 6 In addition, the Occupational Safety and Health Act of 1970 protects all workers.7States have separate laws for workers younger than 18 years of age and can enact provisions that strengthen rather than weaken federal laws. 
In Canada, employment legislation for young workers is limited at the federal level, with responsibility falling primarily to the individual provinces and territories. However, there are federal-level age restrictions, sand individual provinces have passed regulations limiting the types of jobs or exposures permitted for young people. For example, in 2003, British Columbia added a requirement stipulating that all workers younger than 18 years of age be under constant and immediate supervision from a person who is at least 19 years of age.9

Work has multiple effects on young people, both positive and negative. It can help young people develop new skills, explore potential career options, earn money for essential needs, and enjoy increased self-esteem.10 At the same time, work can be dangerous, exposing young people to unsafe tasks or environments, particularly in situations where training and supervision may be limited. For example, a recent national U.S. study ${ }_{11}$ reported that $26 \%$ of workers younger than 18 years of age worked at least part of the day without an adult supervisor, and as many as one-third of them reported not having any health and safety training. A similar Ontario study ${ }_{12}$ revealed that $38 \%$ of young workers spent at least part of their day working without supervision.

Scholarship on work among adolescents and young adults spans multiple disciplines but is poorly integrated. To address this problem, we embarked on the project entitled "Improving the Experiences of Young Workers in the U.S. and Canada: An Interdisciplinary Educational Program." Funded by the National Institute for Occupational Safety and Health (NIOSH) and the Ontario Neurotrauma Foundation, the project used a series of invitational meetings to engage an array of scholars and practitioners in setting an agenda for more integrated approaches to improving the safety and quality of work for young workers. We describe the methods used in this process and the recommendations that resulted from this four-year project, which was conducted from 2006 to 2010.

\section{Methods}

An organizing committee comprising U.S. and Canadian professionals identified white paper authors and selected a diverse group of multidisciplinary participants for each meeting, including sociologists, psychologists, physicians, lawyers, nurses, public health professionals, and business representatives.

Each of the first three meetings incorporated a series of white papers and discussion of major research and policy issues. The first meeting addressed developmental perspectives on work for young people, the second examined work for young people from a public health perspective, and the third focused on interventions and program evaluation. We used nominal group techniques to develop a list of needed research and policy interventions.

For the fourth meeting, we synthesized the ideas that had emerged from the prior sessions and organized them using the socioecological framework to provide a foundation for setting a research and policy agenda. In this meeting, a facilitator (William Flexner) helped the participants prioritize the topics, using the OptionFinder group decision support system, which allowed rapid voting on priorities with immediate display of findings.13 This system enabled participants to focus their attention on the topics of greatest perceived importance. Participants first engaged in silent brainstorming to generate ideas and then shared these ideas in small groups. Ideas from the small groups were compiled into a common list, discussed as a large group, and 
then prioritized by perceived importance. Members of the organizing group and authors of this article further refined these lists after the meeting. Topics within this domain are organized within the context of the socioecological framework.14,15 Although the research issues were common to both the U.S. and Canada, we focused this article on policy ideas for the U.S. A similar process to address Canadian policy ideas is in the planning stages.

\section{Policy Recommendations: U.S.}

Issues affecting young workers can be too easily overlooked when they are not differentiated from those affecting adults. Multiple agencies are involved in protecting young workers, and there are few coordinated mechanisms to monitor needs, set priorities, and facilitate progress. To remedy this problem, the group urged that the U.S. and Canada each develop a clear governmental focus on young worker safety, cutting across relevant agencies to more nimbly allow for the compilation and use of surveillance data, as well as the development, implementation, and evaluation of evidence-based programs and policies. They advocated for planned strategies to communicate across the U.S.-Canada border to facilitate the sharing of information and ideas about best practices. One specific idea was the development of a resource center to facilitate an information exchange about evidence-based interventions and translational research.

Specific recommendations for policy interventions in the U.S. include the following:

1) Develop a comprehensive and coordinated plan for surveillance of young worker health and safety, including monitoring of morbidity, mortality, and hazardous exposures.

a) Establish a national database with standard measures of young worker deaths and information about hazards and violations, through collaborative efforts of the Occupational Safety and Health Administration (OSHA) and NIOSH.

b) Develop standard definitions and protocols for ascertaining who is a young worker, what is work, what are hazardous conditions, and what are injury outcomes.

2) Assure that young people working in agriculture receive the same level of protection under the law as those in other industries.

3) Develop a focus on young worker labor within the U.S. Department of Labor and the U.S. Department of Health and Human Services to ensure continued attention to the issues of safety and health for young workers, including:

a) Facilitating the exchange of information about evidence-based practices for improving working conditions for young workers;

b) Establishing business-based health and safety committees, including input from young workers, to facilitate the development of workplace policies;

c) Mandating evidence-based health and safety training as an integral component of all government-sponsored workforce development programs; and

d) Regularly evaluating and reporting progress in improving young worker safety and health, drawing on surveillance data as well as program and policy evaluations.

4) Ensure adequate funding for the enforcement of child labor laws and OSHA standards at both the federal and state levels.

a) Expand protection to young workers up to 25 years of age, consistent with Canadian practice. 
b) Support small and/or family-owned businesses in meeting the obligations of adhering to OSHA and child labor regulations.

\section{Rationale}

Surveillance. The group agreed that it is imperative to develop more comprehensive and coordinated plans for the surveillance of mortality and morbidity among young workers. This plan is crucial for assessing trends in injury, developing evidence-based interventions and evaluating their implementation and effectiveness, and enforcing laws. Existing surveillance systems are inadequate for capturing the range of hazards and injuries as well as age and worker type. Young worker injuries are systematically underreported, and there are inadequate mechanisms to link data across sources. To enhance surveillance, standard definitions need to be developed and employed within all the various data systems that may pertain to the surveillance of young worker injury; for example, in medical records, death certificates, employer data systems, and workers' compensation systems. Also, it is strongly recommended that the U.S. Bureau of Labor Statistics expand surveillance definitions to include workers younger than 16 years of age, as many young people begin work before age 16 years,16yet their employment and injury experiences are not captured in current data systems.

In addition, the age range considered for "young workers" in U.S. surveillance systems should extend to 25 years of age, as is done in Canada, recognizing that those in the 19- to 24year age group are at particularly high risk for injury. As such, adequately protecting these young people may require special protections or the extension of some provisions of the Fair Labor Standards Act to these young adult workers.

OSHA and NIOSH should develop a mechanism to track hazard exposures and violations of state and federal laws at least in those cases of serious injury or death to a young worker. This information could facilitate identifying specific job tasks and environments in which young people are most at risk and provide guidance on improved intervention and enforcement activities.

Protection for young people working in agriculture. A high priority for policy improvement is ensuring that there is parity in the protection of young people working in the agriculture industry compared with those working in nonagricultural settings. For young people of all ages, working in agriculture poses significant risks for serious and fatal injury, with this industry having the second highest fatality rate for workers between the ages of 14 and 24 years.4 This protection should include family-run farms as well as non-family-run farms and agribusiness.

Though additional research on the effectiveness of workplace safety programs is strongly recommended, efforts to incorporate evidence-based approaches to training and supervising young workers should be part of standard practices in all businesses. Safety committees are one way to provide an interface with practice innovations and monitor progress to improve safety. A number of ideas emerged about how and where to conduct safety training (e.g., school-based vs. work-based programs, programs incorporating mentoring by more experienced workers, programs addressing workers' rights generically as well as those focused on safety issues in specific industries or jobs, ongoing training vs. at the start of a new job, and use of specific curricula and teaching methodologies). Because so little evaluation of interventions 
has been conducted to date, much more testing is necessary to determine which types of interventions will be effective.

In addition, because of the increased risks to new workers, it is highly recommended that special policy provisions ensure that new and young workers are assigned to tasks with gradually increasing difficulty, allowing them time to learn new environments and roles. This approach parallels the graduated driver licensing policies that have successfully reduced adolescent motor vehicle crash risks by as much as $20 \%-30 \%$ by giving new drivers progressively more independence as they learn to drive.17

Child labor law enforcement. It is critically important to assure that there is sufficient support to properly enforce child labor laws at both the state and federal levels. Currently, labor agencies have very limited resources for oversight of child labor and face significant challenges in monitoring violations.18-20 As a result, serious violations can go unnoticed and policies may be unenforced.21,22 It was also noted that small and/or family-owned businesses may require special attention to ensure compliance with child labor laws.

\section{Research Recommendations: U.S. and Canada}

During the course of the symposia, participants generated scores of research questions that fell into several broad domains. One domain was understanding the dynamics of employment and its effects on adolescent health and social development. Another domain addressed how best to improve working conditions and/or health outcomes for young workers. Ideas included studies of employers as well as workers and of research about how to gain adoption of evidence-based approaches.

In addition, evaluations of the implementation, effectiveness, and cost-effectiveness of young worker employment policies is critical, including cross-national comparisons (e.g., comparing U.S. and Canadian approaches).

\section{Understanding factors associated with young workers' experiences in the socioecological context}

Included in this category are issues related to social and cultural values about adolescents who are working and acceptability of worker risk. It includes social and cultural norms about worker safety and factors associated with the context of work by young people, including demographic and economic factors and trends. Sample research questions include:

- What are the key elements of a successful campaign to change social and cultural norms about health and safety?

- How does the mix of young and old workers in the labor pool affect young worker safety?

- What is the likely impact of demographic shifts on the jobs available to young people in the next 15 years?

- What factors enhance worker safety as a community value?

- What level of risk for young workers is acceptable within the U.S. and Canada? 
- How much control is it politically feasible to impose on businesses in support of young worker protection?

- How can businesses be more profitable by improving young worker safety?

\section{Organizational and institutional contexts of work}

Included in this category are issues related to the policies of organizations (e.g., industry and schools) that relate to work by young people (e.g., practices associated with training and supervision). It also includes factors associated with the overall workplace climate and a commitment to safety consciousness, as well as to actual hazards and safety practices. Sample research questions include:

- What work conditions and practices of supervisors, coworkers, and young workers contribute to safety?

- How do training, supervision, other safety practices, and employer attitudes about young workers vary across different types or sizes of businesses?

- What differentiates worksites with and without a positive safety culture?

- What factors facilitate the successful movement of young people to jobs in school-towork transition programs?

- What school factors are associated with young workers successfully managing the dual role of worker and student?

\section{Interpersonal relationships between young workers and significant other people related to their work}

This topic includes relationships between employers and parents, employers and teens, parents and teens, and teens and their peers as they relate to work practices and safety. Sample research questions include:

- What roles do parents play in their adolescents' work decisions?

- What level of workplace injury risk and protection from risk is acceptable to parents?

- How can parents be helpful in negotiating safer work for their children?

- How do the social networks of young workers influence their safety and risk-taking at work?

- What types of peer relationships are conducive to positive vs. negative work experiences among young workers, and how do they differ by gender?

- How do power relations at work between young workers and supervisors impact health and safety?

\section{Effects of young workers' characteristics and behaviors on work and work outcomes}

Research in this area is directed toward the knowledge, attitudes, beliefs, behaviors, and developmental characteristics of adolescents in selecting their roles as young workers and considers the outcomes of work for adolescent development. Sample research questions include:

- How do job choices and timing of job initiation among young people vary by socioeconomic factors, race/ethnicity, and gender? 
- What are the short- and long-term developmental psychosocial benefits and risks of young worker employment, specifically concerning having multiple jobs in succession or simultaneously and having jobs of differing qualities?

- How well do young workers correctly estimate their competency to perform specific types of jobs or tasks?

- How, if at all, does work change the risks among adolescents with regard to specific health outcomes (e.g., sexual debut, unwanted pregnancy, drug abuse, and use of alcohol or other drugs)?

- What role does sleep deprivation play in young worker injury risk?

- What specific characteristics of young workers (e.g., socioeconomic status, racial/ethnic minority status, and learning or physical disabilities) increase or mitigate worker safety?

- What is the lifetime disability among people who are injured at work during adolescence?

- What risk factors are associated with workplace violence among young workers?

\section{Intervention Research Recommendations: U.S. and Canada}

Our interdisciplinary symposia addressed a range of topics and issues important in setting policies that enable young people to work safely. The group acknowledged the importance of evaluating interventions, whether policies or programs, and generated numerous ideas for developing and applying evidence-based interventions. These interventions include policy interventions-both federal and state/provincial governmental policies, their adoption and enforcement, as well as organizational policies as they affect health and safety. The interventions also include efforts to translate successful interventions into new settings or to adapt interventions developed for one purpose (e.g., graduated driver licensing or increasing productivity) to worker safety.

\section{Policy approaches: federal, state, and organizational}

In this area, the group generated ideas that address both governmental policies to regulate the work environment and practices, as well as policies that could be adopted by organizations that employ young workers or provide services to young people.

- To what extent do workers' compensation policies enhance young worker safety?

- How can the model of graduated driver licensing be applied to protect young workers?

- What would be the impact on teen work and work safety if the minimum ages for specific hazardous work tasks were increased?

- How much do worker safety committees, supervisor training programs, work permits, prohibited work, and/or work hour restrictions improve young worker safety?

\section{Interventions to improve young worker safety}

This focus area is directed at changing the knowledge and/or practices of employers, young workers, or others (e.g., health professionals). Research questions include: 
- What factors constitute the effective supervision of young workers?

- What types of interventions could create incentives for employers/management to create safer work environments?

- What are the minimum best practices for making work safer for adolescents in specific settings? For example, would it be feasible to require companies with a certain proportion of new workers to have a designated risk manager/safety supervisor?

- What selection and training processes are most effective in preparing young supervisors to be successful? For example, are certification courses a viable approach?

- How effective are safety training and workers' rights training in improving young worker safety?

- What are effective mentoring strategies that can be replicated across work settings?

- What are the effects of formal apprenticeship programs in improving outcomes (educational, health, and safety) for young workers who participate in them?

- What training of health-care professionals can enhance their provision of occupational health and safety preventive care for young workers?

\section{Translational research and dissemination}

Translational research is directed at learning how to take interventions that have been demonstrated to be effective in one or more settings and apply them in new settings, thereby expanding their impact. Dissemination and knowledge mobilization practices take knowledge gained from research and share it to advance the science or to facilitate practice improvements.

Research questions include:

- What strategies facilitate the widespread adoption of interventions that improve young worker safety (e.g., incorporating attention to safety into the training of business leaders or increasing visibility of businesses employing sound practices)?

- How can the strongest evidence about prevention best be disseminated and applied in places employing young workers?

- What are the best methods for reaching young workers with information about health and safety (e.g., requiring businesses to mentor young workers for the first few months of employment)?

- What is necessary to get businesses to adhere to corporate policies that promote worker safety (e.g., tax or other financial incentives, appropriate training)?

- How can occupational safety and health best be incorporated into school curricula?

\section{Conclusions}

We advocate for more visible and vigorous attention to young workers as part of public health broadly and occupational health and safety more specifically. As with other public health issues, a comprehensive approach requires good surveillance as well as sound research to understand the etiology of problems and create evidence-based policy and programs. Evidence of successful interventions is minimal, so continued work is needed to develop and evaluate interventions to add to the body of evidence. There also is a need to conduct translational research 
to understand how interventions that are effective in one setting can be successfully implemented in others.

Organized efforts must track outcomes of interventions through improved surveillance employing the information to improve interventions using systematic evidence-based approaches. Ineffective approaches should be replaced by those with proven worth. The notion that "we know what works because we've been doing it this way for years" needs to be replaced with scientifically sound approaches to good practice. At the same time that we employ good research to inform practice, we must also be sure to incorporate practice experiences in informing research.

The integration of knowledge across disciplines is valuable, as in this series of meetings, drawing on theories and methods from the social sciences, industrial hygiene, injury control, and intervention practice. There is also much to be learned by comparing experiences in different social and political environments (e.g., the U.S. and Canada). Including input from diverse stakeholders is also important. These stakeholders include representatives of both management and labor, individuals representing governmental and private interests, and young workers themselves.

As we think boldly about the future of protecting young workers, we are impressed by the approach used in traffic safety in Sweden to adopt Vision Zero, aiming to eliminate traffic fatalities. The Vision Zero concept (http://www.visionzeroinitiative.com) is based on the premise that no loss of life is acceptable and that humans make mistakes. Consequently, the road system is designed to protect people at every turn. We believe a similar approach, with a goal of eliminating serious and fatal injuries to young workers by 2015 , is worthy of consideration.

\section{Acknowledgements}

This work was jointly supported by funding from the National Institute for Occupational Safety and Health of the Centers for Disease Control and Prevention to The University of North Carolina Injury Prevention Research Center and by the Ontario Neurotrauma Foundation to the Laurentian University Centre for Research in Human Development and the University of North Carolina Injury Prevention Research Center. The authors thank the members of the Joint Organizing Committee (Robert W. Blum, Letitia Davis, Sandra Miller, Jeylan Mortimer, and Richard Volpe) for their assistance in helping to structure the series of meetings and select white paper authors and participants; Cindy Lynne Tremblay for her many types of assistance during the four symposia; Mariana Garrettson for her help in managing the final meeting and contributing to data analysis; and William Flexner for donating his time in facilitating the final meeting and helping to organize the information from the discussions. The authors also thank all the authors of white papers and participants of the four symposia for their active engagement in understanding the issues of young worker safety and developing ideas for improvement. 


\section{References}

1. Bureau of Labor Statistics (US). Labor force statistics from the Current Population Survey. Washington: Bureau of Labor Statistics; 2010. Also available from: URL: http://www.bls.gov/cps/cps over.htm [cited 2011 Nov 28].

2. Statistics Canada. CANSIM table 282-0002: labor force survey estimates (LFS), by sex and age group, annual (persons unless otherwise noted). Ottawa (Ontario): Statistics Canada; 2010. Also available from: URL: http://www5.statcan.gc.ca/cansim/a05?lang=eng\&id=2820002\&paSer=\&pattern=2820002\&stByVal=2\&csid= [cited 2011 Nov 28].

3. Statistics Canada. CANSIM table 052-0005: projected population, by projection scenario, sex and age group as of July 1-Canada, provinces and territories, annual. Ottawa (Ontario): Statistics Canada; 2010.

4. Estes CR, Jackson LL, Castillo DN. Occupational injuries and deaths among younger workers-United States, 1998-2007. MMWR Morb Mortal Wkly Rep 2010;59(15):449-55.

5. Association of Workers' Compensation Boards of Canada. Young worker statistics [cited 2011 Dec 4]. Available from: URL: http://www.awcbc.org/en/youngworkerresourcesinformation.asp\#statistics

6. Department of Labor (US), Wage and Hour Division. Child labor bulletin 102: child labor requirements in agricultural occupations under the Fair Labor Standards Act. Washington: Department of Labor; 2007. Report No. WH-1295. Also available from: URL: http://www.dol.gov/whd/regs/compliance/childlabor102.pdf [cited 2011 Dec 1].

7. Pub. L. 91-596. 84 Stat. 1590 (1970).

8. Minister of Justice. Canada Labor Code [cited 2011 Nov 29]. Available from: URL: http://laws.justice.gc.ca/PDF/Statute/L/L-2.pdf

9. Employment Standards Act, Employment Standards Regulation. B.C. Reg 396/95 [cited 2011 Nov 29]. Available from: URL: http://www.bclaws.ca/EPLibraries/bclaws new/document/ID/freeside/11 39695

10. Staff J, Messersmith E, Schulenberg J. Adolescents and the world of work. In: Lerner RM, Steinberg L, editors. Handbook of adolescent psychology. 3rd ed. Vol. 2. Hoboken (NJ): John Wiley \& Sons; 2009. p. 270-313.

11. Runyan CW, Schulman M, Dal Santo J, Bowling JM, Agans R, Ta M. Work-related hazards and workplace safety of U.S. adolescents working in the retail and service sectors. Pediatrics 2007;119:526-34.

12. Lewko JH, Runyan CW, Tremblay CL, Staley JA, Volpe R. Workplace experiences of young workers in Ontario. Can J Public Health 2010;101:380-4.

13. Flexner WA, Wheatley KL. When you really must have them: face-to-face meetings using keypad electronic meeting systems. In: Coleman D, editor. Collaborative strategies for corporate LANs and intranets. Upper Saddle River (NJ): Prentice Hall; 1997.

14. Bronfenbrenner $U$. The ecology of human development: experiments by nature and design. Cambridge (MA): Harvard University Press; 1979.

15. Runyan CW. Introduction: back to the future-revisiting Haddon's conceptualization of injury epidemiology and prevention. Epidemiol Rev 2003;25:60-4.

16. Department of Labor (US). Report on the youth labor force. Washington: Department of Labor; 2000.

17. Chen LH, Baker SP, Guohua L. Graduated driver licensing programs and fatal crashes of 16-year-old drivers: a national evaluation. Pediatrics 2006;118:56-62.

18. Child Labor Coalition. The government's striking decline in child labor enforcement activities. Washington: Child Labor Coalition; 2006.

19. General Accounting Office (US). Child labor: labor can strengthen its efforts to protect children who work. Washington: GAO; 2002.

20. National Consumers League. 2004 child labor state survey. Washington: NCL; 2005.

21. Rauscher KJ, Runyan CW, Schulman MD, Bowling JM. U.S. child labor violations in the retail and service industries: findings from a national survey of working adolescents. Am J Public Health 2008;98:1693-9.

22. Kruse DL, Mahony D. Illegal child labor in the United States: prevalence and characteristics. Ind Labor Relations Rev 2000;54:17-40. 


\section{Appendix I: List of Symposia Participants}

Note: Organizations reflect the participants' affiliations at the time of the symposium.

\section{Symposium I: Youth Employment in Developmental Context \\ December 7 - 9, 2007 \\ Toronto, Ontario, Canada}

Carol W. Runyan, MPH, PhD (Principal Investigator

(PI)) (U.S.)

Director

Injury Prevention Research Center University of North Carolina

John Lewko, PhD (Co-Investigator (Co-I) \& Presenter)

(Canada)

Director

Center for Research in Human Development

Laurentian University

Kimberly Rauscher, MA, ScD (Co-I) (U.S.)

Research Scientist

Injury Prevention Research Center University of North Carolina

Letitia Davis, ScD, EdM (JOG Member) (U.S.)

Director

Occupational Health Surveillance Program

Massachusetts Department of Public Health

Sandra Miller, MA (JOG Member) (Canada)

Director of Innovation

Ontario Service Safety Alliance

Richard Volpe, PhD (JOG Member) (Canada)

Professor and Projects Director

Life Span Adaptation Projects

Institute of Child Study

Department of Human Development and Applied

Psychology

University of Toronto

Baruch Fischhoff, PhD (White Paper Author \& Presenter) (U.S.)

Howard Heinz University Professor

Department of Social and Decision Sciences

Carnegie Mellon
E. Kevin Kelloway, PhD (Presenter) (Canada)

Professor

Department of Management

Saint Mary's University

Jeylan Mortimer, PhD (JOG member, White Paper

Author \& Presenter) (U.S.)

Professor

Department of Sociology

University of Minnesota

Jeremy Staff, PhD (White Paper Author \& Presenter)

(U.S.)

Assistant Professor

Department of Sociology \& Crime, Law and Justice

Pennsylvania State University

Brian Bigelow, PhD (Canada)

Professor

Department of Psychology

Laurentian University

David Blustein, PhD (U.S.)

Professor

Department of Counseling, Developmental, and Edu-

cational Psychology

Boston College

Sue Boychuk (Canada)

Manager

Young Worker Health and Safety

Ontario Ministry of Labour

F. Curtis Breslin, PhD (Canada)

Scientist

Institute for Work and Health

Diane Bush, MPH (U.S.)

Coordinator of Public Programs

Labor Occupational Health Program

University of California, Berkeley 
Dawn Castillo, MPH (Presenter) (U.S.)

Chief

Surveillance \& Field Investigations Branch

Division of Safety Research

National Institute for Occupational Safety and Health

Helene Gagne (Canada)

Program Director - Injury Prevention

Ontario Neurotrauma Foundation

Nancy Galambos, PhD (Canada)

Professor and Associate Chair of Graduate Studies

and Research

Department of Psychology

University of Alberta

Philip Groff, PhD (Canada)

Director

Research \& Evaluation

SMARTRISK

Mary Agnes Hamilton, PhD (U.S.)

Director

Cornell Youth in Society Program

Cornell University

Elise Ledoux, PhD (Canada)

Researcher

Research Department

IRSST

\author{
Liz Mansfield (Canada) \\ Department of Public Health Sciences \\ University of Toronto
}

Michael Schulman, PhD (U.S.)

William Neal Reynolds Professor

Department of Sociology and Anthropology

North Carolina State University

Kate Tilleczek, PhD (Canada)

Professor

Department of Sociology

Laurentian University

Cindy-Lynne Tremblay (Canada)

Research Associate

Centre for Research in Human Development

Laurentian University

Sean Tucker (Canada)

PhD Candidate

Queen's University School of Business

James Westaby, PhD (U.S.)

Associate Professor

Program in Social-Organizational Psychology 


\section{Symposium II: The Health Implications of Work among Youth Chapel Hill, North Carolina, U.S. October 3-5, 2008}

Carol W. Runyan, MPH, PhD (PI \& White Paper Author) (U.S.)

Director

University of North Carolina

Injury Prevention Research Center

John Lewko, PhD (Co-I) (Canada)

Director

Center for Research in Human

Development

Laurentian University

Kimberly Rauscher, MA, ScD (Co-I, White Paper Author \& Presenter) (U.S.)

Research Scientist

University of North Carolina

Injury Prevention Research Center

Jeylan Mortimer, PhD (JOG Member) (U.S.)

Professor

Department of Sociology

University of Minnesota

Richard Volpe, PhD (JOG Member) (Canada)

Professor and Projects Director

Life Span Adaptation Projects

Institute of Child Study

Department of Human Development and Applied

Psychology

University of Toronto

Robert Blum, MD, PhD (JOG Member \& White Paper Author) (U.S.)

Professor

Population, Family and Reproductive Health

School of Public Health

Johns Hopkins University

F Curtis Breslin, PhD (White Paper Author\& Presenter) (Canada)

Scientist

Institute for Work and Health
Letitia Davis, ScD, EdM (JOG Member, White Paper Author \& Presenter) (U.S.)

Director

Occupational Health Surveillance Program

Massachusetts Department of Public Health

Mieke Koehoorn, PhD (Presenter) (Canada)

Associate Professor

Department of Health Care and Epidemiology

University of British Columbia

Beatriz Pazos Vautin, MPH (White Paper Author)

(U.S.)

Project Coordinator

Teens at Work Project

Occupational Health Surveillance Program

Massachusetts Department of Public Health

Peter M. Smith, PhD (White Paper Author \& Presenter) (Canada)

Scientist

Institute for Work and Health

May Sudhinaraset (White Paper Author) (U.S.)

Doctoral Student

Population, Family and Reproductive Health

School of Public Health

Johns Hopkins University

Enzo Armata (Canada)

Controller

427 Auto Collision

Diane Bush, MPH (U.S.)

Coordinator of Public Programs

Labor Occupational Health Program

University of California, Berkeley

Sue Boychuk (Canada)

Young Worker Health and Safety

Ontario Ministry of Labour

Nicole Charles (U.S.)

Recruitment Coordinator

Philadelphia Area Project on Occupational Safety \& Health 
Marcy Goldstein-Gelb (U.S.)

Executive Director

Massachusetts Coalition for Occupational Safety \& Health

Andy King (Canada)

Department Leader

National Health Safety and Environment

United Steelworkers Canadian National Office

Mary Miller, MN, RN (U.S.)

Child Labor Specialist

Employment Standards Program

Washington State Department of Labor and Indus-

tries

Sandra Miller, MA (Canada)

(JOG Member)

Director of Innovation

Ontario Service Safety Alliance

Joel Rabideau (Canada)

National Manager

Health and Safety and Risk Management

Gap, Inc., Canadian Operations

Andrea Tullos (U.S.)

Owner

Gulf Rim Café
Helene Gagne (Canada)

Program Director

Injury Prevention

Ontario Neurotrauma Foundation

Seymour Moskowitz, JD (U.S.)

Professor of Law

School of Law

Valparaiso University

Douglas Myers, ScD (U.S.)

Assistant Professor

Occupational \& Environmental Medicine Division

Duke University Medical Center

David Parker, MD, MPH (U.S.)

Physician \& Epidemiologist

Park Nicollet Clinic

Matthew Pierce (U.S.)

Post-Doctoral Fellow

University of North Carolina

Injury Prevention Research Center

Michael Schulman, PhD (U.S.)

William Neal Reynolds Professor

Department of Sociology and Anthropology

North Carolina State University

John Staley, PhD (U.S.)

Post-Doctoral Fellow

University of North Carolina

Injury Prevention Research Center 


\section{Symposium III: Young Worker Health \& Safety Interventions and Knowledge Mobilization Strategies Toronto, Ontario, Canada \\ June 20-22, 2009}

\author{
Carol Runyan, MPH, PhD (PI) (U.S.) \\ Director \\ University of North Carolina \\ Injury Prevention Research Center \\ John Lewko, PhD (Co-I) (Canada) \\ Director \\ Center for Research in Human Development \\ Laurentian University
}

Kimberly Rauscher, MA, ScD (Co-I) (U.S.)

Research Scientist

University of North Carolina

Injury Prevention Research Center

Letitia Davis, ScD, EdM (JOG Member) (U.S.)

Director

Occupational Health Surveillance Program

Massachusetts Department of Public Health

Sandra Miller, MA (JOG Member) (Canada)

Director of Innovation

Ontario Service Safety Alliance

Jeylan Mortimer, PhD (JOG Member) (U.S.)

Professor

Department of Sociology

University of Minnesota

Richard Volpe, PhD (JOG Member) (Canada)

Professor and Projects Director

Life Span Adaptation Projects, Institute of Child

Study

Department of Human Development \& Applied Psy-

chology

University of Toronto

Sue Boychuk, MS (Presenter) (Canada)

Young Worker Health and Safety

Ontario Ministry of Labour
Sue Gallagher, MPH (White Paper Author \& Presenter) (U.S.)

Director

MS in Health Communication Program

Public Health and Family Medicine

Tufts University School of Medicine

Harry Shannon, MSc, PhD (White Paper Author \& Presenter) (Canada)

Professor

Department of Clinical Epidemiology \& Biostatistics

McMaster University

Peter Levesque, MA, PhD (White Paper Author \& Presenter) (Canada)

Director

Systems and Operations

Knowledge Mobilization Works

Robin Baker, MPH (U.S.)

Director

Labor Occupational Health Program

University of California, Berkeley

F. Curtis Breslin, PhD (Canada)

Scientist

Institute for Work and Health

Diane Bush, MPH (U.S.)

Young Worker Project Coordinator

Labor Occupational Health Program

University of California, Berkeley

Lester Claravall, MHR (U.S.)

Child Labor Specialist

Employment Standards Division

Oklahoma Department of Labor

Helene Gagne (Canada)

Program Director

Injury Prevention

Ontario Neurotrauma Foundation

Sofia Gallagher (Canada)

Specialist High Skills Major Project Coordinator

Rainbow District School Board 
Kim Grant (Canada)

Manager

Research and Product Development

Ontario Service Safety Alliance

Mieke Koehoorn, PhD (Canada)

Associate Professor

Population and Public Health School

University of British Columbia

Barbara Lee, RN, PhD (U.S.)

Director

National Farm Medicine Center

Marshfield Clinic Research Foundation

Darren Linker, MEd (U.S.)

Program Manager

Department of Environmental and Occupational

Health Sciences

University of Washington

Tom McQuiston, DrPH (U.S.)

Researcher

Tony Mazzocchi Center for Health, Safety, \& Environmental Education

Reid Maki, MA (U.S.)

Director, Social Responsibility and Fair Labor Stand-

ards

Coordinator, Child Labor Coalition

National Consumers League

Chris Miara, MS (U.S.)

Co-Director

Young Worker Safety Resource Ctr.

Education Development Center, Inc.

Mary Miller, MN, RN (U.S.)

Child Labor Specialist

Employment Standards Program

Washington State Department of Labor and Industries
Nancy Morales (U.S.)

Youth Project Coordinator

Labor Occupational Safety and Health Program

University of California, Los Angeles

Andrea Okun, DrPH (U.S.)

Deputy Director

Education and Information Division

National Institute for Occupational Safety and Health

Michael Schulman, PhD (U.S.)

William Neal Reynolds Professor

Department of Sociology and Anthropology

North Carolina State University

Sara Rattigan, MS (White Paper Author) (U.S.)

Doctoral Student

Public Health and Family Medicine

Tufts University School of Medicine

Joseline Sikorski, PhD (Canada)

President \& CEO

Ontario Safety Association for Community \& Healthcare

Peter M. Smith, MPH, PhD (Canada)

Scientist

Institute for Work and Health

Cindy-Lynne Tremblay, MA (Canada)

Research Associate

Centre for Research in Human Development

Laurentian University

Linda Urisk (Canada)

Program Coordinator

Learning to 18

Rainbow District School Board 


\section{Symposium IV: Developing a Research and Policy Agenda to Improve Young Worker Health and Safety in the US and Canada Washington DC, US \\ November 18-20, 2010}

Carol Runyan, MPH, PhD (PI) (U.S.)

University of North Carolina

Injury Prevention Research Center

John Lewko, PhD (Co-I) (Canada)

Director

Center for Research in Human Development

Laurentian University

Letitia Davis, ScD, EdM (JOG Member) (U.S.)

Director

Occupational Health Surveillance Program

Massachusetts Department of Public Health

Sandra Miller (JOG Member) (Canada)

Director of Innovation

Workplace Safety and Prevention Services (formerly

Ontario Service Safety Alliance)

Jeylan Mortimer, PhD (JOG Member) (U.S.)

Professor

Department of Sociology

University of Minnesota

Kimberly J. Rauscher, MA, ScD (Co-I) (U.S.)

Assistant Professor

Department of Community Medicine

Injury Control Research Center

West Virginia University

Richard Volpe, PhD (JOG Member) (Canada)

Professor and Projects Director

Life Span Adaptation Projects, Institute of Child Study

Department of Human Development \& Applied Psy-

chology

University of Toronto

F. Curtis Breslin, PhD (Canada)

Scientist

Institute for Work and Health
Dawn Castillo (U.S.)

Chief

Surveillance and Field Investigations

Branch, Division of Safety Research

National Institute for Occupational Safety \& Health

Helene Gagne (Canada)

Program Director

Injury Prevention

Ontario Neurotrauma Foundation

Sue Gallagher, MPH (U.S.)

Public Health and Family Medicine

Tufts University

School of Medicine

Mariana Garrettson, MPH (U.S.)

Program Director Evaluation and Dissemination

University of North Carolina

Injury Prevention Research Center

Arthur Kerschner, Jr. (U.S.)

US Department of Labor

Wage and Hour Division

Barbara Lee, RN, PhD (U.S.)

Director

National Farm Medicine Center

Marshfield Clinic Research Foundation

Peter Levesque, MA, PhD (Canada)

Director

Systems and Operations

Knowledge Mobilization Works

Reid Maki, MA (U.S.)

Director, Social Responsibility and

Fair Labor Standards

Coordinator, Child Labor Coalition

National Consumers League

Mary Miller, MN, RN (U.S.)

Health Scientist

US Department of Labor - OSHA 
Sy Moskowitz, JD (U.S.)

Professor at Law

Valapraiso University

Jackie Nowell (U.S. \& Canada)

United Food and Commercial Workers
Joel Rabideau (Canada)

Senior Manager, Corporate Health and Safety Business Integration

Gap, Inc - Global Operations

Michael Schulman, PhD (U.S.)

William Neal Reynolds Professor

Department of Sociology and Anthropology

North Carolina State University 


\title{
Appendix II: Symposia Agendas
}

\author{
Symposium I: Youth Employment in Developmental Context \\ December 7 - 9, 2007 \\ Toronto, Ontario, Canada
}

\section{DAY 1}

Friday Evening, December 7, 2007

6:00 - 6:45 Reception and Welcome

Carol Runyan, MPH, PhD, Director, University of North Carolina Injury Prevention Research Center (UNC IPRC)

John Lewko, PhD, Director, Centre for Research in Human Development, Laurentian University

Kent Bassett-Spiers, CEO, Ontario Neurotrauma Foundation

Dawn Castillo, MPH, Chief, Surveillance and Field Investigations Branch, Division of Safety Re-

search, National Institute for Occupational Safety and Health

6:45 - 8:00 Dinner followed by Short video and Informal Discussion

Objectives: As a result of this session, participants will:

- be able to identify some of the health and safety issues young workers face; and

- get acquainted with other participants and their interdisciplinary perspectives on youth labor issues.

\section{DAY 2}

Saturday, December 8, 2007

8:30-8:45 Continental breakfast

8:45 - 9:00 Overview of Symposium: Goals, processes and charge to the group

Carol Runyan, $\mathrm{MPH}, \mathrm{PhD}$, Director, UNC IPRC

9:00 -10:00 Presentations and Discussion: "Youth Employment and the Health and Safety Issues of Young Workers in the United States and Canada: An Overview"

Presenters: Dawn Castillo, MPH, Division of Safety Research, National Institute for Occupational Safety and Health (presenting the U.S. picture), and John Lewko, PhD, Director, Centre for Research in Human Development, Laurentian University (presenting the Canadian picture)

Moderator: Sandra Miller, MA, Director of Innovation, Ontario Service Safety Alliance

The purpose of this session is to ground participants in the contexts of youth labor in each country.

Objectives: As a result of this session, participants will be able to:

- describe the extent and patterns of youth employment in each country;

- differentiate the policy environments affecting young workers in each country; and

- describe the hazards to which teens are exposed and the nature and magnitude of health outcomes, especially injuries, associated with adolescent work, in each country. 
10:15 - 11:45 White Paper and Discussion: "The Organizational Context of Youth Employment" Presenter: E. Kevin Kelloway, PhD, Professor of Management and Psychology, Sobey School of Business, Saint Mary's University, Halifax, Nova Scotia

Moderator: Letitia Davis, ScD, EdM, Director, Occupational Health Surveillance Program, Massachusetts Department of Public Health

The purpose of this paper is to ground participants in the literature on the role of organizational culture in affecting the work environments of youth from a business/ organizational psychology perspective.

Objectives: As a result of this session, participants will be able to:

- describe three salient dimensions of young workers' organizational experiences;

- identify how each of these dimensions contributes to young workers' health and safety ; and

- understand youth employment beyond the traditional focus on work in the "regular" economy.

$\underline{11: 45-1: 00 \quad \text { Lunch and Networking }}$

1:00 - - 2:00 White Paper and Discussion: "Adaptation to the World of Work and the Role of Worker" Presenter: Jeremy Staff, PhD, Asst. Professor, Department of Sociology, Pennsylvania State University Moderator: John Lewko, PhD, Director, Centre for Research in Human Development, Laurentian University

The purpose of this paper to give an overview of theory and research related to the issues encountered by youth as they enter and adapt to work.

Objectives: As a result of this session, participants will understand:

- the key developmental research findings that could influence the way in which youth enter into and adapt to occupational settings as paid workers;

- three key issues that youth face as they enter occupational settings as paid workers, 1) How many hours should they work? (2) Will they work with adult coworkers and supervisors? (3) What types of jobs are the most and least desirable?

2:00 -3:15 White Paper and Discussion: "Assessing Adolescent Decision-Making Competence"

Presenter: Baruch Fischhoff, PhD, Howard Heinz University Professor, Department of Social and Decision Sciences, Carnegie Mellon University

Moderator: Richard Volpe, PhD, Professor, Department of Human Development and Applied Psychology, University of Toronto

The purpose of this paper is to ground participants in the best research on youth and their understanding of and response to risks and hazards in their lives, with particular concern for workplace experiences. Objectives: As a result of this session, participants will understand:

- the application of decision theory to individual decisions;

- the major results regarding adolescent decision-making competence; and

- how to formulate interventions that are informed by both risk analysis and behavioral science.

3:15-3:30 Break 


\section{3:30-4:15 Breakout Session}

The purpose of this session is to break into four small multidisciplinary groups to discuss the material covered in the program thus far. Questions to consider in these discussions should include:

1. What do we know?

What have the presentations so far identified as understandings about youth work and how it can be improved as a part of healthy adolescent development?

2. What else do we need to know?

What additional perspectives about the context and culture of work for adolescents do we need to consider so we can understand the experiences of adolescents more fully as workers?

What aspects of youth employment and its relationship to youth development should receive further attention, whether through new research, policy or program activities?

3. What further research do we need to learn what we need to know?

4:15 - 4:45 Report Back and Discussion

Moderator: Carol Runyan, $\mathrm{MPH}, \mathrm{PhD}$, Director, UNC IPRC

$\underline{4: 45-5: 00 \quad \text { Wrap-up }}$

6:00-8:00 Reception

\section{DAY 3}

Sunday, December 9, 2007

8:15 - Breakfast

8:45-9:00 Brief Overview of the Day (topics and process)

John Lewko, PhD, Director, Centre for Research in Human Development, Laurentian University

9:00-10:15 White Paper and Discussion: "Work and its Positive and Negative Effects on Youth's Psychosocial Development"

Presenter: Jeylan Mortimer, PhD, Professor of Sociology, University of Minnesota, Minneapolis

Moderator: Kimberly Rauscher, MA, SCD, Research Scientist, UNC IPRC

The intent of this paper is to explore the ways in which work is known to promote positive as well as negative psychosocial development.

Objectives: As a result of this session, participants will understand:

- the extant literature on the positive and negative impacts of youth employment, including both short and long-term influences;

- the ways youths' selection to work may contribute to the purported "impacts" of work; and

- the features, both temporal investment and the quality of work, that may account for work's developmental influence.

$\underline{10: 15-10: 30 \quad \text { Break }}$ 
10:30 - 12:00 Synthesis Discussion: If Prevention is Our Goal, What Do We Know and What Should We Know?

Moderator: Carol W. Runyan, MPH, PhD, Director, UNC IPRC

Objective: During this session, participants will:

- reflect on common themes and ideas that have emerged in the two days of discussion;

- identify key issues in need of further research, policy and programmatic attention; and

- identify issues for discussion at future symposia.

12:00-1:00 Lunch, Overview of Next Steps, Evaluation and Closing Remarks

Kimberly Rauscher, MA, SCD, Research Scientist, UNC IPRC

John Lewko, PhD, Director, Centre for Research in Human Development, Laurentian University

Carol Runyan, MPH, PhD, Director, UNC IPRC

1:00_Adjourn 


\section{Symposium II: The Health Implications of Work among Youth Chapel Hill, North Carolina, U.S. October 3-5, 2008}

\section{DAY 1}

Friday, October 3, 2008

6:00-9:00 Welcome Reception

Carol Runyan, MPH, PhD, Director, UNC IPRC

John Lewko, PhD, Director, Centre for Research in Human Development, Laurentian University

\section{DAY 2}

Saturday, October 4, 2008

8:30-9:00 Breakfast and Overview of the Project and Symposium II: Goals, Processes and Our Charge

Carol Runyan, MPH, PhD, Director, UNC IPRC

9:00 -9:20 White Paper 1: “Risk Factors for Nonfatal Work Injury for Young Workers: A Review of Two Relevant Literatures "

Presenter: Curtis Breslin, PhD, Scientist, Institute for Work and Health

The purpose of this session is to inform participants of the injury and other health and health-related behavioral risks associated with youth employment.

Objectives: As a result of this session, participants will be able to:

- describe risk factors (e.g., equipment, fast pace) for acute occupational injury among youth; and,

- describe other negative health outcomes associated with the work of young people (e.g., disease and illness, musculoskeletal disorders, mental health issues) and their causes (e.g., chemical exposure, repetitive work, low quality jobs).

\section{9:20 - 10:10 Group Discussion}

\section{$\underline{10: 10-10: 20 \quad \text { Break }}$}

10:20 - 10:50 White Paper 2: "Data Collection Systems used in the U.S. \& Canada to Understand the Injury and other Health Risks of Work"

Presenters: Part 1 - The U.S. Perspective: Letitia Davis, ScD, EdM, Director, Occupational Health Surveillance Program, Massachusetts Department of Public Health; and

Part 2 - The Canadian Perspective: Miekie Koehoorn, PhD, Associate Professor, Department of Health Care and Epidemiology, University of British Columbia

The purpose of this paper is to review and critique the quality of the surveillance systems and other data collection mechanisms used to track the work injury outcomes of young workers in each country.

Objectives: As a result of this session, participants will be able to:

- describe the primary data sources and surveillance systems used to collect information on injury and other work-related health outcomes in U.S. and Canada; and,

- understand the strengths and weaknesses of each. 
10:50 - 11:40 Group Discussion

$\underline{11: 45-12: 45 \quad \text { Lunch }}$

12:45 - 1:15 White Paper 3: "The State of the Science: A Review of the Research on How Work-based Injury Risks Are Distributed Across Youth's Jobs in the United States and Canada"

Presenters: Part 1 - The U.S. Perspective: Kimberly J. Rauscher, MA, ScD, Research Scientist, UNC IPRC; and

Part 2 - The Canadian Perspective: Peter M. Smith, PhD, Scientist, Institute for Work and Health

The purpose of this session is to describe what the science shows with respect to how widespread the known and suspected work-based risk factors for injury are in the two countries.

Objectives: As a result of this session, participants will understand the prevalence of work-based injury risks in the jobs held by youth in the U.S. and Canada, including but not limited to the following:

- work in hazardous industries and occupations, exposure to hazardous equipment and tools, fast paced work, working without proper supervision and training; and,

- how such conditions differs by age group (14-17 vs.18-24) and by country (U.S. vs. Canada).

1:15-2:00 Discussion

2:00 - 3:30 Panel Response followed by Group Discussion: The View from the Field: U.S. and Canadian Practitioners' Provide their Thoughts on Working Conditions, Injuries and Other Health Risks Related to Youth Employment

Panelists: From the U.S.: Mary Miller, MN, RN, Employment Standards, Washington Department of Labor and Industries and Diane Bush, MPH, Coordinator of Public Programs, Labor Occupational Health Program, University of California-Berkeley.

From Canada: Sue Boychuk, MPH, Manager, Young Worker Health and Safety, Ontario Ministry of Labour, and Sandra Miller, MA, Director of Innovation, Ontario Service Safety Alliance

The purpose of this session is to give practitioners a chance to respond to the material presented thus far in the symposium and then to engage them in a discussion with the entire group.

Objective: As a result of this session, participants will understand what practitioners in the two countries have seen with respect to working conditions and injury and health risks among youth.

\section{3:30-4:15 Breakout Session}

The purpose of this session is to break into four small multidisciplinary groups to discuss the material covered in the program thus far.

4:15 - 5:00 Report Back and Group Discussion

Moderator: Carol Runyan, MPH, PhD, UNC IPRC

The purpose of this discussion is to report back the major issues raised in the break out group discussions, continue these discussions with the entire group, and summarize what we have learned from the day's events up until this point.

5:00 Wrap-up

John Lewko, PhD, Centre for Research in Human Development, Laurentian University

5:45 Dinner and Panel 


\section{DAY 3}

Sunday, October 5, 2008

\section{8:30 - 9:00 Brief Overview of the Day (topics and process)}

9:00 - 9:20 White Paper 4: “Adolescents' and Young Adults Unique Developmental Factors in Relation to Work-related Health Risks"

Presenter: May Sudhinaraset, Doctoral Student, Department of Population, Family and Reproductive Health, Johns Hopkins University

The purpose of this session is to provide participants with an understanding of the developmental features of adolescents and how these may put youth at increased risk for work-related injury.

Objectives: As a result of this session, participants will be able to:

- describe the cognitive, physiological, social issues unique to adolescents and young adults;

- understand how these issues put working adolescents at increased risk of injury; and,

- understand the implications of these developmental factors for work-based practices (i.e., increased supervision, proper task assignments, limits on duties).

\section{9:20 - 10:10 Group Discussion}

\section{$\underline{10: 10-10: 20 \quad \text { Break }}$}

10:20 - 11:45 Employer Panel \& Discussion: The Employer Perspective on Young Worker Health and Safety

Panelists: From Canada: Joel Rabideau, National Manager, Health and Safety and Risk Management Canadian Operations Gap Inc., and Enzo Armata, Controller, 427 Auto Collision.

From the US: Andrea Tullos, Owner, Gulf Rim Café.

The purpose of this panel is to learn from representative employers of youth what their thoughts are on employing young workers and workplace health and safety as it relates to youth:

- What are the dynamics of how these organizations function relative to young workers?

- What are the advantages and disadvantages associated with employing youth vs. older workers?

- What is the organizational perspective on governmental regulations and their enforcement?

11:45 - 1:00 Synthesis Discussion: If Prevention is Our Goal, What Do We Know and What Should We Know?

The purpose of this session is to reflect on common themes and ideas that have emerged in the two days of discussion, identify key issues in need of further research, policy and programmatic attention, and identify issues for discussion at future symposia.

1:00 - 1:30 Closing Remarks

John Lewko, PhD, Centre for Research in Human Development, Laurentian University

Carol Runyan, MPH, PhD, UNC IPRC

$\underline{1: 30 \quad \text { Adjourn }}$ 
Symposium III: Young Worker Health \& Safety Interventions and Knowledge Mobilization

Strategies

Toronto, Ontario, Canada

June 20-22, 2009

\section{DAY 1}

Saturday, June 20, 2009

6:00-8:00 Reception and Welcome

Dr. John Lewko, Director, Centre for Research in Human Development, Laurentian University

Dr. Carol Runyan, Director, UNC IPRC

Ms. Helen Gagne, Injury Prevention Program Director, Ontario Neurotrauma Foundation

\section{DAY 2}

Sunday, June 21, 2009

8:30 - 9:30 Breakfast and Overview of the Project and Symposium III: Goals, Processes and Charge Dr. Carol Runyan, UNC IPRC

9:30 -10:15 White Paper 1: "The State of the Art in Young Worker Safety Interventions in the U.S. and Canada"

Presenters: Ms. Sue Boychuk, Ministry of Labour, Ontario, Canada -and-Ms. Susan Gallagher, Tufts University School of Medicine

The purpose of this presentation is to inform participants of the current intervention efforts being conducted in both countries. As a result, participants will be able to:

- describe the range of activities underway to address young worker safety in the U.S. and Canada;

- summarize the evidence on effectiveness of these interventions; and,

- identify future intervention directions for improving safety for young workers.

\section{0:15-10:30 Break}

10:30 - 12:30 Reports from the Field and Group Discussion

Moderator: Dr. Kimberly Rauscher, UNC IPRC

The purpose of this discussion is to hear from participants from the U.S. and Canada about the intervention projects in which they are currently engaged. Participants are encouraged to share their successes and challenges and to exchange ideas and strategies with the group. This will be followed by a group discussion.

\section{2:30-2:00 Lunch and Networking}

2:00-2:30 White Paper 2: "Knowledge Mobilization and Dissemination Practices in Occupational Safety and Health"

Presenter: Dr. Peter Levesque, Knowledge Mobilization Works, Ottawa

The purpose of this presentation is to share with participants strategies for disseminating and mobilizing knowledge about occupational safety and health. As a result, participants will be able to:

- define how knowledge mobilization (KM) and dissemination are used in the U.S. and Canada; 
- identify evidence about the success of alternative $\mathrm{KM} /$ dissemination practices, with emphasis on the occupational health and safety domain; and,

- identify best practices in $\mathrm{KM} /$ dissemination, even if evidence is not yet clear.

2:30-4:30 Group Discussion

Moderator: Dr. Carol Runyan, UNC IPRC

4:30 Wrap-up

Dr. John Lewko, Centre for Research in Human Development, Laurentian University

6:00-9:00 Dinner

DAY 3

Monday, June 22, 2009

8:30-9:00 Breakfast and Brief Overview of the Day (topics and process)

9:00 -9:30 White Paper 3: "Evaluating Interventions to Prevent Injuries to Young Workers"

Presenter: Dr. Harry Shannon, McMaster University

The purpose of this session is to provide participants with an understanding of what good evaluations include and how to conduct them. As a result of this session, participants will be able to:

- identify the major quantitative and qualitative methodological challenges in designing evaluations of young worker safety interventions; and,

- consider approaches to assessing cost-effectiveness of different intervention options.

9:30 -11:30 Group Discussion

Moderator Dr. John Lewko, Centre for Research in Human Development, Laurentian University

$\underline{11: 30-11: 45 \quad \text { Break }}$

11:45-1:30 Lunch and Discussion: Moving Forward in Creating Recommendations for Development, Evaluation and Dissemination of Effective Interventions

The purpose of this discussion is to develop recommendations for improving the science to support young worker safety interventions and develop ideas for enhancing the dissemination of knowledge on effective interventions for improving young worker safety the U.S. \& Canada.

1:30-2:00 Closing Remarks and Evaluation

Dr. John Lewko, Centre for Research in Human Development, Laurentian University and Drs. Kimberly Rauscher and Carol Runyan, UNC IPRC 
Symposium IV: Developing a Research and Policy Agenda to Improve Young Worker Health and Safety in the U.S. and Canada

Washington D.C., U.S.

November 18-20, 2010

\section{DAY 1}

Thursday, November 18, 2010

6:00-8:00 Reception and Welcome

\section{DAY 2}

Friday, November 19, 2010

8:30-9:00 Breakfast

9:00-9:30 Welcome and introductions

Dr. Carol Runyan, UNC IPRC

9:30 - 9:50 Overview of meeting goals, agenda, process

Dr. John Lewko, Director, Centre for Research in Human Development, Laurentian University

Dr. Carol Runyan, Director, UNC IPRC

Dr. William Flexner, Private Consultant, Chapel Hill, North Carolina

9:50-10:15 AM: Overview of research topics generated at prior sessions

Dr. Carol Runyan, UNC IPRC

10:15-10:30 AM: Break

10:30 AM - 12:30 PM: Creating a research agenda (All; Facilitator: Dr. William Flexner)

12:30 - 1:30 PM: Lunch

1:30 - 2:00 PM: Child labor policy update

Art Kerschner, U.S. Department of Labor

2:00 - 2:40 PM - Overview of policy topics generated at previous sessions

Dr. John Lewko, Centre for Research in Human Development, Laurentian University

Mary Miller, MN, RN, U.S. Department of Labor, OSHA

2:40-3:00 PM - Break

3:00 - 5:00 PM - Creating a policy agenda (All; Facilitator: Dr. William Flexner)

5:00-5:15 PM: Wrap up and plans for Saturday 


\section{DAY 3}

Saturday, November 20, 2010

8:00-9:00 Breakfast

9:00 - 11:30 Large group synthesis discussion (All; facilitator Dr. William Flexner)

A. Finalizing research and policy agenda

B. Dissemination planning

11:30-12:00 Wrap up and evaluation (Carol Runyan, John Lewko, William Flexner)

Dr. John Lewko, Director, Centre for Research in Human Development, Laurentian University

Dr. Carol Runyan, Director, UNCIPRC

Dr. William Flexner, Private Consultant, Chapel Hill, North Carolina

\section{2:00 Adjourn}

12:00 - 2:00 PM: Joint Organizing Committee to discuss project completion and publication plan 